INSTITUTO DE PESQUISAS ENERGÉTICAS E NUCLEARES Autarquia associada à Universidade de São Paulo

\title{
ANÁLISE DE SISTEMAS MULTIFÁSICOS UTILIZANDO TOMOGRAFIA COMPUTADORIZADA GAMA MONOENERGÉTICA E POLIENERGÉTICA
}

PABLO ANTONIO VASQUEZ SALVADOR

Tese apresentada como parte dos requisitos para obtenção do Grau de Doutor em Ciências na Área de Tecnologia Nuclear -Aplicações.

Orientadora:

Dra. Margarida Mizue Hamada

Co-Orientador:

Dr. Galo A. C. LeRoux

SÃO PAULO 
Aos meus pais, Helena e Enrique; a Neuza e ao Joel e a minha esposa Maria Djiliah dedico este trabalho. 


\section{AGRADECIMENTOS}

Ao Instituto de Pesquisas Energéticas e Nucleares pela op ortunidade de realizar este trabalho, especialmente ao Centro de Tecnologia das Radiações;

À Dra. Margarida Mizue Hamada e ao Dr. Galo A.C. LeRoux pela orientação, incentivo e amizade;

Ao Dr. Wilson A.P. Calvo, Gerente do Centro de Tecnologia das Radiações do IPEN-CNEN/SP p elo apoio durante todo o trabalho.

Ao Dr. Carlos H. de Mesquita e sua equipe de trabalho formada pelo João Carlos S.M. Pereira e o João Francisco T. Martins pelo desenvolvimento do sistema de coleta de dados utilizado no tomógrafo do CTR/IPEN, e por sua colaboração constante, amizade e estímulo.

Ao Dr. Muthanna Al-Dahhan e ao Dr. Mirolad Dudukovic do Laboratório de Engenharia da Reação Química (CREL) da Washington University em St. Louis (WUSTL) pela orientação e op ortunidade única de trabalhar em seus projetos, por seus conselhos e apoio.

Ao Dr. Rajneesh Varma da WUSTL pelo auxílio na realização dos trabalhos experimentais e desenvolvimento dos algoritmos iterativos para reconstrução de imagens, por sua amizade e ajuda.

A minha esposa Dra. Maria Djiliah de Souza Vasquez pelo seu amor, estímulo, amparo e motivação constantes, sem os quais este trabalho não teria sido concluído.

Ao Conselho Nacional de Pesquisa e Desenvolvimento (CNPq) pelas bolsas de doutorado e sanduíche con cedidas e pelo apoio financeiro.

À Agência Internacional de Energia Atômica pelo sup orte financeiro.

E a todos que de alguma forma contribuíram para realização deste trabalho. 


\title{
ANÁLISE DE SIS TEMAS MULTIFÁS ICOS UTILIZANDO TOMOGRAFIA COMPUTADORIZADA GAMA MONOENERGÉTIC A E POLIEN ERGÉTIC A
}

\author{
Pablo Antonio Vásquez Salva dor \\ RESUMO
}

\begin{abstract}
A tecnologia de reatores multifásicos é o coração das transformações químicas de todos os processos industriais, concretamente $99 \%$ dos reatores trabalham com a presença de uma ou mais fases. A tomografia é uma técnica poderosa capaz de determinar o efeito de parâmetros operacionais e de desenho na distribuição do holdup das fases, visualizando sistemas opacos de uma forma não invasiva. Um tomó grafo computadorizado de fonte única (SSCT) com capacidade de gerar imagens para as distribuições de holdup em sistemas com duas fases dinâmicas foi desenvolvido e validado com sucesso no CTR/IPEN. Algoritmos para reconstrução de imagens analíticos e discretos ou iterativos (estatísticos) foram desenvolvidos e implementados para tais aplicações e depois comparados. O SSCT foi utilizado para determinar as distribuições de porosidades e de holdup dos sólidos para uma coluna de recheio aleatório. Na Washington University em St. Louis, no Laboratório de Engenharia da Reação Química (CREL), um tomógrafo com duas fontes radioativas (DSCT) capaz de gerar imagens da distribuição do holdup das fases para sistemas dinâmicos com três fases móveis foi validado com êxito. Uma nova metodologia para reconstrução de imagens, que garantiu alta precisão na geração das distribuições do holdup em sistemas de grande porte, foi aplicada. O DSCT permitiu avaliar a influência de parâmetros de operação e do desenho de um aerador em um bioreator na escala piloto. $\mathrm{O}$ efeito do desenho de um distribuidor de gás - líquido e do regime de escoamento foram determinados para um reator monolítico utilizando o DSCT. Os equipamentos e técnicas desenvolvidas neste trabalho podem ser considerados como uma ferramenta efetiva de pesquisa, intensificando estudos experimentais em uma grande gama de sistemas multifásicos através de geração de imagens. Para isto, foram superadas várias limitações comuns a outras técnicas tomográficas existentes utilizadas no estudo de sistemas com duas e três fases dinâmicas, onde os conhecimentos adquiridos nestes estudos poderão melhorar a compreensão básica dos efeitos de desenho e dinâmica em reatores multifásicos.
\end{abstract}




\title{
MONOENERGETIC AND POLYENERGETIC GAMMA RAY COMPUTER TOMOGRAPHY FOR MULTIPHAS E S YS TEMS ANALYSIS
}

\section{Pablo Antonio Vásquez Salva dor}

\begin{abstract}
It is important to recognize that at the heart of chemical transformations in all process and energy industries is multiphase reator technology, as over $99 \%$ of reator systems require the presence of more than one phase for proper op eration. Tomography is a powerful technique capable of determining the effect of operating and design parameters on the phase holdup distribution by visualization in opaque flow systems in a noninvasive manner. A single source computed tomography (SSCT) system capable of imaging phase holdup distribution in two phases flow was successfully developed and validated at CTR/IPEN. Analytical and discrete (statistical) image reconstruction algorithms were developed and compared between them. SSCT has been applied to characterize the gas holdup and porosity distributions in a random packed column. At the Chemical Reaction Engineering Laboratory (CREL) of Washington University in St Louis, a novel dual source computed tomography (DSCT) system capable of imaging phase holdup distribution in three phases flow was successfully developed and validated. A new image reconstruction methodology was applied for the image reconstruction of the DSCT which enables accurate imaging of the phase holdup distribution in large scale multiphase systems. DSCT has been applied to characterize the effect of operating parameters and sparger design on the liquid flow behavior of a pilot scale anaerobic bioreactor. Performance studies were carried to access the performance of a gas-liquid distributor and liquid flow in a monolithic reactor using the DSCT. The scanners and techniques developed as part of this work provides an effective research tool for expanding experimental research in a wide range of multiphase flow systems via imaging. It has overcome many limitations, common to the various tomography techniques that exist for imaging sy stems with two and three phase flow. The knowled ge gained from these studies improves the fundamental understanding of the effects of design and dynamics of multiphase reactors.
\end{abstract}




\section{SUMÁRIO}

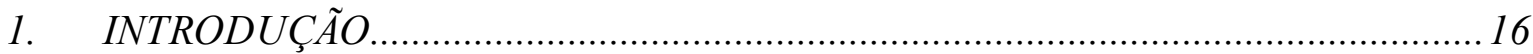

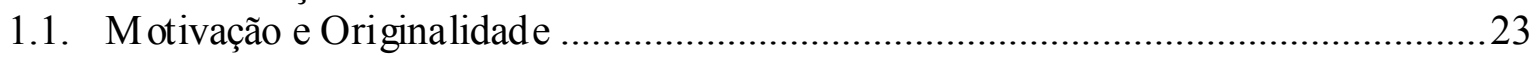

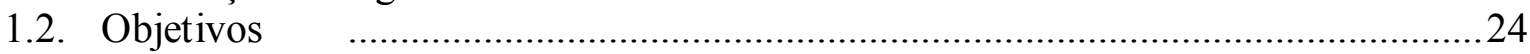

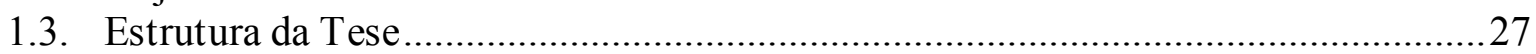

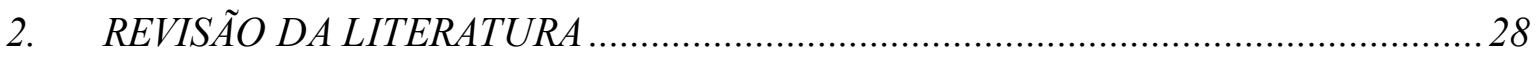

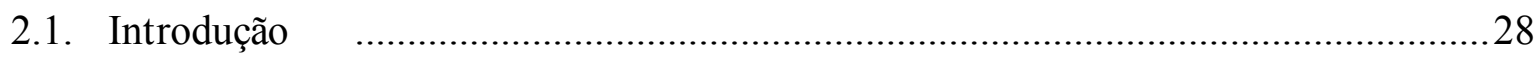

2.2. Estudos de sistemas com duas fases dinâmicas utilizando a tomografia gama ..........29

2.3. Estudos de sistemas com três fases dinâmicas utilizando a tomografia gama e

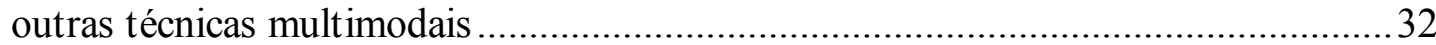

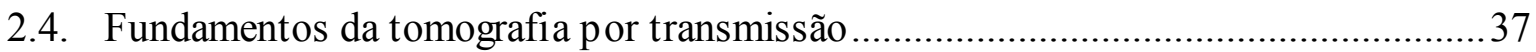

3. ESTUDO SIMULADO DE UM TOMÓGRAFO GAMA DE SEGUNDA GERAÇÃO E RECONSTRUÇÃO DE IMAGENS UTILIZANDO A

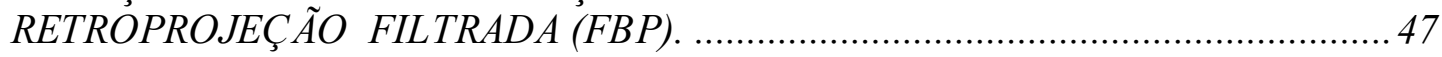

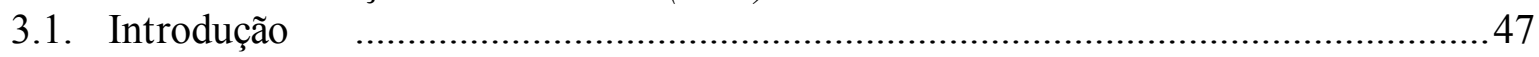

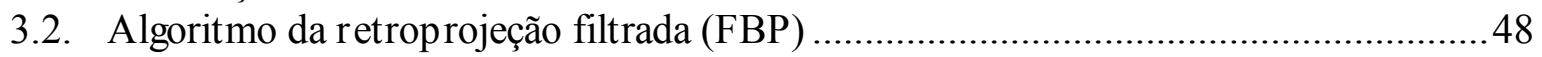

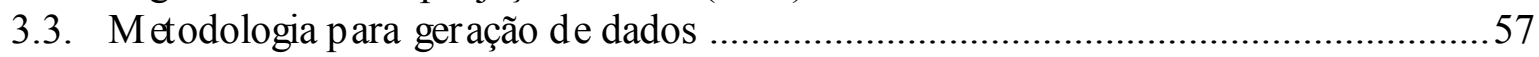

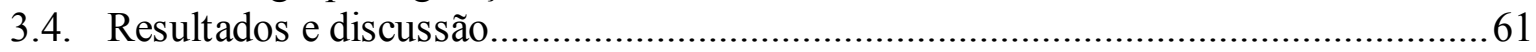

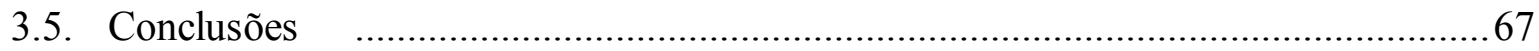

4. DESENVOLVIMENTO DE UM TOMÓGRAFO DE FONTE ÚNICA (SSCT) .......... 69

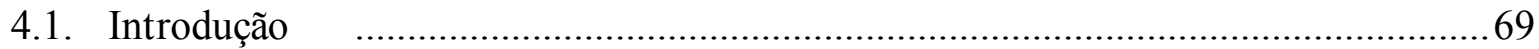

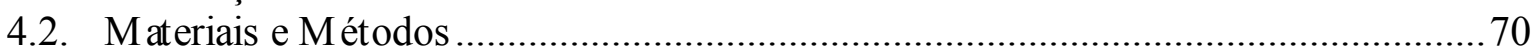

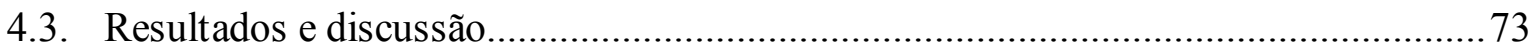

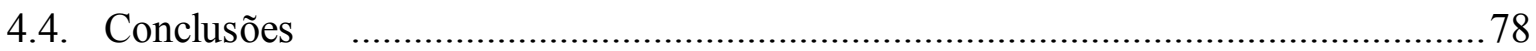

5. COMPARAÇÃO ENTRE RETROPROJEÇÃO FILTRADA (FBP), ESPERANÇA-MAXIMIZAÇÃO (EM) E MINIMIZAÇÃO ALTERNATIVA (MA) PARA A RECONSTRUÇÃO DE IMAGENS MONOENERGÉTICAS ........................ 79

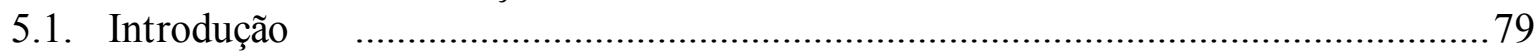

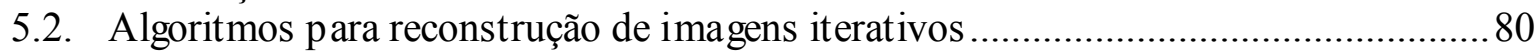

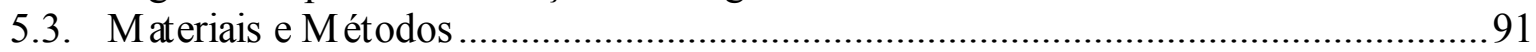

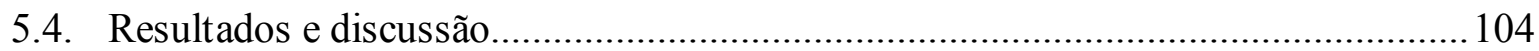

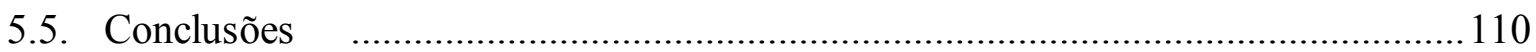

6. ESTUDO DA DISTRIBUIÇÃO DE POROSIDADE E DO HOLDUP DE SÓLIDOS DO RECHEIO DE UMA COLUNA EMPACOTADA …......................... 112

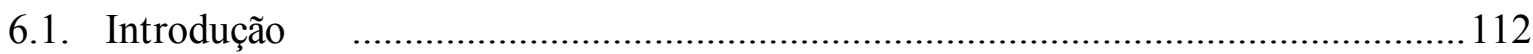

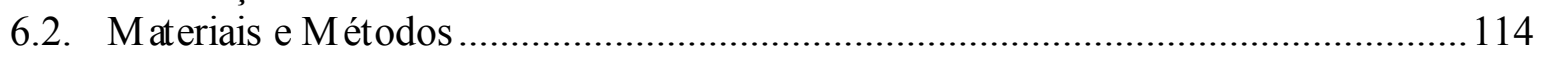

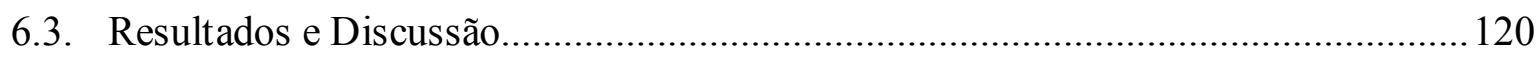

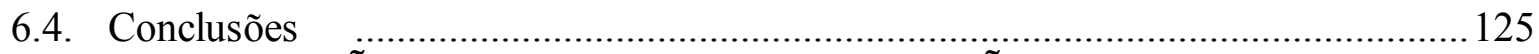

7. COMPARAÇÃO DA MINIMIZAÇÃO ALTERNATIVA MONOENERGÉTICA (MAME) E A MINIMIZAÇÃO ALTERNATIVA POLIENERGÉTICA (MAPE) PARA RECONSTRUÇÃ̃O DE IMAGENS DE

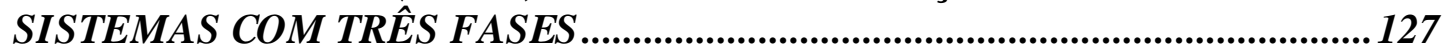

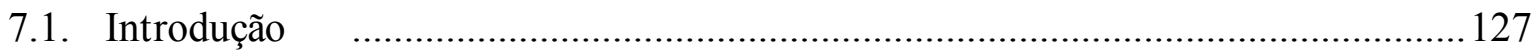

7.2. Seleção das fontes radioativas gama.................................................................. 128

7.3. Aproximação utilizando a Minimização Alternativa Monoenergética (MAME)..... 129

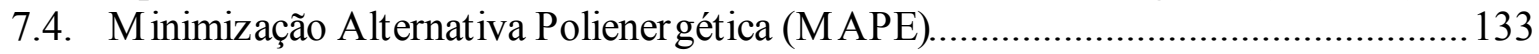

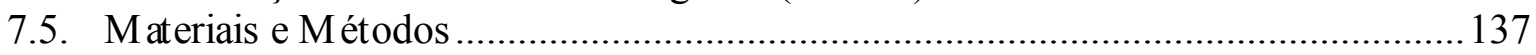

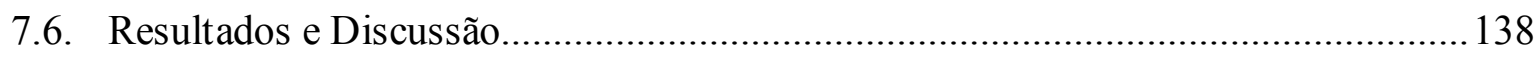


7.7. Conclusões

8. ESTUDO DE UM BIOREATOR ANAERÓBICO EM ESCALA PILOTO UTILIZANDO A TOMOGRAFIA POLIENERGÉTICA - DSCT …........................ 150

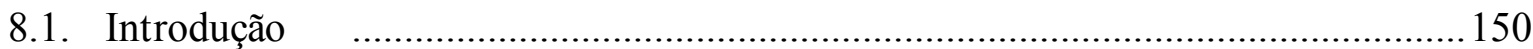

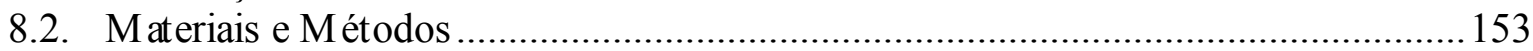

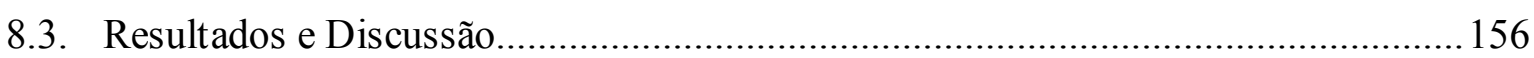

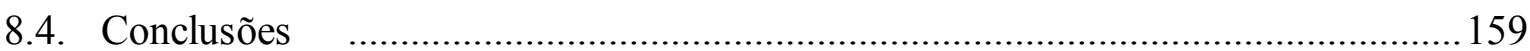

9. ESTUDO DO EFEITO DO DISTRIBUIDOR DE UM REATOR MONOLÍTICO UTILIZANDO A TOMOGRAFIA POLIENERGÉTICA - DSCT …........................... 160

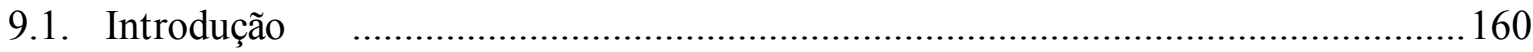

9.2. Características geométricas dos reatores monolíticos .............................................. 164

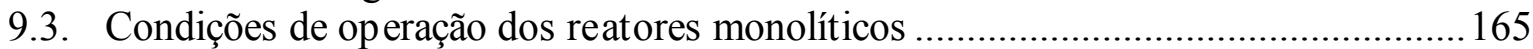

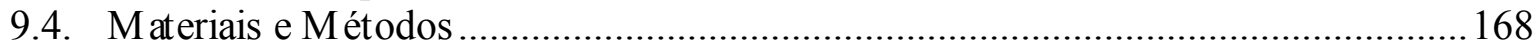

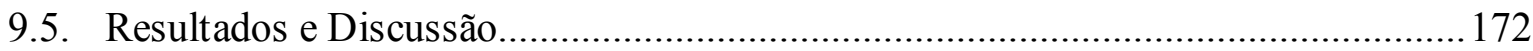

9.6. Conclusões 192

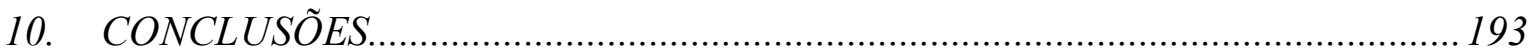

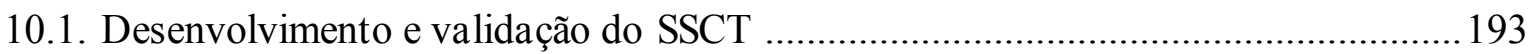

10.2. Algoritmos para tomografia de processos multifásicos ........................................... 193

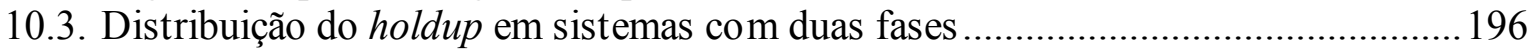

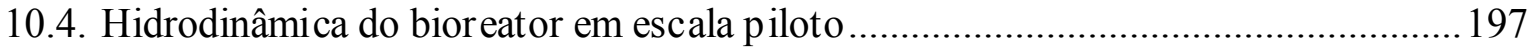

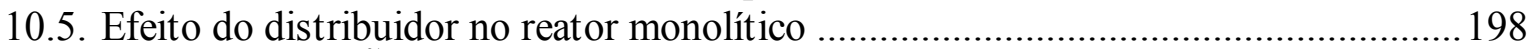

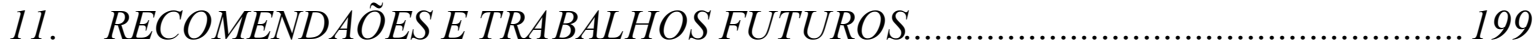

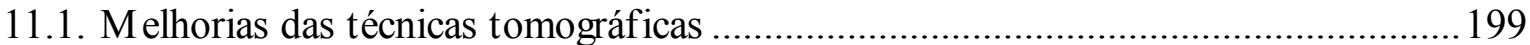

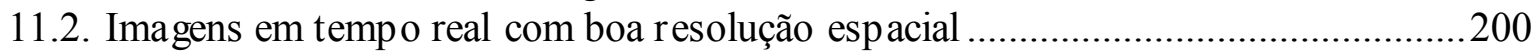

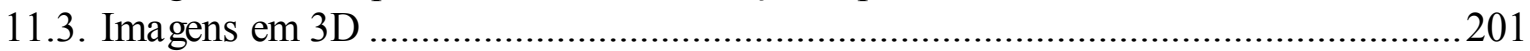

11.4. Outros estudos de sistemas multifásicos com o DSCT ….........................................202

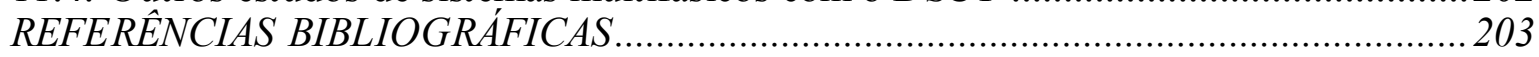




\section{LISTA DE TABELAS}

TABELA 1 - Aplicações da tecnologia de reatores multifásicos.

TABELA 2 - Produção e nível de sofisticação industrial.

TABELA 3 - Possíveis radioisótopos para aplicações tomográficas (Ledere et al., 1996).

TABELA 4 - Filtros utilizados na reconstrução FBP.

TABELA 4 - Detalhes das fases dos subdomínios do phantom......

TABELA 5 - Casos estudados mudando o número de projeções e abertura de colimação.

TABELA 6 - Casos estudados mudando o número de ângulos mantendo fixa a abertura de colimação.

TABELA 7 - Parâmetros estudados nos casos analisados. 74

TABELA 8-RMSE relativos a pixels $(N)$ e coeficientes de atenuação $(\mu)$. 77

TABELA 9 - Detalhes das fases dos subdomínios do phantom (FIGURA 21). 92

TABELA 10 - Coeficientes de atenuação para os materiais do phantom. 93

TABELA 11 - Regiões energéticas de operação para o DSCT. 106

TABELA 12 - Resultados do RMSE(N) para o Caso 1. 109

TABELA 13 - Resultados do RMSE( $\mu$ ) para o Caso 1. 109

TABELA 14 - Resultados do RMSE(N) para o Caso 2. 109

TABELA 15 - Resultados do RMSE( $\mu$ ) para o Caso 2. 110

TABELA 16-Características dos anéis Raschig utilizados fabricados em aço. 114

TABELA 17 - Valores médios e desvios padrões da porosidade obtidos da tomografia.. 122

TABELA 18 - Condições de operação do bioreator. 155

TABELA 19 - Valores médios da distribuição do holdup do gás e valores do fator de má distribuição dentro da tubu lação guia. 158

TABELA 20 - Características do reator monolítico. 169 
TABELA 21 - Condições experimentais das velocidades superficiais de gás e de líquido.

TABELA 22 - Grau de uniformidade $\sigma$ representado pelo desvio padrão da distribuição do holdup do líquido para $L / D=2$.

TABELA 23 - Grau de uniformidade representado pelo desvio padrão da distribuição do holdup do líquido para $L / D=5$.

TABELA 24 - Grau de uniformidade representado pelo desvio padrão da distribuição do holdup do líquido para $L / D=7$. 


\section{LISTA DE FIGURAS}

FIGURA 1 - Esquema das etapas seguidas para atingir os objetivos planejados neste estudo.

FIGURA 2 - Esquema do princípio de um sistema tomográfico.

FIGURA 3 - (A) translação-rotação de um feixe em paralelo (primeira geração); (B) translação - rotação de múltiplas fontes em paralelo (segunda geração); (C) rotação de um feixe em leque (terceira geração); (D) detector fixo - rotação da fonte (quarta geração). D: detectores; F: fonte; $C$ : colimador; O: objeto estudado.

FIGURA 4 - Esquema geométrico das projeções obtidas de um objeto (Kak \& Slaney, 2001).

FIGURA 5 - Teorema da fatia central (Kak \& Slaney, 2001). .52

FIGURA 6 - Representação esquemática da transformada de Fourier de um determinado número de conjuntos de projeções para diferentes ângulos no plano (u.v). Os dados experimentais são discretos (pontos azuis) e portanto finitos. (Kak \& Slan ey, 2001)........53

FIGURA 7 - Processo de reconstrução de imagens utilizando a FBP. 55

FIGURA 8 - Exemplo da aplicação de uma função de apodização nas frequências w: Filtro Hann 56

FIGURA 9 - Esquema do phantom gerado por simulação. 58

FIGURA 10 - Esquema do arranjo para fontes e detectores do CT gama de segunda geração simulado. O CT gira ao redor do objeto para várias posições (views) e faz a medição da rad iação transmitida para cada detector.

FIGURA 11 - Vista superior das simulações do CT e phantom para as condições estudadas. Efeito do número de projeções e a abertura da colimação (A) Caso 1, (B) Caso2, (C) Caso 3 e (D) Caso 4.

FIGURA 12 - Vista frontal do phantom e a posição das fontes e detectores para o caso geral.

FIGURA 13 - Amostragem feita pela simulação dos fótons dos raios gama gerados pelas fontes para os Casos 1-4 no sistema espacial X-Y-Z.

FIGURA 14 - Efeito da abertura da colimação (A)Caso1: 2,1 cm, (B)Caso2: 1,0 cm, (C)Caso3: 0,67 cm e (D)Caso 4: 0,5 cm. 
FIGURA 15 - Número de ângulos de rotação (A)Caso 1: 11, (B)Caso 2: 44, (C)Caso 3: 90 e (D)Caso 4: 360

FIGURA 16 - Efeito do filtro para 0,67 cm de colimação e 90 ângulos de rotação (A)

Shepp-Logan, (B) cosine, (C) Hamming e (D) Hann.

FIGURA 17 - Descrição do sistema tomográfico SSCT.

FIGURA 18 - Detalhes do phantom da AIEA fabricado em polipropileno.

FIGURA 19 - Sinogramas obtidos com o phantom. (A) Caso 1, (B) Caso 2, (C) Caso 3, (D) Caso 4

FIGURA 20 - Distribuição dos coeficientes de atenuação utilizando a FBP para: (A) Caso 1, (B) Caso 2, (C) Caso 3, (D) Caso 4, (E) Caso 5, (F) Caso 6, (G) Caso 7............. 76

FIGURA 21 - Imagens $3 D$ reconstruidas a partir de várias fatias transversais: (A) Caso 1, (B) Caso 2, (C) Caso 3.

FIGURA 22 - Esquema da tomografia por transmissão. Os quadrantes representam os pixels.

FIGURA 23 - Esquema do phantom estudado (3 fases). (A) Regiões C1 e C2 (fase gasosa) confeccionadas com tubulação de Perplex de 2 pol. Regiões S1-S3 fabricadas com vidro plumbifero (fase sólida). As regiões C1, C2 e S1-S3 estão compreendidas dentro da região B. (B) Detalhe das dimensões do phantom (altura aproximada 2,5 pol.) 92

FIGURA 24 - Esquema do sistema DSCT - Vista superior. Regiões marcadas em vermelho (entre a fonte e os detectores) indicam o campo de ação das fontes radioativas. 94

FIGURA 25 - Vista superior do DSCT. 95

FIGURA 26 - Vista frontal do DSCT. 96

FIGURA 27 - Vista superior de um leque do DSCT formado pelos arranjos de colimadores e detectores. 97

FIGURA 28 - Detalhe dos colimadores externos fabricado em chumbo colocados na parte frontal de cada detector. 98

FIGURA 29 - Detalhes do irradiador do DSCT. 99

FIGURA 30 - Seção A-A mostrando o irradiador, detectores e o raio de ação da fonte radioativa. 
FIGURA 31 - Motores de passo e mecanismo associado ao deslocamento dos detectores.

FIGURA 32 - Espectro de energias das fontes de ${ }^{137} \mathrm{Cs} e{ }^{60}$ Co mostrando as regiões de operação dos fotopicos.

FIGURA 33 - Sinogramas obtidos do phantom multifásico. (A,C) Fotopico de $1332 \mathrm{keV}$ para o ${ }^{60}$ Co dos Casos 1 e 2 (TABELA 10). (B,D) Fotopico de $662 \mathrm{keV}$ para o ${ }^{137} \mathrm{Cs}$ para os Casos 1 e 2 .

FIGURA 34 - I-divergência em função do número de iterações para ${ }^{137} \mathrm{Cs}$ e ${ }^{60} \mathrm{Co}$ dos casos 1 e 2 106

FIGURA 35 - Caso 1: Reconstruções monoenergéticas teóricas, FBP, EM e MA dos coeficientes de atenuação $\left(\mathrm{cm}^{-1}\right)$ nas regiões dos fotopicos $R 1$ (1173 keV), R2 (1332 keV) e R3 (1173 keV e $1332 \mathrm{keV}$ ) em imagens de 80x80 pixels.

FIGURA 36 - Caso 2: Reconstruções monoenergéticas teóricas, FBP, EM e MA dos coeficien tes de atenuação $\left(\mathrm{cm}^{-1}\right)$ nas regiões dos fotopicos $R 1$ (1173 keV), R2 (1332 keV) e R3 (1173 keV e $1332 \mathrm{keV}$ ) em imagens de 80x80 pixels.

FIGURA 37 - Esquema do SSCT e da coluna analisada. (A) Vista frontal. (B) Vista superior.

FIGURA 38 - Distribuições da porosidade e do holdup de sólidos dos anéis Raschig para $L / D=2$. (A,B) $12,6 \mathrm{~mm}$. (C,D) $37,9 \mathrm{~mm}$. (E,F) $76 \mathrm{~mm}$

FIGURA 39 - Histogramas da distribuição da porosidade obtidos da tomografia e a função de distribuição da porosidade dos anéis Raschig: (A) 12,6 mm. (B) 37,9 mm. (C) 76 $m m$

FIGURA 40 - Distribuição radial da porosidade para os anéis Raschig utilizados.

FIGURA 41 - Distribuição radial do holdup do sólido para os anéis Raschig utilizados.

FIGURA 42 - Coeficiente de atenuação em função da energia para vidro plumbífero, pyrex é água(a). NIST (Hubbell and Seltzer 1996)....

FIGURA 43 - MAME - Distribuição do holdup para o Caso 1. (A) Gás, (B) Líquido e (C) Sólido.

FIGURA 44 - MAME - Distribuição do holdup para o Caso 2. (A) Gás, (B) Líquido e (C) Sólido. 
FIGURA 45 - I-divergência em função do número de iterações para diferentes valores inicia is do holdup para os Casos 1 e 2.

FIGURA 46 - MAPE - Distribuição do holdup para o Caso 1. (A) Gás, (B) Líquido e (C) Sólido.

FIGURA 47 - MAPE Distribuição do holdup para o Caso 2. (A) Gás, (B) Líquido e (C) Sólido.

FIGURA 48 - Comparação do holdup ideal com os resultados obtidos com MAPE e MAME ao longo da linha do diâmetro (seção transversal) para o Caso 1.

FIGURA 49 - Comparação do holdup ideal com os resultados obtidos com MAPE e MAME ao longo da linha do diâmetro (seção transversal) para o Caso $2 .$.

FIGURA 50 - Bioreator estudado com o sistema DSCT. (A) Reator vazio. (B) Reator carregado.

FIGURA 51 - Esquema do bioreator e aerador utilizados.

FIGURA 52 - Distribuições do holdup (time averaged) na tubu lação guia para os Níveis 1 e 2. (A) $Q_{g}=4,5 \mathrm{l} / \mathrm{min},(B) Q_{g}=9,0 \mathrm{l} / \mathrm{min},(C) Q_{g}=18,9 \mathrm{l} / \mathrm{min}$.

FIGURA 53 - Esquema de um reator monolitico.

FIGURA 54 - Seção transversal de uma celular simples. $R$ é o raio de curvatura do canal (normalmente não é especificado). (Roy, 2006).

FIGURA 55 - Regime de escoamento em um capilar simples $(d=0,5 \mathrm{~mm})$ : em bolhasbubbly flow, pistonado ou intermitente - slug, agitante - churn e anular; Mishima et al. 1996. Janela com as condições experimentais aplicadas neste trabalho.

FIGURA 56 - Esquema dos regimes de escoamentos recomendados para reatores monolíticos (A) Pistonado ou in termitente (Slug), (B) Anular.

FIGURA 57 - Detalhe do reator monolitico instalado no centro do sistema DSCT.

FIGURA 58 - Esquema do reator monolítico operado em co-corrente. Detalhe do distribuidor. Niveis escaneados pelo DSCT $L / D=2$, 5 e 7.

FIGURA 59 - Distribuição do holdup do gás para $L / D=2$.

FIGURA 60 - Distribuição do holdup do líquido para $L / D=2$.

FIGURA 61 - Distribuição do holdup do gás para $L / D=5$. 
FIGURA 62 - Distribuição do holdup do líquido para $L / D=5$.

FIGURA 63 - Distribuição do holdup do gás para $L / D=7$.

FIGURA 64 - Distribuição do holdup do líquido para $L / D=7$.

FIGURA 65 - Valores médios do holdup para (A) $L / D=2$, (B) $L / D=5$, (C) $L / D=7$

FIGURA 66 - Influên cia da velocidade do gás na distribuição radial do holdup do líquido para $L / D=2:$ (A) $U_{L}=5 \mathrm{~cm} / \mathrm{s}$, (B) $U_{L}=10 \mathrm{~cm} / \mathrm{s}$, (C) $U_{L}=20 \mathrm{~cm} / \mathrm{s}$ e (D) $U_{L}=26 \mathrm{~cm} / \mathrm{s}$

FIGURA 67 - Influência da velocidade do líquido na distribuição radial do holdup do líquido para $L / D=2$. (A) $U_{G}=13 \mathrm{~cm} / \mathrm{s}$, (B) $U_{G}=20 \mathrm{~cm} / \mathrm{s}$, (C) $U_{G}=50 \mathrm{~cm} / \mathrm{s}$ e (D) $U_{G}=100$ $\mathrm{cm} / \mathrm{s}$

FIGURA 68 - Influência da velocidade do gás na distribuição radial do holdup do líquido para $L / D=5$. (A) $U_{L}=5 \mathrm{~cm} / \mathrm{s}$, (B) $U_{L}=10 \mathrm{~cm} / \mathrm{s}$, (C) $U_{L}=20 \mathrm{~cm} / \mathrm{s}$ e (D) $U_{L}=26 \mathrm{~cm} / \mathrm{s}$ 184

FIGURA 69 - Influência da velocidade do líquido na distribuição radial do holdup do líquido para $L / D=5$. $U_{G}=13 \mathrm{~cm} / \mathrm{s}$, (B) $U_{G}=20 \mathrm{~cm} / \mathrm{s}$, (C) $U_{G}=50 \mathrm{~cm} / \mathrm{s}$ e (D) $U_{G}=100 \mathrm{~cm} / \mathrm{s}$ 185

FIGURA 70 - Influência da velocidade do gás na distribuição radial do holdup do líquido para $L / D=7$. (A) $U_{L}=5 \mathrm{~cm} / \mathrm{s}$, (B) $U_{L}=10 \mathrm{~cm} / \mathrm{s}$, (C) $U_{L}=20 \mathrm{~cm} / \mathrm{s}$ e (D) $U_{L}=26 \mathrm{~cm} / \mathrm{s}$ 186

FIGURA 71 - Influência da velocidade do líquido na distribuição radial do holdup do líquido para $L / D=7$. (A) $U_{G}=13 \mathrm{~cm} / \mathrm{s}$, (B) $U_{G}=20 \mathrm{~cm} / \mathrm{s}$, (C) $U_{G}=50 \mathrm{~cm} / \mathrm{s}$ e (D) $U_{G}=100$ $\mathrm{cm} / \mathrm{s}$

FIGURA 72 - Grau de uniformidade para (A) $L / D=2$, (B) $L / D=5$, (C) $L / D=7$. Valores baixos significam maior uniformidade (azul).

FIGURA 73 - Reconstrução $3 D$ do holdup do líquido para $L / D=2, L / D=5$ e $L / D=7$. 


\section{LISTA DE ABREVIATURAS E/OU SIGLAS}

AIEA: Agencia Internacional de Energia Atômica (IAEA)

ART: $\quad$ Técnica de Reconstrução Algébrica

CNPq: Conselho Nacional de Desenvolvimento Científico e Tecnoló gico

CREL: Laboratório de Engenharia da Reação Química (Chemical Reaction Engineering Laboratory)

CT: $\quad$ Tomografia Computadorizada

CTR: $\quad$ Centro de Tecnologia das Radiações.

DSCT: $\quad$ Tomógrafo de fonte dual (Dual source CT)

EM: $\quad$ Esperança - Maximização

FPB: $\quad$ Retroprojeção Filtrada (Filtered BackProjection)

IPEN: Instituto de Pesquisas Energéticas e Nucleares

MA: $\quad$ Minimização Alternativa

MAME: M inimização Alternativa Monoenergética

MAPE: M inimização Alternativa Polienergética

MCNP: $\quad$ A General Monte Carlo N-Particle Transport Code

MMC: $\quad$ Método de Monte Carlo

RMSE: $\quad$ Erro Médio Quadrático (Root Mean Squared Error)

SSCT: $\quad$ Tomógrafo de fonte única (Single source CT)

WUSTL: Washington University em St. Louis 


\section{INTRODUÇÃO}

Nas últimas décadas a humanidade tem criado consciência da limitação dos recursos naturais, motivo que vem pressionando a indústria a desenvolver processos mais limpos e modernos que permitam alcançar um verdadeiro desenvolvimento sustentável. Fornecimento de energia, alimento, moradia e saúde de uma população em crescimento sem danificar irreversivelmente o meio ambiente é a chave para enfrentar os desafios globais que enfrentamos na atualidade. Países em desenvolvimento aspiram incrementar o mercado dos seus produtos e, consequentemente, aspiram melhorar seus padrões de vida. Considerando o fato de que há incertezas sobre o aquecimento global e a certeza de que alguns recursos são finitos, o desafio para a indústria de processos é melhorar a eficiência do uso da energia e recursos materiais, enquanto que o impacto ambiental deve ser reduzido drasticamente.

Existem dois fatores que influenciam o meio ambiente global e a sustentabilidade das nossas atividades; estes são o número de habitantes e seu estilo de vida. Práticas agrícolas, desmatamentos para cultivo de terras, irrigação de desertos, incremento no uso de herbicidas e pesticidas, etc. são todos obviamente importantes. Exploração de minerais não renováv eis ou recursos energéticos com técnicas de mineração subterrânea ou de decapeamento afetam o meio ambiente. Eficiência na utilização de energia, perfurações petroleiras de ár eas virgens e de oceanos, uso de energia hidroelétrica tem impacto ambiental. Atividades de lazer, tais como, dirigir veículos motorizados na neve, nas dunas das praias e desertos (buggy) tem diferentes impactos ambientais. Tão 
importante quanto as anteriormente citadas é a fabricação de todos os produtos, tais como combustíveis, químicos, plásticos, pesticidas, e farmacêuticos que fazem alternativos os estilos de vida, e que fazem parte do campo da engenharia química e de processos. Este campo consiste em todas as transformações físicas e químicas (incluindo as biológicas) de matérias-primas provenientes de recursos renováveis e não renováveis em uma variedade de produtos nos quais temos baseado a nossa qualidade de vida.

A poluição total gerada em primeira aproximação pode estar relacionada com quatro fatores: a) poluição gerada por unidade de energia utilizada, a mesma que depende do nível tecnológico disponível e da eficiência dos processos, (b) energia utilizada para geração do PIB, que depende dos fatores do mercado, (c) PIB/ per capita, afetado pelo crescimento econômico, e (d) população total. Desta forma, o impacto do meio ambiental global pode ser apresentado como o produto do consumo per capita vezes a população vezes a ineficiência do processo (1-eficiência do processo).

$$
\left(\begin{array}{c}
\text { Impacto no meio } \\
\text { ambiente global }
\end{array}\right) \propto 1 \text { - eficiência do processo (consumo per capita) (população) }
$$

Devido ao fato da população e do consumo per capita aumentarem sem barreiras, é evidente que a poluição ambiental pode ser diminuída controlando o crescimento populacional ou o consumo per capita ou ambos. Controlar o crescimento populacional é o parado xo de duas importantes religiões e a redução no consumo per capita é uma heresia contra o sistema de livre comércio. Nenhuma destas é uma solução politicamente correta. Portanto, a solução a longo prazo para o desafio global na redução do impacto ambiental das atividades tecnológicas está no aumento integral da eficiência dos processos em energia e materiais. Está mudança pode tomar muito tempo e pode estar 
influenciada por fatores sócio-econômicos como a globalização; de forma geral a solução baseia-se na implementação de processos mais eficientes e inovadores e a aplicação de processos químicos limpos (green chemistry ${ }^{1}$ ). Grandes investimentos da parte do governo e da indústria em pesquisas básicas para gerar produtos químicos "verdes" e melhores catalisadores seriam necessários, além de novas políticas como a de isenção de impostos que incentivem esta transformação. Este fato gera um risco associado, porém, investindo mais na ciência da "amp liação da escala" (scale-up), o risco envolvido na comercialização de novas tecnologias diminuiria consideravelmente e, como consequência, a abertura para implementação de novas tecnologias aumentaria. Esta última é o desafio da engenharia da reação multifase nas próximas décadas.

O coração das transformações químicas nas indústrias que envolvem processos e energia utilizam tecnologia de reatores multifásicos ${ }^{2}$, concretamente $99 \%$ dos reatores trabalham com a presença de uma ou mais fases. As principais aplicações desta tecnologia estão relacionadas na TABELA 1.

Para a implementação comercial de novas tecnologias e desenho de reatores, faz-se necessário predizer como diferem o comportamento das moléculas de reagentes (contato e reação), a variação da velocidade e a seletividad e das reações destes sistemas em relação as observadas no laboratório. Assim, a transferência das descobertas na escala molecular para o uso comercial é outro objetivo fundamental. Os métodos mais precisos de ampliação da escala (scale-up) permitem um risco baixo na comercialização de novas tecnologias (Dudukovic, 2002).

\footnotetext{
${ }^{1}$ Green chemistry, química verde, química limpa, química auto-sustentável.

${ }^{2}$ Reator multifásico, presença de duas ou mais fases: sólido, líquido, gás, etc.
} 
TABELA 1 - Aplicações da tecnologia de reatores multifásicos.

\begin{tabular}{|l|l|}
\hline \multicolumn{1}{|c|}{ Processo } & \multicolumn{1}{c|}{ Produtos } \\
\hline Refino de petróleo & $\begin{array}{l}\text { HDS, HDN, HDM, desparafinagem, combustíveis, } \\
\text { aromáticos, olefinas }\end{array}$ \\
\hline Geração de energia & Carvão, petróleo, gás, reatores nucleares. \\
\hline $\begin{array}{l}\text { Conversão de } \\
\text { biomassa }\end{array}$ & $\begin{array}{l}\text { Gás de síntese, metanol, etanol, azeites, produtos de } \\
\text { valor agregado }\end{array}$ \\
\hline $\begin{array}{l}\text { Conversão de gás de } \\
\text { síntese (syngas) e de } \\
\text { gás natural }\end{array}$ & $\begin{array}{l}\text { MeOH, DME, MTBE, parafinas, olefinas, álcoo is } \\
\text { superiores }\end{array}$ \\
\hline Produtos químicos & $\begin{array}{l}\text { Aldeidos, álcoois, aminas, ácidos, ésteres, LABs, } \\
\text { ácidos inor gân icos }\end{array}$ \\
\hline $\begin{array}{l}\text { Produtos químicos } \\
\text { especiais e } \\
\text { farmacêuticos }\end{array}$ & $\begin{array}{l}\text { Compostos de Ag, tinturas, fragrâncias, sabores, } \\
\text { fármacos, herbicid as, pesticidas }\end{array}$ \\
\hline $\begin{array}{l}\text { Polímeros e produção } \\
\text { de materiais }\end{array}$ & $\begin{array}{l}\text { Policarbonatos, PPO,poliolefinas, plásticos especiais, } \\
\text { semicondutores, fibra óptica }\end{array}$ \\
\hline Remediação ambiental & $\begin{array}{l}\text { De-NOx, De-SOx, HCFCs, DPA, processos limpos - } \\
\text { (green process } \text { ) }\end{array}$ \\
\hline
\end{tabular}

A ampliação da escala com êxito é influenciada pela escolha adequada do reator e pelas condições de operação para um determinado processo, mediante o entendimento de vários fatores cinéticos e de transporte. Por consequência, esta escolha afetará também a seletividade e a produção volumétrica, sendo que o problema está relacionado ao fato de que as possíveis interações (comportamento) nas várias escalas são dependentes da escala do equipamento.

Indústrias, tais como as petroquímicas, de forma geral tem acolhido estas mudanças e apresentam um nív el alto de sofisticação, produzindo uma quantidade pequena de produto indesejável por unidade de produto desejável. Esta relação é conhecida como fator E. Indústrias de tecnologia de ponta (alto valor agregado), como as de eletrônicos ou farmacêuticos apresentam altos valores de $\mathrm{E}$, mas do ponto de vista ambiental não são mais consideradas de tecnologia de ponta como mostrado na TABELA 2. Atualmente, o nível 
de tecnologia está diretamente relacionado ao retorno efetivo que estas tem pelos produtos fabricados, mas pelas condições atuais, a tendên cia é uma mudança nesta visão.

TABELA 2 - Produção e nível de sofisticação industrial.

\begin{tabular}{|c|c|c|}
\hline Indústria & $\begin{array}{c}\text { Produção } \\
\text { (ton/ano) }\end{array}$ & $\begin{array}{c}\text { Fator E - rejeito/produto } \\
\text { (w/w) }\end{array}$ \\
\hline Refino de petróleo & $10^{\circ}-10^{8}$ & $\sim 0,1$ \\
\hline Produtos químicos & $10^{4}-10^{\circ}$ & $<1-5$ \\
\hline Produtos químicos especiais & $10^{2}-10^{4}$ & $5-50$ \\
\hline Farmacêuticos & $10^{0}-10^{5}$ & $25 \rightarrow 100$ \\
\hline
\end{tabular}

Fonte - Trost, B.M., 1991

A função específica da engenharia é transferir novas descobertas científicas a novas tecnologias e práticas para o benefício da humanidade. Normalmente, estas atividades são desenvolvidas pelo departamento de pesquisa e desenvolvimento (P\&D) de cada companhia. Lamentavelmente, o P\&D da maioria das empresas não segue os passos adequados para a realização do scale-up, onde, a química envolvida é feita mediante teste e erro (análise combinatória, aproximações estatísticas etc.). A base do conhecimento, na maioria dos casos, utiliza correlações da década de cinquenta carregadas em planilhas de Excel. Desta forma, plantas concebidas desta maneira, mesmo utilizando os mais modernos catalisadores tem problemas de start-up com durações indefinidas, assim como, os testes contínuos em nível industrial se tornam uma norma. Então, a op eração "otimizada” de um reator proveniente de uma escolha errada sempre será inferior daquela que proporcionaria um reator selecionado e desenhado adequadamente, resultando na geração de mais rejeito e de baixa eficiência. Portanto, uma vez que as condições de conversão, rendimento e seletividade são otimizadas no laboratório, o seguinte passo seria reproduzir estes resultados em nível industrial, sem minimizar a importância das plantas piloto, cuja 
fabricação resulta lucrativa. Um scale-up adequado precisa do conhecimento dos tempos médios de residência ou tempos de contato entre as fases. Para isto, precisa-se conhecer o holdup ${ }^{3}$ das fases e velocidades e padrões de fluxos, entre outras condições.

Antigamente sistemas com duas fases dinâmicas eram modelados com aproximações de reatores em batelada (CSTR) ou fluxo pistão (PFR). O modelo de dispersão axial (ADM) satisfazia as observações experimentais, mas não era preditivo. Devido à dificuldade envolvida na análise de sistemas multifásicos em relação à medida de holdup e à distribuição de velocidades, faz-se fundamental ter ferramentas adequadas para estas determinações para que possam fornecer dados essenciais para a validação de modelos CFD (fluidodinâmica computacional), pois não existe na atualidade um código completamente preditivo, por causa da complexa interação das fases e da complexa modelagem da turbulência multifásica. Assim, os passos para o scale-up de um reator podem estar resumidos em 3 pontos: (a) obter os parâmetros físicos do fluxo mediante técnicas experimentais, (b) testar um CFD adequado e validar seus resultados experimentalmente e (c) desenvolver modelos físicos para fluxo e mistura e acoplá-los aos esquemas cinéticos do processo de interesse. Neste ponto, técnicas utilizando radio isótopos como a tomografia computadorizada gama (CT) e o CARPT (computer-assisted radioactive particle tracking) fornecem uma solução que permite obter parâmetros que descrevem completamente os fluxos, como, a distribuição de densidade e velocidades em diferentes posições do reator. Uma vez validado o CFD, este pode ser utilizado para gerar dados para o desenvolvimento do modelo do reator. Na presença de um grande número de reações químicas em várias fases, a resolução de balanços de espécies com CFD ainda é

\footnotetext{
${ }^{3}$ Holdup é a retenção de uma fase - fração volumétrica ocupada por uma fas e (gás, líquido, sólido).
} 
impraticável e demorada. No entanto, um reator baseado em um modelo físico desenvolvido a partir do CFD e validado com CT/CARPT pode obter as constantes de tempo para mistura e fluxo, podem assim ser acopladas à cinética (Dudukovic, 2007). Técnicas utilizando radioisótopos têm sido uma ferramenta muito importante para a aplicação do método de scale-up indicado anteriormente e as variações desta técnica tem sido usadas, por exemplo, no estudo de slurry bubble columns ${ }^{4}$ (SBC), risers líquido sólido e gás sólido, tanques agitados, reatores de leito fixo (trickle bed), etc.

A tomografia gama monoenergética tem obtido êxito no estudo de sistemas com duas fases dinâmicas, incluindo gás - líquido, líquido - sólido e gás - sólido. Esta também tem sido aplicada a sistemas gás - líquido - sólido quando a fase sólida é estacionária. Muitas aplicações, como as citadas anteriormente, apresentam três fases dinâmicas (gás - líquido - sólido), onde estes sistemas não podem ser estudados com os tomógrafos monoenergéticos pelas limitações no número de variáveis na resolução de um sistema de equações.

Muitas tentativas para a resolução de sistemas com três fases dinâmicas, mediante tomografia polienergética têm tido resultados limitados, ainda não comparáveis com os obtidos pela tomografia monoenergética para duas fases. Estas limitações estão relacionadas diretamente ao tipo de fonte radioativa (baixa energia) utilizada que não permite estudo de sistemas grandes (até 3 pol.); assim como, as técnicas de reconstrução de imagens e métodos para o cálculo de holdup, que em muitos casos não levam em conta a natureza estatística dos processos de desintegração radio ativa. Sistemas tomográficos duais que utilizam a tomografia gama em conjunto com a tomografia elétrica, ainda precisam de

\footnotetext{
${ }^{4}$ Slurry bubble colums, coluna de lama com borbulhamento, coluna de bolhas com sólidos.
} 
muito investimento em hardware experimental. Sistemas elétricos apresentam baixa resolução espacial e estão baseados em um número indeterminado de equações. Esta situação cria incerteza no que se refere as imagens obtidas por métodos duais (dual tomography). Assim, as técnicas para determinar o holdup de sistemas com três fases dinâmicas estão ainda longe do nív el atingido pelos sistemas com duas fases.

\subsection{Motivação e Originalidade}

A tomografia computadorizada (CT) para fins de imageamento do corpo humano foi implementada com sucesso desde a década de 70. Grandes empresas de equipamentos médicos se dedicaram a produzir em escala os CTs e hoje estes são encontrados em muitos hospitais. A sua produção em escala foi viabilizada, devido principalmente, a pouca variabilidade dimensional do corpo humano. Ao contrário, nas indústrias, os materiais a serem tomografados diferem muito entre si. Consequentemente, as aplicações da CT na indústria requerem uma análise e uma abordagem diferen ciada para cada caso e, portanto, necessitam de profissionais especializados diferentemente daqueles usados na medicina. Por outro lado, a tecnologia de fabricação da tomografia médica é de domínio de algumas empresas de grande porte e a maioria das referências encontradas na literatura se restringem aos desenvolv imentos matemáticos que nem sempre são ap licáveis na prática.

A contribuição original deste trabalho no Brasil diz respeito a aplicação e a validação de equipamentos tomográficos (SSCT) projetados no CTR/IPEN e ao desenvolvimento de técnicas de reconstrução de imagens para sistemas multifásicos (2 fases dinâmicas). Apesar do grande número de indústrias químicas e petroquímicas no país, que podem usufruir desta técnica tomográfica, visando aprimorar e melhorar a 
eficiência da sua produção; no Brasil, ainda não existem trabalhos relacionados a tomografia gama para a análise deste tipo de sistemas. A originalidade a nível mundial reside nos estudos realizados com o DSCT, pois, não são encontrados na literatura, análises de sistemas multifase utilizando duas fontes radioativas simultâneas que permitem estudar ate três fases dinâmicas, como realizado neste trabalho. Para este estudo, foram desenvolvidos e implementados algoritmos específicos como a Minimização Alternativa Polienergética (MAPE).

Este estudo está inserido nos projetos de cooperação internacional "Development of a computarized tomography for multiphase systems analyses" (n.12459/R0/RBF) e “Implementation of Gamma Industrial Process Computerized Tomography for Multiphase System Analysis in Brazil" (Proc. BRA 8031), apoiados pela Agência Internacional de Energia Atômica (AIEA), que tem como finalidade a difusão da tomografia computadorizada nas indústrias brasileiras. O projeto "Desenvolvimento de um Sistema Tomográfico Computadorizado para Análise de Processos Multifase em Torres de Refino" Ed ital CT-Petro/CNPq 17/2004 possibilitou a implementação do laboratório para o desenvolvimento de detectores de radiação, e outros equip amentos que foram utilizados no presente trabalho. No último ano, a Washington University em St. Louis (WUSTL) abriu suas portas oferecendo valiosas informações que fizeram possível a concretização das metas.

\subsection{Objetivos}

Este trabalho tem como propósito desenvolver e aplicar as técnicas de tomografia gama por transmissão monoenergética e polienergética para o estudo de sistemas multifásicos. O termo monoen ergético refere-se ao uso de uma fonte radioativa 
única (uma en ergia), enquanto o termo polienergético diz respeito ao uso de duas ou mais fontes (duas ou mais energias).

Portanto, inicialmente foi desenvolvido e implementado o algoritmo para reconstrução de imagem denominado retroprojeção filtrada (FBP). Para isto foram obtidas projeções simulando sistemas multifase estáticos (phantoms) utilizando o método de Monte Carlo para o transp orte da radiação. A seguir, foi construído um tomó grafo de fonte única (SSCT) no CTR/IPEN que permitiu o estudo de um phantom enviado pela AIEA. Na Washington University em St. Louis (WUSTL), no Laboratório de Engenharia da Reação Química (CREL) foram desenvolvidos e implementados os algoritmos para reconstrução de imagem Esperança-Maximização (EM) e Minimização Alternativa (MA). O SSCT foi utilizado para estudar a distribuição dos anéis Raschig metálicos de uma coluna de recheio e usando a MA foram obtidas as distribuições de porosidades e de holdups do sólido. Também foi testado e validado um tomó grafo com duas fontes denominado DSCT (dual source computer tomograph). Para este último foram implementados e desenvolvidos os algoritmos de reconstrução de imagens denominados Minimização Alternativa Polienergética (MAPE) e Minimização Alternativa Monoenergética (MAME). Um phantom multifase foi estudado, onde foram obtidas as distribuições de holdup aplicandose MAME e MAPE. As reconstruções monoenergéticas deste phantom utilizando-se FBP, EM e MA foram também comparadas. Um reator multifase monolítico e o seu distribuidor foram analisados utilizando-se o DSCT onde foram determinadas as distribuições de holdup (gás, líquido e sólido) assim como as cond ições de uniformidade.

A FIGURA 1 mostra o esquema das etapas desenvolvidas neste estudo para atingir os objetivos planejados. 


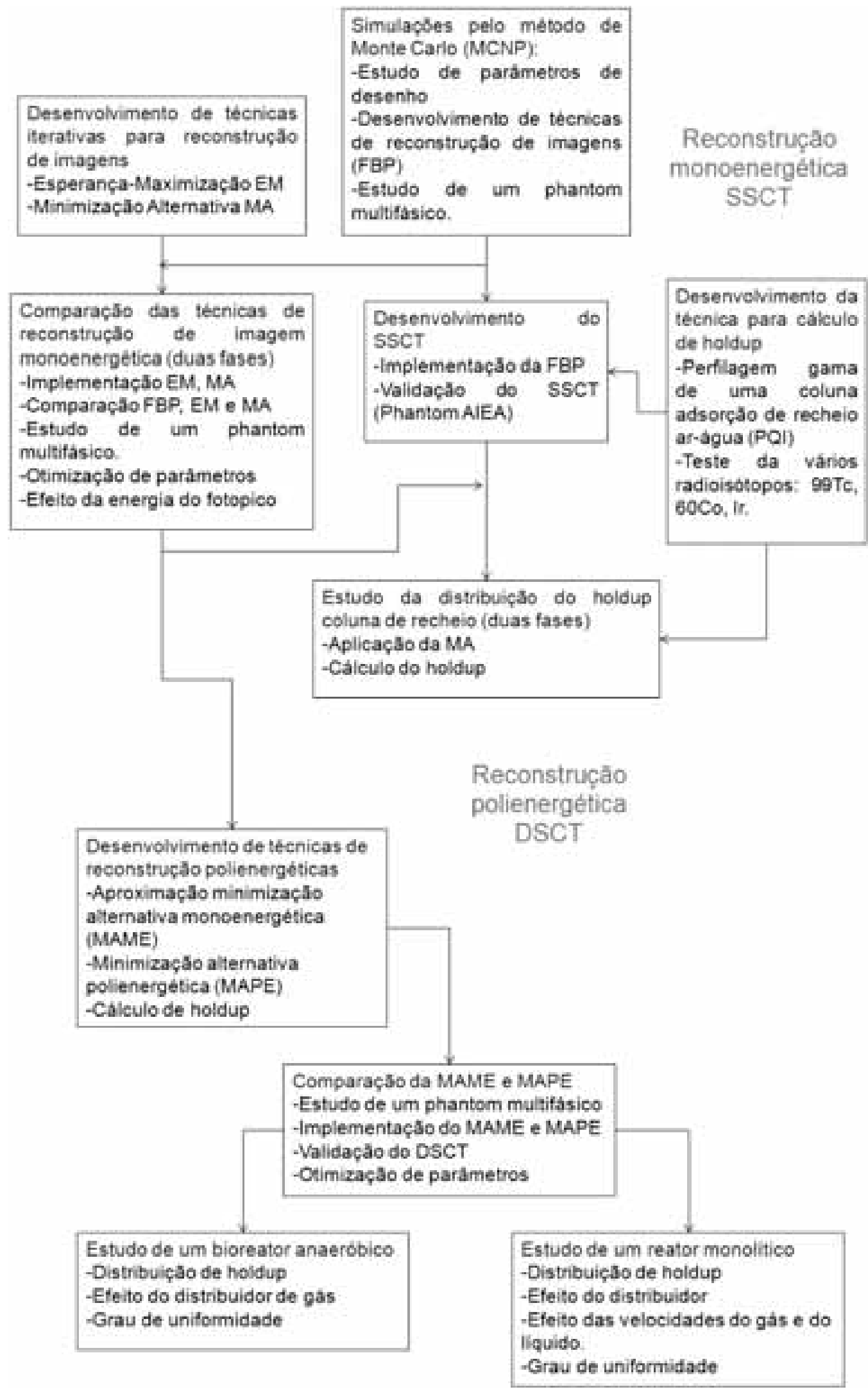

FIGURA 1 - Esquema das etapas seguidas para atingir os objetivos planejados neste estudo. 


\subsection{Estrutura da Tese}

A estrutura da tese nos próximos capítulos consiste de:

Capítulo 2: Revisão da literatura contendo os fundamentos da tomografia, assim como os métodos tomográficos utilizados para a determinação de parâmetros hidrodinâmicos em sistemas de duas e três fases.

Capítulos 3 e 4: Reconstrução de imagens utilizando retroprojeção filtrada e validação de um sistema tomográfico de fonte única.

Capítulo 5: Comparação entre os algoritmos analíticos e iterativos utilizados para reconstrução de imagens monoenergéticas com duas fases dinâmicas.

Capítulo 6: Reconstrução iterativa de imagens e cálculo de holdup para o caso de uma coluna de recheio aleatório com duas fases.

Capitulo 7: Discussão dos algoritmos polienergéticos utilizados para reconstrução de imagens hidrodinâmicas de sistemas com três fases.

Capítulo 8: Estudo de um bio-reator anaeróbico com as técnicas tomográficas polienergéticas e análise do efeito de um distribuidor de gás.

Capitulo 9: Estudo de um reator monolítico e o seu desempenho utilizando um distribuidor aperfeiçoado utilizando as técnicas polienergéticas.

Capítulos 10 e 11: Principais conclusões e recomendações obtidas nesta pesquisa. 


\section{REVIS ÃO DA LITERATURA}

\subsection{Introdução}

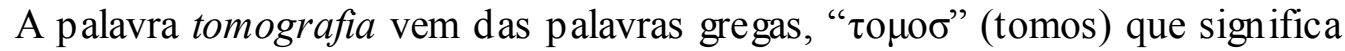
corte e " $\gamma \rho \alpha \varphi \varepsilon ı v "$ (graphein) que significa escrever. A tomo grafia surge como uma técnica de diagnóstico não invasiva, tradicionalmente utilizada na medicina, que permite a obtenção de imagens que revelam detalhes da distribuição da estrutura interna de um objeto com alta precisão e exatidão não sendo influen ciad as pela estrutura externa da seção estudada. Neste contexto, esta técnica oferece uma alternativa localizada e conveniente para a verificação de modelos matemáticos de processos, substituindo assim, técnicas tradicionais globais, como, o uso de traçadores e modelos compartimentais. A técnica da tomografia gama por transmissão não fornece dados em tempo real (baixa resolução temporal) e sim como uma média em relação ao tempo (time average), no entanto, possui alta resolução espacial. Uma revisão detalhada do desenvolvimento da tomografia, bem como, dos seus fundamentos foi discutida por Kumar \& Dudukovic (1997).

A tomografia, pode também, obter a distribuição, assim como, os perfis de concentração, limites e tamanhos das fases de vários tipos de reatores, fornecendo desta forma, dados valiosos para o projeto e otimização de equipamentos em grande escala. As imagens obtidas por esta técnica podem ser utilizadas também para propósitos de controle de uma planta, para funções de alarme, ou para monitorar o balanço de massa global ou parcial de um sistema ( Schiewe \& Tuzla, 1999). 
No Brasil, o grupo de Instrumentação Nuclear da Universidade Federal do Rio de Janeiro tem tido um papel importante no desenvolvimento e ap licação da tomografia em vários campos. Os primeiros trabalhos referem-se ao desenvolvimento de um sistema tomográfico por transmissão gama com dois detectores em forma de leque (Lopes, 1988). Este tem também trabalhado com tomografia de raios-X e nêutrons (Souza et. al, 2003; Lopes et. al, 2005; Pereira et. al, 2007; Almeida et. al, 2007 e Ribeiro et. al, 2007) e com simulaçõ es computacionais de sistemas tomográficos (Almeida et. al, 2004). As suas aplicações, na maioria dos casos, têm sido enfocadas a análise de diversos materiais e

ensaios não destrutivos, bem como, a estudos de compactação de solos e misturas asfálticas (Braz et. al, 2004; Braz et. al, 2007). Estudos utilizando a microtomografia para a análise de vários tipos de amostras também tem sido realizados por este laboratório (Pereira et. al, 2006; Pereira et. al, 2007; Lima et. al, 2008).

\subsection{Estudos de sistemas com duas fases dinâmicas utilizando a tomografia gama}

Esta modalidade de tomografia gama está bem estabelecida e vem sendo aplicada no estudo de sistemas com duas fases dinâmicas. Na literatura podem ser encontrados vários trabalhos estudando o efeito das condições de op eração e parâmetros de desenho em sistemas com duas fases dinâmicas. Para resolver estes sistemas, uma aproximação da equação básica da tomografia é aplicada a partir dos dados dos coeficientes de atenuação. Esta aproximação envolve o fato físico de que a soma total dos holdups das fases é igual à unidade para um determinado pixel ou para o sistema de forma global. Existem também trabalhos utilizando tomógrafos com raios $\mathrm{X}$, e a principal diferença com os sistemas com fontes gama é que estes podem ser utilizados para distinguir materiais que apresentam pouco contraste das densidades, pois, os raios $\mathrm{X}$ usam baixas energias. Este fato pode ser uma limitação devido à pouca penetração que os raios $\mathrm{X}$ 
têm em sistemas de escalas maiores (interferências das paredes) ou que possuam densidades elevadas (Toye et. al., 1998; Toye et. al., 2001; Barouch et. al., 2004).

Fincke et al.(1980) usaram a tomografia com raios gama para a determinação dos valores médios da densidade e a sua distribuição em função do tempo em fluxos multifásicos horizontais, conseguindo assim, diferenciar vários tipos de escoamentos. $\mathrm{O}$ equipamento utilizado tinha nove detectores em um arranjo em forma de arco com uma fonte de $18,5 \mathrm{GBq}(0,5 \mathrm{Ci}) \mathrm{de}{ }^{241} \mathrm{Am}$ colimada em forma de leque com um ân gulo de $32^{\circ}$. De Vuono et. al. (1980) e Schlosser et. al. (1980) desenvolveram um sistema tomográfico com radiação gama para o estudo de sistemas com duas fases. Uma análise baseada nos requerimentos de resolução espacial e de densidade, no tamanho da seção estudada (sentido longitudinal) com relação as limitações na taxa de contagem máxima disponível (tipo e atividade da fonte) e o tempo adequado para efetuar as tomografias (resolução temporal) foi realizada. O sistema CT utilizado tinha características da quarta geração com uma fonte de ${ }^{137} \mathrm{Cs}$ que girava em um círculo entre 48 detectores cintiladores de NaI e a seção estudada. Seshadri et. al. (1986) apresentou um esquema geral de reconstrução com filtro para este tomógrafo com a idéia de melhorar os resultados obtidos para a densidade de ar e de água. Os valores da densidade para o sistema ar - água for am estimados com um erro absoluto de máximo $0,01 \mathrm{~g} / \mathrm{cm}^{3}$ para emulsões com densidades entre 0,6 e 1,0 g/ $\mathrm{cm}^{3}$. Um feixe monoenergético gama de 59,6 keV de 3,7 GBq (100 mCi) de ${ }^{241} \mathrm{Am}$ e um detector simples colimado de $\mathrm{NaI}(\mathrm{Tl})$ foram utilizados para produzir imagens tomográficas na entrada de um leito fluidizado a gás de $51 \mathrm{~mm}$ de diâmetro e $200 \mathrm{~mm}$ de altura por McCuaig et. al. (1985). Posteriormente, Seville et al. (1986) realizaram medições de holdup para gás em leitos fluidizados usando tomografia gama, demonstrando a versatilidade do $\mathrm{CT}$ ao comparar estimativas teóricas com dados experimentais. Uma 
versão melhorada deste CT foi reportada por Simons \& Williams (1993). O sistema tinha 153 fontes de ${ }^{153} \mathrm{Gd}$ com seis detectores cintiladores colimados de CsI. O conjunto foi montado em um sistema fixo de rotação e a seção de teste era baixada ou elevada através do sistema tomográfico. Este sistema foi utilizado para estudar as diferenças no comportamento de um leito fluidizado, determinando os perfis de holdup. Hosseini-Ashrafi \& Tuzun (1993) adaptaram o mesmo sistema para girar ao redor de uma seção de teste, para estudar sistemas granulares, onde foram obtidas as distribuições do holdup de sólido de uma seção transversal, assim como, os valores médios da holdup do gás.

No Laboratório da Engenharia da Reação Química (CREL) da WUSTL foram desenvolvidos tomógrafos de fonte única por Kumar et al. (1995) e por Roy (2006). Muitos dos estudos encontrados na literatura com sistemas de duas fases dinâmicas foram originados no CREL. O efeito de parâmetros operacionais e de desenho, tais como, velocidade superficial do gás, diâmetro de coluna, desenho de distribuidores e tensão sup erficial da distribuição de holdup têm sido estudados em coluna de bolhas (bubble columns) gás - líquido (Kumar \& Dudukovic, 1997), utilizando um CT de terceira geração composto por 32 detectores cintiladores de $\mathrm{NaI}$ montados em leque e uma fonte de ${ }^{137} \mathrm{Cs} . \mathrm{O}$ holdup de sólidos tem sido determinado em leitos fluidizados circulantes sólido - líquido (Roy et al., 1997) e em risers gás - sólido (Bhusarapu, 2005), como uma função da velocidade superficial do gás. Colunas de bolha de até $45 \mathrm{~cm}$ de diâmetro foram estudadas para determinar as distribuições de holdup de sistemas gás - líquido. Distribuições de holdup em tanques agitados (gás - líquido) também têm sido determinadas (Hampel et al., 2007; Khopkar et al., 2005; Rammohan, 2002). Em um foto-reator para produção de algas (Luo, 2005) e bio-digestores para produção de metano (Karim et al. 2004; Varma and Al- 
Dahhan 2007) foram determinadas as distribuições de holdup, verificando o efeito da velocidade superficial do gás e de parâmetros do desenho.

Os CT de fonte únicas também podem ser utilizados para o estudo de sistemas com três fases (gás, líquido e sólido) quando uma destas é estacionária (sólido). Devido ao fato de que o gás e o líquido são as fases dinâmicas, primeiramente são estudados os sistemas líquido - sólido e gás sólido (duas fases) para determinar o holdup do sólido que permanece constante para qualquer condição de operação. Assim, os holdups do gás e do líquido são calculados como os mesmos procedimentos dos sistemas com duas fases dinâmicas. Estas ap roximações foram utilizadas para determin ar o efeito dos distribuidores e das velocidades de gases e líquidos na distribuição de holdup em reatores monolíticos (Roy \& Al-Dahhan, 2005) e em colunas empacotadas com recheio estruturado (Roy et al. 2004). Estudos similares foram realizados em reatores de leito fixo (Chen et al., 2001).

Portanto, a tomografia gama com duas fases dinâmicas tem atingido um nível de maturidade, tanto na pesquisa como no diagnóstico aplicado ao estudo de vários tipos de processos e reatores.

\subsection{Estudos de sistemas com três fases dinâmicas utilizando a tomografia gama e outras técnicas multimodais}

A maior dificuldade encontra-se na resolução de um sistema de equaçõ es para a determinação do holdup gerado pelas informações obtidas das imagens tomográficas. A medida da radiação que atravessa um sistema que apresenta três fases (gás, líquido e sólido) representa indiretamente a propriedade física chamada atenuação $(\mu)$. De forma 
geral a equação ( 1 ) caracteriza a relação entre a atenuação de um sistema multifásico $\mu_{G L S}$ e as frações de holdup das fases constituintes $\varepsilon_{G}, \varepsilon_{L}$ e $\varepsilon_{S}$

$$
\mu_{G L S}=f\left(\varepsilon_{G}, \varepsilon_{L}, \varepsilon_{S}\right)
$$

Para um determinado pixel, a equação ( 1 ) pode ser descrita em função dos coeficientes de atenuação e holdups das fases, assim:

$$
\mu_{G L S}=\mu_{G} \varepsilon_{G}+\mu_{L} \varepsilon_{L}+\mu_{S} \varepsilon_{S}
$$

$\mathrm{Na}$ expressão anterior, $\mu_{G L S}$ é conhecido, enquanto que $\varepsilon_{G}, \varepsilon_{L}$ e $\varepsilon_{S}$ são desconhecidos. A segunda equação provêm do fato de que a soma das frações do holdup é igual a unidade.

$$
\varepsilon_{G}+\varepsilon_{L}+\varepsilon_{S}=1
$$

Para sistemas com duas fases, o problema se resume a resolução de duas equações com duas incó gnitas. Portanto, é necessária uma equação adicional que introduza o holdup em função de algum parâmetro conhecido. Esta equação é obtida estudando o sistema com uma fonte radioativa adicional que apresente outra energia. Devido ao fato de que a atenuação está em função da energia, esta equação poderia relacionar os mesmos valores de holdup com os coeficientes de atenuação provenientes da fonte radioativa adicional.

$\mathrm{Na}$ literatura foram encontrados poucos trabalhos relacionados a estudos de sistemas com 3 fases com a tomografia gama e raios $\mathrm{X}$, apresentadas a seguir. 
Nikitidis et al. $(1998,1999)$ estudaram um sistema gás - sólido - sólido contendo uma mistura binária de sólidos de um cone alimentador de $14.4 \mathrm{~cm}$ de diâmetro utilizando um CT dual de terceira geração (leque) com uma fonte de ${ }^{153} \mathrm{Gd}$ de $37 \mathrm{GBq}$ (1 Ci). $\mathrm{O}{ }^{153} \mathrm{Gd}$ emite dois gamas, um com $44 \mathrm{keV}$ e outro com $100 \mathrm{keV}$.

Rados et al. $(2003,2005)$ estudaram uma coluna de lama borbulhante (slurry bubble column) contendo gás - líquido - sólido para a determinação da distribuição do holdup. Sensores de pressão foram utilizados para fornecer uma equação adicional. Assumindo que o holdup do sólido (valor global) permanece constante, os holdups restantes podem ser determinados.

Froystein et al. (2005) analisaram um phantom $^{5}$ de $7,6 \mathrm{~cm}$ de diâmetro multifásico gás - líquido - líquido (ar, agua e petróleo) utilizando um tomógrafo dual de primeira geração com um detector simples que trabalhou com as atenuações geradas pelos dois fotopicos ${ }^{6}(31 \mathrm{e} 81 \mathrm{keV})$ de uma fonte de ${ }^{133} \mathrm{Ba}$ com $1,11 \mathrm{GBq}(30 \mathrm{mCi})$. O tomógrafo registrou 20 projeções paralelas para cada posição da fonte (12 no total). Este tip o de fonte radioativa tem pouca penetração, assim os autores fabricaram o phantom com um polímero especial.

$\mathrm{Hu}$ et al. (2005) estudaram um sistema gás - líquido - sólido em uma tubulação horizontal de $10 \mathrm{~cm}$ de diâmetro, utilizando um tomógrafo dual de raios $\mathrm{X}$ com $160 \mathrm{keV}$. Devido a natureza polienergética dos raios $\mathrm{X}$, foram aplicados dois filtros que permitiram separar as energias destes em uma região de altas e outra de baixas, obtendo-se

\footnotetext{
${ }^{5}$ Phantom é um objeto de teste que apresenta propriedad es similares às de um sistema de interesse.

${ }^{6}$ Fotopico é a região do espectro de energias característica dos emissores gama onde toda a energia é depositada no detector.
} 
dois grupos de atenuações correspondentes a equação ( 2 ). O tomógrafo foi construído com dois leques fixos limitando o número de projeções e ângulos (views). As imagens foram reconstruídas utilizando o algoritmo denominado técnica algébrica de reconstrução (ART) e apresentaram uma definição pobre pela limitação de dados.

Gehrke \& Wirth (2005) estudaram um leito fluidizado (gás, líquido e sólido) de 1,8 m de cumprimento e $10 \mathrm{~cm}$ de diâmetro, fabricado em Plexiglass para a determinação da distribuição do holdup utilizando um sistema dual de raios X com en ergias de 80 e 140 $\mathrm{keV}$. As imagens foram obtidas utilizando o ART.

Outras técnicas utilizam dois tipos de tomografia simultaneamente (gama, raios X, capacitância, impedância, condutância etc.) para resolver o problema de 3 fases dinâmicas, onde estas denominam-se multimodais. A seguir são apresentados as publicações referentes a esta modalidade.

Rapaport et al. (1995) fizeram testes não destrutivos em peças para indústria aeronáutica utilizando um $\mathrm{CT}$ dual com um gerador de raios $\mathrm{X}$ e uma fonte radioativa. Os autores não reportaram estudos de sistemas multifásicos, mas este tomógrafo podia ter cumprido as exigências necessárias.

Johansen et al., (1995) trabalharam com tubulações de $10 \mathrm{~cm}$ de diâmetro com água - petróleo - gás para a determinação da distribuição do ho ldup utilizando um sistema tomográfico gama fixo constituído por 5 leques com 17 detectores cada. Adicionalmente a mesma região avaliada pelo $\mathrm{CT}$ gama, foi estudado um sistema tomográfico de capacitância (ECT) com 8 eletrôdos e detectores de alta sensibilidade. A qualidade dos resultados ficou limitada ao número de projeções adquiridas e à escolha do tamanho das imagens reconstruídas. 
George et al. (2001) desenvolveram um sistema combinando CT gama com tomografia de impedância (EIT). Este tomógrafo estudou uma coluna de lama com borbulhamento de $20 \mathrm{~cm}$ de diâmetro. Os resultados restringiram-se aos perfis do holdup radial sem detalhes da distribuição do mesmo. Os cálculos efetuados pelos autores assumiram que existe uma distribuição uniforme do holdup, assim como, outras correlações entre os dados obtidos pelo EIT e a condutividade.

Hjertaker et at. (2005) estudaram as implicações do estudo de Johansen et al. (1996), devido aos efeitos da salinidade do sistema ar - petróleo - água com relação ao desempenho do ECT. O ECT precisa de uma fase dinâmica não condutiva e mudanças nesta propriedade introduzem erros. Um medidor de campo magnético de alta frequência foi introduzido no sistema para medir a fração de água.

Na tomografia de três fases dinâmicas ainda não existe o nív el de entendimento atingido com a de duas fases. Várias conjecturas que discordam das situações reais têm sido levantadas criando limitações inerentes. Estas limitações estão relacionadas ao tamanho da seção estudada (domínio), considerações de homogeneidade de uma das fases, condições específicas de operação ou contraste e definição pobres, impossibilitando a aplicação destas técnicas para o diagnóstico. Métodos baseados em propriedades elétricas estão limitados pela geometria e pelo regime de escoamento, além de um número indeterminado de equações para resolver. Outras restrições estão relacionadas ao número de sensores utilizados (limitado), diminuindo a resolução espacial dos resultados.

Os métodos baseados na radiação gama ou nos raios $\mathrm{X}$ não apresentam restrições, quanto ao tipo de sistema analisado, geometria e regime de escoamento, além de estarem fundamentados no simples princípio da atenuação. As dificuldades encontradas 
com estes métodos estão relacionadas à energia utilizada (penetração da radiação no meio) e portanto à capacidade limitada para estudar seções maiores $(5-7,5 \mathrm{~cm})$, atividades elevadas para compensar a deficiên cia anterior, tempos de contagem elevados para garantir boa significância estatística e número limitado de projeções que restrinjam a qualidade das imagens.

De forma geral, pode-se afirmar que a tomografia de sistemas dinâmicos com três fases tem conseguido sucesso parcial. Portanto, existe uma forte motivação para desenvolver um sistema robusto que não seja afetado pelas deficiências indicadas anteriormente e que forneça informação acurada para formulação de modelos e validação de CFD. Os problemas relatados são na sua maior parte resolvidos utilizando radio isótopos

$\left({ }^{137} \mathrm{Cs},{ }^{60} \mathrm{Co}\right.$, etc.) que possuam a penetração adequada e tempos de contagem pequenos e uma quantidade suficiente de detectores que permitam estudar sistemas de dimensões maiores com precisão.

\subsection{Fundamentos da tomografia por transmissão}

\subsubsection{Atenuação da radiação gama}

A radiação gama interage com a matéria por meio do efeito fotoelétrico, efeito Compton, e produção de pares. Todas estas interações dependem da energia do fóton incidente e do número atômico do material absorvedor. A passagem pela matéria de um feixe fino e bem colimado de fótons de raios gama é regida pela lei de B eer para um feixe monoenergético (Kak \& Slaney, 2001):

$$
\frac{I}{I o}=e^{-\mu(E) \cdot L}
$$


Onde Io é a intensidade do feixe da radiação incidente, $I$ é a intensidade do feixe emergente, $\mu(E)$ é o coeficiente linear $\left(\mathrm{cm}^{-1}\right)$ de atenuação específico para cada material e dependente da energia da fonte radioativa $E$ e $L$ é a espessura do objeto. Muitas vezes, substitui-se o termo $\mu$ por $\mu_{\mathrm{m}} \rho$, onde $\mu_{\mathrm{m}}$ é o coeficiente de atenuação mássico $\left(\mathrm{cm}^{2} / \mathrm{g}\right)$ e $\rho$ é a densidade $\left(\mathrm{g} / \mathrm{cm}^{3}\right)$. Devido à natureza do fenômeno de desintegração radioativa, a expressão anterior representa a probabilidade de que um fóton atravesse um objeto sem interagir com o meio, que no campo da tomografia é conhecida co mo projeção.

\subsubsection{Princípio da tomografia gama CT}

O princípio da tomografia computadorizada por transmissão consiste na passagem de um feixe de raios gama através de um meio heterogêneo seguida pela atenuação da radiação incidente. A medida desta atenuação representa a integral de linha da distribuição dos coeficientes de atenuação através do caminho percorrido pelo feixe. A medição de vários feixes com diferentes orientações, tanto angulares (views) como espaciais (projeções) em relação ao objeto estudado, seguida de um processo de reconstrução de imagem, fornece a distribuição espacial dos coeficientes ou de alguma outra propriedade de interesse (holdup) com um alto grau de resolução. Se a coleta de dados for automática e o procedimento para a reconstrução de imagem for realizado por um computador, este processo pode ser chamado tomografia computadorizada (CT). Os sistemas tomográficos baseados na transmissão utilizam fontes radioativas encapsuladas e detectores colocados nos lados opostos do objeto a ser estudado, como mostrado na FIGURA 2. 


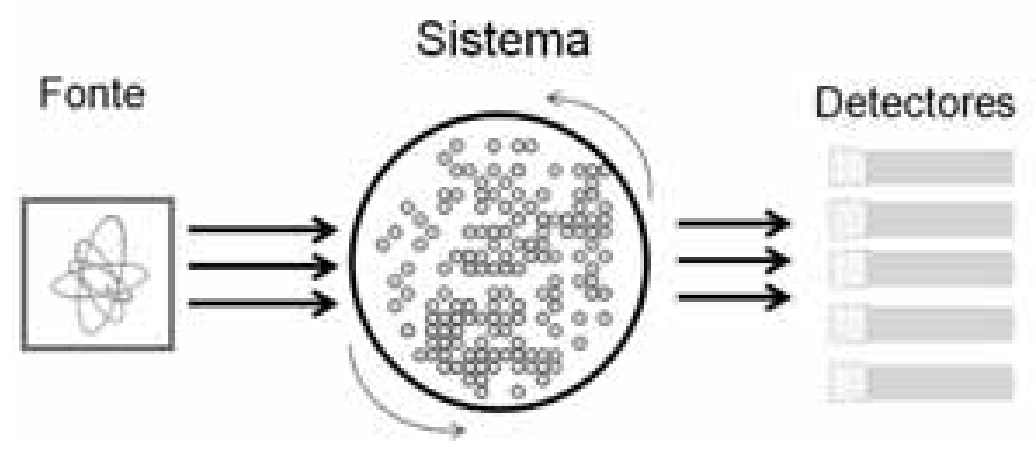

FIGURA 2 - Esquema do princípio de um sistema tomográfico.

A reconstrução da imagem basicamente pode ser realizada por métodos analíticos, como, a retroprojeção filtrada (FBP) ou por métodos iterativos, como, a técnica algébrica de reconstrução (ART), a esperança - maximização EM ou a minimização alternativa MA (Chouki et al., 1997; O'Sullivan \& Benac, 2007). Os detalhes destes métodos, bem como, suas vantagens e desvantagens são discutidas nos capítulos 3 e 5 .

\subsubsection{Tipos de sistemas tomográficos}

Vários tipos de sistemas tomográficos têm sido testados e melhorados com o objetivo de aumentar a quantidade de informaçõ es obtidas do sistema de interesse como mostrado na FIGURA 3 (Chaouki et al., 1997). 

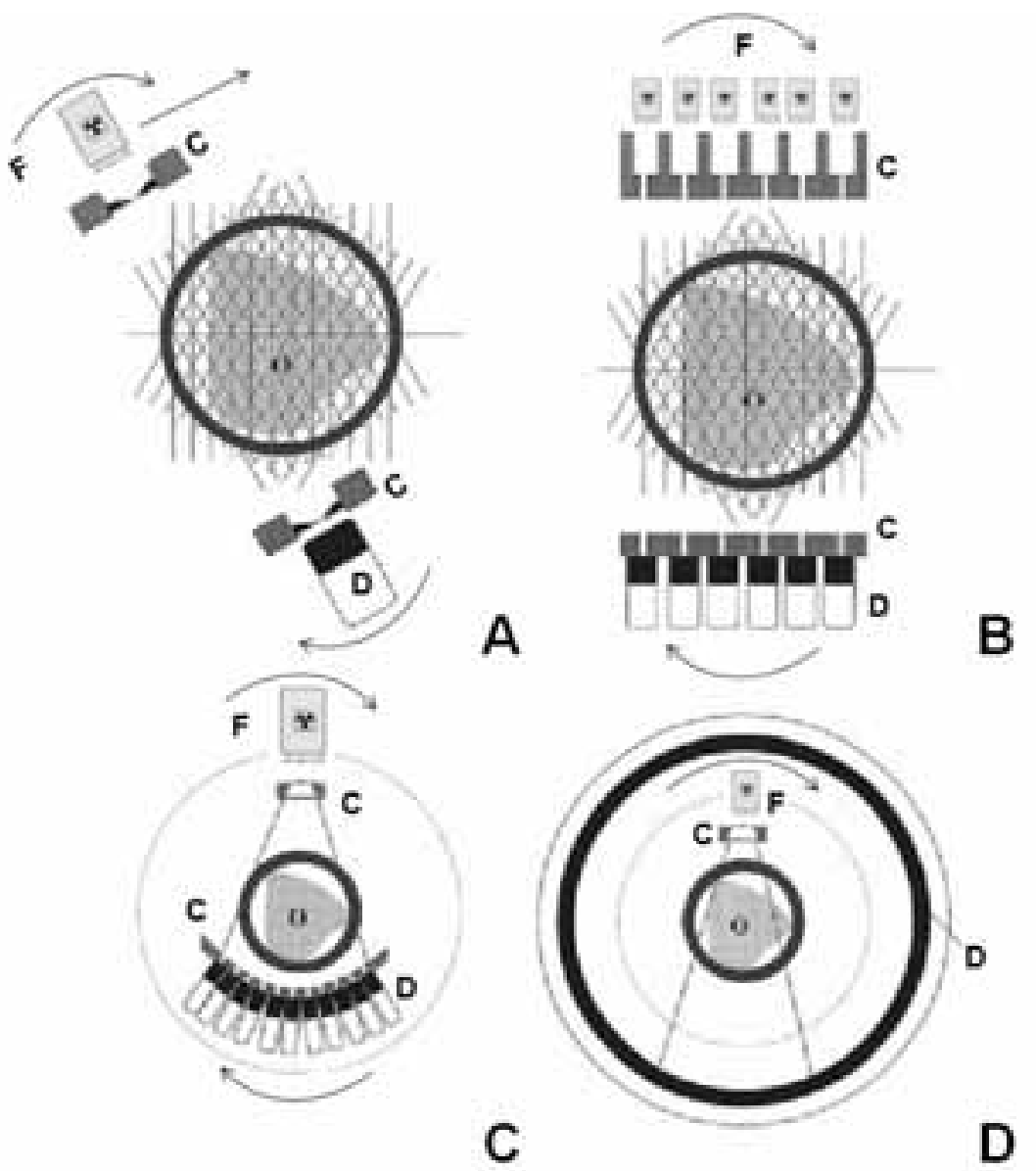

FIGURA 3 - (A) translação - rotação de um feixe em paralelo (primeira geração); (B) translação - rotação de múltiplas fontes em paralelo (segunda geração); (C) rotação de um feixe em leque (terceira geração); (D) detector fixo - rotação da fonte (quarta geração). D: detectores; $F$ : fonte; $C$ : colimador; O: objeto estudado.

\subsubsection{Sistemas tomográficos de primeira geração}

Estes sistemas consistem de uma fonte que emite um feixe pontual de radiação e um detector simples (FIGURA 3-A). Estes se movimentam pelos lados op ostos do objeto de estudo, medindo a atenuação da radiação em cada posição. Este método tomográfico depende do tempo e não é capaz de coletar vários dados para movimentos rápidos do sistema sem introduzir erros importantes na reconstrução da imagem. 


\subsubsection{Sistemas tomográficos de segunda geração}

Nestes, conjuntos de detectores são colocados na frente de uma fonte radioativa simples que se movimentam ao redor do objeto estudado fornecendo um número de projeções igual ao número de detectores (FIGURA 3-B). Algumas vezes, estes sistemas de segunda geração utilizam também fontes radioativas múltiplas para reduzir o tempo de análise do sistema. Empregando-se este método, o tempo de aquisição de dados pode levar menos de $1 \mathrm{~min}$.

\subsubsection{Sistemas tomográficos de terceira geração (tipo leque)}

A fonte utilizada neste tipo de sistema é colimada de forma que o caminho percorrido pelos feixes seja semelhante a um leque (FIGURA 3-C). O sistema movimentase ao redor do objeto estudado, obtendo-se uma vista particular (view) para uma posição específica do conjunto fonte - detectores. Neste tipo de sistema podem ser utilizados várias fontes e vários arranjos de detectores.

\subsubsection{Sistemas tomográficos de quarta geração}

Estes sistemas utilizam um arranjo composto de um detector fixo (grande número de detectores montados em um anel fixo) e uma fonte rad ioativa que se movimenta ao redor do objeto, como mostrado na FIGURA 3-D. No seu interior, o feixe em forma de

leque é detectado em $10^{-3}$ segundos. Os registros de qualquer medida são provenientes do detector, representando uma vista do objeto. No entanto, todos os CT são constituídos principalmente das mesmas partes, ou seja, um sistema de aquisição de dados do objeto estudado e um computador adequado. 


\subsubsection{Fatores determinantes no desempenho de um sistema tomográfico}

De maneira geral, o desempenho de um CT está limitado pelas características da fonte radioativa, tipo de detectores utilizados, eletrônica associada à detecção e aquisição de dados, assim como, por disposições geométricas do desenho. Desalinhamento de fontes e detectores, incertezas na estatística de contagem, efeito do espalhamento (Compton), problemas eletrônicos, técnicas de reconstrução de imagens podem também afetar o sistema.

\subsubsection{Seleção da fonte radioativa e dos sistemas de detecção}

Os tipos de radiação mais adequados para usos industriais são a radiação gama e os raios $\mathrm{X}$, pois, por serem eletromagnéticos têm a vantagem de maior penetrabilidade. A seleção adequada da fonte radioativa gama a ser utilizada em um CT é muito importante. Decaimento, atenuação, considerações técnicas, tais como, custos, disponibilidade, licenciamento de instalações radiativas e características de construção influenciam o processo de seleção. De forma geral, enquanto a energia dos fótons aumenta, os coeficientes de atenuação dos materiais diminuem. Froystein et al. (2005) e Van Santen et al. (1995) discutiram o critério da seleção da energia da fonte radioativa baseado nas características do material e nas incertezas do sinal medido. Esta aproximação é válida para raios $\mathrm{X}$, mas para o caso da tomografia gama, a energia dos fótons é restrita à disponibilidade dos radioisótopos naturais ou artificiais. Assim, se não existe um radioisótopo com a energia de fótons desejada, os fatores mais importantes são custos e meia vida. 
Os radioisótopos decaem continuamente e tem vida útil fixa, devido ao fato de que, a atividade ou con centração destes se reduz exp onencialmente em função do tempo. A meia vida é definida como o tempo necessário para que a atividade de uma amostra radioativa se reduza a metade. $\mathrm{O}$ radio isótopo utilizado deve ter uma meia vida que permita a realização dos experimentos sem afetar os resultados e possibilite um tempo de vida útil adequado. Nem todos os decaimentos radioativos geram as energias desejadas. Fótons gama são geralmente uma fração do decaimento total. Este fator de emissão deve ser próximo da unid ade.

Por razões óbvias, o custo do radioisótopo deveria ser relativamente baixo incluindo a disposição deste quando o tempo de vida útil tenha sido completado. $\mathrm{O}$ custo deve ser comparado com a vida média da fonte. Fontes seladas são comercializadas em forma especial (encapsuladas em aço).

As aplicações tomográficas requerem fontes radioativas pontuais (geometria da fonte) para a obtenção de imagens sem borrões. Na prática utilizam-se fontes com dimensões finitas, tão pequenas quanto seja possível, com formas geométricas esféricas.

TABELA 3 - Possíveis radioisótopos para aplicações tomográficas (Ledere et al., 1996).

\begin{tabular}{|c|c|c|c|}
\hline Radioisótopo & Meia vida & $\begin{array}{c}\text { Energia do } \\
\text { fotopico }(\mathrm{keV})\end{array}$ & $\begin{array}{c}\text { Fator de emissão } \\
\text { gama }\end{array}$ \\
\hline${ }^{241} \mathrm{Am}$ & 421 anos & 66 & 0,38 \\
\hline${ }^{105} \mathrm{Yb}$ & 32 dias & $63,109,130$ & ------ \\
\hline${ }^{109} \mathrm{Cd}$ & 1,27 anos & 88 & 0,04 \\
\hline${ }^{105} \mathrm{Gd}$ & 214 dias & 98 & 0,55 \\
\hline${ }^{J} \mathrm{Co}$ & 271 dias & 122 & 0,86 \\
\hline${ }^{10} \mathrm{Cs}$ & 30 anos & 662 & 0,85 \\
\hline${ }^{{ }^{0}} \mathrm{Co}$ & 5,24 anos & 1173,1332 & 1,0 \\
\hline${ }^{75} \mathrm{Se}$ & 120 dias & $\begin{array}{c}121,136,264, \\
279,401\end{array}$ & $\begin{array}{c}0,170,580,57 \\
0,250,11\end{array}$ \\
\hline
\end{tabular}


A TABELA 3 apresenta uma lista de possíveis radioisótopos a serem utilizados em tomografia em função dos critérios expostos anteriormente. No entanto, cada um destes radioisótopos apresenta características peculiares, o que torna um mais adequado que outro, dependendo da aplicação. A meia vida do ${ }^{167} \mathrm{Yb}$ é considerada curta tornando-o impraticável para as ap licações tomográficas. A meia vida do ${ }^{241}$ Am é adequada, mas a sua energia é muito baixa. Por exemplo, para estudar um domínio de tamanho fixo com água, são necessários 3,7 GBq $(0,1 \mathrm{Ci})$ de ${ }^{137} \mathrm{Cs}$ ou $296 \mathrm{GBq}(8 \mathrm{Ci})$ de ${ }^{241} \mathrm{Am}$. Quanto maior é a atividade, maiores são os riscos envolvidos na manipulação de material radioativo. $O$ ${ }^{241}$ Am é um auto-absorvedor ou auto- atenuador, devido ao seu alto número atômico o que impossibilita a fabricação de fontes pontuais acima de $7,4 \mathrm{GBq}(200 \mathrm{mCi}) . \quad \mathrm{O}{ }^{75} \mathrm{Se}$ apresenta a vantagem de possuir quatro fotopicos que poderiam ser utilizados redundantemente na coleta de dados, mas esta fonte precisa de altas atividades quando comparada com o ${ }^{137} \mathrm{Cs}$ e o ${ }^{60} \mathrm{Co}$. Este fato poderia criar o inconv eniente de limitação de áreas de trabalho (áreas controladas). Assim, considerando a meia vida, a atenuação por materiais de alta densidade, os domínios de estudo relativamente grandes e os custos; o ${ }^{137} \mathrm{Cs}$ e o ${ }^{60} \mathrm{Co}$ são as fontes mais indicadas para aplicações industriais. $\mathrm{O}{ }^{137} \mathrm{Cs}$ tem sido muito utilizado em medidores nucleares industriais pela sua meia vida e porque emite um fotopico simples e claro, sem a interferência do espalhamento de fótons de outras energias. O ${ }^{60} \mathrm{Co}$ é a segunda melhor escolha em virtude dos seus fotopicos de alta energia. Adicionalmente, devido à proximidade do segundo fotopico, os efeitos de espalhamento são mínimos. Estas duas fontes têm sido amplamente utilizadas em várias aplicações e podem ser facilmente adquiridas.

A sensibilidade de detecção está relacionada com o radioisótopo e o detector utilizados. Atualmente, para aplicações em tomografia, os detectores de radiação mais 
utilizados são os cintiladores (Ex. $\mathrm{NaI}(\mathrm{Tl}), \mathrm{CsI}(\mathrm{Tl})$ ) e as câmaras de ionização. Os detectores mais adequados são aqueles que atendem o compromisso de maior eficiência de contagem e menor "tempo morto".

\subsubsection{Resolução espacial}

A resolução espacial é a distância mínima na qual dois objetos pontuais de alto contraste podem ser distinguidos pelo CT (Kumar \& Dudukovic, 1997). Yester \& Barnes (1977) definiram esta resolução como:

$$
d_{e f f}=\frac{1}{M} \sqrt{d_{a}^{2}+(M-1)^{2} s^{2}}
$$

Onde $d_{e f f}$ é a resolução espacial, $d_{a}$ é a largura de colimação do detector, $s$ é a largura da fonte e $\mathrm{M}$ é um fator de ampliação (razão entre a largura da fonte e a largura de colimação do detector)

Assumindo que $\mathrm{M}=1$ (a largura da fonte é a mesma que a largura de colimação do detector) a resolução espacial é a mesma que a largura da abertura de colimação do detector.

\subsubsection{Resolução temporal}

A resolução temporal é o tempo necessário para que o sistema possa produzir uma nova imagem. Os dados obtidos pela tomografia gama para a distribuição da concentração de fases (holdup) são na maioria dos casos, valores médios, pois, é requerido um período significativo de tempo para que os equipamentos registrem a taxa de contagens 
para todas as projeções (time average). Dependendo do desenho do equipamento, este período pode levar, desde poucos minutos até horas (4-5), sendo esta a limitação básica para o estudo de sistemas que envolvem fenômenos de fluxo em função do tempo. No entanto, é possível obter informações dinâmicas de sistemas que apresentem taxas de dispersão e velocidades baixas (Hosseini-Ashrafi \& Tuzun, 1993).

\subsubsection{Resolução de densidade}

A resolução de densidade relaciona-se com a capacidade do sistema em diferenciar pequenas variações entre os coeficientes de atenuação de massa. De Vuono (1980) definiu está propriedade como:

$$
\frac{\sigma_{p}}{\rho}=\frac{n}{2 \mu_{w} \rho_{w} d_{i} \sqrt{m N}}
$$

Onde $\sigma_{p}$ é a resolu ção de densidade, $\rho$ é a densidade do material, $n$ é o número de projeções em ân gulo dado (view), m é o número de ân gulos, $N$ é o número de fótons por feixe, $\mu_{w}$ e $\rho_{w}$ são o coeficiente de atenuação e a densidade da água, respectivamente.

Da equação ( 6 ), para melhorar a resolução em densid ade são necessários mais ângulos o que provocaria o incremento do tempo total de análise. Aumentando a atividade também, poderia-se incrementar esta resolução, mas surgiriam consequências referentes à seguran ça pela proteção radioló gica. 


\section{ESTUDO SIMULADO DE UM TOMÓGRAFO GAMA DE SEGUNDA GERAÇÃO E RECONSTRUÇÃO DE IMAGENS UTILIZANDO A RETROPROJEÇÃO FILTRADA (FBP).}

\subsection{Introdução}

O problema de reconstrução de imagens tem sido abordado nos últimos 25 anos nas áreas médica, científica e técnica. A escala de aplicação é sumamente ampla, desde dados obtidos por microscópios eletrônicos utilizados para reconstruir a estrutura molecular de microorganismos até dados coletados por satélites enviados fora da atmosfera terrestre utilizados para reconstruir a estrutura de raios $\mathrm{X}$ e gama de restos de supernovas ou mesmo para reconstruir a imagem do universo nos seus primeiros anos logo após do Big-Bang coletando informações das microondas criadas por esta grande explosão ${ }^{7}$. Estas e muitas outras aplicações têm os mesmos fundamentos matemáticos e computacionais.

O método mais usado é conhecido como Retroprojeção Filtrada (Filtered BackProjection - FBP), porém, muitas hipóteses adotadas nesta metodologia não são verificadas na prática. Por exemplo, assume-se resolução espacial perfeita do detector e não são consideradas as flutuações estatísticas (Bieberle \& Hampel, 2006). No sistema tipo leque, utiliza -se uma variação da FBP que pondera ou "pesa" os valores por fatores geométricos. O método conhecido como rebining (Dreike \& Boyd, 1976) transforma as

\footnotetext{
${ }^{7}$ KAKU, M. Parallel Words. 2005. Anchor Books, New York, p. 6-21.
} 
projeções obtidas com geometrias em forma de leque para as suas equivalentes com geometrias em paralelo antes da reconstrução.

Neste estudo, o algoritmo de retroprojeção filtrada FBP proposto por Kak \& Slaney (2001) foi implementado para o caso monoenergético na reconstrução de imagens. Propriedades e fatores que influen ciam o sistema tomo gráfico (resolu ção espacial), tais como, abertura de colimação dos detectores e número de ângulos ou posições (views) foram estudados. Outros fatores que repercutem na reconstrução de imagens com a FBP, tais como o tipo de interpolação utilizada e o tipo de filtro implementado (Shepp-Logan, Cosine, Hamming e Hann) também for am analisados. Os programas baseados no código de Monte Carlo: MCNP e MACALU peritiram simular um CT de segunda geração tomando em conta parâmetros relacionados a geração e transmissão de raios gama, colimação dos detectores e fontes, eficiência dos detectores (NaI-Tl) e rotação do sistema fontesdetectores ao redor do objeto estudado. Este trabalho foi publicado e representa a primeira incursão na implementação da FBP e no estudo de parâmetros de desenho CT gama por transmissão, que posteriormente, seriam utilizados do desenho do SSCT (Vasquez et al. 2005).

\subsection{Algoritmo da retroprojeção filtrada (FBP)}

Este é um método que basicamente trabalha só com projeções paralelas. Quando os dados forem obtidos de tomógrafos com geometrias em leque, faz-se necessário arranjar as projeções para geometria em paralelo antes da reconstrução. A FIGURA 4 mostra o esquema de um objeto representado no sistema de coordenadas $(x-y)$ sendo atravessado por feixes de raios gama paralelos (A-B). O sistema de coordenadas $\left(x^{\prime}-y^{\prime}\right)$ é perp endicular à direção dos raios gama e mantém um ân gulo $\theta$ com relação ao sistema $(x$ - 
$y$ ). $t$ e $s$ representam as distâncias à origem dos eixos $x^{\prime}$ e $y^{\prime}$ respectivamente. Cada medida do feixe atenuado de radiação para uma determinada orientação an gular e espacial constitui a projeção do objeto. Na parte sup erior pode ser observada a representação dos valores das projeções $p(t, \theta)$ obtidas do objeto ao longo de uma linha quando vários feixes de radiação paralelos atravessam este. Desta forma, uma projeção está definida em função da sua posição $t$ e do ângulo $\theta$ entre $x$ e $x^{\prime}$. A posição relativa $t$ pode ser representada por sistema de coordenadas (x-y) utilizando uma relação trigonométrica simples.

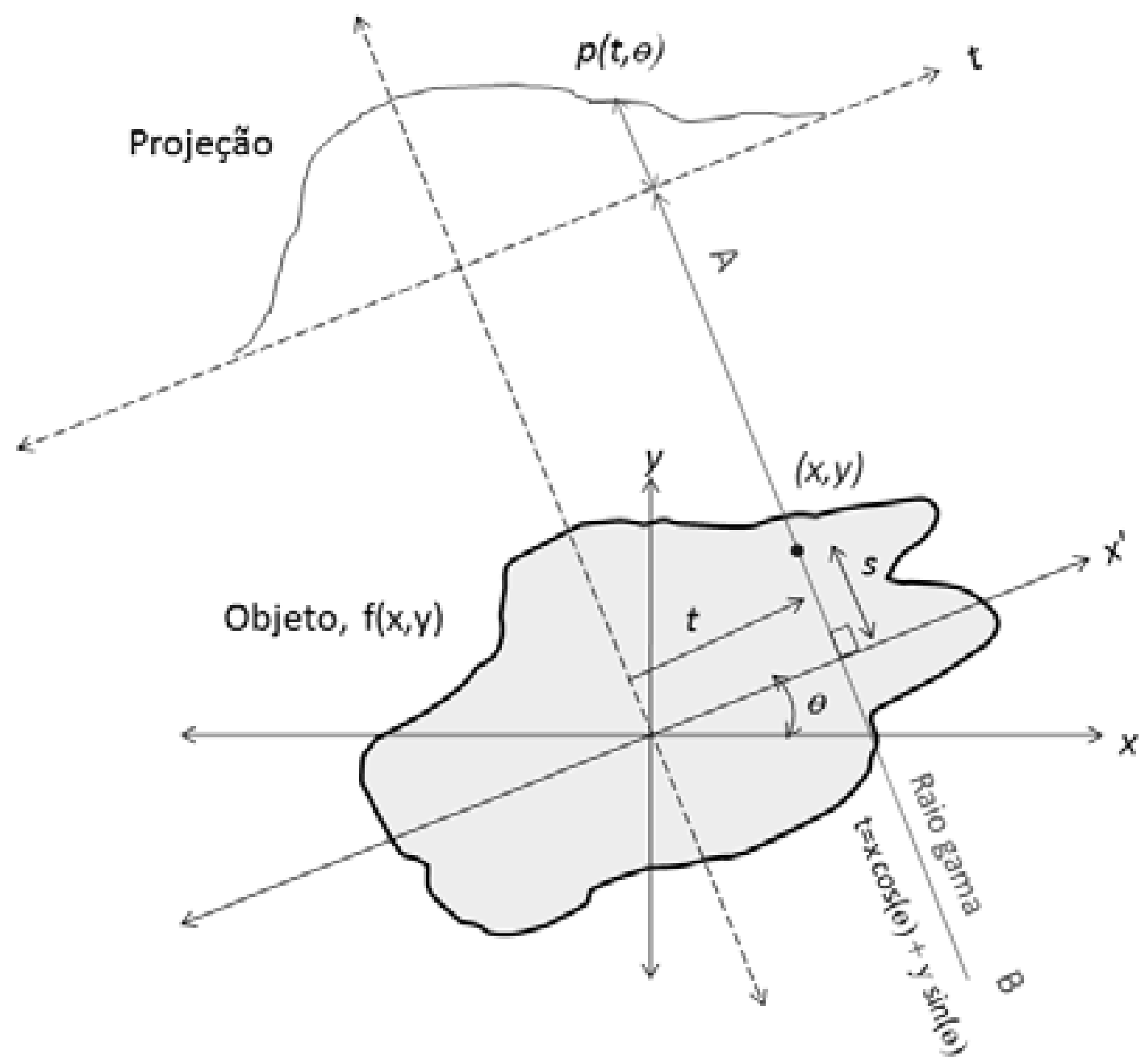

FIGURA 4 - Esquema geométrico das projeções obtidas de um objeto (Kak \& Slaney, 2001). 
Se $p(t, \theta)$ representar um grupo de projeções de $f(x, y)$ obtidos de vários feixes paralelos de ângulo $\theta(0<\theta<\pi)$, e $t$ representar a distância desde a origem $(-r \leq t \leq r, r=$ dimensão da seção estudada), a relação entre estes será dada pela equação integral:

$$
p(t, \theta)=\int_{\theta, t} f(x, y) d s
$$

A equação anterior pode ser redefinida utilizando uma função delta $\delta$ como segue:

$$
p(t, \theta)=\int_{-\infty}^{+\infty} \int_{-\infty}^{+\infty} f(x, y) \delta(x \cos \theta+y \sin \theta-t) d x d y
$$

A equação ( 8 ) é conhecida como transformada de Radon de $f(x, y)$. Assim, uma simples projeção $p(t, \theta)$, representa a coleção de integrais paralelas para um determinado ângulo $\theta$. A função $f(x, y)$ para o caso do processo da transmissão da radiação gama equivale aos coeficientes de atenuação do meio $\mu(x, y)$ e tem as características de uma função de distribuição de probabilidades (pdf).

A transformada de Fourier apresenta-se como um método adequado para tratar este problema pelas suas propriedades relacionadas ao tratamento de dados que respondem às variações de frequên cia $w$. Para isto, é nec essário aplicar o teorema da fatia central TFC (Fourier Slice Theorem) mostrado na FIGURA 5. O TFC estabelece que a transformada de Fourier $S(w, \theta)$, monodimensional de um conjunto de projeções paralelas $p(t, \theta)$ para um determinado ângulo $\theta$ através de uma distribuição bidimensional $f(x, y)$ é igual à fatia da transformada de Fourier bidimensional $F(u, v)$ da distribuição a reconstruir $f(x, y)$ orientada no mesmo ân gulo no plano $(u-v)$. 
Por definição da transformada de Fourier tem-se:

$$
\begin{gathered}
S(w, \theta)=\int_{-\infty}^{+\infty} p(t, \theta) e^{-i 2 \pi w t} d t \\
F(u, v)=\int_{-\infty-\infty}^{+\infty} \int_{-\infty}^{+\infty} f(x, y) e^{-i 2 \pi(x u+y v)} d x d y
\end{gathered}
$$

Substituindo a equação ( 7 ) na equação ( 9 ):

$$
S(w, \theta)=\int_{-\infty-\infty}^{+\infty} \int_{-\infty}^{\infty} f(x, y) e^{-i 2 \pi w t} d t d s
$$

Do sistema $(u, v)$ podem ser verificad as as seguintes prop riedades geométricas:

$$
\begin{aligned}
& u=w \cos (\theta) \\
& v=w \operatorname{sen}(\theta) \\
& d x \cdot d y=d u d v \\
& d u \cdot d v=w d w \cdot d \theta \\
& t=x \cos (\theta)+y \operatorname{sen}(\theta)
\end{aligned}
$$

Substituindo as relações geométricas acima na equação ( 11 ) tem-se :

$$
S(w, \theta)=\int_{-\infty-\infty}^{+\infty} \int_{-\infty}^{+\infty} f(x, y) e^{-i 2 \pi w t} d t d s=\int_{-\infty}^{+\infty+\infty} \int_{-\infty}^{\infty} f(x, y) e^{-i 2 \pi(x u+y v)} d x d y
$$

e portanto:

$$
S(w, \theta)=F(u, v)
$$


Em outras palavras, aplicando a transformada de Fourier a um conjunto de projeções paralelas de um objeto para um determinado ângulo, obtêm-se os valores de $F(u, v)$ ao longo da linha A-A'. Cada conjunto de projeções para uma determinada direção angular no espaço real representa uma amostra independente de $F(u, v)$ no espaço de Fourier. Informação mais detalhada pode ser encontrada em Kak \& Slaney (2001).

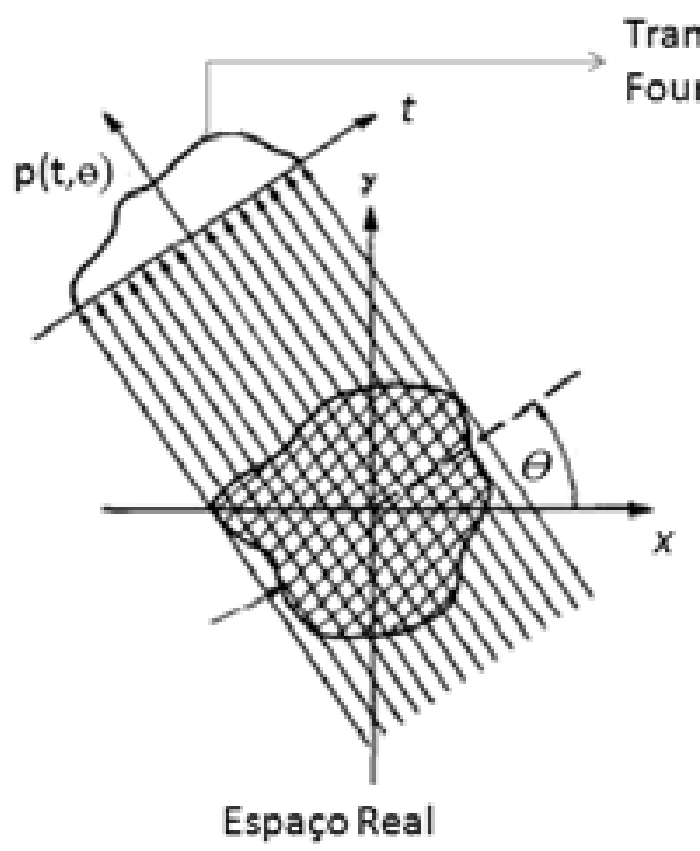

Transformada de Fourier

FIGURA 5 - Teorema da fatia central (Kak \& Slaney, 2001).

Desta forma, obtendo-se os conjuntos de projeções de um objeto $p\left(t, \theta_{1}\right)$, $p\left(t, \theta_{1}\right), \ldots, p\left(t, \theta_{k}\right)$ para vários ângulos $\theta_{1}, \theta_{2}, \ldots \theta_{k}$, e aplicando-se a transformada de Fourier, obtêm-se os valores de $F(u, v)$ nas linhas radiais mostradas na FIGURA 6 . Assim, com um determinado número de conjuntos de projeções podem ser conhecidos todos os pontos do plano $(u, v)$ e consequentemente $\mathrm{f}(\mathrm{x}, \mathrm{y})$ pode ser obtida, aplicando-se a transformada de Fourier inv ersa: 


$$
f(x, y)=\int_{-\infty-\infty}^{+\infty+\infty} \int_{-\infty} F(u, v) e^{i 2 \pi(x u+y v)} d u d v
$$

$$
f(x, y)=\sum_{u} \sum_{v} F(u, v) e^{i 2 \pi(x u+y v)}
$$

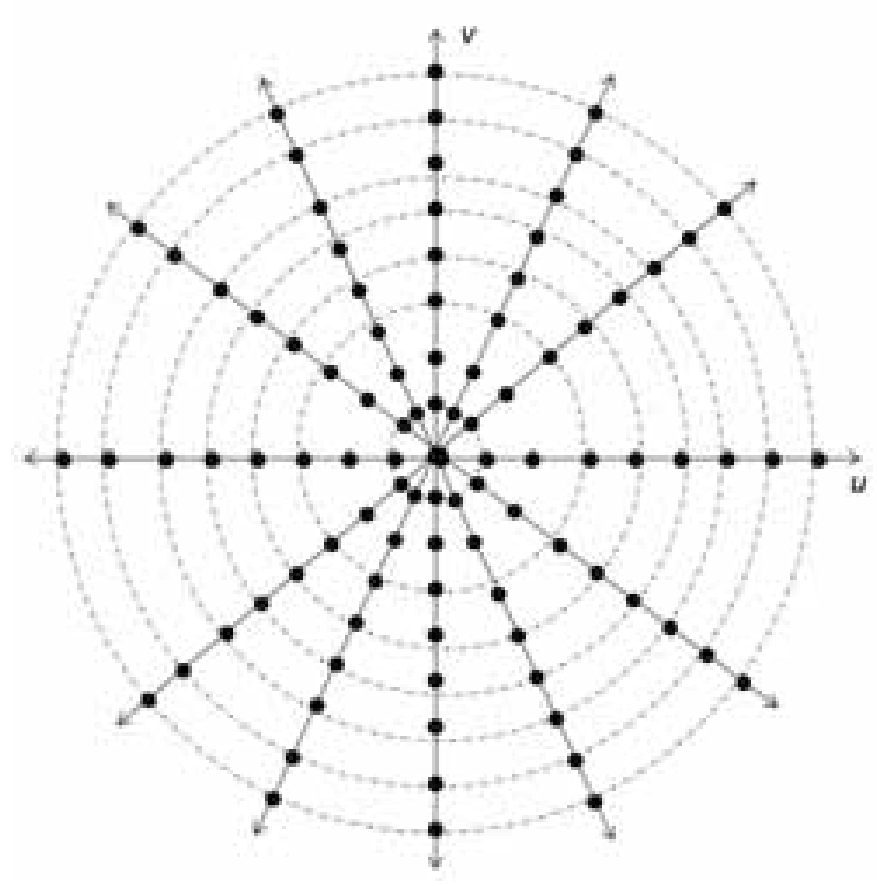

FIGURA 6 - Representação esquemática da transformada de Fourier de um determinado número de conjuntos de projeções para diferentes ângulos no plano $(u, v)$. Os dados experimentais são discretos (pontos azuis) e portanto fin itos. (Kak \& Slaney, 2001).

O número de conjuntos de projeções experimentais é finito, portanto, a função $\mathrm{F}(\mathrm{u}, \mathrm{v})$ só é conhecida ao longo de um número finito de linhas radiais como mostrado na FIGURA 6. Assim, para poder determinar a equação ( 16 ), os pontos radiais devem ser interpolados para formar uma grade quadrada. Comumente são utilizados métodos para interpolações lineares, cúbicas ou do vizinho mas próximo (nearest neighbor). Devido à 
escassez dos pontos radiais, o erro da interpolação é grande. Isto implica que o cálculo de parâmetros que se encontram entre as regiões de alta e baixa frequência provocaram degradação da imagem final.

Substituindo as relações geométricas mostradas na expressão ( 12 ), na equação ( 15 ) e mudando de variáv eis $(u, v) \rightarrow(w, \theta)$ tem-se:

$$
f(x, y)=\int_{0}^{\pi} \int_{-\infty}^{+\infty} S(w, \theta)|w| e^{i 2 \pi v t} d w d \theta
$$

A equação ( 17 ) pode ser escrita assim:

$$
f(x, y)=\int_{0}^{\pi} Q(t, \theta) d \theta
$$

com:

$$
Q(t, \theta)=\int_{-\infty}^{+\infty} S(w, \theta)|w| e^{i 2 \pi w t} d w
$$

$Q(t, \theta)$ representa as projeções filtradas e $|\downarrow|$ o filtro rampa. Portanto, o objeto $f(x, y)$ a reconstruir é igual a retroprojeção das projeções filtradas. A equaçõ es ( 18 ) e ( 19 ) são conhecid as como algoritmos da retroprojeção filtrada.

A FIGURA 7 mostra um esquema do processo de reconstrução de imagens com a retroprojeção filtrada a partir de projeções paralelas. 


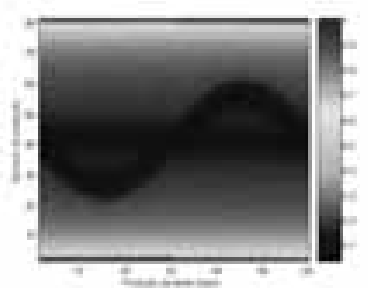

1) Projesbes: $p(t, \theta)$

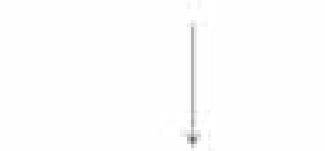

2) Transformada de Fourier: (integrạăo numerica das projesōes)

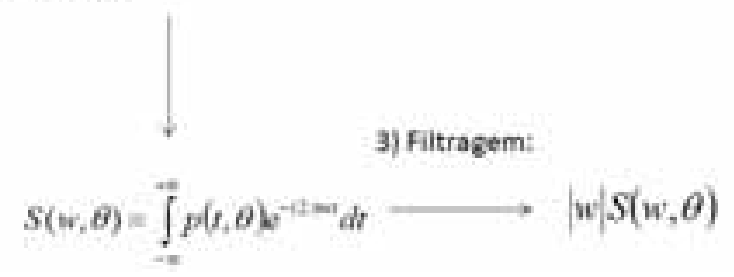

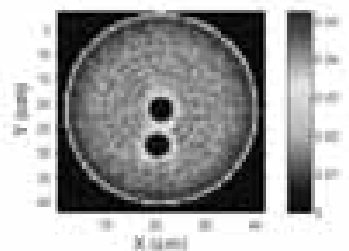

$$
f(x, y)=\int_{0}^{\pi} Q(t, \theta) d \theta
$$$$
\uparrow
$$

5) Retroprojeção:

4) Transformada de

Fourier inversa:

$Q(t, \theta)=\int_{-\infty}^{+\pi} S(w, \theta) w / e^{i 2 s t} d w$

FIGURA 7 - Processo de reconstrução de imagens utilizando a FBP.

Em muitos casos, a utilização do filtro rampa (função) não é suficiente e é necessário utilizar outros filtros, onde se substitui a expressão:

$$
|w|=|w| b(w)
$$

Onde, $b(w)$ é uma função de apodização que pode tomar diversas formas de acordo com o filtro aplicado. A FIGURA 8 mostra o exemplo da aplicação desta função para a obtenção do filtro Hann a partir do filtro rampa. 


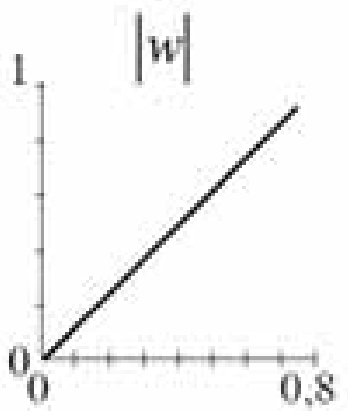

Filtro rampa

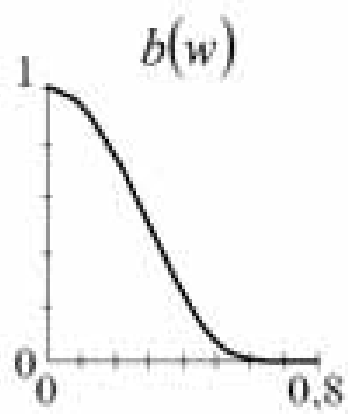

Função de apodização de Hann

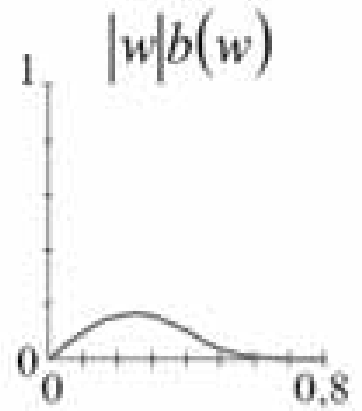

Filtro Hann

FIGURA 8 - Exemplo da aplicação de uma função de apodização nas frequências w: Filtro Hann.

Na TABELA 4 são apresentados os principais filtros usados na reconstrução de imagens tomográficas, sendo $w_{c}$ a freqüência de corte.

TABELA 4 - Filtros utilizados na reconstrução FBP.

\begin{tabular}{|c|c|c|}
\hline Filtro & Expressão & Propriedades \\
\hline Rampa & $|x|$ & $\begin{array}{l}\text { Melhor resolução espacial, } \\
\text { mais forte amplificação do } \\
\text { ruído em altas frequências }\end{array}$ \\
\hline Hann & $\begin{array}{c}b(w)=0,5 .\left(1+\cos \left(\pi w / w_{c}\right)\right) \text { se } w<w_{c} \\
b(w)=0 \text { se } b \geq b_{c}\end{array}$ & $\begin{array}{l}\text { Modifica os valores médios } \\
\text { de freqüência. *Preservam - } \\
\text { se menos os detalhes de alta } \\
\text { freqüência e o efeito de } \\
\text { alissamento é mais forte. }\end{array}$ \\
\hline Hamming & $\begin{array}{c}b(w)=0,54+0,46\left(\cos \left(\pi w / w_{c}\right)\right) \text { se } w<w_{c} \\
b(w)=0 \text { se } w \geq w_{c}\end{array}$ & $\begin{array}{l}\text { *Preservam -se menos os } \\
\text { detalhes de alta freqüência e } \\
\text { o efeito de alissamento é } \\
\text { mais forte. }\end{array}$ \\
\hline Gaussiano & $\begin{array}{c}c(x)=(1 / \sigma \sqrt{2 \pi}) \cdot \exp \left[-\left(x-x_{0}^{2} / 2 \sigma^{2}\right)\right] \text { se } w<w_{c} \\
c(x)=0 \text { se } w \geq w_{c}\end{array}$ & $\begin{array}{l}\text { Alta dispersão. } \\
\text { *Preservam -se menos os } \\
\text { detalhes de alta freqüência e } \\
\text { o efeito de alissamento é } \\
\text { mais forte. }\end{array}$ \\
\hline Butterworth & $\begin{array}{c}b(w)=1 /\left[1+\left(w / w_{c}\right)^{2 n}\right] \text { se } w<w_{c} \\
b(w)=0 \text { se } w \geq w_{c}\end{array}$ & $\begin{array}{l}\text { Dois parâmetros: } w_{c} \text { e a } \\
\text { ordem } n \text {. } \\
\text { *Preservam -se menos os } \\
\text { detalhes de alta freqüência e } \\
\text { o efeito de alissamento é } \\
\text { mais forte. }\end{array}$ \\
\hline
\end{tabular}




\subsection{Metodologia para geração de dados}

Os dados de transmissão obtidos para um phantom com 3 fases foram processados para a reconstrução das imagens utilizando a FBP. O phantom e um CT de segunda geração foram simulados e as projeções obtidas foram tratadas e analisadas. O CT foi simulado com uma fonte de ${ }^{60} \mathrm{Co}$. As distribuições dos coeficientes de atenuação foram determinadas em função da variação de parâmetros de desenho e da reconstrução.

\subsubsection{Descrição do phantom analisado}

Neste estudo foi analisado um phantom sintético com as dimensões indicadas na FIGURA 9. O phantom tem dimensões equivalentes a um modelo experimental que foi utilizado posteriormente para validar o tomógrafo SSCT, o diâmetro foi fixado em $23 \mathrm{~cm}$. e a altura em $30 \mathrm{~cm}$. (não mostrada na figura). A região $\mathrm{R} 1$ foi preenchida com água, a região R2 continha polietileno e a região R3 continha alumínio. A TABELA 5 mostra os detalhes dos subdomínios utilizados neste exp erimento.

A idéia principal na utilização destes materiais foi representar a estrutura interna de colunas de processos industriais que apresentam variações nas densidades dos materiais que estão sendo tratados e os que são parte constituinte dos equipamentos.

TABELA 5 - Detalhes das fases dos subdomínios do phantom.

\begin{tabular}{|c|c|c|c|}
\hline $\begin{array}{c}\text { Região } \\
\text { do } \\
\text { phantom }\end{array}$ & Material utilizado & $\begin{array}{c}\text { Densidade } \\
\left(\mathrm{g} / \mathrm{cm}^{3}\right)\end{array}$ & $\begin{array}{c}\text { Coeficiente de atenuação } \\
\text { para }{ }^{60} \mathrm{Co}\left(\mathrm{cm}^{-1}\right)\end{array}$ \\
\hline R1 & Agua $\left(\mathrm{H}_{2} \mathrm{O}\right)$ & 1,0 & 0,1433 \\
\hline R2 & Polietileno (PE) & 0,954 & 0,0612 \\
\hline R3 & Alumínio (Al) & 2,694 & 0,06 \\
\hline
\end{tabular}

*NIST (Hubbell \& Seltzer, 1996). 


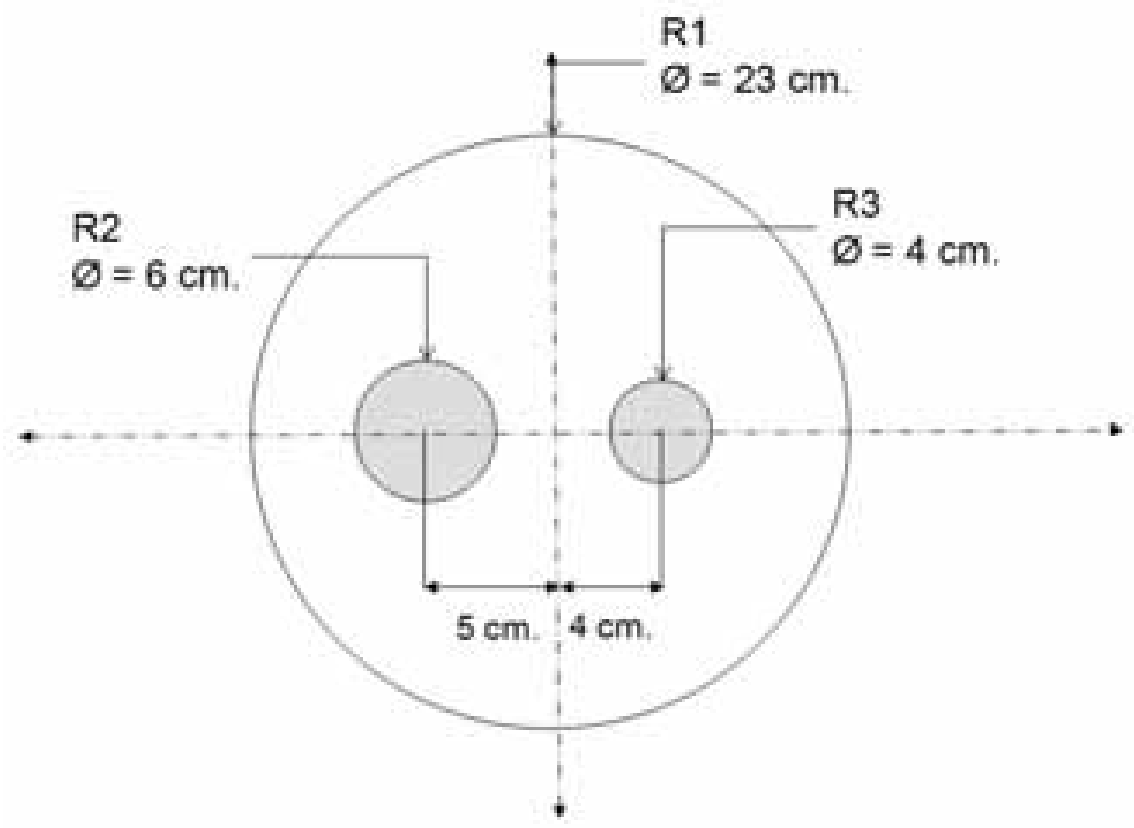

FIGURA 9 - Esquema do phantom gerado por simulação.

\subsubsection{Descrição do CT gama simulado}

A FIGURA 10 mostra o esquema do CT gama utilizado neste estudo para a simulação da transmissão da radiação gama. O tomógrafo de segunda geração possui várias fontes de ${ }^{60} \mathrm{Co}$ colocadas do lado oposto dos detectores, onde foi mantida uma distância fixa de $25 \mathrm{~cm}$.

O número de fontes e detectores foi mudado para se poder verificar a influência do número de projeções e da abertura de colimação nas imagens reconstruídas. Cada detector coletou a radiação transmitida da fonte que estava oposta a este, assim a distância fonte-detector permaneceu constante. O CT girou $360^{\circ}$ ao redor do phantom coletando-se as informações das atenuações em cada posição (view). O CT foi fixado a 15 $\mathrm{cm}$ de altura o que correspondia a metade do phantom. 


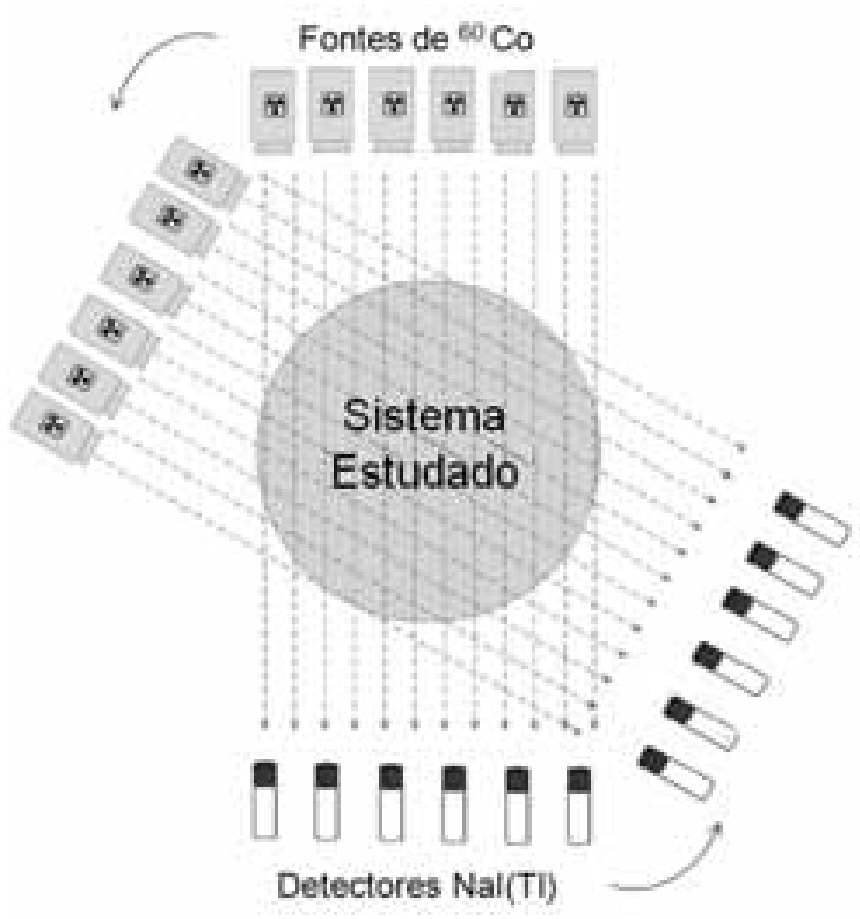

FIGURA 10 - Esquema do arranjo para fontes e detectores do CT gama de segunda geração simulado. O CT gira ao redor do objeto para várias posições (views) e faz a medição da radiação transmitida para cada detector.

\subsubsection{Simulação da transmissão da radiação gama pelo Método de Monte Carlo}

A transmissão da radiação foi simulada utilizando os programas MCNP ( $A$ General Monte Carlo N-Particle Transport Code) - Los Alamos, e o MACALU desenvolvido pela Comissão Francesa de Energia Atómica, cedido ao IPEN pela Agência Internacional de Energia Atômica (AIEA).

O Método de Monte Carlo (MMC) é um método estatístico de simulação, que por sua vez pode ser definido como qualquer método que utiliza uma sequência de números aleatórios para realizar uma simulação. Neste sentido, o MMC difere dos métodos determinísticos convencionais de discretização numérica que são aplicados a um sistema 
de equações diferenciais parciais ou ordinárias que descrevem um processo físico ou matemático.

Em muitas aplicações do MMC o processo físico é simulado diretamente, sem a necessidade de se escrever as equações diferenciais que o descrevem. $O$ único requerimento é que o sistema físico/matemático possa ser descrito por funções de densidade de probabilidade (pdf). Uma vez que as pdf's são conhecidas, a simulação de M.M.C. é realizada através da amostragem aleatória destas pdf's. O resultado é obtido como uma média sobre o número de observações sobre muitas simulações (tentativas ou histórias). Em muitas aplicações práticas, pode-se estimar o erro estatístico (variân cia) associado ao resultado obtido.

Assumindo-se então, que a evolução de um sistema físico possa ser descrita pelas pdf's, a simulação de M.C. pode ser processada fazendo-se a amostragem a partir destas pdf's, que por sua vez necessitariam de um gerador de números aleatórios distribuídos uniformemente no intervalo [0,1]. Os resultados destas amostragens aleatórias devem ser acumulados ou armazenados de uma forma apropriada para produzir o resultado final desejado. A característica essencial do MMC é o uso de técnicas de amostragem para se chegar à solução desejada. Em termos de transporte de radiação, o processo estocástico pode ser visto como uma família de partículas, sendo que as coordenad as de cada partícula individual mudam aleatoriamente a cada colisão. O comportamento médio destas partículas é descrito em termos de grandezas macroscópicas como fluxo ou densidade de partículas. O valor esperado destas grandezas corresponde à solução determinística da equação de Boltzman (que rege o fenômeno de transporte de radiação). Grandezas específicas, como energia depositada ou dose são derivadas destas grandezas (MCNP Manual, 1997). 


\subsection{Resultados e discussão}

Nesta seção são analisadas as reconstruções obtidas das simulações do phantom sob várias condições relativas ao desenho e a reconstrução, visando-se obter a melhor resolução espacial.

\subsubsection{Número de projeções e abertura de colimação}

A TABELA 6 apresenta quatro casos com as condições relacionadas ao número de projeções e abertura de colimação sob as quais o phantom foi analisado. $\mathrm{O}$ phantom foi analisado com 72 posições (views) para o conjunto de fontes e detectores percorrendo um ân gulo total de $360^{\circ}$, onde, os dados foram amostrados assim a cada $5^{\circ}$.

TABELA 6 - Casos estudados mudando o número de projeções e abertura de colimação.

\begin{tabular}{|c|c|c|c|c|}
\hline & $\begin{array}{c}\text { Abertura de colimação } \\
(\mathrm{cm})\end{array}$ & $\begin{array}{c}\text { Projeções por } \\
\text { ângu lo }\end{array}$ & $\begin{array}{c}\text { Número de } \\
\text { ângulos (views) }\end{array}$ & $\begin{array}{c}\text { No. Total } \\
\text { Projeções }\end{array}$ \\
\hline Caso 1 & 2,1 & 11 & 72 & 792 \\
\hline Caso 2 & 1,0 & 23 & 72 & 1656 \\
\hline Caso 3 & 0,67 & 33 & 72 & 2376 \\
\hline Caso 4 & 0,50 & 47 & 72 & 3384 \\
\hline
\end{tabular}

Para poder analisar os casos indicados na tabela anterior foi necessário simular quatro configurações do CT gama com as condições particulares. O programa MCNP permite verificar a modelagem geométrica do sistema no que se refere a posição e ao número de fontes e detectores, como mostrado na FIGURA 11 e na FIGURA 12. 

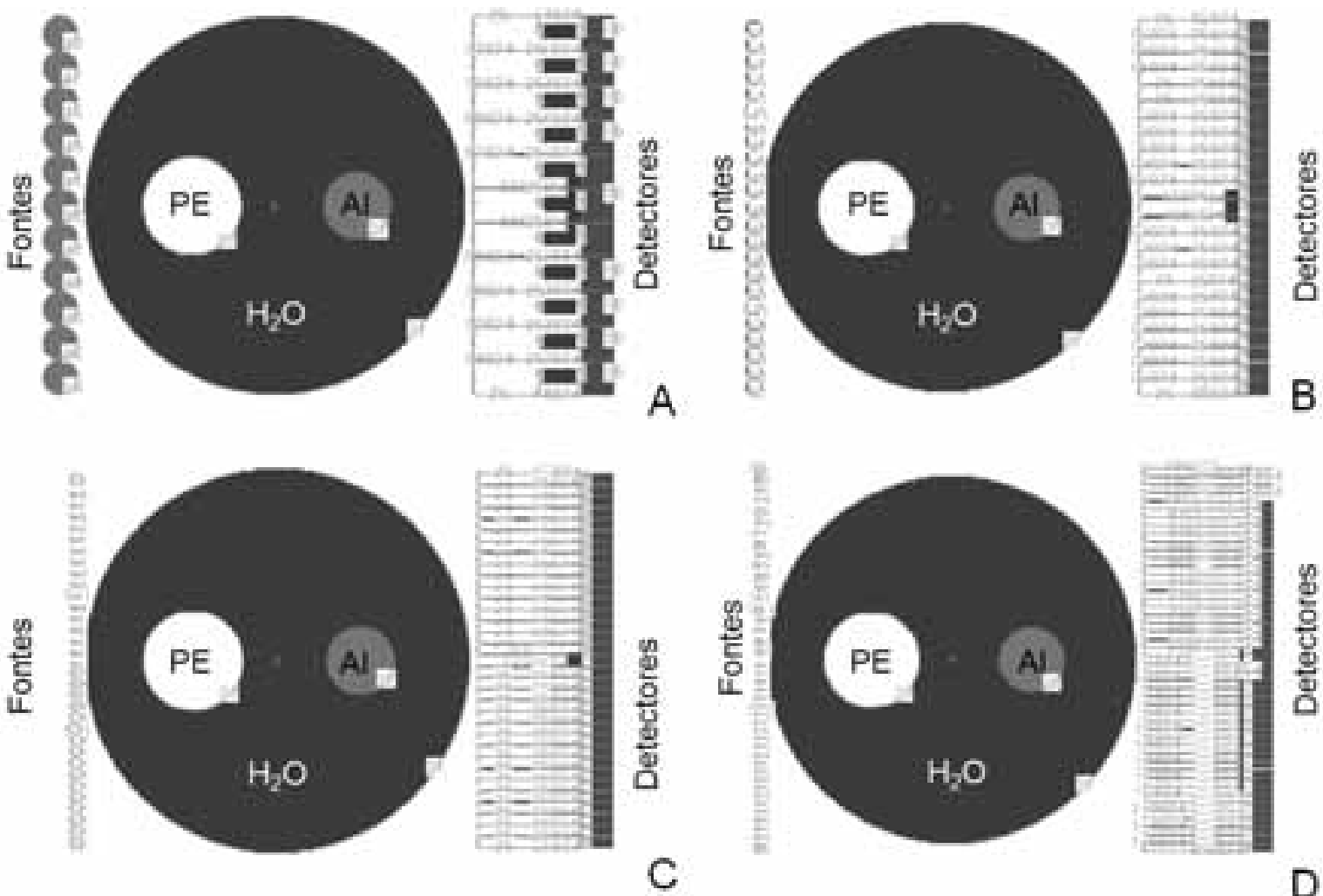

FIGURA 11 - Vista superior das simulações do CT e phantom para as condições estudadas. Efeito do número de projeções e a abertura da colimação (A) Caso 1, (B) Caso2, (C) Caso 3 e (D) Caso 4.

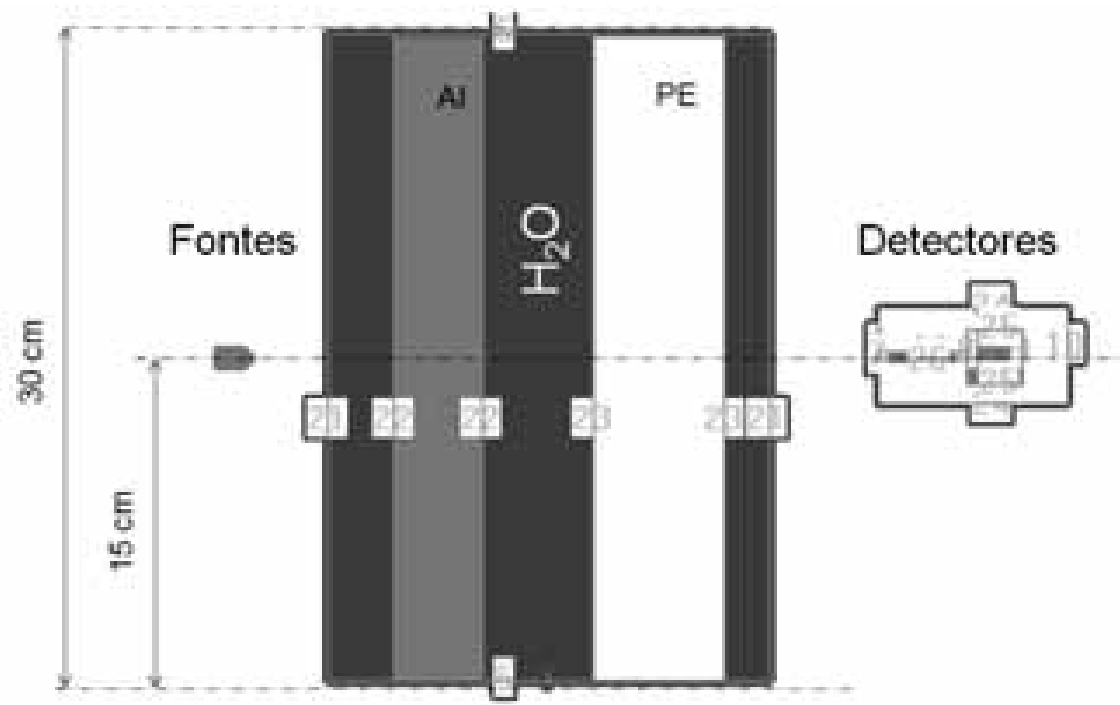

FIGURA 12 - Vista frontal do phantom e a posição das fontes e detectores para o caso geral. 
Devido ao fato do MCNP ser um método estatístico de amostragem, em outras palavras que gera uma grande quantidade de dados, permite-se também verificar se os dados foram gerados na posição adequada do espaço (coord enadas X-Y-Z), como mostra a FIGURA 13. A direção dos fótons dos raios gama foi condicionada, dentro do programa, para ser horizontal a direção da região dos detectores. Nas simulaçõ es foram amostradas $1,5 \times 10^{6}$ eventos por caso.

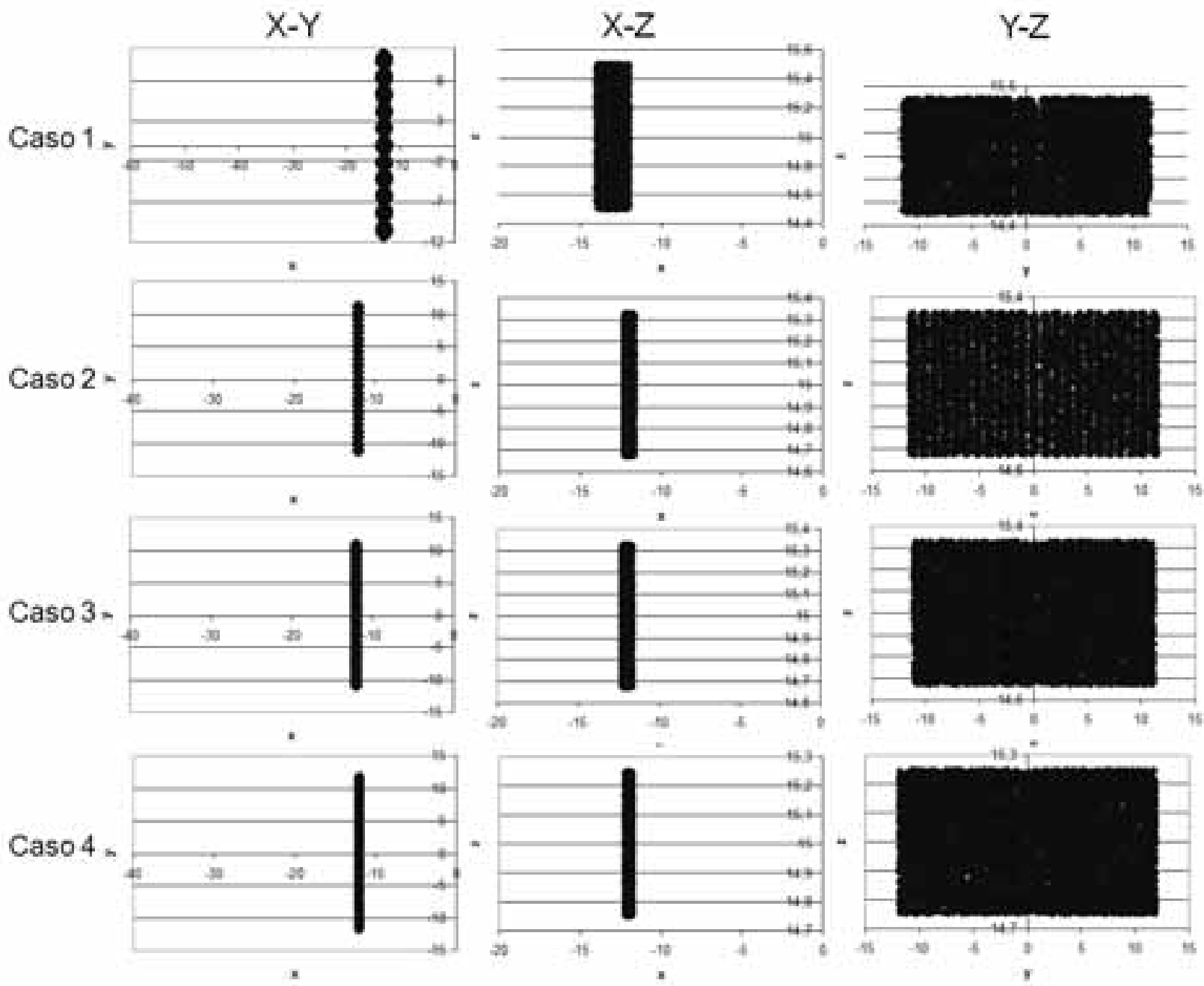

FIGURA 13 - Amostragem feita pela simulação dos fótons dos raios gama gerados pelas fontes para os Casos 1-4 no sistema espacial X-Y-Z. 
Na FIGURA 14 são apresentados os resultados da reconstrução utilizando a FBP para os quatro casos estudados. A escala representa o coeficiente de atenuação linear normalizado. A resolução espacial do sistema melhora para os menores valores de colimação, sendo o melhor resultado aquele atingido com $0,5 \mathrm{~cm}$. No entanto, com 0,67 o sistema já apresenta uma boa resolução. A fonte ${ }^{60} \mathrm{Co}$ apresenta fotopicos com energias de 1173 e $1332 \mathrm{keV}$ (alta energia) o que provoca uma sombra ao redor dos objetos de maior densidade. Este comportamento se mantém até no caso 4, que apresentou a melhor resolução. O algoritmo FBP consegue distinguir objetos que possuem grande diferença na densidade.
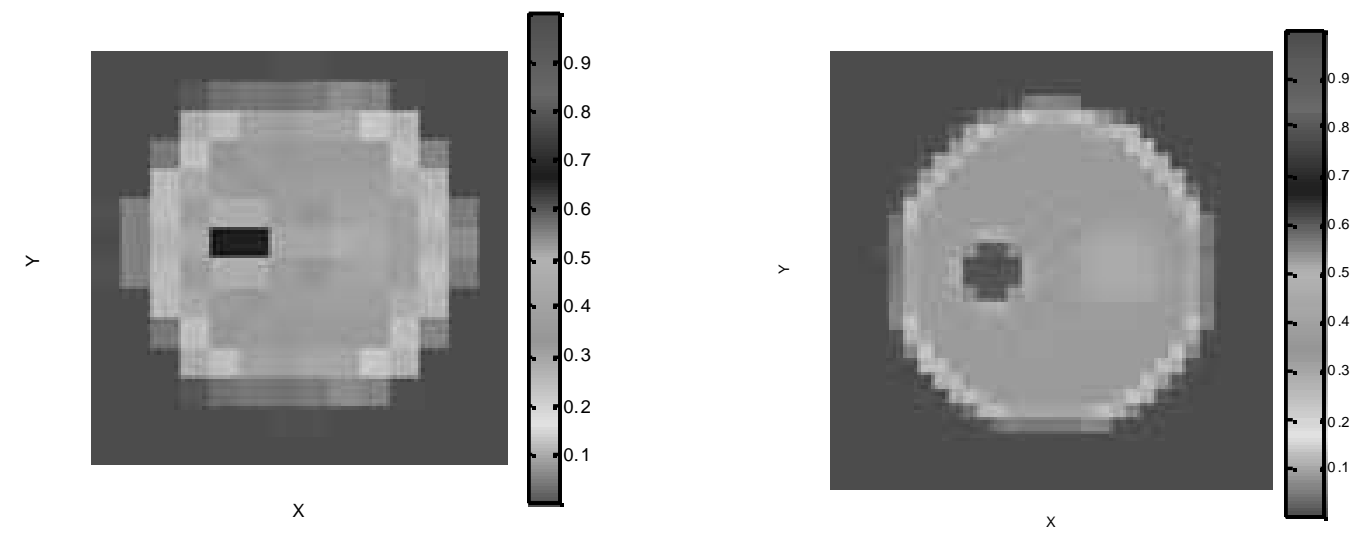

A
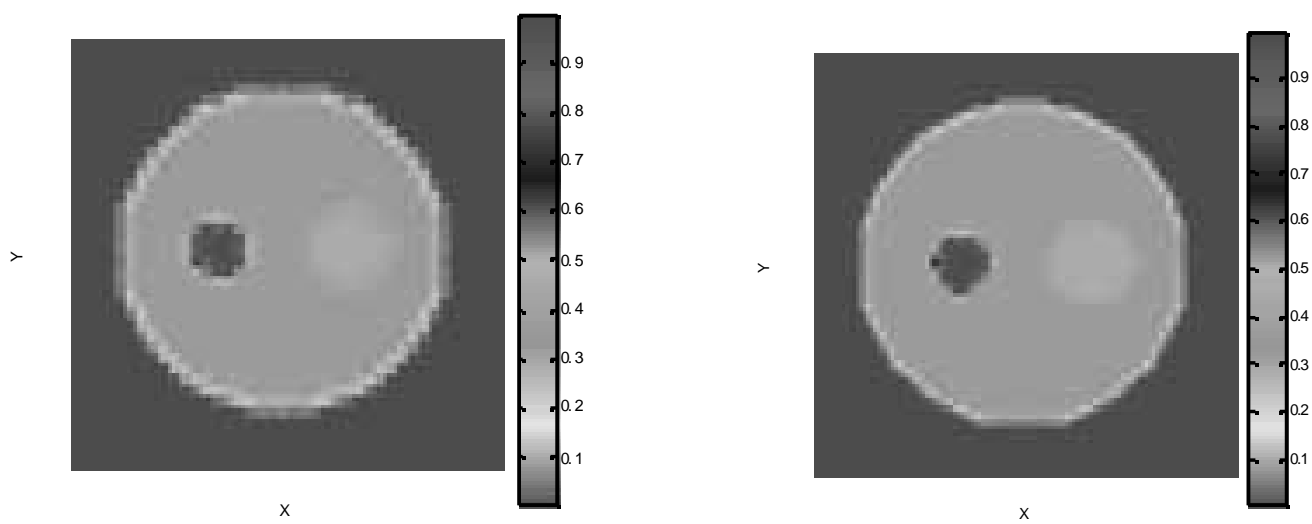

$\mathrm{C}$

FIGURA 14 - Efeito da abertura da colimação (A)Caso1: 2,1 cm, (B)Caso2: 1,0 cm, (C)Caso3: 0,67 cm e (D)Caso 4: $0,5 \mathrm{~cm}$ 


\subsubsection{Número de ângulos o posições das fontes (views)}

A FIGURA 15 mostra os resultados usando diferentes números de ângulos de rotação do sistema fontes - detectores mantendo fixa a ab ertura de colimação em $0,67 \mathrm{~cm}$. (33 projeções por ângulo). A TABELA 7 apresenta os quatro casos estudados. O espaço de amostragem do sistema analisado foi $16,4^{\circ}, 8,2^{\circ}, 4^{\circ}$ e $1^{\circ}$ para os casos $1,2,3$ e 4 , respectivamente. Portanto, com as condições dos casos 3 e 4 pode-se garantir uma boa resolução. Na prática a escolha de um número adequado de ângulos depende do tamanho do objeto estudado e do tempo de coleta de dados (resolução temp oral).
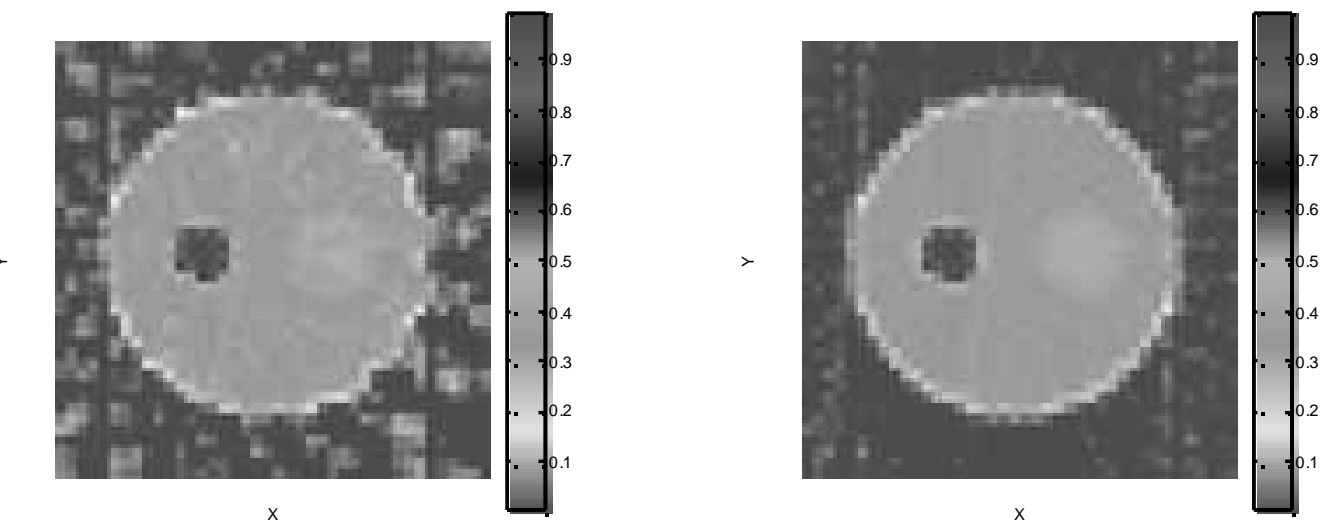

A
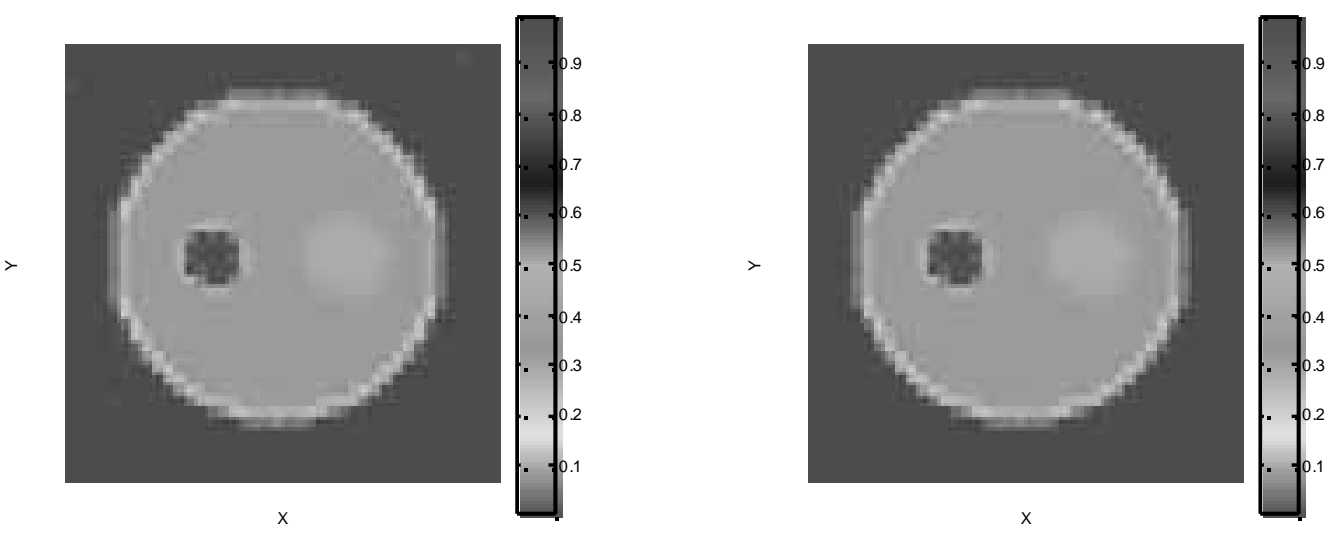

$\mathrm{C}$

FIGURA 15 - Número de ângulos de rotação (A)Caso 1: 11, (B)Caso 2: 44, (C)Caso 3: 90 e (D)Caso 4: 360. 
TABELA 7 - Casos estudados mudando o número de ângulos mantendo fixa a abertura de colimação.

\begin{tabular}{|l|c|c|c|c|}
\hline & $\begin{array}{c}\text { Abertura de colimação } \\
(\mathrm{cm})\end{array}$ & $\begin{array}{c}\text { Projeções por } \\
\text { ângu lo }\end{array}$ & $\begin{array}{c}\text { Número de } \\
\text { ângulos (views) }\end{array}$ & $\begin{array}{c}\text { No. Total } \\
\text { Projeções }\end{array}$ \\
\hline Caso 1 & 0,67 & 33 & 22 & 242 \\
\hline Caso 2 & 0,67 & 33 & 44 & 1012 \\
\hline Caso 3 & 0,67 & 33 & 90 & 2970 \\
\hline Caso 4 & 0,67 & 33 & 360 & 16920 \\
\hline
\end{tabular}

\subsubsection{Interpolação e filtros utilizados na reconstrução}

Vários tipos de interpolações lineares e cúbicas (nearest neighbor, linear, spline, pchip- shape preserving piecewise cubic, cubic) foram testados. De forma geral, não foram encontradas grandes diferenças, mas os melhores resultados foram obtidos com a interp olação linear e os mais deficientes utilizando a interpolação "nearest neighbor”. Os resultados deste último não são apresentados neste trabalho. Todas as imagens apresentadas neste trabalho foram obtidas utilizando-se a interpolação linear.

O fato de envolver a filtragem nas imagens introduz uma função degrau antes do processo de reconstrução. Esta filtragem recebe o nome de Ram-Lak (Kak \& Slaney, 2001). As imagens apresentadas nas seções 3.4 .1 e 3.4 .2 foram filtradas com este procedimento. Na FIGURA 16 são apresentados os resultados utilizando os filtros SheppLogan, Cosine, Hamming e Hann (seção 3.2) para uma abertura de colimação de 0,67 cm. e 90 ân gulos de rotação. De forma geral, os filtros apresentam pequenas diferenças no objeto de maior densidade sendo que o filtro Hann intensifica levemente o contraste da imagem. 

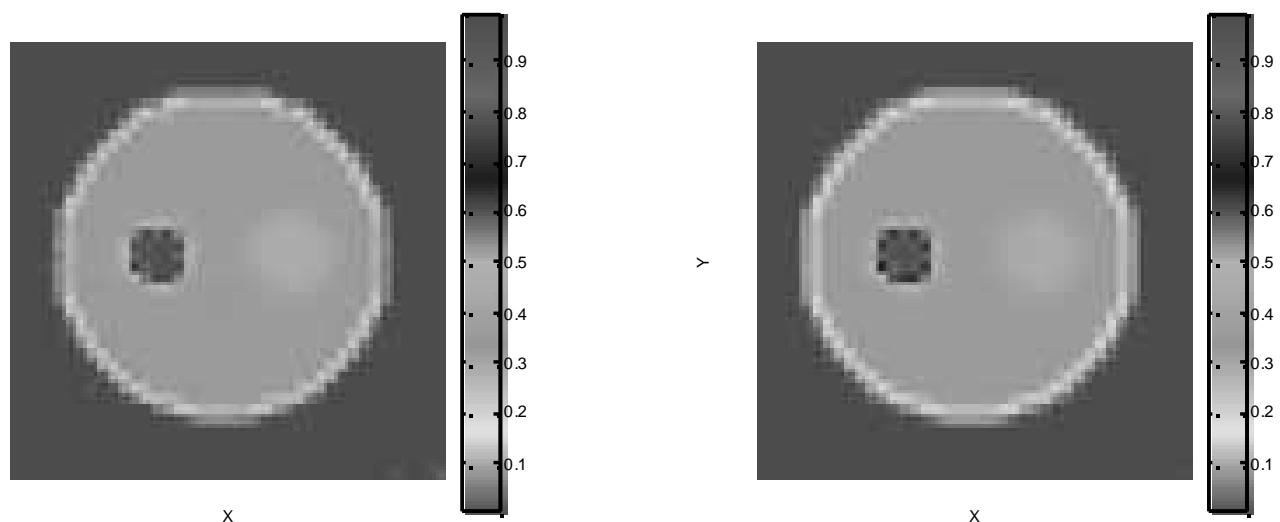

A
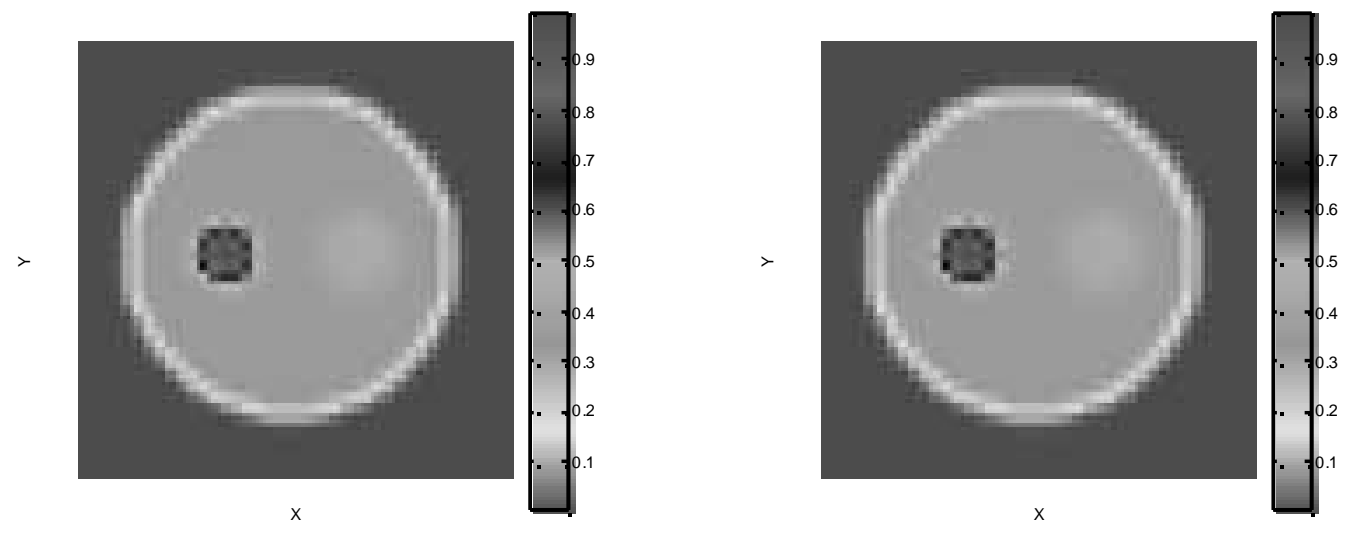

C

FIGURA 16 - Efeito do filtro para 0,67 cm de colimação e 90 ângulos de rotação (A) Shepp-Logan, (B)cosine, (C) Hamming e (D) Hann.

\subsection{Conclusões}

As simulações computacionais representam uma poderosa ferramenta para otimização de critérios e parâmetros no laboratório evitando investimentos desnecessários e diminu indo o tempo de pesquisas. No entanto, muitos dos resultados obtidos devem ser cuidadosamente observados, pois, na prática, vários efeitos, como, sensibilidades e eficiências, assim como, número de detectores terão limitações que diminu irão a eficiên cia da detecção e, consequentemente, a resolução de imagem. 
O algoritmo de retroprojeção filtrada foi implementado com êxito para o caso monoenergético e possibilitou a reconstrução das imagens de todos os casos avaliados. A filtragem e/ou apodização na FBP para evitar o ruído numérico decorrente do fato de usar uma aproximação "finita”. A FBP não toma em conta a natureza estatística do processo de desintegração radioativo.

A resolução espacial é inv ersamente proporcional à abertura de colimação, mas este fato tem restrições físicas relacionadas à atividade da fonte, pois quanto menor o espaço com que a radiação penetra no detector, faz-se necessário aumentar a atividade para manter a eficiên cia do detector, aumentando-se assim o risco radioló gico na manipulação de fontes (blindagem pesada). Uma boa resolução espacial pode ser encontrada com aberturas de colimação entre 0,5 e 0,67 cm, utilizando 90 ân gulos de rotação.

A simulação de Monte Carlo apresenta-se como um dos melhores métodos para simulação de sistemas sem a introdução de equações diferenciais complexas. No entanto, são necessários computadores rápidos ou associados a redes tipo Linux, pois em um PC normal (dual core) cada simulação leva de 5 a 6 dias. 


\section{DES ENVOLVIMENTO DE UM TOMÓGRAFO DE FONTE ÚN ICA (SS CT)}

\subsection{Introdução}

A Agência Internacional de Energia Atômica (AIEA) iniciou o projeto de pesquisa (CRP) Tomografia Gama para Processos Industriais (2003 - 2007) visando testar e validar técnicas para análise de processos multifásicos industriais por meio da CT. Laboratórios da Argentina, Brasil (CTR/IPEN), República Tcheca, França, Coréia, Malásia, Noruega, Polônia, Reino Unido e os Estados Unidos participaram deste projeto. Os objetivos específicos deste CRP foram avaliar métodos tomográficos para estudos de sistemas multifásicos e desenhar protótipos simples de CT para sua transferência a países em desenvolvimento. A AIEA enviou para todos os países que participaram do projeto de tomografia industrial, um phantom de polipropileno, para verificar o nível de precisão e resolução dos sistemas utilizados, assim como, os métodos de reconstrução de imagens disponíveis. Os resultados destes estudos foram publicados no IAEA-TECDOC-1589 (2008).

No CTR/IPEN foi desenvolvido e validado um tomógrafo de primeira geração onde foi implementado o algoritmo para reconstrução de imagens FBP. Um phantom de 40 cm de diâmetro enviado pela AIEA foi analisado, reconstruindo-se as imagens das distribuições dos coeficientes de atenuação em duas e três dimensões. A precisão destas medidas foi quantificada em fun ção dos erros médios quadráticos. 


\subsection{Materiais e Métodos}

\subsubsection{Tomógrafo de fonte única SSCT}

A FIGURA 17 mostra o tomógrafo de fonte única SSCT desenvolvido no CTR/IPEN. Este sistema apresenta as características de primeira geração, onde objeto de estudo foi girado e deslocado, mantendo-se fixa a posição da fonte e do detector.

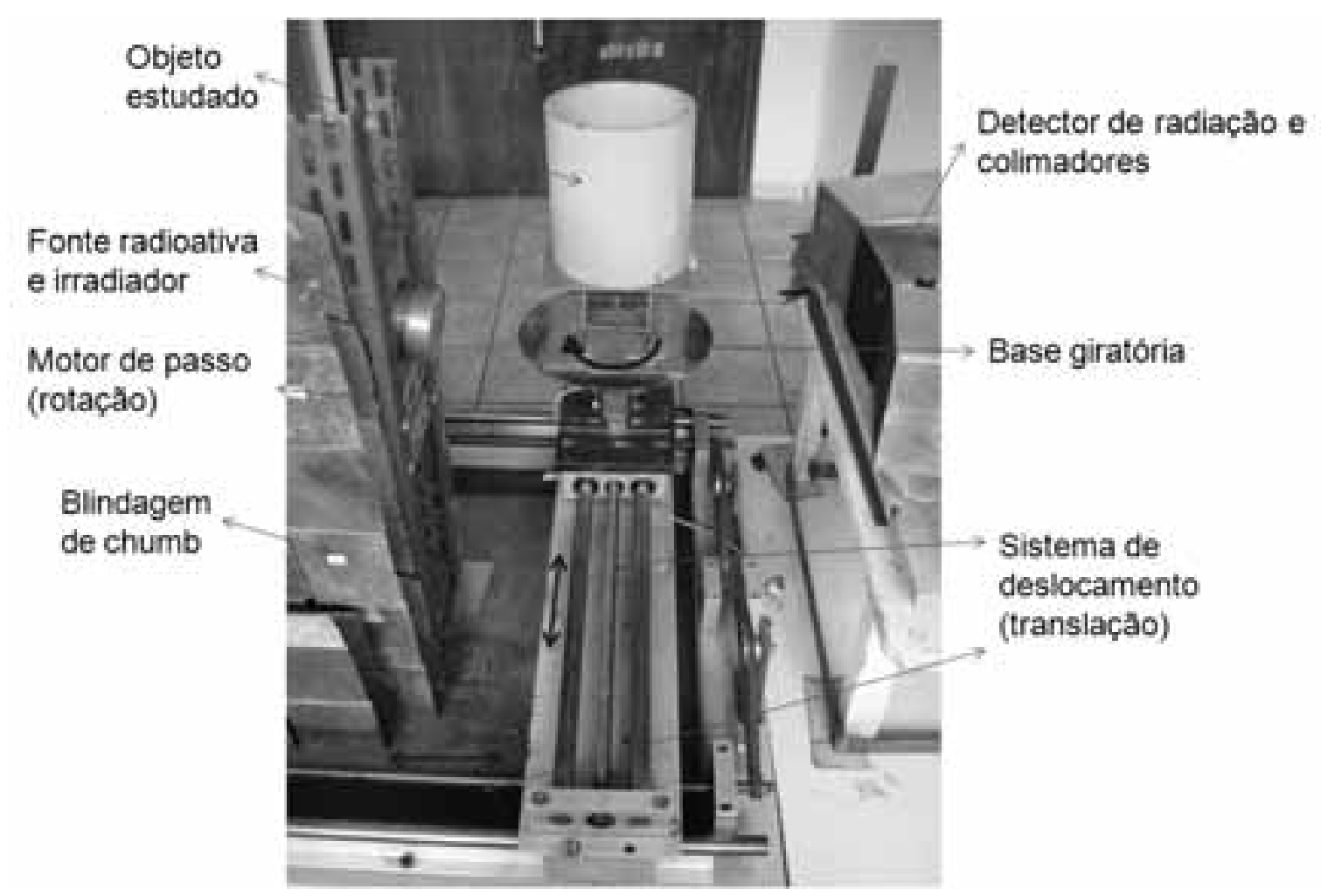

FIGURA 17 - Descrição do sistema tomográfico SSCT.

O hardware do SSCT foi fabricado e montado no CTR/IPEN. O sistema de aquisição de dados foi desenvolvido pelo Dr. Carlos H. de Mesquita do CTR/IPEN. O sistema foi desenhado para analisar objetos de até $40 \mathrm{~cm}$ de diâmetro. 
O SSCT permite a troca de fontes radioativas de acordo com a aplicação. No CTR estavam disponíveis duas fontes de ${ }^{137} \mathrm{Cs}$ de $37 \mathrm{MBq}(1 \mathrm{mCi})$ e de 3,6 GBq (97 mCi) e uma fonte de ${ }^{60} \mathrm{Co}$ de $18,5 \mathrm{MBq}(500 \mu \mathrm{Ci})$. O detector utilizado foi um cintilador de $\mathrm{NaI}(\mathrm{Tl})$ de 2 × 2 pol. O sistema é composto de 3 motores de passo, onde, um deles girava o objeto, e os outros dois serviam para o deslocamento horizontal deste. $\mathrm{Na}$ frente do detector foi colocado um colimador de chumbo que definiu a resolução espacial. Para este sistema, estavam disponíveis duas opções, uma de 5 x $5 \mathrm{~mm}$ e outra de 2,39 x 4,38 mm. O controle do tempo de contagem, o número de ângulos de rotação e a discriminação de energias foram feitos via computador.

Para a coleta de dados foi desenvolvida uma placa eletrônica específica que permitiu armazenar os dados, constituída por duas ADC de 8 bits cada um com 256 canais $(0-5 \mathrm{~V})$. Esta placa permitiu adicionar mais de um detector e registrar os dados individualmente.

\subsubsection{Detalhes do phantom enviado pela AIEA}

Um phantom cilíndrico de $40 \mathrm{~cm}$ fabricado em polipropileno foi estudado com o SSCT, como apresentado na FIGURA 18. O phantom tem dois orifícios internos de $5 \mathrm{~cm}$ de diâmetro cada. 

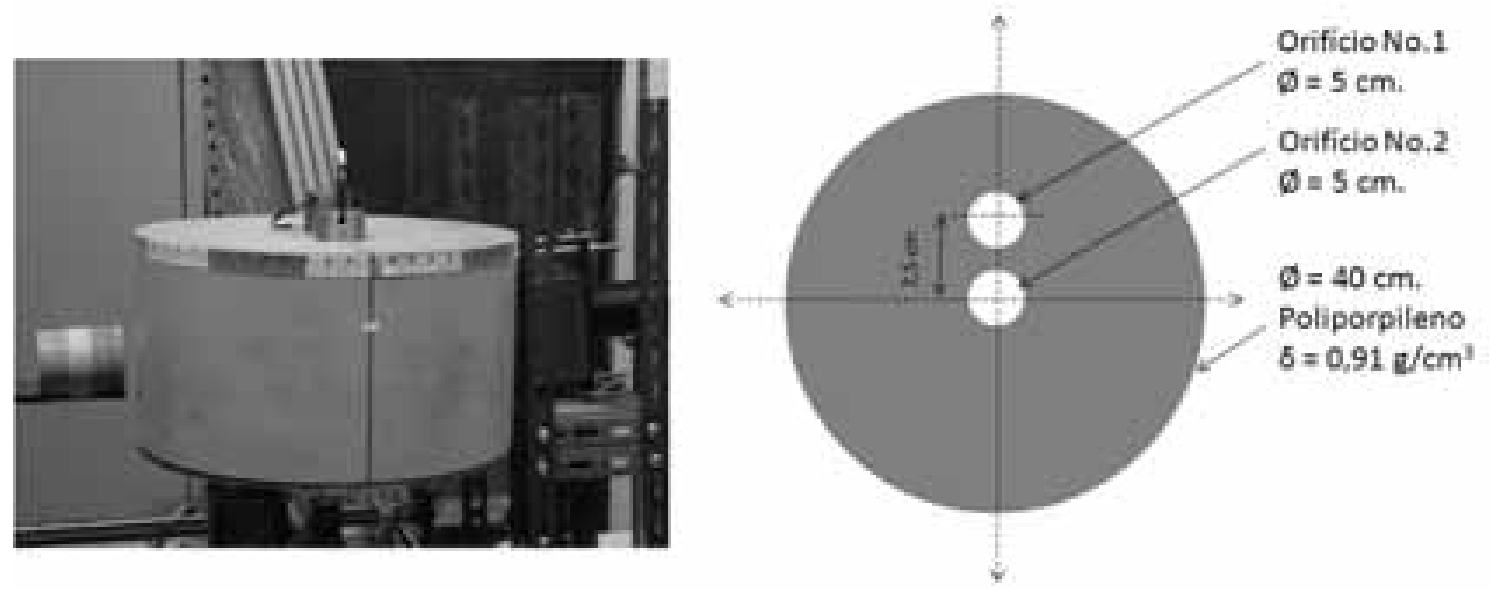

FIGURA 18 - Detalhes do phantom da AIEA fabricado em polipropileno.

\subsubsection{Condições de operação do SSCT}

O SSCT utilizou uma fonte de $18,5 \mathrm{MBq}(500 \mu \mathrm{Ci})$ de ${ }^{60} \mathrm{Co}$. A atividade necessária para este estudo foi calculada utilizando-se o programa de simulação JANU, onde foram assumidos um nível de confiança de 95\% e um erro relativo de $10 \%$ para um tempo de contagem de $10 \mathrm{~s}$. A colimação do detector foi mantida fixa em $5 \mathrm{~mm}$ e o objeto foi estudado utilizando-se 30 ân gulos (varredura de $6^{\circ}$ ). Aproximadamente 6400 projeçõ es por imagem foram obtidas, onde cada tomografia durou 4 horas.

\subsubsection{Validação do tomógrafo S SCT com um phantom da AIEA}

Esta seção descreve o estudo realizado para validar o SSCT e implementar o algoritmo FBP (seção 3.2) utilizando um phantom enviado pela AIEA. Vários parâmetros, tais como, tempo de contagem, capacidade de diferenciar fases (materiais internos) e a discrimin ação na região dos fotopicos foram estudados. Neste ponto é importante destacar que o phantom forneceu informações para várias fases (materiais de diferentes densidades). Para poder comparar a precisão do SSCT foram calculados os erros médios quadráticos 
(root mean squared error) dos coeficientes de atenuação ponderados pelo número de pixels RMSE(N) e os erros médios quadráticos relativos dos coeficientes de atenuação $\operatorname{RMSE}(\mu)$ como mostrados nas equações a seguir.

$$
\begin{aligned}
& \operatorname{RMSE}(N)=\frac{\sqrt{\sum_{x \in X}(\hat{\mu}(x)-\mu(x))^{2}}}{N} \\
& \operatorname{RMSE}(\mu)=\sqrt{\frac{\sum_{x \in X}(\hat{\mu}(x)-\mu(x))^{2}}{\sum \mu(x)^{2}}}
\end{aligned}
$$

Onde $x$ é o índice do pixel, $\mu(x)$ é o coeficiente de atenuação efetivo de cada pixel $\mathrm{x}\left(\mathrm{cm}^{-1}\right)$ na fase $i$ (conhecido); $\hat{\mu}(x)$ é o coeficiente de atenuação estimado mediante a reconstrução.

\subsection{Resultados e discussão}

Para poder avaliar a eficiência do SSCT e da técnica de reconstrução utilizada (FBP), vários casos foram estudados como mostrado na TABELA 8. O caso 1 estudou o phantom com ambos orifícios internos vazios. O caso 2 avaliou o phantom com o orifício externo preenchido com óleo de densidade $0,92 \mathrm{~g} / \mathrm{cm}^{3}$ (similar a do phantom). No caso 3 ambos os orifícios foram preenchidos com chumbo $\left(\rho=11,3 \mathrm{~g} / \mathrm{cm}^{3}\right)$ para poder avaliar a capacidade do sistema para diferenciar matérias de densidades diferentes. Nos casos 4, 5 e 6 somente o orifício externo foi preenchido com chumbo e o tempo de contagem foi avaliado a 20s, 15 s e 5 s respectivamente. Finalmente no caso 7 foi estudada a região do fotopico, pois, em todos os casos anteriores (1-6) foi admitida uma pequena região do Comptom para melhorar a estatística de contagens. 
TABELA 8 - Parâmetros estudados nos casos analisados.

\begin{tabular}{|c|c|c|c|}
\hline Caso & $\begin{array}{c}\text { Tempo de } \\
\text { contagem (s) }\end{array}$ & Orifício No.1 & Orifício No.2 \\
\hline 1 & 15 & $\mathrm{Ar}$ & $\mathrm{Ar}$ \\
\hline 2 & 15 & $\mathrm{Ar}$ & Oleo \\
\hline 3 & 20 & Chumbo & Chumbo \\
\hline 4 & 20 & Chumbo & $\mathrm{Ar}$ \\
\hline 5 & 15 & Chumbo & $\mathrm{Ar}$ \\
\hline 6 & 5 & Chumbo & $\mathrm{Ar}$ \\
\hline 7 & $\begin{array}{c}20 \\
\text { Na região do } \\
\text { fotopico }\end{array}$ & Chumbo & $\mathrm{Ar}$ \\
\hline
\end{tabular}

\subsubsection{Sinogramas de validação}

A FIGURA 19 mostra os sinogramas obtidos para os casos 1-4. Cada pixel dos sinogramas representa o raio de transmissão corr espondente a uma determinada projeção e posição da fonte (view) ou ângulo de rotação. Os sinogramas mostraram tons azuis-escuros para os objetos de maior densidade. Um sinograma permite verificar a qualidade das medidas obtidas no processo de amostragem da tomografia. A ausência de bandas paralelas ou manchas que poderiam ser atribuídas ao mal funcionamento de detectores garantiu o resultado final. 

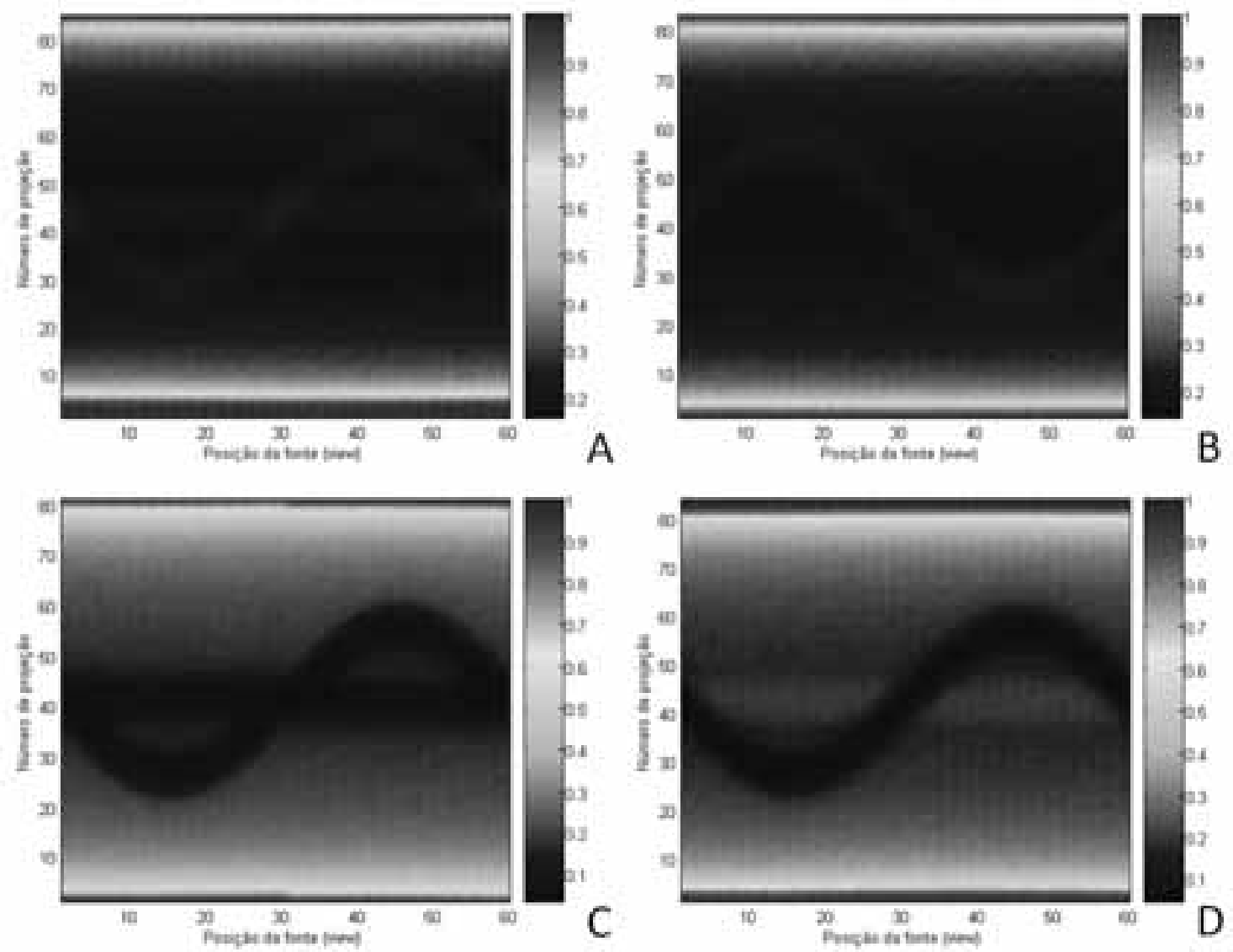

FIGURA 19 - Sinogramas obtidos com o phantom. (A) Caso 1, (B) Caso 2, (C) Caso 3, (D) Caso 4.

\subsubsection{Reconstrução de imagens e erros médios quadráticos}

A FIGURA 20 mostra os resultados das reconstruções (FBP) nos casos citados anteriormente, como uma distribuição dos coeficientes de atenuação $\hat{\mu}_{i}(x)\left(\mathrm{cm}^{-1}\right)$ para os diferentes materiais. O SSCT não conseguiu diferenciar variações na densidade de 0,01 $\mathrm{g} / \mathrm{cm}^{3}$. Este fato pode ser explicado pela alta en ergia da fonte de ${ }^{60} \mathrm{Co}(1332 \mathrm{keV})$ que provoca valores de atenuação muito similares gerando também sombras ao redor dos objetos de alta densidade (artefatos). Quando foi diminuído o tempo de contagem pode ser observada uma deterioração da imagem. A atividade da fonte utilizada foi relativamente 
baixa, fazendo-se necessários tempos de contagem maiores ou iguais a $10 \mathrm{~s}$. A reconstrução na região do fotopico apresentou pouca definição devido a baixa taxa de contagem registrada.
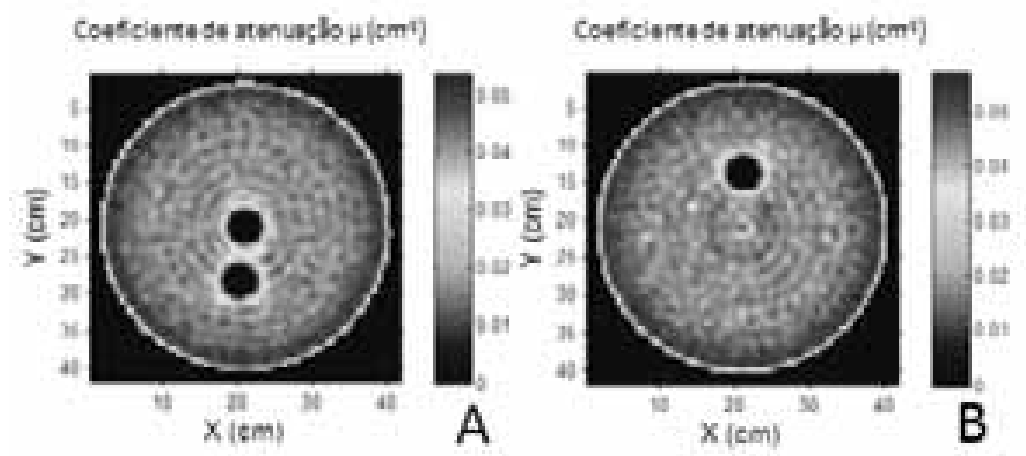

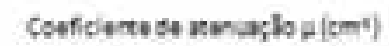
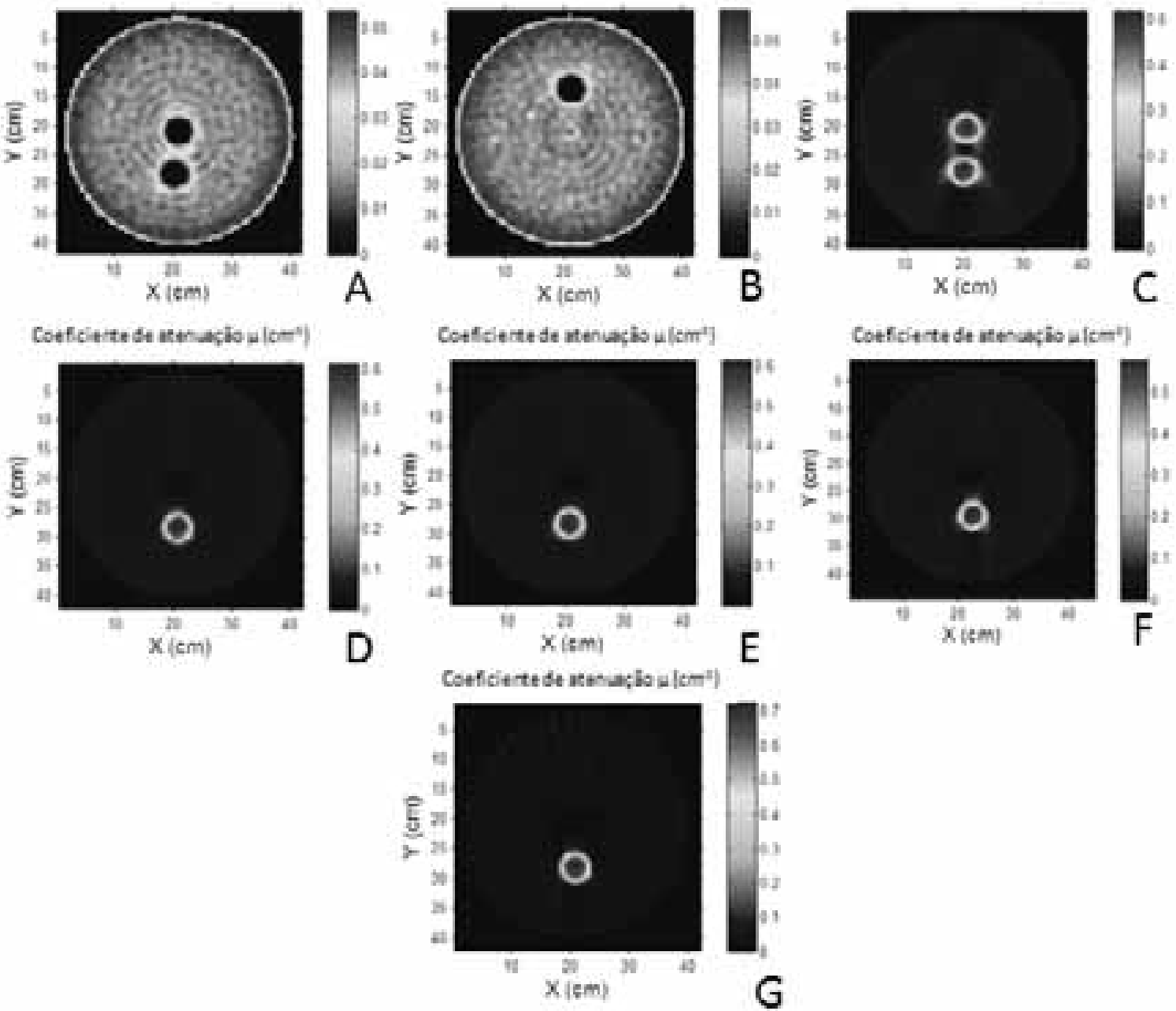

FIGURA 20 - Distribuição dos coeficientes de atenuação utilizando a FBP para: (A) Caso 1, (B) Caso 2, (C) Caso 3, (D) Caso 4, (E) Caso 5, (F) Caso 6, (G) Caso 7.

A TABELA 9 apresenta os resultados dos RMSE dos casos estudados (Vasquez et al. 2007). Os erros referentes à posição são menores que os erros relativos ao valor dos coeficientes de atenuação. Isto significa, que não houve falhas mecân icas e que o 
controle dos motores de passo tanto para rotação como para deslocamento foi muito preciso. Os erros relacionados às atenuações podem ser diminuídos reduzindo-se o tamanho da colimação e assim, melhorando a resolução espacial e aumentando o número de ângulo ou posições das fontes. Em geral, o erro aumenta quando são estudados materiais de densidades muito diferentes (polipropileno e chumbo) e com a diminuição do tempo de contagem, como é esperado. A utilização de uma fonte de maior atividade melhorar ia consideravelmente esta situação, permitindo trabalhar com tempos de contagem muito menores.

TABELA 9 - RMSE relativos a pixels $(\mathrm{N})$ e coeficientes de atenuação $(\mu)$.

\begin{tabular}{|c|c|c|}
\hline Caso & RMSE(N) & RMSE $(\mu)$ \\
\hline 1 & $1,71 \times 10^{-4}$ & 0,129 \\
\hline 2 & $1,29 \times 10^{-4}$ & 0,227 \\
\hline 3 & $6,36 \times 10^{-4}$ & 0,443 \\
\hline 4 & $3,79 \times 10^{-4}$ & 0,370 \\
\hline 5 & $3,76 \times 10^{-4}$ & 0,394 \\
\hline 6 & $3,62 \times 10^{-4}$ & 0,366 \\
\hline 7 & $4,62 \times 10^{-4}$ & 0,436 \\
\hline
\end{tabular}

A FIGURA 21 representa a reconstrução volumétrica 3D dos coeficientes de atenuação a partir de várias fatias 2D utilizando o método de convolução de Gauss ( box Gaussian convolution kernel smoothing voxel) para os casos 1,2 e 3. Nesta figura pode ser observada a imagem sólida com transparência e de um corte longitudinal do phantom. 


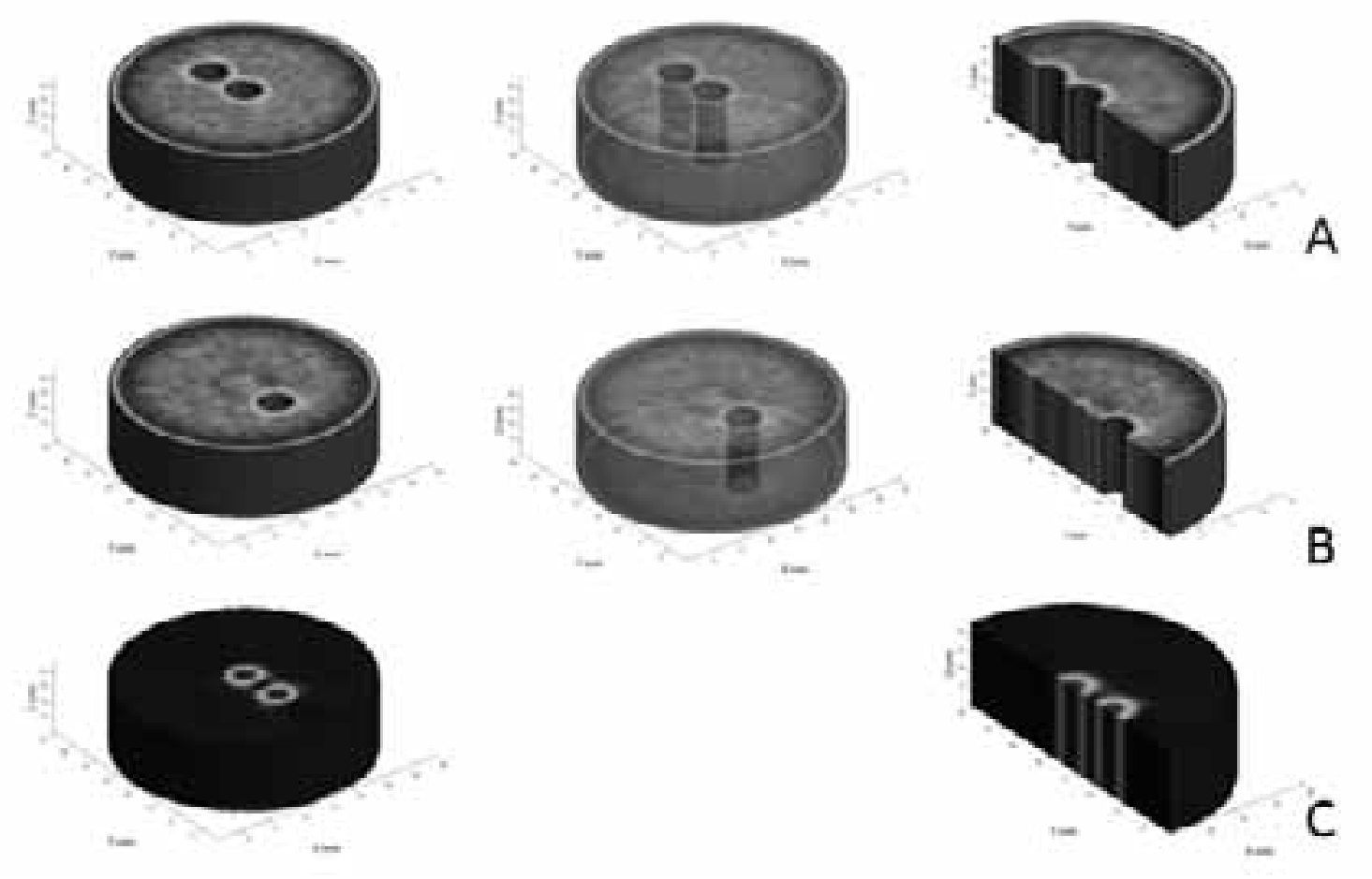

FIGURA 21 - Imagens 3 D reconstruídas a partir de várias fatias transversais: (A) Caso 1, (B) Caso 2, (C) Caso 3.

\subsection{Conclusões}

O SSCT foi validado satisfatoriamente com a implementação da FBP, sendo determinadas as distribuições dos coeficientes de atenuação de vários materiais. O sistema apresentou estabilidade e boa resolução espacial para as condições analisadas. Melhorias nas imagens reconstruídas podem ser alcançadas diminuindo a colimação utilizada para o detector de radiação e aumentando a atividade da fonte. A utilização de uma fonte de menor energia $\left({ }^{137} \mathrm{Cs}\right)$ definiria melhor materiais de densidades similares. A utilização de outras técnicas de reconstrução de imagens poderia melhorar estes resultados. 


\section{COMPARAÇÃO ENTRE RETROPROJEÇÃO FILTRADA (FBP), ES PERANÇA-MAXIMIZAÇÃO (EM) E MINIMIZAÇÃO ALTERNATIVA (MA) PARA A RECONSTRUÇÃO DE IMAGENS TOMOGRÁFICAS MONOENERGÉT ICAS}

\subsection{Introdução}

As informações coletadas que representam as atenuações da radiação através do objeto a ser estudado (projeções) devem ser processadas matematicamente para obter a imagem. Uma imagem é um conjunto de pixels, cada pixel representa uma pequena região espacial do domínio (objeto). Os coeficientes de atenuação linear de cada pixel do do mínio quando representados em forma coletiva representam a imagem de atenuação do do mínio.

Brooks \& Dichiro (1976) e mais recentemente Kumar \& Dudukovic (1997) fizeram uma coletânea sobre as diferentes técnicas utilizadas para reconstrução de imagens da tomografia por transmissão gama. Dentro das técnicas analíticas, a retro projeção filtrada FBP (Kak \& Slaney, 2001) é a mais usada nos CT comerciais, mas este algoritmo não leva em conta a natureza estatística do processo de desintegração radioativa. Algoritmo do tipo iterativo, tal como, a esperança - maximização EM (Lange \& Carson, 1984) e a minimização alternativa MA (O’Sullivan \& Benac, 2007) tem-se mostrado mais preciso para a determinação do holdup por levar em consideração a natureza estocástica da radiação. 
$\mathrm{O}$ algoritmo EM tem sido usado largamente em CT gama para a determinação do holdup em sistemas dinâmicos de duas fases (Kumar et al. 1995; Kumar et al. 1997; Roy et al. 1997; Rammohan, 2002; Roy et al. 2004; Karim et al. 2004; Roy \& Al-Dahhan 2005; Patel et al. 2007). Comparações entre a FBP e a técnica algébrica de reconstrução (ART) têm sido feitas no CREL (WUSTL) por Kumar (1994). Recentemente, Patel et al. (2007) fizeram um estudo similar para tomógrafos com geometrias em leque e paralelo. Ambos trabalhos concluíram que a EM é superior as outras técnicas.

Neste estudo foi analisado um phantom com três fases para a determinação da distribuição dos coeficientes de atenuação utilizando o DSCT (WUSTL) na modalidade monoenergética. Os detalhes do algoritmo FBP encontram-se descritos na seção 3.2, enquanto os algoritmos EM e MA serão descritos a seguir. O phantom foi analisado primeiramente com uma fonte radioativa de ${ }^{137} \mathrm{Cs}(662 \mathrm{keV})$ e depois com uma fonte de ${ }^{60} \mathrm{Co}(1173 \mathrm{keV}$ e $1332 \mathrm{keV})$. As imagens foram reconstruídas nas regiões dos fotopicos utilizando a FBP, EM e MA e os resultados para os coeficientes de atenuação foram comparados calculando os erros médios quadráticos.

\subsection{Algoritmos para reconstrução de imagens iterativos}

\subsubsection{Esperança - Maximização (EM)}

Lange \& Carson (1984) definiram a reconstrução de imagens para tomografia como um problema de maximização da função de verosimilhança máxima (maximum likelihood) de onde derivaram o algoritmo expectation - maximization (EM) para maximizar a função de verosimilhança da imagem. Em experimentos nos quais a taxa de contagem é alta ( $\sim 500$ contagens por projeção), ignorar a natureza estatística dos dados não 
representa uma limitação séria, pois o ruído de Poisson $^{8}$ na contagem é uma parte do ruído total do sistema. Assim, em experimentos com taxa de contagem baixa, espera-se que o EM melhore a qualidade da reconstrução.

O algoritmo EM é um método iterativo de estimação de máxima verosimilhança para problemas com dados incompletos (quantidades provenientes de processos estatísticos). A idéia concreta é estimar parâmetros de máxima verosimilhança em modelo de dados. Cada iteração do algoritmo EM consiste de duas etapas: (a) esperança $^{9}$ (etapa E) e (b) maximização (etapa M).

A FIGURA 22 representa o objeto de estudo quando este é atravessado por um feixe de raios gama caracterizado pela linha entre a fonte $(\mathrm{F})$ e o detector $(\mathrm{D})$. O domínio de estudo está dividido em quadrantes, onde cada quadrante representa um pixel. Assim, $x$ é o índice de pixel (coordenada na imagem), $y$ representa o índice de projeção, $h(y \mid x)$ é o comprimento $(\mathrm{cm})$ do segmento da projeção $y$ que está dentro do pixel $x$ e $d(y)$ são os dados da transmissão para um determinado índ ice de projeção $y$.

\footnotetext{
${ }^{8}$ A desintegração radioativa é um fenômeno que obedece à distribuição de Poisson Knoll (2000).

${ }^{9}$ Esperança, média, ou valor esperado.
} 


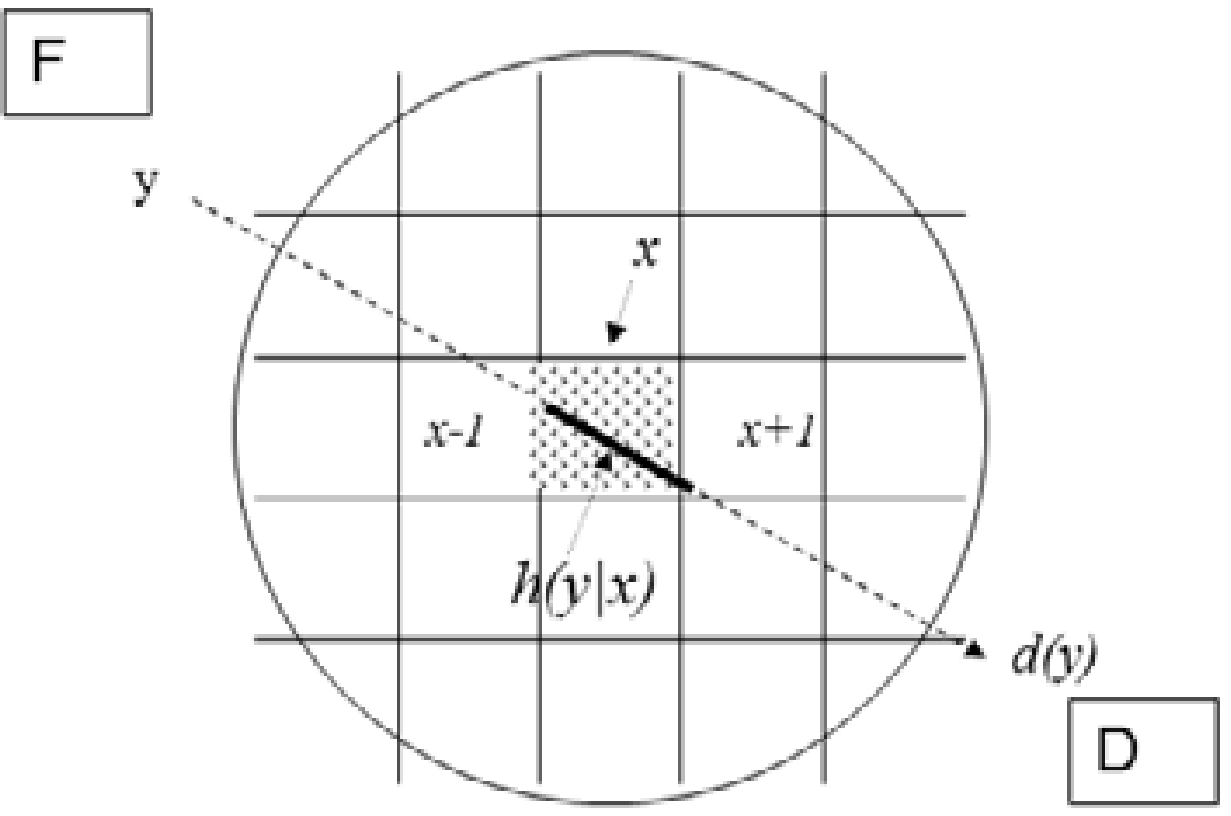

FIGURA 22 - Esquema da tomografia por transmissão. Os quadrantes representam os pixels.

Portanto, a forma matemática básica da atenuação representada na equação ( 4) pode ser escrita assim:

$$
\frac{I(y)}{I_{o}(y)}=\exp \left[-\int_{0}^{L} \mu(x) h(y \mid x) d x\right]
$$

Onde $I_{o}(y)$ representa a radiação incidente para o índice de projeção $y, I(y)$ é a radiação detectada após o objeto para o índice de projeção $y, \mu(x)$ é o coeficiente de atenuação $\left(\mathrm{cm}^{-1}\right)$ para o pixel $x$ e $L$ é o caminho total percorrido pelo feixe.

Na etapa E (esperança) é estimada a esperança condicional do conjunto "total" ou "completo" de dados em função das informações medidas (taxa de contagem dos detectores) e de um conjunto de parâmetros (atenuações). O conjunto total de dados representa a intensidade da radiação que entra e sai de cada pixel do sistema para todas as 
projeções. Se para um determinado pixel $x$ ao longo de uma projeção $y$, é definido $X(y \mid x)$ como o número aleatório de fótons (contagens) que entram em $x$, e $X(y \mid(x+1))$ é o número aleatório de fótons que sobrevivem ou saem de $x$ (não atenuados); então este fenômeno pode ser modelado como uma distribuição binomial com duas probabilidades: sobrevivência do fóton $e^{(-h(y \mid x) \mu(x))}$ e absorção dos fótons $\left[1-e^{(-h(y \mid x) \mu(x))}\right]$. Assim, a probabilidade do conjunto total de dados está dada pela probabilidade deste processo binomial e pode ser rep resentada pela equação ( 24 ):

$$
P_{X(y \mid(x+1))}=\left(\begin{array}{c}
X(y \mid x) \\
X(y \mid(x+1))
\end{array}\right)\left[e^{(-h(y \mid x) \mu(x))}\right]^{X(y \mid(x+1))}\left[1-e^{(-h(y \mid x) \mu(x))}\right]^{X(y \mid x)-X(y \mid(x+1))}
$$

O primeiro pixel ao longo de qualquer projeção $y$ recebe os fótons emitidos pela fonte radioativa. A desintegração radioativa é um processo estatístico que obedece a distribuição de Poisson, com uma média dada por Io que representa a intensidade da fonte; onde, a probabilidade dos fótons emitidos para o primeiro pixel é:

$$
P_{X(y \mid 1)}=\frac{I_{o}^{X(y \mid 1)} e^{\left(-I_{o}\right)}}{X(y \mid 1) !}
$$

Devido ao fato dos pixels serem independentes, a função de verosimilhança do conjunto completo de dados (para todos os pixels ao longo da projeção y) pode ser representado como o produto das funções de verosimilhança individuais para cada pixel ao longo de $y$, como segue:

$f(N(y): \mu)=\frac{I_{O}^{X(y \mid 1)} e^{\left(-I_{o}\right)}}{X(y \mid 1) !} \prod_{x \in X}\left(\begin{array}{c}X(y \mid x) \\ X(y \mid(x+1))\end{array}\right)\left[e^{(-h(y \mid x) \mu(x))}\right]^{X(y \mid(x+1))}\left[1-e^{(-h(y \mid x) \mu(x))}\right]^{X(y \mid x)-X(y \mid(x+1))}$ 
Se o conjunto completo de dados fosse conhecido, o cálculo dos valores dos coeficientes de atenuação $\mu(x)$ para cada pixel poderia ser realizado diretamente. Porém, este não é o caso, pois, só são disponíveis as medidas de contagem registradas pelos detectores que representam o número aleatório de fótons que sobreviveram (não foram atenuados) ao percorrerem os pixels ao longo de todas as projeções disponíveis. A etapa $\mathrm{E}$ envolve o cálculo da esperança (média) do conjunto completo de dados $X(y \mid x)$ para um pixel determinado, condicional aos dados observados $d(y)$ e ao estimador atualizado da função de atenuação $\hat{\mu}(x),{ }^{(k)}$ mostrado a seguir:

$$
\mathrm{E}\left[X(y \mid x) \mid d(y), \hat{\mu}(x)^{(k)}\right]
$$

Lange \& Carson (1984) mostram que a equação ( 27 ) pode ser aproximada por:

$$
\mathrm{E}[X(y \mid x) \mid d(y)]=d(y)+\mathrm{E}[X(y \mid x)]-\mathrm{E}[d(y)]
$$

Antes da etapa $M$, a equação ( 28 ) é utilizada para determinar $M(y \mid x)$ e $N(y \mid x)$ que são os valores da esperança (média) dos fótons que entram e saem do pixel $x$ respectivamente. $M(y \mid x)$ e $N(y \mid x)$ são esperanças condicionais referidas a $X(y \mid x)$ e $X(y \mid(x+1))$ respectivamente pela equação $(27)$.

Na etapa M, a esperança condicional é maximizada com relação a um conjunto de parâmetros. No caso da tomografia gama por transmissão, o conjunto de parâmetros são os valores das atenuações dos pixels $\mu(x)$ do domínio estudado e as medidas registradas pelos detectores $d(y)$ para cada projeção $y$. A equação ( 28 ) é utilizada para determinar os valores condicionais da esperança $M(y \mid x)$ e $N(y \mid x)$ para cada pixel da imagem, os 
mesmos que são somados a todas as projeções e substituídos na função de verosimilh ança. O algoritmo natural desta equação está dado pela expressão a seguir, que representa a função de log-verosimilhança para o conjunto de dados completo para todas as projeções $y$ :

$$
\ln [f(N(y): \mu)]=\sum_{y \in Y} \sum_{x \in X}\left\{N(y \mid x) \ln \left[e^{(-h(y \mid x) \mu(x))}\right]+(M(y \mid x)-N(y \mid x)) \ln \left[1-e^{(-h(y \mid x) \mu(x))}\right]\right\}+R
$$

Onde, $R$ representa todos os termos que não dependem de $\mu(x)$. A maximizando da equação ( 29 ) é feita obtendo-se a derivada parcial com relação a $\mu(x)$ e igualando-a a zero, como mostrado a segu ir:

$$
\sum_{y \in Y}-N(y \mid x) h(y \mid x)+\sum_{y \in Y}[M(y \mid x)-N(y \mid x)] \frac{h(y \mid x)}{e^{(h(y \mid x) \mu(x))}-1}=0
$$

A equação ( 30 ) não pode ser resolvida analiticamente por causa do termo exponencial, portanto, Lange \& Carson (1984) sugeriram a utilização de uma aproximação baseada nas séries de Taylor para poder simplificar a solução:

$$
\frac{1}{e^{(h(y \mid x) \mu(x))}-1}=\frac{1}{h(y \mid x) \mu(x)}-\frac{1}{2}+\frac{h(y \mid x) \mu(x)}{12}+O\left[(h(y \mid x) \mu(x))^{3}\right]
$$

Os autores recomendaram a utilização dos três primeiros termos da equação ( 31 ). Desta forma a equação ( 30 ) modifica-se assim:

$$
\sum_{y \in Y}[M(y \mid x)-N(y \mid x)] \frac{h(y \mid x)^{2}}{12} \mu(x)^{2}-\sum_{y \in Y}[M(y \mid x)-N(y \mid x)] \frac{h(y \mid x)}{2} \mu(x)+\sum_{y \in Y}[M(y \mid x)-N(y \mid x)]=0
$$

A equação ( 32 ) é da forma quadrática e a sua solução está dada a seguir: 


$$
\hat{\mu}(x)^{(k+1)}=\frac{B-\sqrt{B^{2}-4 A C}}{2 A}
$$

onde: $\quad A=\sum_{y \epsilon Y}[M(y \mid x)-N(y \mid x)] \frac{h(y \mid x)^{2}}{12} ; \quad B=-\sum_{y \epsilon Y}[M(y \mid x)-N(y \mid x)] \frac{h(y \mid x)}{2} \quad \mathrm{e}$ $C=\sum_{y \in Y}[M(y \mid x)-N(y \mid x)]$

O processo iterativo inicia-se quando utilizado um valor inicial para $\hat{\mu}(x)^{k}$ $(k=0)$ no cálculo dos valores condicionais das esperanças $M(y \mid x)$ e $N(y \mid x)$ usando $d(y)$ com base na equação ( 28 ). Estes valores são utilizados para calcular a próxima estimação de $\hat{\mu}(x)^{k+1}$ com base na equação ( 32 ). Definindo $k=k+1$, este processo é repetido, iniciando na equação ( 28 ) até encontrar um valor de $\hat{\mu}(x)^{k+1}$ que maximize a função logverosimilhança do conjunto completo de dados.

A aproximação da equação ( 30 ) utilizando a equação ( 31 ) é valida para valores pequenos de $[h(y \mid x) \mu(x)]$ e não é muito precisa para aplicações envolvendo regiões de alta densidade ou coeficientes de atenuação mássico $\mu(x) / \delta\left(\mathrm{cm}^{2} / \mathrm{g}\right)$ elevados e para resoluções de pixels densas com valores elevados de $h(y \mid x)$. Esta é a maior limitação para sistemas multifásicos, já que estes são construídos com estruturas internas metálicas. Para melhorar a precisão, outros autores têm proposto modificações na etapa E (Browne \& Holmes, 1992) e na etapa M (Ollinger, 1994) para aplicações específicas, como a tomografia por emissão de pósitrons (PET). Obviamente, pode obter-se melhora na aplicação destas propostas para a CT gama. Neste trabalho foram comparados os algoritmos FBP e MA com a versão de EM desenvolvida por Lange \& Carson (1984) pela sua precedência na determinação do holdup de sistemas multifásicos com raios gama (Kumar, 1994; Kumar et al. 1995; Kumar et al. 1997; Kumar \& Dudukovic 1997; Roy et al. 1997; Kemoun et al. 2001; Rammohan, 2002; Roy et al. 2004; Karim et al. 2004; Rados 
et al. 2005; Roy \& Al-Dahhan, 2005; Luo, 2005; Roy, 2006; Al-Dahhan et al. 2007, Patel et al. 2007).

\subsubsection{Minimização Alternativa (MA)}

O algoritmo EM é um caso especial do algoritmo de minimização alternativa (O’Sullivan \& Benac 2007). Este algoritmo tem sido estudado amplamente nas aplicações que envolvem raios X para equipamentos médicos (Benac,2005). O’Sullivan \& Benac (2007) reformularam o problema da função de verosimilhança máxima como uma dupla minimização de uma I-divergência para obter a família de algoritmos de reconstrução de imagens. A I-divergência, introduzida por Csiszár (1991) é a medida da discrepância de duas funções $a(y)$ e $b(y)$, dada por:

$$
I(a \| b)=\sum_{y \in Y}\left[a(y) \ln \left(\frac{a(y)}{b(y)}\right)-(a(y)-b(y))\right]
$$

Onde, $y$ é uma dimensão espacial finita.

Csiszár (1991) estudou uma vasta variedade das medidas de discrepância (ex: mínimos quadrados, entropia) incluindo a I-divergência de duas funções $a(y)$ e $b(y)$ mostrada na equação ( 33 ). Analisou as restrições relacionadas à não-negatividade e concluiu que se as funções envolvidas são todas reais, tendo tanto valores positivos como negativos, a minimização via mínimos quadrados, é a única escolha consistente, enquanto que, se todas as funções são requeridas como sendo não-negativas, então, a minimização da I-divergência é também a única escolha consistente, onde, I-divergên cia foi utilizada pela primeira vez para a reconstrução de imagens por Snyder et al. (1992). 
Cada etapa de minimização do algoritmo MA é concebida para ser exata sem aproximações (como no caso EM - equação ( 31 )), sendo esta uma das principais vantagens deste algoritmo. Assim, o algoritmo MA formulado por O'Sullivan \& Benac (2007) garante um incremento constante da função log-verosimilhança a cada iteração. Este algoritmo para reconstrução da imagem está baseado em um modelo estatístico para os dados medidos na lei de Beer e em um modelo determinístico para função de espalhamento pontual conhecida.

Sendo $q(y: \mu)$ o modelo de transmissão de fótons dado pela lei de Lambert e Beer, tem-se:

$$
q(y: \mu)=I_{o}(y) \exp \left(-\sum_{x \in X} h(y \mid x) \mu(x)\right)
$$

Onde $I_{o}(y)$ representa a intensidade da radiação (contagem) incidente, $h(y \mid x)$ é a função de espalhamento pontual ou comprimento da projeção $y$ no pixel $x$. Na equação ( 34 ) que representa a I-divergência, a função $a(y)$ equivale aos dados medidos $d(y)$ (número aleatório de Poisson) e $\mathrm{b}(\mathrm{y})$ equivale ao modelo não linear $q(y: \mu)$ que representa a transmissão de fótons. O termo $q(y: \mu)$ é função da atenuação $\mu(x)$, onde $\mathrm{x}$ é o índice do pixel. Desta forma, a equação ( 34 ) pode ser escrita assim:

$$
I(d \| q(y: \mu))=\sum_{y \in Y}\left\{d(y) \ln \left(\frac{d(y)}{q(y: \mu)}\right)-[d(y)-q(y: \mu)]\right\}
$$


O objetivo principal do algoritmo pode ser descrito por:

$$
\min _{\mathbf{q} \in \boldsymbol{\mu}} I(\mathbf{d} \| \mathbf{q})
$$

calculando o mínimo de $I(\mathbf{d} \| \mathbf{q})$ com relação a $\mu$.

Os termos na função log-verosimilhança que dependem do conjunto de parâmetros (valores de atenuação a serem estimados) são de sinal oposto aos correspondentes da I-divergên cia. Então, minimizar a I-divergência em relação ao conjunto de parâmetros de $\mu$ é equivalente a maximizar a função log-v erosimilhança. Minimizar a Idivergência traz a vantagem única de conhecer o limite inferior (igual a zero) para dados de projeções processados de qualquer sistema. Este não é o caso, quando maximizada a função log-verosimilhança, pois, o limite superior não é conhecido.

Minimizando a equação ( 36 ) com as condições da equação ( 37 ) obtêm-se uma expressão iterativa para atualização do conjunto de parâmetros (valores das atenuações):

$$
\hat{\mu}^{(k+1)}(x)=\hat{\mu}^{(k)}(x)-\frac{1}{Z(x)} \ln \left(\frac{\tilde{b}(x)}{\hat{b}^{(k)}(x)}\right)
$$

Onde, os termos com “^” significam estimadores. $\widetilde{b}(x)$ e $\hat{b}^{(k)}(x)$ são as retroprojeções para $\boldsymbol{d}$ e para o estimador atualizado $\hat{\mathbf{q}}^{(k)}$ respectivamente. Em outras palavras, estes valores representam as retroprojeções dos valores medidos e do modelo não linear utilizado (baseado na lei da Lambert \& Beer) e são descritos a seguir: 


$$
\begin{gathered}
\tilde{b}(x)=\sum_{y \in Y} h(y \mid x) d(y) \\
\hat{b}^{(k)}(x)=\sum_{y \in Y} h(y \mid x) \hat{q}^{(k)}(y)
\end{gathered}
$$

onde,

$$
\hat{q}^{(k)}(y)=I_{o}(y) \exp \left(-\sum_{x \in X} h(y \mid x) \hat{\mu}^{(k)}(x)\right)
$$

O processo iterativo para o cálculo da imagem caminha em ordem inverso, iniciando-se na equação ( 42 ) até a equação ( 38 ). Primeiramente, um valor inicial para $\hat{\mu}^{(k=0)}(x)$ é escolhido para calcular $\hat{\mathbf{q}}(x)$ na equação ( 41$)$, logo $\hat{\mathbf{q}}(x)$ é utilizado para calcular $\hat{\mathbf{b}}(x)$ na equação ( 40 ). A retroprojeção $\widetilde{\mathbf{b}}(x)$ é calculada só uma vez, baseada nos valores medidos. $\hat{\mu}^{(k=1)}(x)$ é atualizado segundo a equação ( 38 ), onde o processo inicia-se novamente, definindo $k=k+1$ utilizando os valores atualizados da atenuação. A condição de não-negatividade aplica-se para os valores da atenuação. Por este motivo e para qualquer iteração, quando $\hat{\mu}^{(k+1)}(x)<0$, este valor é corrigido com $\hat{\mu}^{(k+1)}(x)=0 . Z(x)$ na equação ( 38 ) é uma função de escalonamento apropriada, escolhida para o pixel $x^{\text {th }}$, para satisfazer o seguinte critério:

$$
\sum_{x \in X}\left(\frac{h(y \mid x)}{Z(x)}\right) \leq 1
$$


Para cada pixel $x$ o comprimento da maior projeção $y$ que passa através deste, foi escolhida como o valor de $Z(x)$ para o qual a equação ( 42 ) é satisfeita. Os valores utilizados para $Z(x)$ não influ enciam nos resultados finais convergentes.

O algoritmo MA, anteriormente descrito, não modela a região de espalhamento de Comptom. Neste estudo foram utilizados os dados de transmissão de fótons (não atenuados) correspondentes às regiões dos fotopicos. Quando o espalhamento é significativo e inevitável, deve ser utilizado um algoritmo mais sofisticado (O'Sullivan \& Benac, 2007).

\subsection{Materiais e Métodos}

\subsubsection{Detalhes do phantom estudado}

Um phantom multifásico (gás - líquido - sólido) foi confeccionado com o intuito de se poder variar as proporções das fases. A FIGURA 23 mostra o sistema estudado composto de um anel externo de 10 pol. de diâmetro montado em uma superfície plana do mesmo material. Dentro da região de estudo foram colocados os subdomínios $\mathrm{C} 1$ e C2, fabricados com tubulação de Perplex de 2 pol.; e os subdomínios S1-S3 fabricados em vidro plumbífero. Duas configurações do phantom multifásico foram escolhidas; Caso 1 e Caso 2. A idéia era alternar as fases líquidas e gasosa mantendo-se a sólida fixa. A TABELA 10 apresenta os detalhes destes casos. 

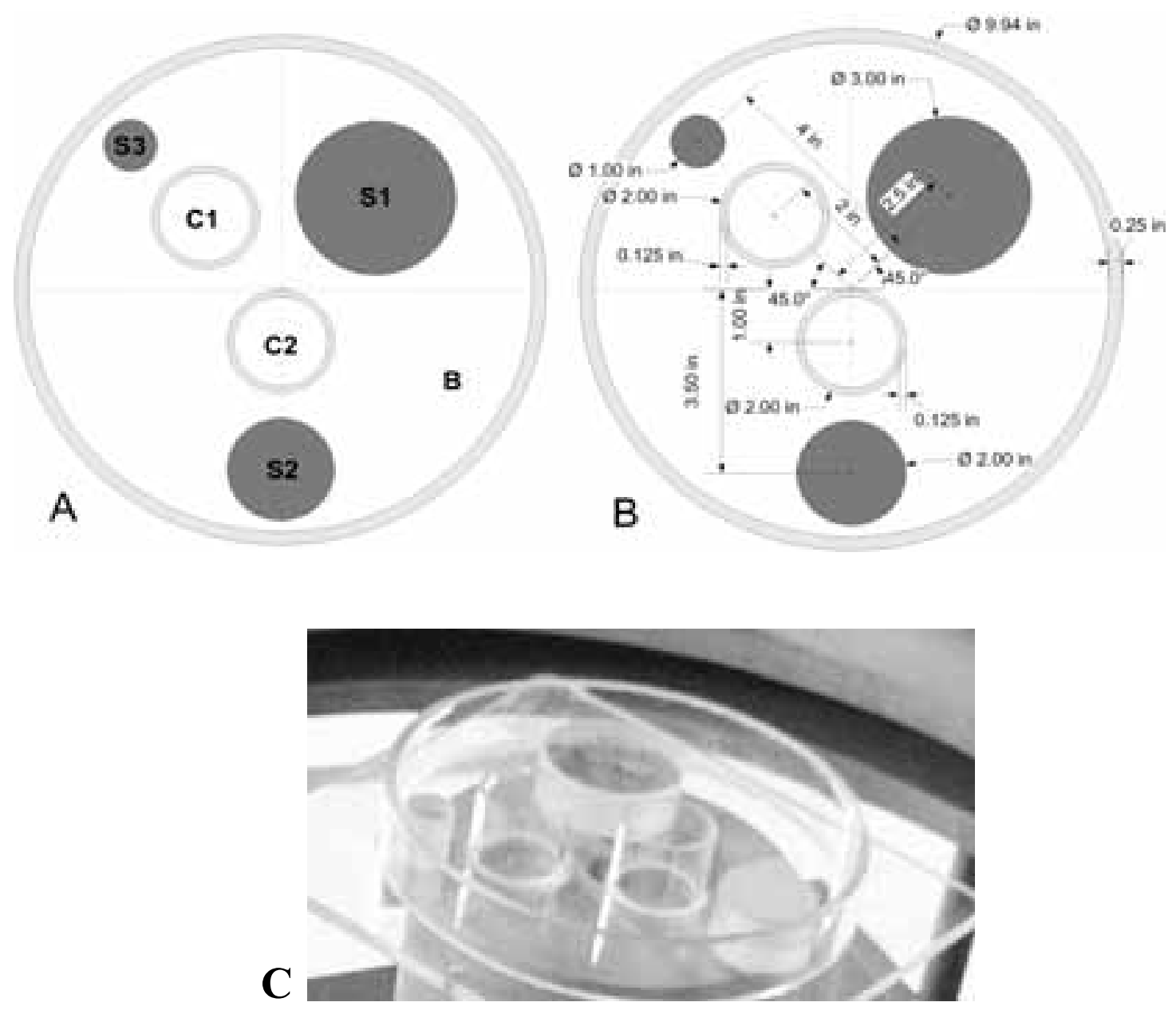

FIGURA 23 - Esquema do phantom estudado (3 fases). (A) Regiões C1 e C2 (fase gasosa) confeccionadas com tubulação de Perplex de 2 pol. Regiões S1-S3 fabricadas com vidro plumbífero (fase sólida). As regiões $C 1, C 2$ e S1-S3 estão compreendidas dentro da região B. (B) Detalhe das dimensões do phantom (altura aproximada 2,5 pol.)

TABELA 10 - Detalhes das fases dos subdomínios do phantom (FIGURA 23).

\begin{tabular}{|c|c|c|}
\hline Phantom & Fase na região B & Fases nos subdomínios C1 e C2 \\
\hline Caso 1 & Água & Ar \\
\hline Caso 2 & Ar & Agua \\
\hline
\end{tabular}

Para poder comparar os resultados das três técnicas de reconstrução são necessários os valores dos coeficientes de atenuação para os materiais que constituem o phantom (fases puras). Hubell \& Seltzer (1996) criaram uma base de dados denominada NIST (http:/ / physics.nist.gov) onde estão disponíveis valores dos coeficientes de atenuação 
em função da energia para um material ou composto específico. Nestes experimentos, os valores das atenuações foram determinados utilizando-se a densitometria gama, procedimento que consiste na aplicação direta da equação ( 4 ) usando somente um detector, onde o material a ser medido é co locado no caminho da radiação:

$$
\mu(E)=-\frac{1}{\rho L} \ln \left(\frac{I}{I o}\right)
$$

O comprimento do objeto exposto à radiação $L$ e a sua densidade $\rho$ são conhecidos, Io e $I$ foram medidos na ausência e presença do objeto, respectivamente. As medidas foram repetidas várias vezes $\left(3 \times 10^{4}\right)$, utilizando-se a média destes valores para calcular os coeficientes de atenuação. A TABELA 11 apresenta os valores dos coeficientes de atenuação utilizados.

TABELA 11 - Coeficientes de atenuação para os materiais do phantom.

\begin{tabular}{|c|c|c|c|}
\hline \multirow{2}{*}{ Energia $(\mathrm{keV})$} & \multicolumn{3}{|c|}{ Coeficientes de Atenuação $\left(\mathrm{cm}^{-1}\right)$} \\
\cline { 2 - 4 } & Ar & Agua & Vidro plumbífero \\
\hline $662\left({ }^{10} \mathrm{Cs}\right)$ & 0,000091 & 0,0813 & 0,3836 \\
\hline $1173\left({ }^{\circ} \mathrm{Co}\right)$ & & 0,0653 & 0,2293 \\
\hline $1332\left({ }^{\circ 0} \mathrm{Co}\right)$ & 0,000065 & 0,0605 & 0,2375 \\
\hline $1173+1332\left({ }^{\circ} \mathrm{Co}\right)$ & & 0,0632 & 0,2329 \\
\hline
\end{tabular}

\subsubsection{Descrição do tomógrafo gama DSCT}

Para este estudo foi utilizado um tomógrafo com duas fontes radioativas denominado dual source CT (DSCT) da WUSTL. Este equipamento pode ser operado nas modalidades monoenergética ou polienergética. No caso monoenergético, os resultados obtidos com cada fonte for am processados de forma independente; no caso polienergético, os resultados foram processados de forma conjunta (DSCT Manual, 2007). Este trabalho 
foi parte da validação do DSCT, pois, este equipamento não tinha sido utilizado. Antes do seu funcionamento, diversos problemas foram solucionados relacionados à electrônica dos detectores, controle dos motores de passo, amplificadores de alta voltagem, etc.

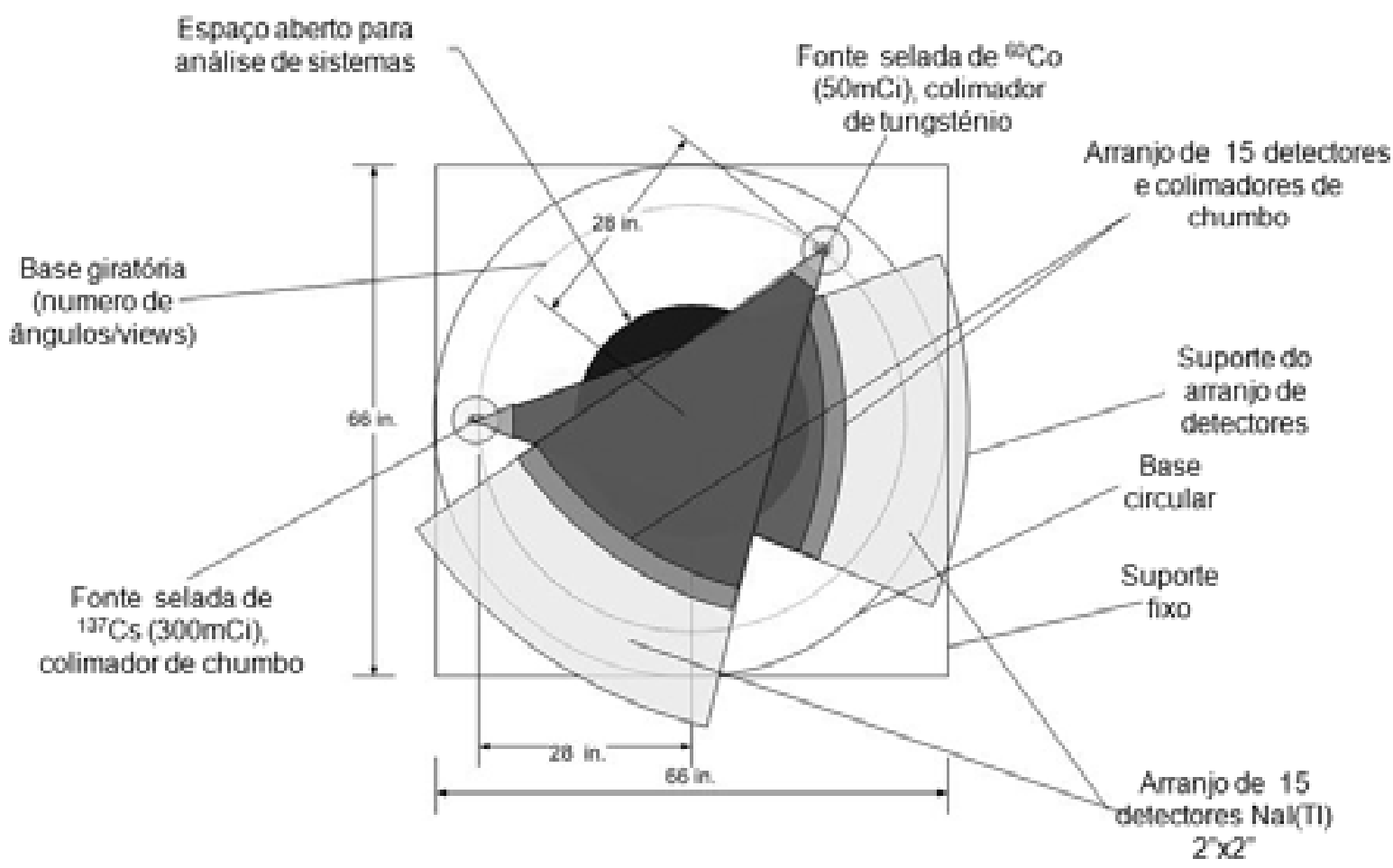

FIGURA 24 - Esquema do sistema DSCT - Vista superior. Regiões marcadas em vermelho (entre a fonte e os detectores) indicam o campo de ação das fontes radioativas.

Na FIGURA 24 é mostrado o sistema DSCT utilizado na WUSTL. Este sistema possui duas fontes radioativas, uma de ${ }^{137} \mathrm{Cs}$ com 9,3 $\mathrm{GBq}(250 \mathrm{mCi})$ e outra de ${ }^{60} \mathrm{Co}$ com 1,9 GBq (50 mCi). O espaço circular aberto (região em preto) permite analisar objetos de até 30 pol. de diâmetro com exposição simultânea às duas fontes. As regiões em vermelho indicam a passagem da radiação das duas fontes. Os detectores encontram-se diametralmente opostos a cada fonte, fazendo com que o sistema formasse dois leques; cada um com 15 detectores (total 30). 


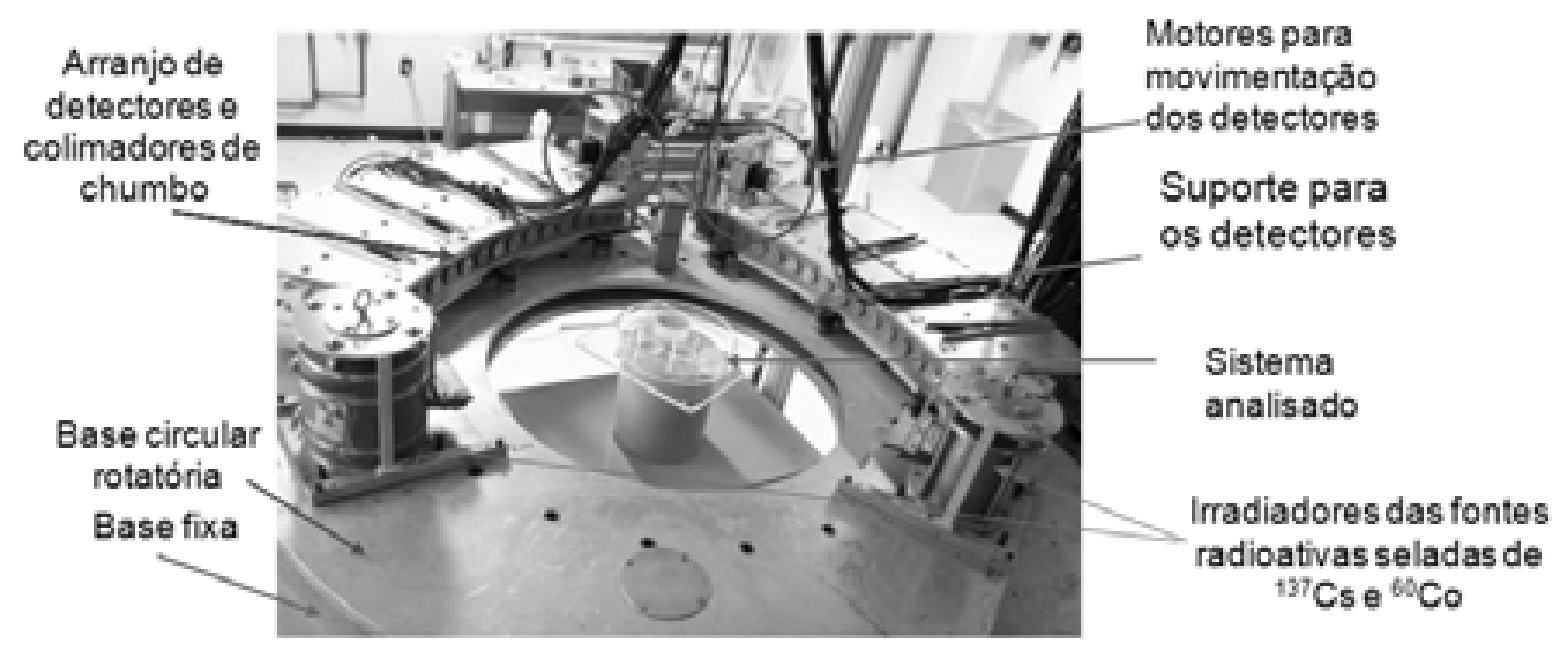

FIGURA 25 - Vista superior do DSCT.

A FIGURA 25 mostra uma fotografia do DSCT e do phantom estudado. Tanto o arranjo de detectores como os irradiadores são fixados a uma base circular rotatória. A base circular está ligada a uma base fixa retangular através de um eixo e engrenagem. Um motor de passo é conectado ao eixo que gira a engrenagem e faz girar a base circular. Desta forma, controla-se o número de ângulos ou posições das fontes (views). O sistema estava configurado com 197 ângulos ou posições, mas este número pode ser mudado em função do tamanho do domínio a ser estudado. A base fixa está conectada a quatro parafusos verticais montados em uma estrutura de alumínio, como, mostrado na FIGURA 26. Estes parafusos são conectados entre si por meio de uma corrente metálica que é acionada por um motor, controlando assim, a altura da base fixa. Este sistema permite atingir alturas de até $3 \mathrm{~m}$. 


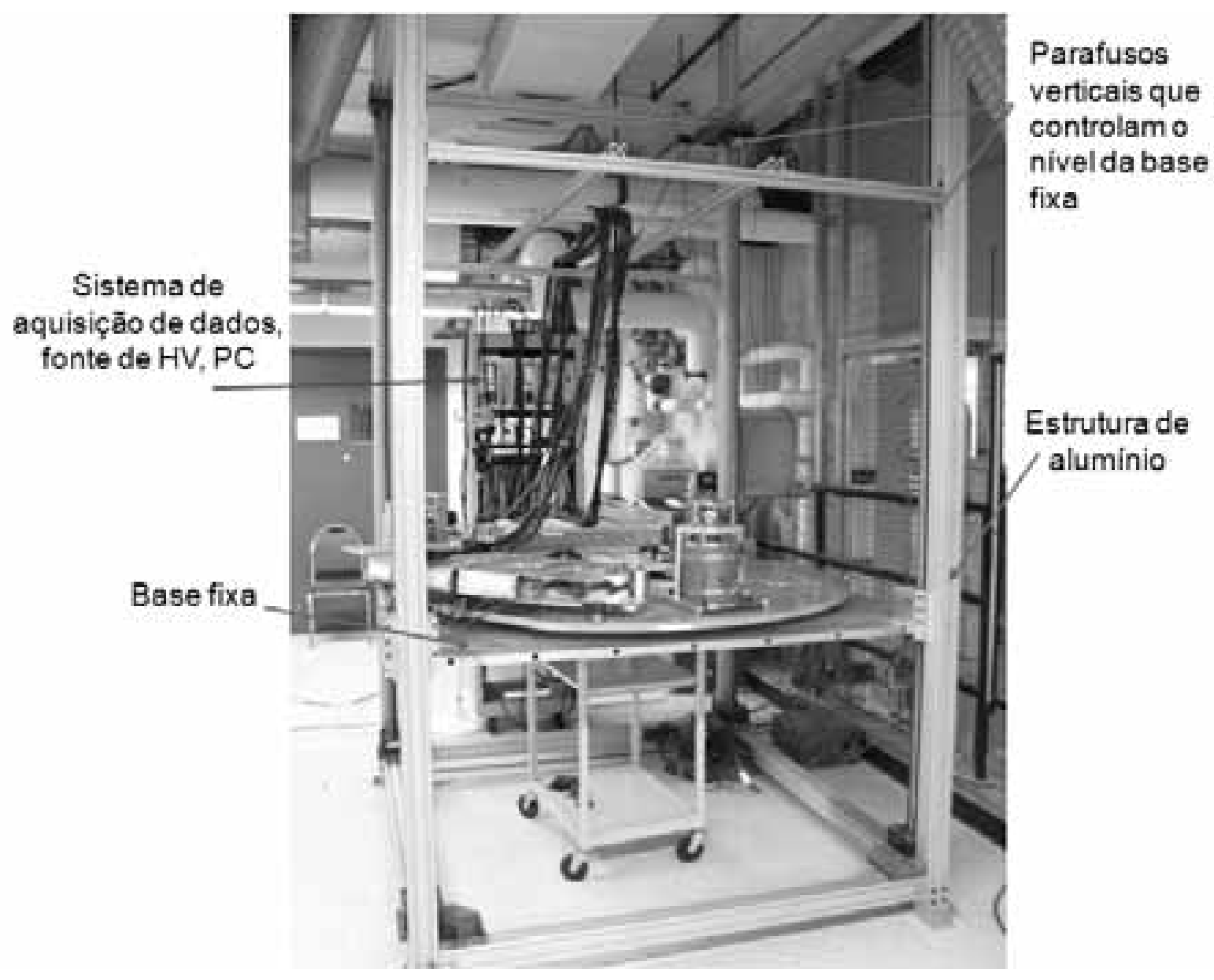

FIGURA 26 - Vista frontal do DSCT.

A FIGURA 27 apresenta o esquema para um leque do DSCT. Os detectores foram encaixados em um colimador projetado para manter fixa a geometria de arco, mantendo-os equidistantes da fonte. O sistema permitiu, também, encaixar os colimadores externos dos detectores, responsáveis pela resolução espacial do equipamento, como mostrado na FIGURA 28. Uma abertura de colimação de 2,4 mm. x 4,8 mm foi utilizada, onde, este valor foi otimizado em estudos anteriores (Roy et al. 2006). Com esta configuração o sistema permitiu obter 21 projeções por detector ou 315 (21x15) projeções por ângulo ou posição da fonte, totalizando $62.055(315 \times 197)$ projeções por varredura. $O$ ângulo total entre o centro do primeiro e décimo quinto detector é de $38,4^{\circ}$. Entre os 
detectores existe um ângulo de $2,78^{\circ}$. O arranjo de detectores foi formado por unidades de $\mathrm{NaI}(\mathrm{Tl})$ cilíndricas de 2"x 2".

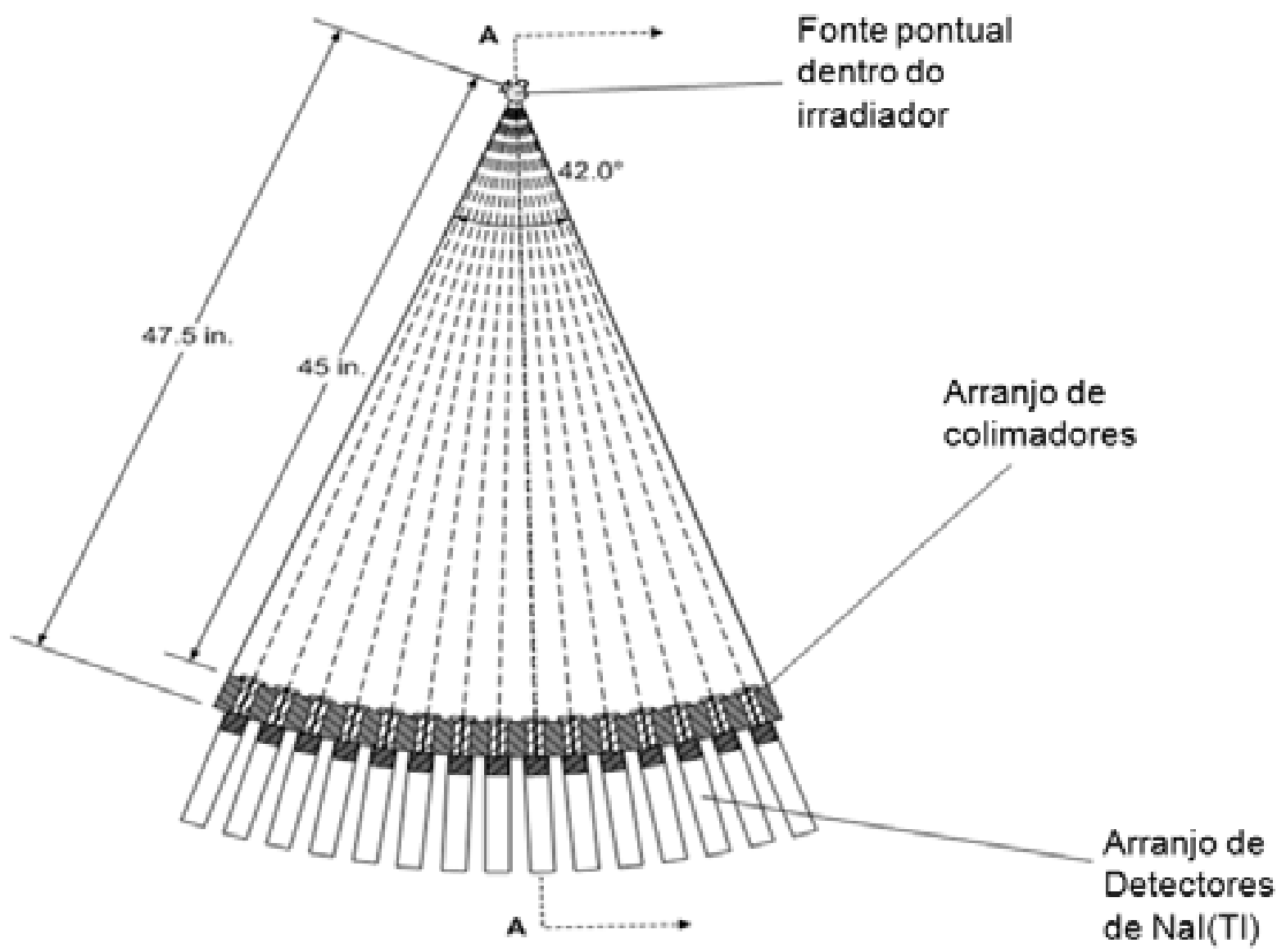

FIGURA 27 - Vista superior de um leque do DSCT formado pelos arranjos de colimadores e detectores. 


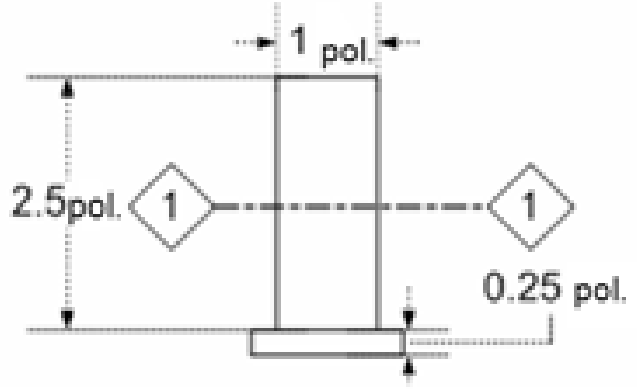

Vista superior

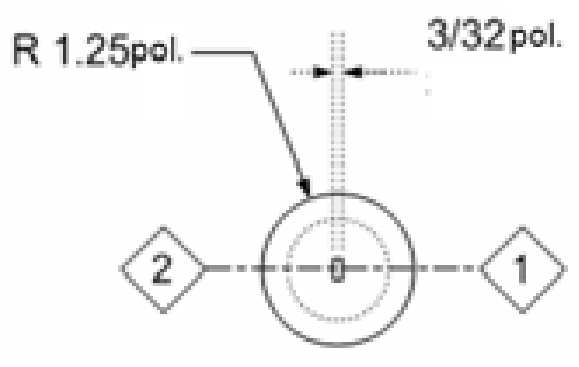

Vista frontal

R 1

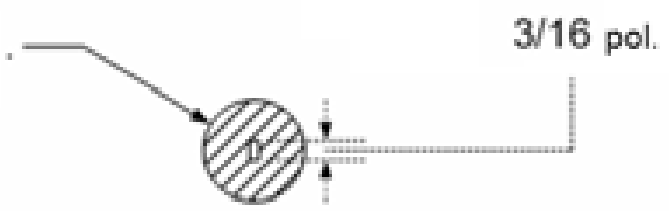

$1-1$

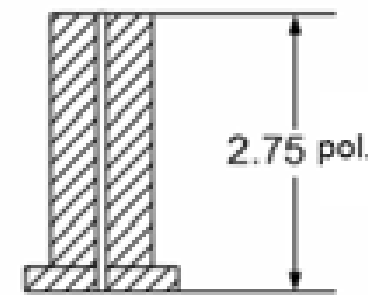

2-1

FIGURA 28 - Detalhe dos colimadores externos fabricado em chumbo colocados na parte frontal de cada detector.

A FIGURA 30 mostra o detalhe da seção A-A da FIGURA 27. A fonte radioativa pontual foi posicionada no centro de um irradiador com um sistema externo para colimação adicional que auxiliava a alinhar o feixe de raios gama na altura dos detectores. Este dispositivo permitiu a saída da radiação em forma de leque. Quando o sistema é acionado, a fonte desce até atingir a altura da abertura de colimação, permitindo a saída da radiação com um ân gulo de $40^{\circ}$ e $5 \mathrm{~mm}$ espessura. Para a fabricação do irradiador da fonte de ${ }^{60}$ Co foi utilizado tungsténio pelas suas características de alta densidade $\left(\rho=18 \mathrm{~g} / \mathrm{cm}^{3}\right)$. Para o caso do ${ }^{137} \mathrm{Cs}$, o irradiador é feito com chumbo. A FIGURA 29 apresenta os detalhes deste dispositivo. 


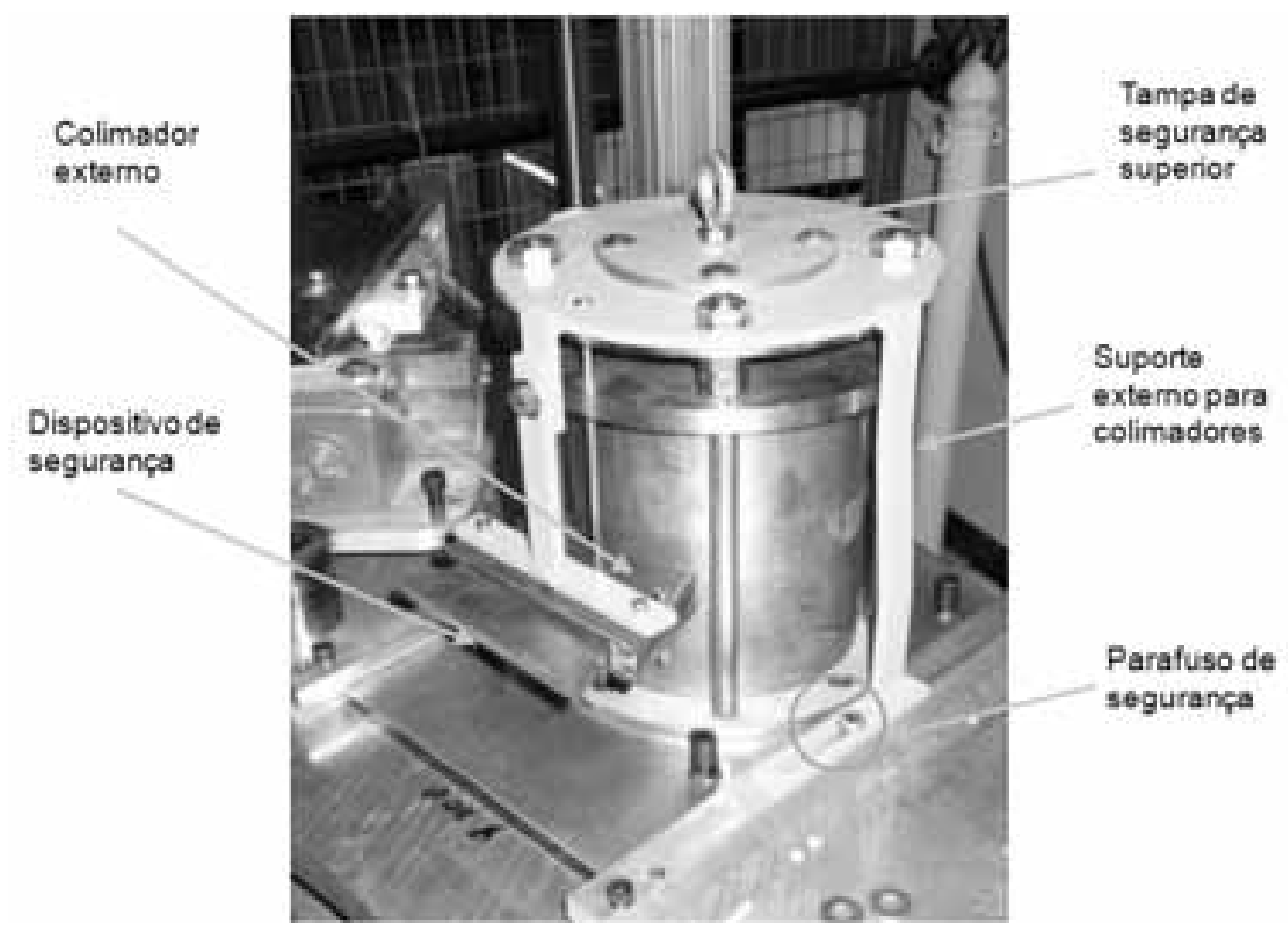

FIGURA 29 - Detalhes do irradiador do DSCT.

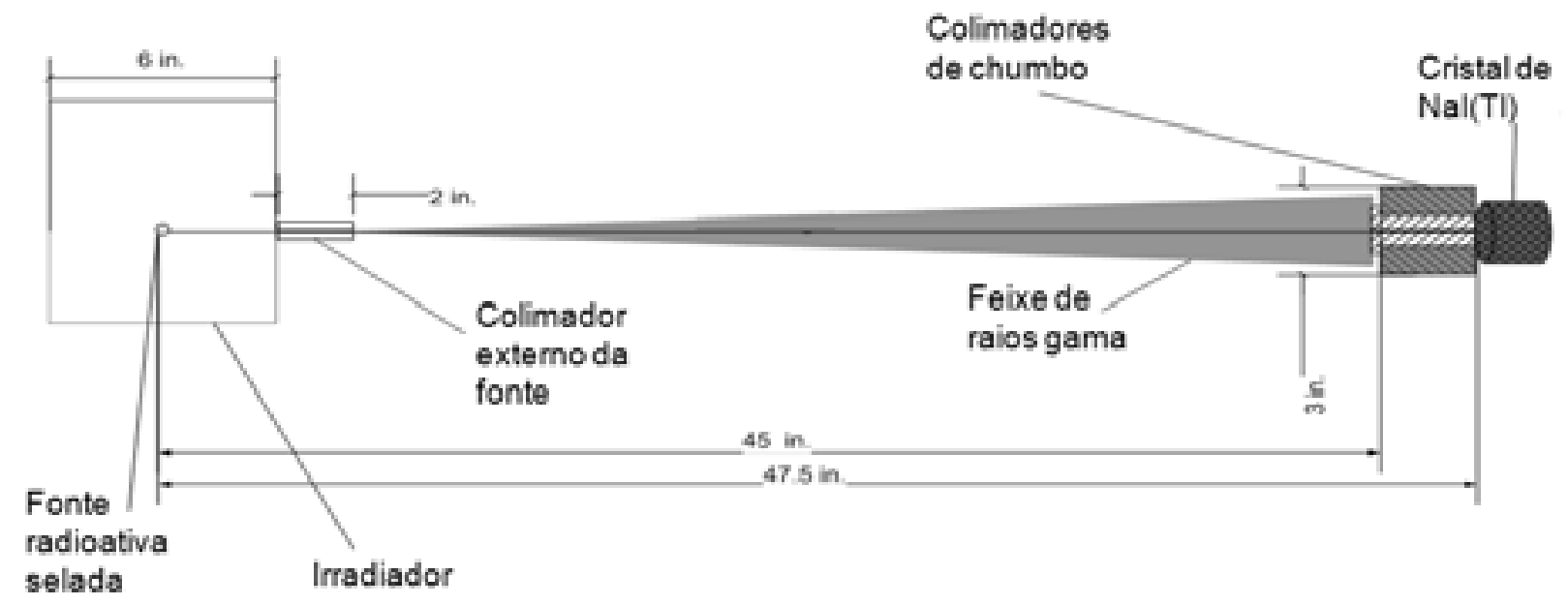

FIGURA 30 - Seção A-A mostrando o irradiador, detectores e o raio de ação da fonte radioativa.

A estrutura total, arranjo de detectores e colimadores é fixada a um suporte. Este suporte constituiu-se de uma base curva móvel (FIGURA 25) que permite a movimentação equidistante do conjunto de detectores em relação a fonte, mantendo-se o 
ângulo dos mesmos, por meio de rodas que controlam o deslocamento. Este mecanismo está associado a dois motores de passo, um para cada arranjo de detectores, que permitem o controle e deslocamento simultâneos. A FIGURA 31 mostra os detalhes deste sistema.

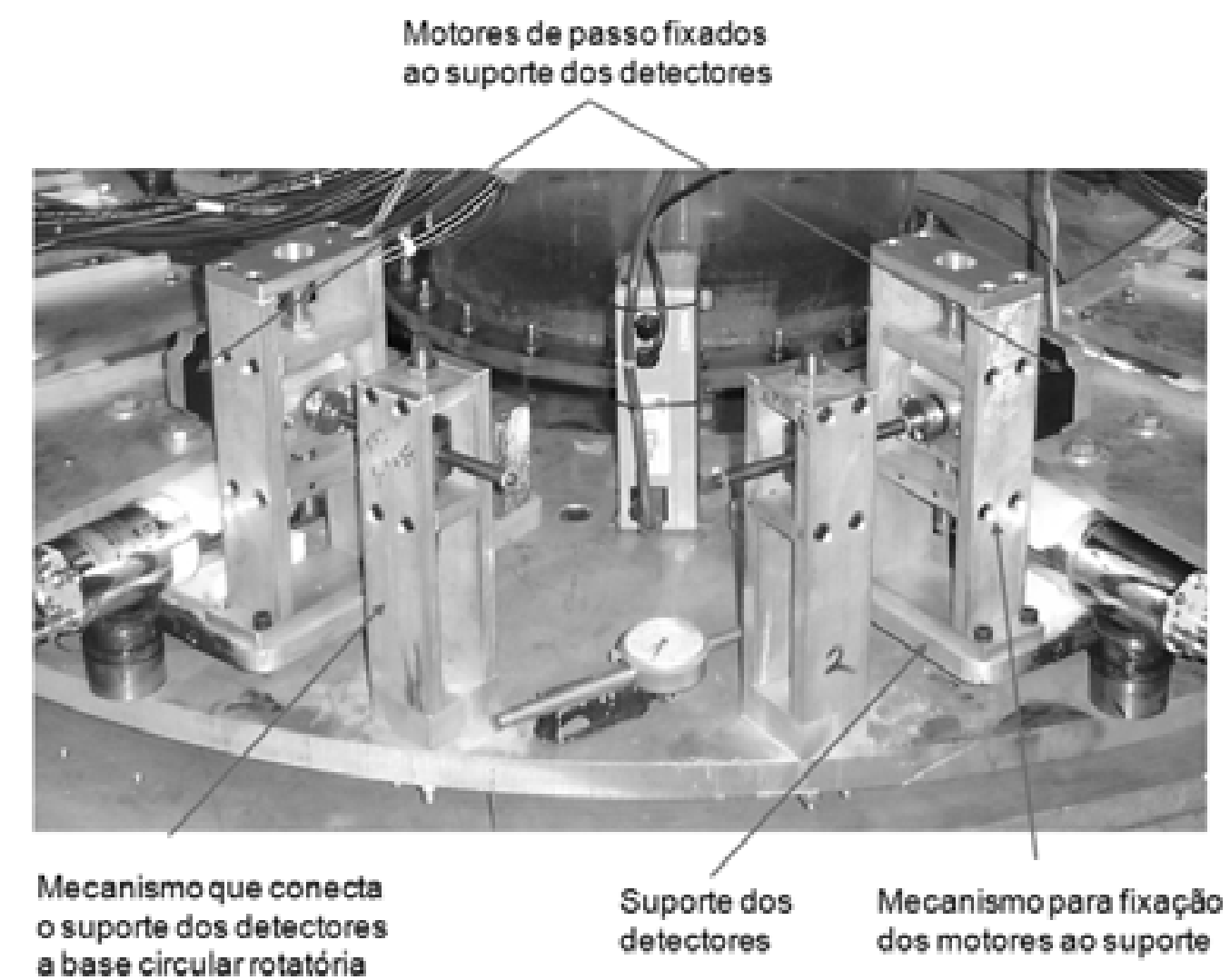

FIGURA 31 - Motores de passo e mecanismo associado ao deslocamento dos detectores.

O sistema de aquisição de dados é constituído por um hardware eletrônico que funciona como interface entre os sistemas de detecção e o computador. Basicamente é formado por detectores, pré-amplificadores, fontes de alta tensão (Canberra), processadores de pulso e motores de passo controlados automaticamente. A radiação é detectada pelo cristal de $\mathrm{NaI}(\mathrm{Tl})$, o pré-amplificador alimenta o sinal a um amplificador sincronizado. O sinal é transmitido a um multi- discriminador (scaler) e os dados finais são armazenados em um arquivo no computador. 
O sistema eletrônico pode trabalhar em duas modalidades: na primeira (fine mode), o sistema coleta dados do espectro energético de material radioativo em 1024 canais, onde cada canal representa entre $0,5-2 \mathrm{keV}$, dependendo do ganho e da voltagem alimentada aos detectores; e na segunda modalidade (coarse mode), o sistema tem capacidade de discriminar a contagem de até oito diferentes regiões ou janelas (windows) simultâneas do espectro, definidas pelo usuário com limites inferiores e superiores para cada um. O dispositivo electrónico baseia-se no hardware ORNL desenvolvido pela Oakridge National Laboratory.

Para o caso das fontes de ${ }^{137} \mathrm{Cs}$ e ${ }^{60}$ Co é possível escolher diferentes janelas de trabalho, dependendo da finalidade. A FIGURA 32 mostra as diferentes possibilidades de escolha, quando o objetivo é medir a atenuação da radiação na região dos fotopicos. A fonte de ${ }^{137} \mathrm{Cs}$ pode ser estudada na região de $662 \mathrm{keV}$ - Cs( I), enquanto que a fonte de ${ }^{60} \mathrm{Co}$ pode ser analisada no fotopico de $1173 \mathrm{keV}$ - Co(I), no fotopico de $1332 \mathrm{keV}$ - Co(II) ou em ambos $\mathrm{Co}(\mathrm{III})$, simultaneamente. A possibilidade de definir o limite inferior e superior das janelas é de vital importância, quando se trabalha com as duas fontes para evitar a interferência de radiação espalhada de um sistema para outro. Quando o objetivo fundamental é analisar um sistema com três fases dinâmicas através do DSCT, deve ser escolhida a melhor combinação das regiões mencionadas, existindo assim, três possibilidades: a) $\mathrm{Cs}(\mathrm{I})$ e $\mathrm{Co}(\mathrm{I})$, b) $\mathrm{Cs}(\mathrm{I})$ e $\mathrm{Co}(\mathrm{II})$ e c) $\mathrm{Cs}(\mathrm{I})$ e $\mathrm{Co}(\mathrm{III})$. A escolha depende das propriedades das fases em relação aos coeficientes de atenuação e densidade. Testes preliminares devem ser realizados para que se consiga analisar os resultados e fazer a melhor escolha, onde possam ser diferenciadas todas as fases na imagem reconstruída. 
a) $\mathrm{Cs}$ (I) \& $\mathrm{Co}$ (I)

b) Cs (I) \& Co (II)

c) Cs (I) \& $\mathrm{Co}$ (III)
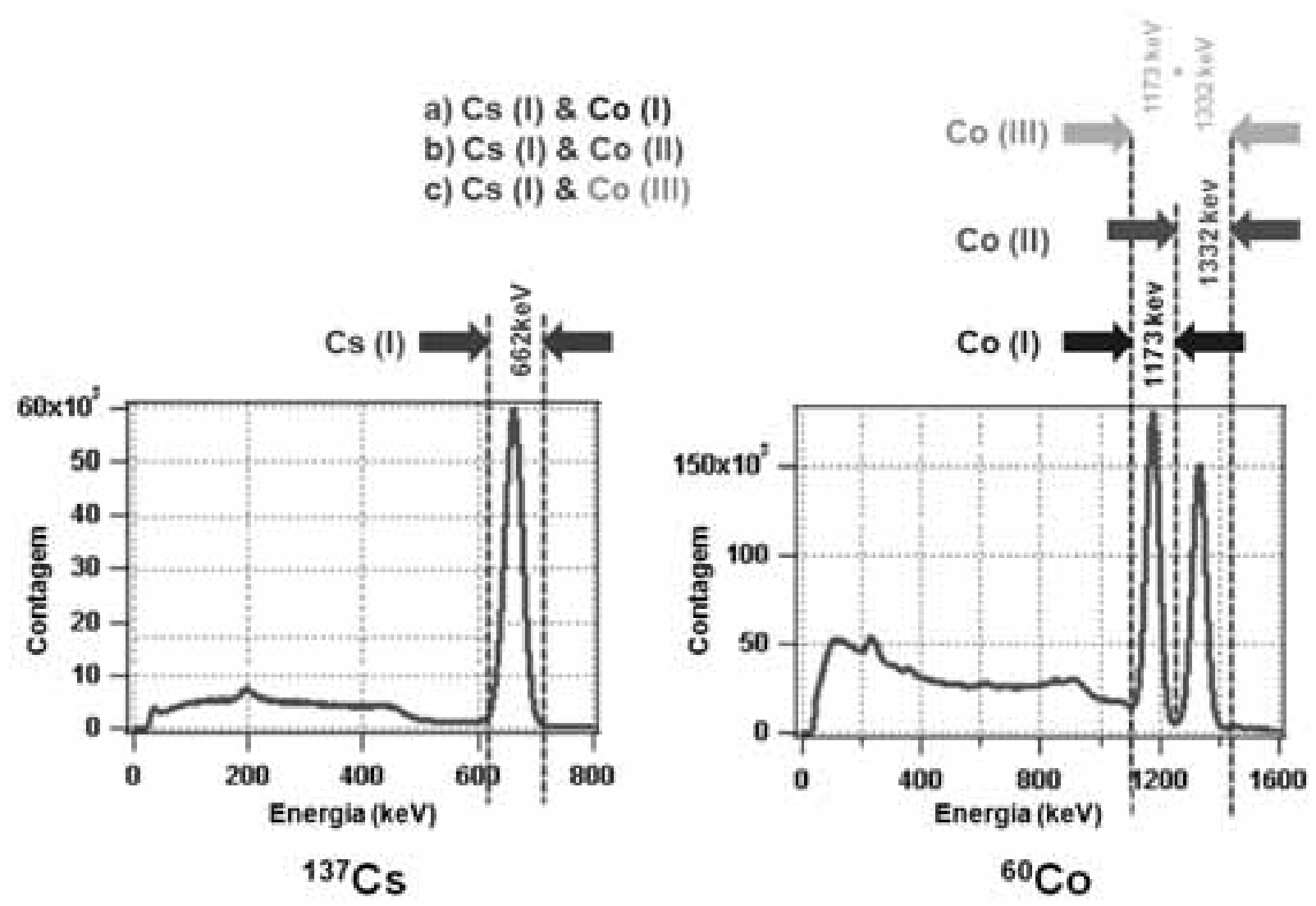

FIGURA 32 - Espectro de energias das fontes de ${ }^{137} \mathrm{Cs} e{ }^{60}$ Co mostrando as regiões de operação dos fotopicos.

Parâmetros tais como o tempo de contagem, número de ângulos (views), regiões para discriminação e número de amostras por coleta por projeção foram definidos e configurados em um arquivo de entrada separado (input file).

\subsubsection{Condições de operação do DSCT}

O DSCT dotado com 15 detectores para ${ }^{137} \mathrm{Cs}$ e 15 detectores para ${ }^{60} \mathrm{Co} . \mathrm{O}$ phantom foi centralizado e estudado usando-se 9 detectores por arranjo, pois, com este número de detectores o leque formado cobria completamente o objeto. 
Os experimentos foram efetuados, utilizando-se 197 ângulos (views) ou posições das fontes e 189 (21 x 9) projeções ou medidas dos detectores por ângulo. Em total foram obtidas 37.233 projeções $(197$ x 189) por experimento, usando-se um tempo de contagem de 0,1 s. (10Hz.). Para melhorar a estatística das medidas, cada projeção foi determinada, como a média de uma amostragem de $80(n=80)$.

Antes de estudar o phantom foi necessário fazer uma varredura de referência. Como explicado em seções anteriores (5.2), a reconstrução de imagem monoen ergética baseia-se nos dados de transmissão $T(y, E)$ que relacionam as médias da radiação incidente $I(y, E)$ com um valor de referência $I o(y, E)$. Assim, a transmitância T foi calculada utilizando-se a expressão a seguir:

$$
T(y, E)=\frac{I(y, E)}{I o(y, E)}
$$

Onde, $y$ representa o índice de projeção e $E$ é a en ergia específica de cada fonte radioativa. Quando colocados em um gráfico os valores de $T(y, E)$ em função do ângulo e da posição relativa de cada detector (número de projeção) se denomina sino grama.

Para este caso, $I o(y, E)$ equivale às projeções obtidas com o phantom vazio. Portanto, $T(y, E)$ representa a atenuação do material (fases) sem o efeito das paredes do phantom. Cada varredura levou entre 6 e 7 horas. 


\subsection{Resultados e discussão}

\subsubsection{Sinogramas de validação}

Os valores médios das projeções representados nos sinogramas são mostrados na FIGURA 33.
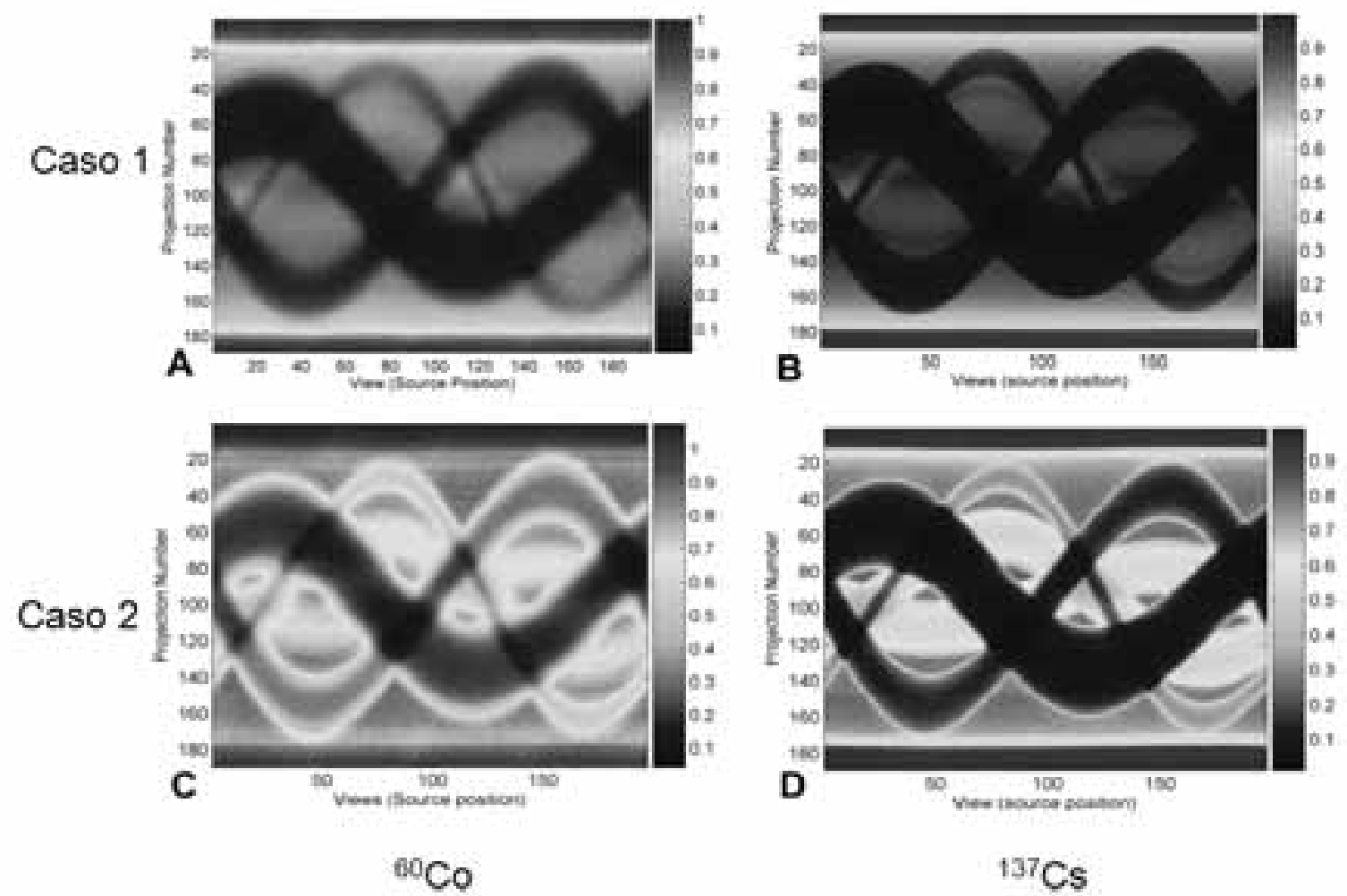

FIGURA 33 - Sinogramas obtidos do phantom multifásico. (A,C) Fotopico de 1332 keV para o ${ }^{60}$ Co dos Casos 1 e 2 (TABELA 10). (B,D) Fotopico de $662 \mathrm{keV}$ para o ${ }^{137}$ Cs para os Casos 1 e 2 . 
Cada pixel dos sinogramas representa o raio de transmissão $T(y, E)$ correspondente a uma determinada projeção e posição da fonte (view) ou ângulo de rotação.

Os sinogramas mostraram claramente os valores máximos de atenuação para os três domínios circulares S1-S3. As regiões C1 e C2 não puderam ser diferenciadas para o Caso 1 pois havia água na região B. Este efeito pode ser observado no Caso 2 quando a região B estava vazia.

Um sinograma permite verificar a qualidade das medidas obtidas no processo de amostragem da tomografia. A ausência de bandas paralelas ou manchas, que poderiam ser atribuídas ao mal funcionamento de detectores, garantiu a qualidade das imagens reconstruídas.

\subsubsection{Convergência da MA}

Para poder garantir a convergência do algoritmo MA foram obtidos os valores da I-divergência quando calculados os coeficientes de atenuação utilizando a equação ( 38) para diferente número de iterações. Os valores da I-divergência foram determinados com base na equação ( 36 ), onde foram utilizados os valores atualizados para $\hat{q}^{(k)}(y)$ da equação ( 41 ) a cada iteração $k$. A FIGURA 34 mostra a I-divergência em função do número de iterações para o ${ }^{137} \mathrm{Cs}(662 \mathrm{keV})$ e o ${ }^{60} \mathrm{Co}(1332 \mathrm{keV})$ para os casos 1 e 2 . 

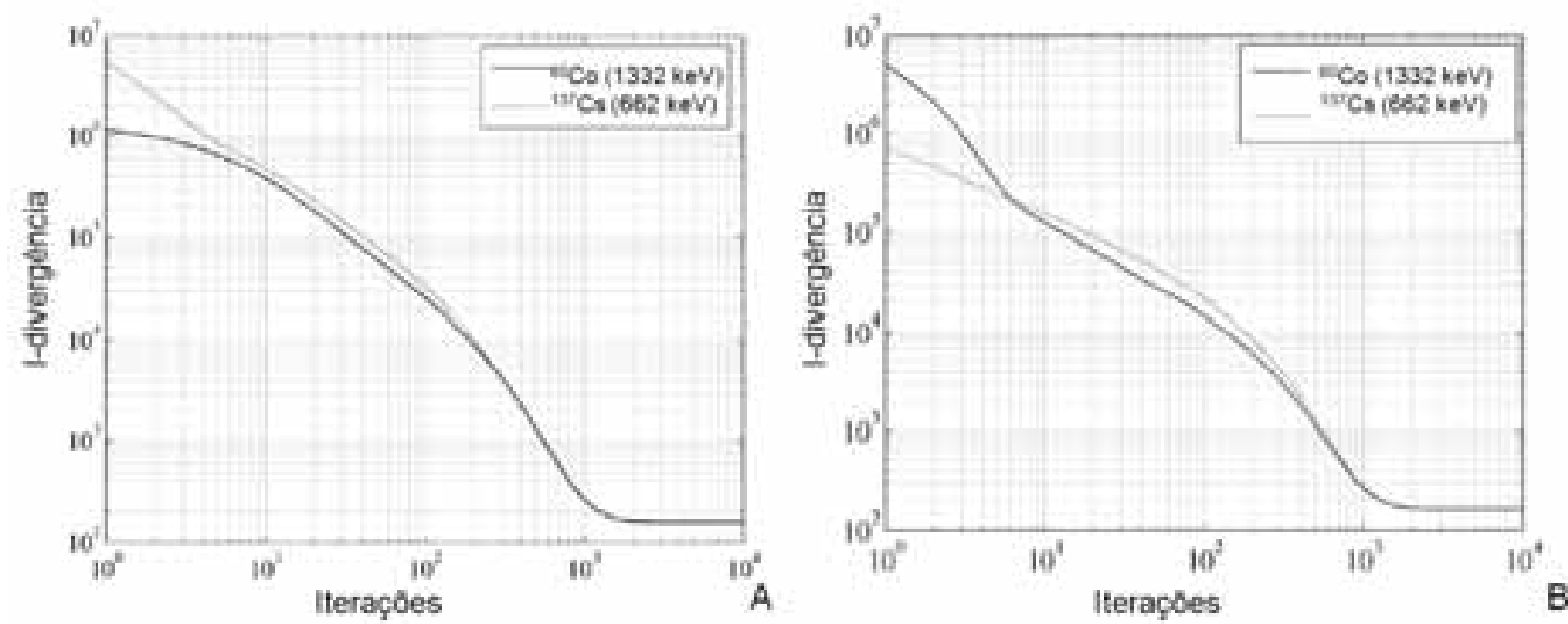

FIGURA 34 - I-divergência em função do número de iterações para ${ }^{137} \mathrm{Cs}$ e ${ }^{60} \mathrm{Co}$ dos casos 1 e 2 .

Claramente as figuras mostram que a I-divergência é minimizada em função do número de iterações, atingindo o valor mínimo com $10^{3}$ iterações. Para garantir um bom critério de conver gência, neste estudo foram utilizadas $10^{4}$ iterações.

\subsubsection{Reconstrução de Imagens}

As projeções monoenergéticas obtidas neste experimento (FIGURA 23) foram reconstruídas em imagens de 80 x80 pixels utilizando a FBP, EM e MA, tanto para o ${ }^{137} \mathrm{Cs}$,como, para ${ }^{60} \mathrm{Co}$ de forma individual para os Casos 1 e 2 (TABELA 10).

A TABELA 12 apresenta as regiões energéticas dos fotopicos para as fontes de ${ }^{137} \mathrm{Cs} \mathrm{e}{ }^{60} \mathrm{Co}$ estudadas neste trabalho.

TABELA 12 - Regiões energéticas de operação para o DSCT.

\begin{tabular}{|c|c|c|}
\hline Região & $\begin{array}{c}\text { Energia do } \\
\text { fotopico }(\mathrm{keV})\end{array}$ & Radioisótopo \\
\hline R1 & 662 & ${ }^{10} \mathrm{Cs}$ \\
\hline R2 & 1173 & ${ }^{\circ 0} \mathrm{Co}$ \\
\hline R3 & 1332 & ${ }^{\circ 0} \mathrm{Co}$ \\
\hline R4 & $1173 \mathrm{e} 1332$ & ${ }^{\circ} \mathrm{Co}$ \\
\hline
\end{tabular}


A FIGURA 35 e a FIGURA 36 mostram as reconstruções monoenergéticas teóricas e as estimadas para FBP, EM e MA dos Casos 1 (água) e 2 (ar), respectivamente. Os métodos de reconstrução são detalhados na seção 5.2 .

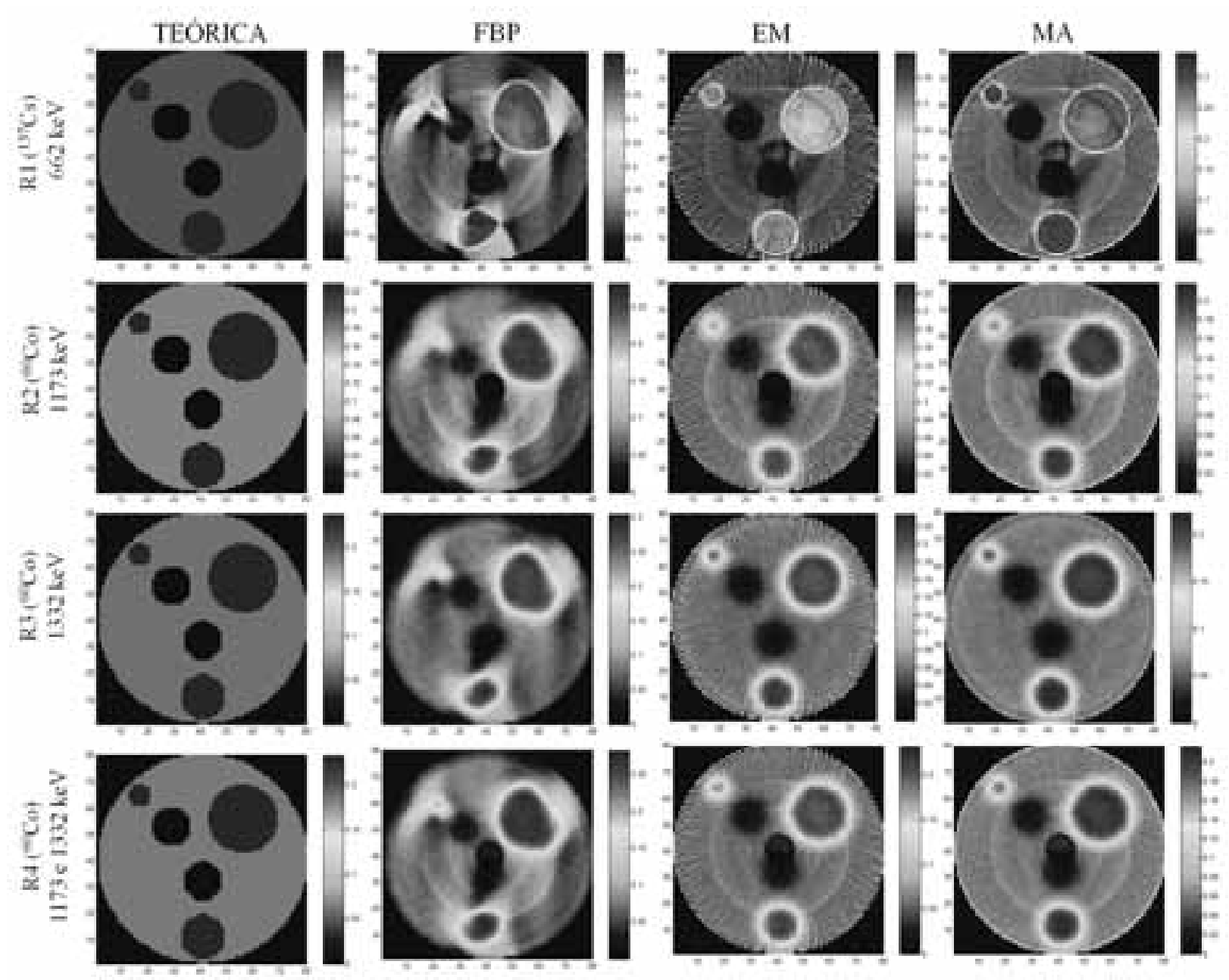

FIGURA 35 - Caso 1 (água): Reconstruções monoenergéticas teóricas, FBP, EM e MA dos coeficientes de atenuação $\left(\mathrm{cm}^{-1}\right)$ nas regiões dos fotopicos $R 1$ (662 keV), R2 (1173 $\mathrm{keV}), R 3(1332 \mathrm{keV})$ e R4 (1173 keV e $1332 \mathrm{keV})$ em imagens de 80x80 pixels. 


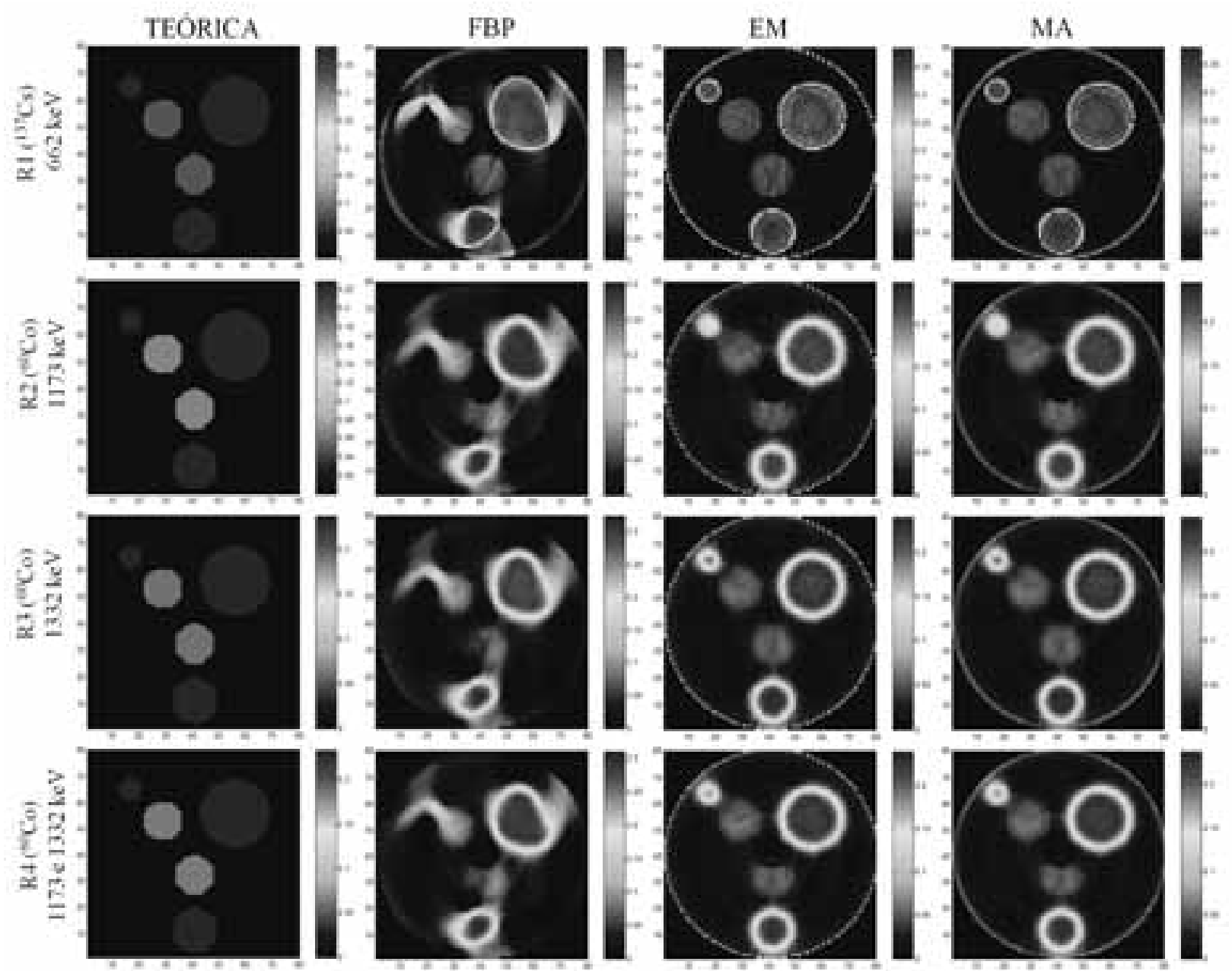

FIGURA 36-Caso 2 (ar): Reconstruções monoenergéticas teóricas, FBP, EM e MA dos coeficientes de atenuação $\left(\mathrm{cm}^{-1}\right)$ nas regiões dos fotopicos $R 1$ (662 keV), R2 (1173 keV), R3 (1332 keV) e R4 (1173 keV e $1332 \mathrm{keV})$ em imagens de 80x80 pixels.

Os dados dos coeficientes de atenuação das figuras anteriores foram analisados calculando os erros médios quadráticos $\operatorname{RMSE}(\mathrm{N})$ e $\operatorname{RMSE}(\mu)$ com relação aos pixels $(\mathrm{N})$ e aos coeficientes de atenuação $(\mu)$, respectivamente. Este cálculo compara os valores estimados dos coeficientes de atenuação com os valores teóricos para os diferentes casos e regiões de estudo. Portanto, menores valores significam melhores reconstruções. 
A TABELA 13 e a TABELA 14 apresentam as comparações para RMSE(N) e $\operatorname{RMSE}(\mu)$ do Caso 1 (água). A TABELA 15 e a TABELA 16 apresentam as comparações para $\operatorname{RMSE}(\mathrm{N})$ e $\operatorname{RMSE}(\mu)$ do Caso 2 (ar).

TABELA 13 - Resultados do RMSE(N) para o Caso 1.

\begin{tabular}{|c|c|c|c|c|c|}
\hline \multirow{2}{*}{ Região } & \multirow{2}{*}{ Isótopo } & \multirow{2}{*}{ Ener gia do fotopico } & \multicolumn{3}{|c|}{ RMSE(N) } \\
\cline { 4 - 6 } & & & FBP & EM & MA \\
\hline R1 & ${ }^{13} \mathrm{Cs}$ & $662 \mathrm{keV}$ & 0,0646 & 0,0609 & 0,0551 \\
\hline R2 & ${ }^{\circ 0} \mathrm{Co}$ & $1173 \mathrm{keV}$ & 0,0379 & 0,0367 & 0,0331 \\
\hline R3 & ${ }^{0} \mathrm{Co}$ & $1332 \mathrm{keV}$ & 0,0397 & 0,0364 & 0,0332 \\
\hline R4 & ${ }^{60} \mathrm{Co}$ & $1173 \mathrm{keV} \mathrm{e} 1332 \mathrm{keV}$ & 0,0382 & 0,0363 & 0,0326 \\
\hline
\end{tabular}

TABELA 14 - Resultados do $\operatorname{RMSE}(\mu)$ para o Caso 1.

\begin{tabular}{|c|c|c|c|c|c|}
\hline \multirow{2}{*}{ Região } & \multirow{2}{*}{ Isótopo } & \multirow{2}{*}{ Energia do fotopico } & \multicolumn{3}{|c|}{$\operatorname{RMSE}(\mu)$} \\
\cline { 4 - 6 } & & & FBP & EM & MA \\
\hline R1 & ${ }^{15} \mathrm{Cs}$ & $662 \mathrm{keV}$ & 0,4299 & 0,4051 & 0,3664 \\
\hline R2 & ${ }^{\circ 0} \mathrm{Co}$ & $1173 \mathrm{keV}$ & 0,3960 & 0,3831 & 0,3455 \\
\hline R3 & ${ }^{\circ 0} \mathrm{Co}$ & $1332 \mathrm{keV}$ & 0,4112 & 0,3774 & 0,3439 \\
\hline R4 & ${ }^{60} \mathrm{Co}$ & $1173 \mathrm{keV}$ e $1332 \mathrm{keV}$ & 0,3970 & 0,3778 & 0,3393 \\
\hline
\end{tabular}

TABELA 15 - Resultados do RMSE(N) para o Caso 2.

\begin{tabular}{|c|c|c|c|c|c|}
\hline \multirow{2}{*}{ Região } & \multirow{2}{*}{ Isótopo } & \multirow{2}{*}{ Ener gia do fotopico } & \multicolumn{3}{|c|}{ RMSE(N) } \\
\cline { 4 - 6 } & & & FBP & EM & MA \\
\hline R1 & ${ }^{13} \mathrm{Cs}$ & $662 \mathrm{keV}$ & 0,0850 & 0,0583 & 0,0555 \\
\hline R2 & ${ }^{60} \mathrm{Co}$ & $1173 \mathrm{keV}$ & 0,0496 & 0,0390 & 0,0380 \\
\hline R3 & ${ }^{\circ 0} \mathrm{Co}$ & $1332 \mathrm{keV}$ & 0,0500 & 0,0394 & 0,0385 \\
\hline R4 & ${ }^{60} \mathrm{Co}$ & $1173 \mathrm{keV}$ e $1332 \mathrm{keV}$ & 0,0494 & 0,0390 & 0,0381 \\
\hline
\end{tabular}


TABELA 16 - Resultados do $\operatorname{RMSE}(\mu)$ para o Caso 2.

\begin{tabular}{|c|c|c|c|c|c|}
\hline \multirow{2}{*}{ Região } & \multirow{2}{*}{ Isótopo } & \multirow{2}{*}{ Ener gia do fotopico } & \multicolumn{3}{|c|}{ RMSE $(\mu)$} \\
\cline { 4 - 6 } & & & FBP & EM & MA \\
\hline R1 & ${ }^{13} \mathrm{Cs}$ & $662 \mathrm{keV}$ & 0,6148 & 0,4219 & 0,4014 \\
\hline R2 & ${ }^{\circ 0} \mathrm{Co}$ & $1173 \mathrm{keV}$ & 0,5954 & 0,4689 & 0,4568 \\
\hline R3 & ${ }^{\circ 0} \mathrm{Co}$ & $1332 \mathrm{keV}$ & 0,5813 & 0,4590 & 0,4476 \\
\hline R4 & ${ }^{\circ 0} \mathrm{Co}$ & $1173 \mathrm{keV} \mathrm{e} 1332 \mathrm{keV}$ & 0,5846 & 0,4623 & 0,4510 \\
\hline
\end{tabular}

A principal diferença entre os casos 1 e 2 é a quantidade de fases líquidas e gasosas. No Caso 1 a fase líquida se encontrou em maior quantidade enquanto no caso 2 foi a fase gasosa. Os RMSE obtidos no caso 1 foram levemente menores que os obtidos no caso 2, mostrando a influência da baixa atenuação da fase gasosa. De forma geral, o algoritmo de MA apresentou menores valores de RMSE e portanto, melhores resultados para ambos casos. As reconstruções obtidas na R1 apresentaram melhor definição, pois, o ${ }^{137} \mathrm{Cs}$ tem menos penetração na matéria que o ${ }^{60} \mathrm{Co}$ e portanto, definiu melhor as fases visualmente. Quando comparados os casos dos fotopicos do ${ }^{60} \mathrm{Co}(\mathrm{R} 2, \mathrm{R} 3$ e R4); a região R4 apresentou os melhores resultados. Este fato é muito importante pois quando configurado o DSCT deve-se selecionar adequadamente a região onde o detector deve trabalhar (ver seção 5.3.3).

\subsection{Conclusões}

Os algoritmos EM e MA foram implementados satisfatoriamente para o caso da tomografia monoenergética para a determinação das imagens da distribuição dos coeficientes de atenuação para um phantom com três fases com diferentes configurações. O desempenho destes algoritmos foi comparado sob os efeitos de parâmetros críticos, como, o nível de ruído e o número de iterações utilizadas para reconstruir as imagens. Uma análise de comparação quantitativa das imagens com a distribuição dos coeficientes de 
atenuação geradas pelos algoritmos FBP, EM e MA foi realizada. O algoritmo MA proposto por O’Sullivan \& Benac (2007) apresentou um melhor desempenho que o algoritmo EM proposto por Lange \& Carson (1984) e que o algoritmo FBP proposto por Kak \& Slaney (2001) para a determinação dos coeficientes de atenuação utilizando a tomografia gama monoenergética. Os resultados obtidos com a FBP foram menos precisos que os obtidos com a MA e a EM.

As diferenças entre o desempenho dos algoritmos estocásticos utilizados (MA e EM) podem ser atribuídas à simplificação introduzida na Etapa-M do algoritmo EM na equação ( 31 ) para estimar a equação ( 30 ). Lange \& Carson (1984) recomendaram a utilização dos três termos da equação ( 31 ), mostrado na equação ( 32 ) para a obtenção da máxima precisão no resultados. Mesmo assim, o algoritmo MA apresentou melhores resultados. Portanto, o algoritmo MA mostrou-se como a melhor escolha para a reconstrução de imagens. 


\section{ESTUDO DA DISTRIBUIÇÃO DE POROSIDADE E DO HOLDUP DE SÓLIDOS DO RECHEIO DE UMA COLUNA EMPACOTADA}

\subsection{Introdução}

Colunas empacotadas ou de recheio têm sido amplamente utilizadas nos processos de destilação e absorção das indústrias química e petroquímica para incentivar o contato entre gás e líquido, pelas suas características de baixa queda de pressão e alta eficiência na separação. O desenho e scale-up destes dispositivos, quando comparados com as colunas de pratos, são menos factíveis devido ao conhecimento parcial dos processos de transferência de massa e hidrodinâmica do escoamento. A destilação tem atingido um nível de maturidade entre as tecnologias de separação, mas o entendimento dos processos que ocorrem dentro de uma coluna ainda não é adequado, sendo uma barreira para a melhora no desempenho destes equipamentos (Adler et al. 1998). Nas três últimas décadas, o desempenho destes dispositivos tem sido estudado com profundidade, surgindo vários modelos empíricos macroscópicos que assumem um regime de escoamento uniforme e unidirecional (Kouri \& Sohlo, 1996; Wagner \& Stichlmair, 1997). Com o avanço dos CFDs, é possível modelar efeitos, como, a heterogeneidade do leito no regime de escoamento, assim como, a sua influência na transferência de massa (Wang et al. 2001). Desta forma, dados experimentais de porosidade são extremadamente valiosos.

No caso de colunas de recheio, a falta de conhecimento da origem e da natureza das más distribuições de gás e líquido em pequena escala, têm criado uma barreira para o desenvolvimento de modelos preditivos. A variação da porosidade tem sido 
reconhecida e estudada extensamente como sendo uma das origens da má distribuição. Muitos estudos foram enfocados na distribuição de partículas esféricas, devido à escassez de informação disponível para recheios modernos de alta eficiência. Roblee et al. (1958) e Benenati \& Brosilow (1962) efetuaram os primeiros estudos utilizando uma resina epóxica e cera para preencher os espaços vazios de uma coluna de recheio. Após a cura da resina, o cilindro contendo o recheio foi removido, assim, o diâmetro deste foi diminuído com torno; enquanto, as frações de material removido eram pesadas e relacionadas ao diâmetro correspondente para obter o valor médio da porosidade. Cohen \& Metzner (1981), Vortmeyer \& Schuster (1983), McGreavy et al. (1986), Chu \& Ng (1989) e Foumeny \& Pahlevanzadeh (1990) mostraram que a distribuição da porosidade tem um efeito significativo na distribuição do líquido, especialmente, nas regiões próximas à parede da coluna. Uma distribuição não uniforme de porosidade provoca má distribuição do líquido, diminuindo a eficiência da separação.

Métodos não destrutivos, como, a tomografia gama e de raios X estão sendo utilizados para a determinação da porosidade em colunas de recheio (Chaouki et. al, 1997; Chen et al., 2001). Niu et al. (1996) utilizaram a tomografia com raios X para determinar a distribuição da porosidade radial de um leito empacotado com recheio esférico e verificaram oscilações na direção radial. Recentemente, Toye et al. (1998) usaram um tomógrafo com raios $\mathrm{X}$ de alta resolução para estudar a distribuição de porosidade e o holdup de líquido de recheios com formas geométricas complexas (Cascade Mini-Rings e Etapak) utilizados na destilação e absorção, mostrando que estas distribuições não são uniformes e não apresentam padrões oscilatórios, como, os encontrados nos estudos que empregam esferas. 
Neste estudo foi analisada uma coluna empacotada de $0,27 \mathrm{~m}$ de diâmetro com diferentes tamanhos de anéis Raschig metálicos (12, 37 e $70 \mathrm{~mm})$ para a determinação das distribuições de porosidade (holdup do gás) e holdup do sólido, usando-se o sistema SSCT. O método para o cálculo do holdup foi inicialmente desenvolvido em estudos anteriores (Vasquez, et al., 2005) e melhorado como mostrado nesta seção. O algoritmo MA foi utilizado para a reconstrução das imagens. A variação da porosidade e do holdup dos sólidos em função do raio da coluna também foram determinados.

\subsection{Materiais e Métodos}

Uma coluna 0,27 m de diâmetro, empacotada com diferentes tamanhos de anéis Raschig metálicos foi estudada, usando-se o sistema SSCT, como, indicado na FIGURA 37. O tomógrafo SSCT utilizado neste estudo foi descrito detalhadamente na seção 4. O sistema fonte - detector foi montado em um suporte fixo enquanto a coluna girava e se deslocava, empregando-se dois motores de passo controlados por um microprocessador. Neste caso foi utilizada uma fonte de 3,6 GBq (97 mCi) de ${ }^{137} \mathrm{Cs}$.

A TABELA 17 mostra as principais características dos anéis Raschig utilizados neste estudo.

TABELA 17 - Características dos anéis Raschig utilizados fabricados em aço.

\begin{tabular}{|c|c|c|c|}
\hline $\begin{array}{c}\text { Tamanho } \\
(\mathrm{mm})\end{array}$ & $\begin{array}{c}\text { Dimensões* } \\
\text { DxLxE } \\
(\mathrm{mm})\end{array}$ & $\begin{array}{c}\text { Densidade } \\
\text { bulk } \\
\left(\mathrm{g} / \mathrm{cm}^{3}\right)\end{array}$ & $\begin{array}{c}\text { Porosidade } \\
(\text { Fabricante })\end{array}$ \\
\hline 12,6 & $12,6 \times 12,6 \times 1,3$ & 1,384 & 0,824 \\
\hline 37,9 & $37,9 \times 37,9 \times 1,3$ & 0,623 & 0,921 \\
\hline 76 & $76 \times 76 \times 1,6$ & 0,324 & 0,959 \\
\hline
\end{tabular}

* $\mathrm{D}=$ diâmetro, $\mathrm{L}=$ cumprimento e $\mathrm{E}=$ espessura. 

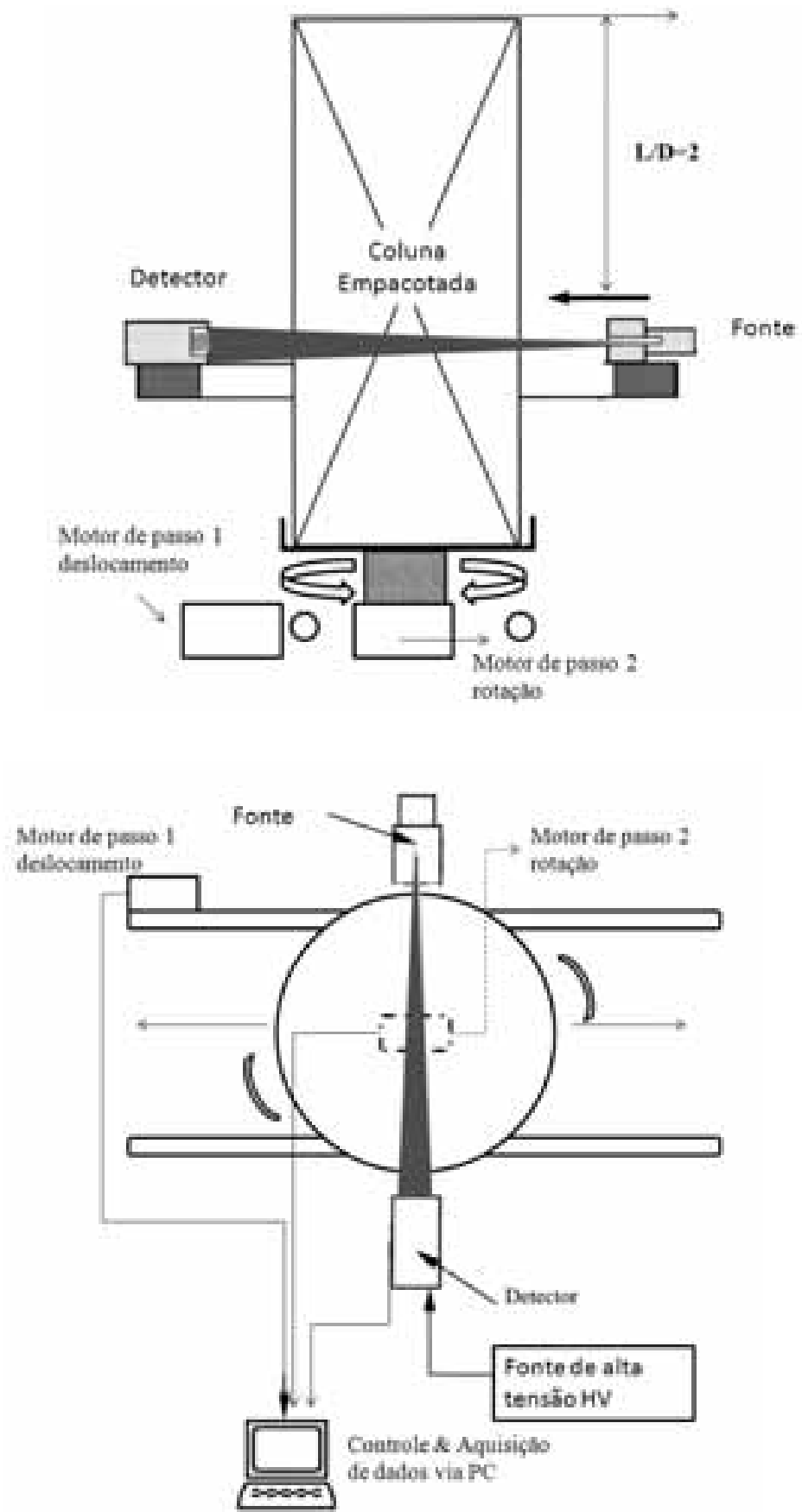

$\mathrm{B}$

FIGURA 37 - Esquema do SSCT e da coluna analisada. (A) Vista frontal. (B) Vista superior. 


\subsubsection{Condições de operação do tomógrafo SSCT}

O SSCT foi dotado de uma fonte de ${ }^{137} \mathrm{Cs}$ e de um detector de NaI(Tl). A coluna foi centralizada para poder manter um nível de referência nas comparações. Um colimador de 4,5 x $5 \mathrm{~cm}$ fabricado em chumbo com uma abertura retân gular de 2,39 x 4,38 mm foi colocado na frente do detector, definindo assim, a resolução espacial do sistema. Os experimentos foram efetuados utilizando-se 130 ângulos (views) ou posições das fontes e 106 projeções ou medidas dos detectores por ângulo. Em total foram obtidas 13.780 projeções $(106$ x 130) por experimento, usando-se um tempo de contagem de $3 \mathrm{~s}$. $(0,33 \mathrm{~Hz}$.$) . Cada varredura tomou entre 4$ e 6 horas.

\subsubsection{Cálculo da distribuição transversal do holdup}

\subsubsection{Sistemas com duas fases}

Em sistemas com duas fases (gás - sólido), os dados obtidos das tomografias, quando reconstruídos utilizando o algoritmo MA, geram a distribuição de coeficientes de atenuação do sistema gás- sólido $\hat{\mu}_{g-s}(x)$. Este coeficiente de atenuação é a soma das frações dos coeficientes de atenuação das fases:

$$
\hat{\mu}_{g-s}(x)=\hat{\mu}_{g}(x) \varepsilon_{g}(x)+\hat{\mu}_{s}(x) \varepsilon_{s}(x)
$$

Os subscritos $g$ e $s$ representam gás e sólido, respectivamente, $\varepsilon(x)$ é a fração de holdup e $\hat{\mu}(x)$ é o coeficiente de atenuação da fase pura. O objetivo da utilização da CT é determinar os valores de $\varepsilon_{S}(x)$. Os valores de $\hat{\mu}(x)$ para o gás puro ou sólido puro, geralmente são determinados efetuando varreduras quando no domínio de estudo está 
presente uma fase pura. Os valores para as atenuações para as fases puras podem ser obtidos de bases de dados literatura ou podem ser calculados mediante experimentos de densitometria. Assim, a equação anterior pode ser escrita:

$$
\hat{\mu}_{g-s}=\mu_{g} \varepsilon_{g}(x)+\mu_{s} \varepsilon_{s}(x)
$$

onde, $\mu$ não possui o indice $x$ e portanto, não representa uma imagem. Outra condição fundamental indica que a soma das frações do holdup das duas fases é igual a unidade:

$$
\varepsilon_{g}(x)+\varepsilon_{s}(x)=1
$$

Para a determinação do holdup a equações ( 45 ) e ( 47 ) foram combinadas, assumindo que, o $\hat{\mu}_{g}(x)$ é igual a zero (imagem de calibração da atenuação - sistema preenchido com gás) para obter a equação ( 48 ). Esta sup osição tem fundamento, pois, o ar proporciona uma contribuição desprezível para a atenuação de fótons raios gama com energia $662 \mathrm{keV}$. Por este motivo, a distribuição do holdup do gás foi calculada utilizandose a equação ( 48 ), e o holdup do líquido com a equação ( 49 ).

$$
\begin{gathered}
\varepsilon_{g}(x)=\frac{\hat{\mu}_{s}(x)-\hat{\mu}_{g-s}(x)}{\hat{\mu}_{s}(x)} \\
\varepsilon_{s}(x)=1-\frac{\hat{\mu}_{s}(x)-\hat{\mu}_{g-s}(x)}{\hat{\mu}_{s}(x)}
\end{gathered}
$$

Nas equações ( 48$)$ e ( 49$), \hat{\mu}_{g-s}(x)$ representa a imagem contendo as atenuações do sistema de estudo, enquanto que $\hat{\mu}_{s}(x)$ representa a imagem contendo as atenuações da fase sólida pura. 


\subsubsection{Sistemas com três fases sendo que uma delas é estacionária}

Quando se trata de sistemas com 3 fases (gás - líquido - sólido), onde a fase sólida é estacionária; analo gamente pode-se afirmar:

$$
\begin{gathered}
\hat{\mu}_{g-l-s}(x)=\hat{\mu}_{g}(x) \varepsilon_{g}(x)+\hat{\mu}_{s}(x) \varepsilon_{s}(x)+\hat{\mu}_{l}(x) \varepsilon_{l}(x) \\
\varepsilon_{g}(x)+\varepsilon_{s}(x)+\varepsilon_{l}(x)=1
\end{gathered}
$$

Da mesma maneira, na equação ( 50 ) pode-se assumir que a contribuição da fase gasosa é muito pequena, então, $\hat{\mu}_{g}(x)$ é igual a zero. Das equações ( 50 ) e ( 51 ) pode-se obter:

$$
\varepsilon_{g}(x)=\frac{\left[\hat{\mu}_{s}(x) \varepsilon_{s}(x)+\hat{\mu}_{l}(x)-\hat{\mu}_{l}(x) \varepsilon_{s}(x)\right]-\hat{\mu}_{g-l-s}(x)}{\hat{\mu}_{l}}
$$

Devido ao fato da fase sólida ser estacionária, são necessários dois varreduras de referência; o primeiro preenchendo o sistema com a fase líquida (sólido - líquido) e o segundo com sistema vazio (sólido - gás), obtendo -se as equações ( 53 ) e respectivamente:

$$
\begin{gathered}
\hat{\mu}_{l-s}(x)=\hat{\mu}_{s}(x) \varepsilon_{s}(x)+\hat{\mu}_{l}(x)-\hat{\mu}_{l}(x) \varepsilon_{s}(x) \\
\hat{\mu}_{g-s}(x)=\hat{\mu}_{s}(x) \varepsilon_{s}(x)
\end{gathered}
$$

Substituindo a equação ( 53 ) na ( 52 ) e a equação ( 54 ) na ( 53 ), tem -se: 


$$
\begin{gathered}
\varepsilon_{g}(x)=\frac{\hat{\mu}_{l-s}(x)-\hat{\mu}_{g-l-s}(x)}{\hat{\mu}_{l}} \\
\varepsilon_{s}(x)=1-\frac{\hat{\mu}_{l-s}(x)-\hat{\mu}_{g-s}(x)}{\hat{\mu}_{l}}
\end{gathered}
$$

Onde, as imagens $\hat{\mu}_{l-g-s}(x), \hat{\mu}_{l-s}(x)$ e $\hat{\mu}_{l}(x)$ representam a distribuição das atenuações do sistema quando presentes as três fases, as fases sólida - líquida e a fase líquida, respectivamente.

Portanto, as equações ( 55) e ( 56) representam o cálculo do holdup para sistemas com três fases, quando a fase sólida é estacionária. Todas as imagens $\hat{\mu}(x)$ foram obtidas reconstruindo os dados obtidos pela tomografia, utilizando-se o algoritmo MA.

\subsubsection{Cálculo da distribuição radial do holdup}

A informação fornecida pelas imagens tomográficas do holdup transversal, também, pode ser interpretada calculando os valores médios do holdup em intervalos concêntricos circulares radiais, partindo-se do centro geométrico da coluna (azimuthal averaging). Em muitas aproximações encontradas na literatura, assume-se que a variação da distribuição de sólidos em função do raio é constante. O cálculo do holdup radial $\varepsilon(r)$ é realizado utilizando-se a expressão apresentada na equação (Kumar, 1994; Kemoun et al., 2001):

$$
\varepsilon(r)=\frac{1}{2 \pi} \int_{0}^{2 \pi} \varepsilon(r, \theta) d \theta
$$


Este procedimento justifica-se devido ao fato dos dados gerados pela CT gama serem os valores médios no tempo, o que é necessário para coletar as informações (projeções) e de certa forma, manterem simetria com relação ao centro geométrico do sistema.

\subsection{Resultados e Discussão}

\subsubsection{Distribuição transversal do holdup}

As distribuições de porosidade $\varepsilon_{g}$ (holdup do gás) e de holdup de sólidos $\varepsilon_{s}$ para $\mathrm{L} / \mathrm{D}=2$ foram determinadas utilizando o algoritmo para reconstrução MA, o mesmo que fornece melhores resultados quando comparados com o EM ou com o FBP (seção 5). Os resultados representam a média dos dados obtidos no intervalo do tempo usado para efetuar a tomografia (time averaged). A FIGURA 38 mostra as imagens reconstruídas da distribuição transversal de $\varepsilon_{s}$ e $\varepsilon_{g}$ para os diferentes tipos de recheios analisados. Para este estudo é entendido que $\varepsilon_{s}+\varepsilon_{g}=1$; assim, a variação da cor indica uma mudança do valor de holdup. Elevados valores de holdup correspondem à cor vermelha nos gráficos, indicando a presença maioritária de uma fase. Nas paredes da coluna, para todos os casos, foram observados valores elevados de porosidade confirmando as informações encontradas na literatura. 

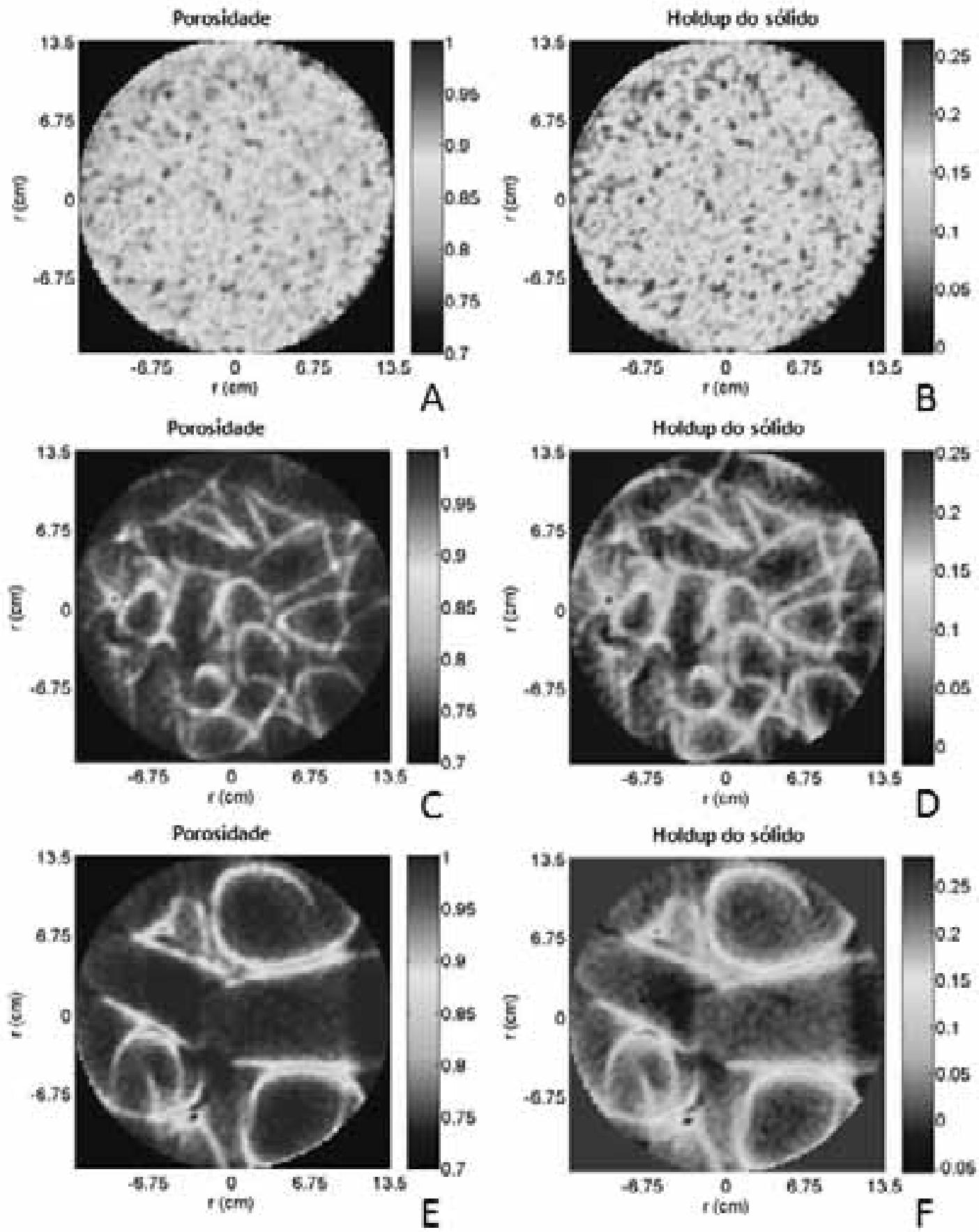

FIGURA 38 - Distribuições da porosidade e do holdup de sólidos dos anéis Raschig para $L / D=2$. (A,B) $12,6 \mathrm{~mm}$. (C,D) $37,9 \mathrm{~mm}$. (E,F) $76 \mathrm{~mm}$

Os dados da distribuição de porosidade para os três casos estudados podem também ser representados como histogramas modelados como uma distribuição normal. 
Assim, uma função de distribuição normal de probabilidade é ajustada às distribuições de porosidade $\varepsilon$ :

$$
P(\varepsilon)=\frac{1}{\sigma \sqrt{2 \pi}} e^{\left[-\frac{1}{2}\left(\frac{\varepsilon-\bar{\varepsilon}}{\sigma}\right)^{2}\right]}
$$

Onde, $\bar{\varepsilon}$ é o valor médio da porosidade, $\sigma$ é o desvio padrão. A TABELA 18 apresenta os valores destes parâmetros para os diferentes tipos de anéis Raschig analisados. A FIGURA 39 mostra a comparação das distribuições da porosidade obtidas pela tomografia e o modelo de distribuição normal de probabilidades. Quando aumenta-se o tamanho do recheio, aumenta-se o desvio padrão e a distribuição da porosidade vai se afastando do comportamento normal.

TABELA 18 - Valores médios e desvios padrões da porosidade obtidos da tomografia

\begin{tabular}{|c|c|c|c|}
\hline $\begin{array}{c}\text { Tamanho } \\
(\mathrm{mm})\end{array}$ & $\begin{array}{c}\text { Porosidade } \\
\bar{\varepsilon}\end{array}$ & Desvio Padrão $\sigma$ & $\begin{array}{c}\text { Porosidade } \\
\text { (Fabricante) }\end{array}$ \\
\hline 12,6 & 0,849 & 0,037 & 0,824 \\
\hline 37,9 & 0,938 & 0,032 & 0,921 \\
\hline 76 & 0,966 & 0,040 & 0,959 \\
\hline
\end{tabular}



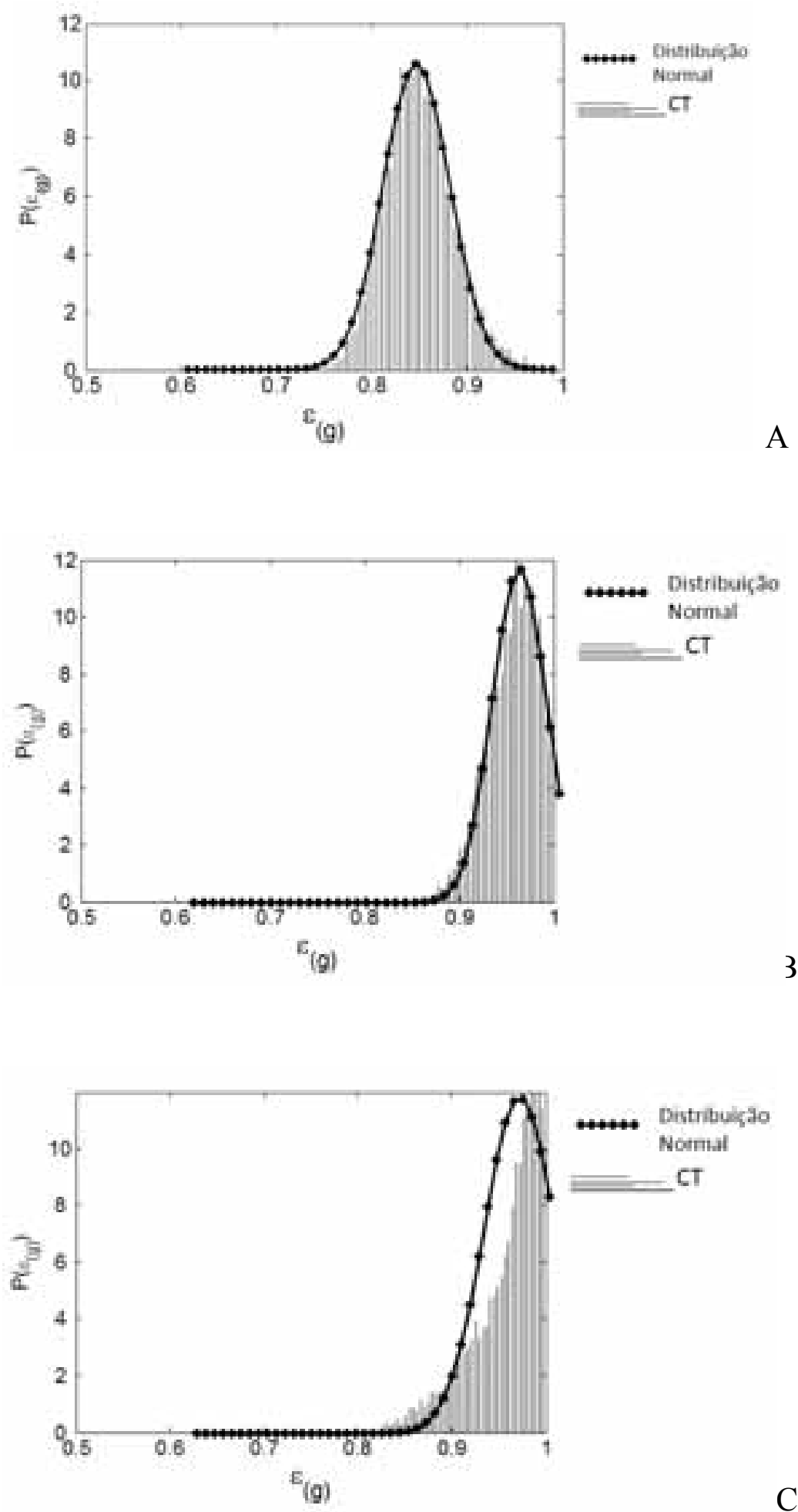

FIGURA 39 - Histogramas da distribuição da porosidade obtidos da tomografia e a função de distribuição da porosidade dos anéis Raschig: (A) 12,6 mm. (B) 37,9 mm . (C) 76 $\mathrm{mm}$ 


\subsubsection{Distribuição radial do holdup}

A informação fornecida pelas imagens tomográficas foi processada, calculando-se as distribuições radiais da porosidade e do holdup dos sólidos em função da distância radial $r / R$, como mostrado na FIGURA 40 e na FIGURA 41. Claramente foi observado que a porosidade não é uniforme e não apresenta um comportamento oscilatório. Adicionalmente, estas figuras mostram os valores médios do holdup encontrados neste estudo. Existem alguns modelos para tentar representar a variação do holdup, alguns destes foram testados, sendo que nenhum deles conseguiu modelar o comportamento observado.

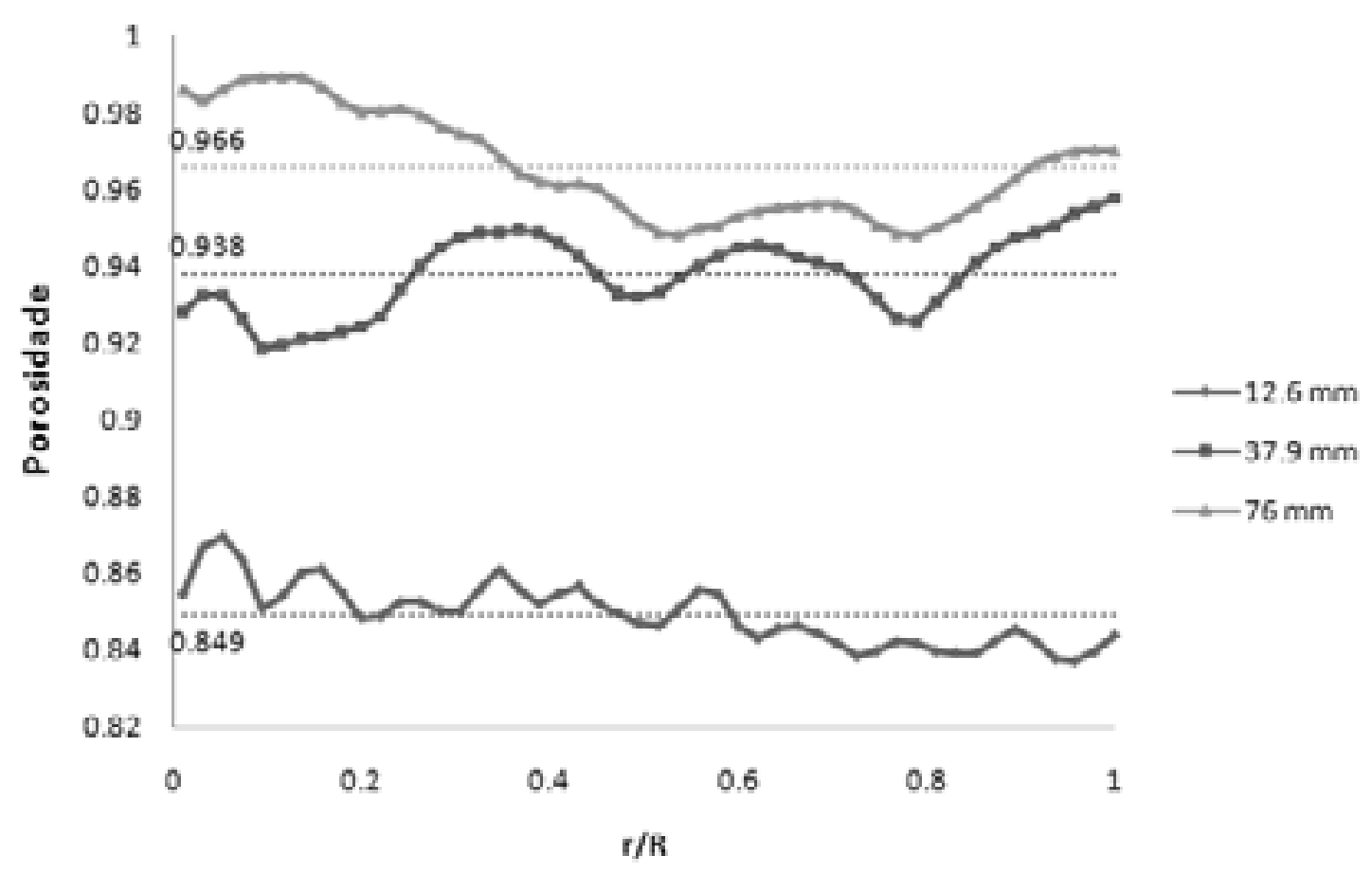

FIGURA 40 - Distribuição radial da porosidade para os anéis Raschig utilizados. 


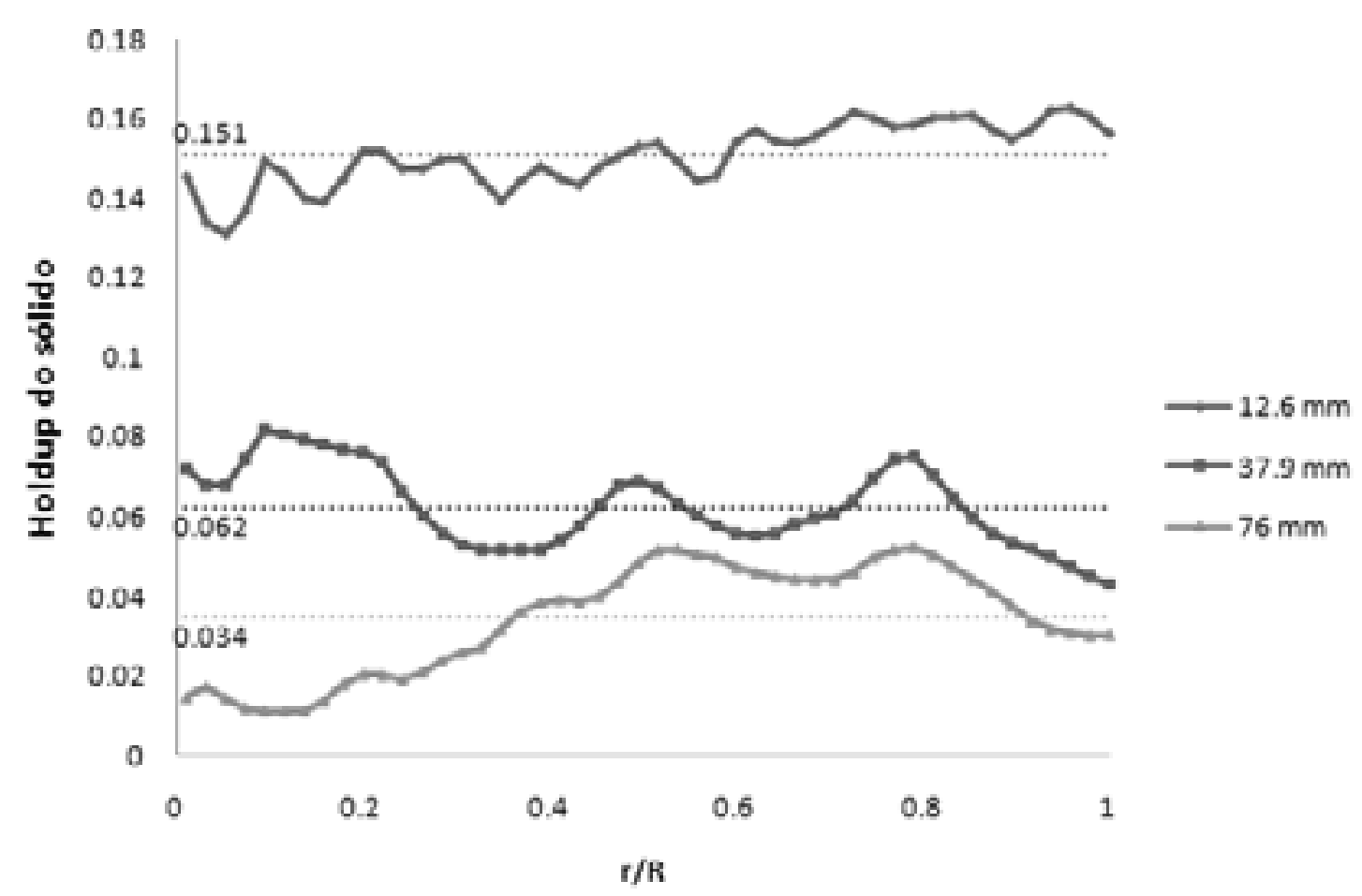

FIGURA 41 - Distribuição radial do holdup do sólido para os anéis Raschig utilizados.

\subsection{Conclusões}

Este estudo serviu para validar o sistema SSCT e mostrou que a tomografia gama pode determinar com boa resolução a distribuição espacial da porosidade e do holdup de sólidos em colunas de diâmetros relativamente grandes com recheios metálicos. As medidas da distribuição da porosidade e de holdup de sólidos foram bem sucedidas na coluna de 0,27 m de diâmetro, utilizando-se anéis Raschig metálicos de 13, 38 e 76 mm para $\mathrm{L} / \mathrm{D}=2$. $\mathrm{O}$ algoritmo para reconstrução de imagens $\mathrm{MA}$ mostrou ser adequado para diferenciar fases de densidades muito diferentes (aço e ar). A distribuição espacial da porosidade em colunas de recheio não foi uniforme, pois estavam presentes espaços vazios que variavam entre 1 e 3 diâmetros do recheio utilizado. $O$ efeito da parede da coluna foi 
mais acentuado para recheios de tamanhos maiores, onde a distribuição da porosidade se afastou da distribuição normal. Desta forma, justificam-se os estudos de recheios aleatórios, pois, não pode ser aplicada uma regra comum para características das distribuições da porosidade, porque, este efeito multiplica-se quando analisados recheios de geometrias mais complexas. Estas propriedades são sumamente importantes em nível industrial, pois, o desempenho destes equipamentos está condicionado à qualidade do contato entre as fases, onde, o desenho e scale-up estão baseados nos parâmetros aqui estudados. Este foi o primeiro estudo rep ortado na literatura utilizando recheios metálicos de alta densidade, pois a maioria destes foi feito com vidro ou polímeros. 


\section{COMPARAÇÃO DA MINIMIZAÇÃO ALTERNATIVA MONOENERGÉTICA (MAME) E A MINIMIZAÇÃO ALTERNATIVA POLIENERGÉTICA (MAPE) PARA RECONSTRUÇÃO DE IMAGENS DE SISTEMAS COM TRÊS FASES}

\subsection{Introdução}

A reconstrução de imagens e o procedimento para o cálculo da distribuição do holdup para sistemas com duas fases dinâmicas foram demonstrados nos capítulos 3 , 5, e 6. Os coeficientes de atenuação da mistura de fases (global) foram utilizados para determinar a distribuição de holdup de cada fase, utilizando as equações que relacionam estas duas propriedades. Os algoritmos FBP, EM e MA foram comparados para o caso de tomografia monoenergética. A exatidão dos resultados depende da precisão das imagens dos coeficientes de atenuação. Desta forma, tomógrafos de fonte única têm sido utilizados e validados extensamente para o estudo de duas fases dinâmicas ou de três fases dinâmicas, quando uma destas é estacionária. Os sistemas SSCT não podem ser usados para o estudo de três fases dinâmicas.

O DSCT foi desenvolvido para poder utilizar duas fontes radioativas que possuam energias dos fotopicos diferentes, tais como, o ${ }^{137} \mathrm{Cs}$ e o ${ }^{60} \mathrm{Co}$. Neste capítulo estende-se a discussão ao estudo para a determinação da distribuição de holdup em sistemas com três fases dinâmicas com o objetivo de estabelecer um algoritmo para o método que possa determinar estas propriedades. O algoritmo é aplicado ao estudo de um phantom com três fases com os dados obtidos do sistema DSCT. Várias fontes de ruído, 
como, hardware e fontes radioativas estão inclusas. Os dados de transmissão da radiação são provenientes das fontes de ${ }^{137} \mathrm{Cs} \mathrm{e}{ }^{60} \mathrm{Co}$. Este trabalho foi desenvolvido em conjunto com Rajneesh Varma da WUSTL.

\subsection{Seleção das fontes radioativas gama}

Um dos fatores mais importantes na utilização de sistemas com duas fontes radioativas como o DSCT é a esco lha adequada dos emissores gama em fun ção da energia característica. Entre as principais propriedades as fontes gama devem constar o alto sinal em relação ao ruído, contraste adequado dos coeficientes de atenuação para poder diferenciar as fases de interesse e disponibilidade física.

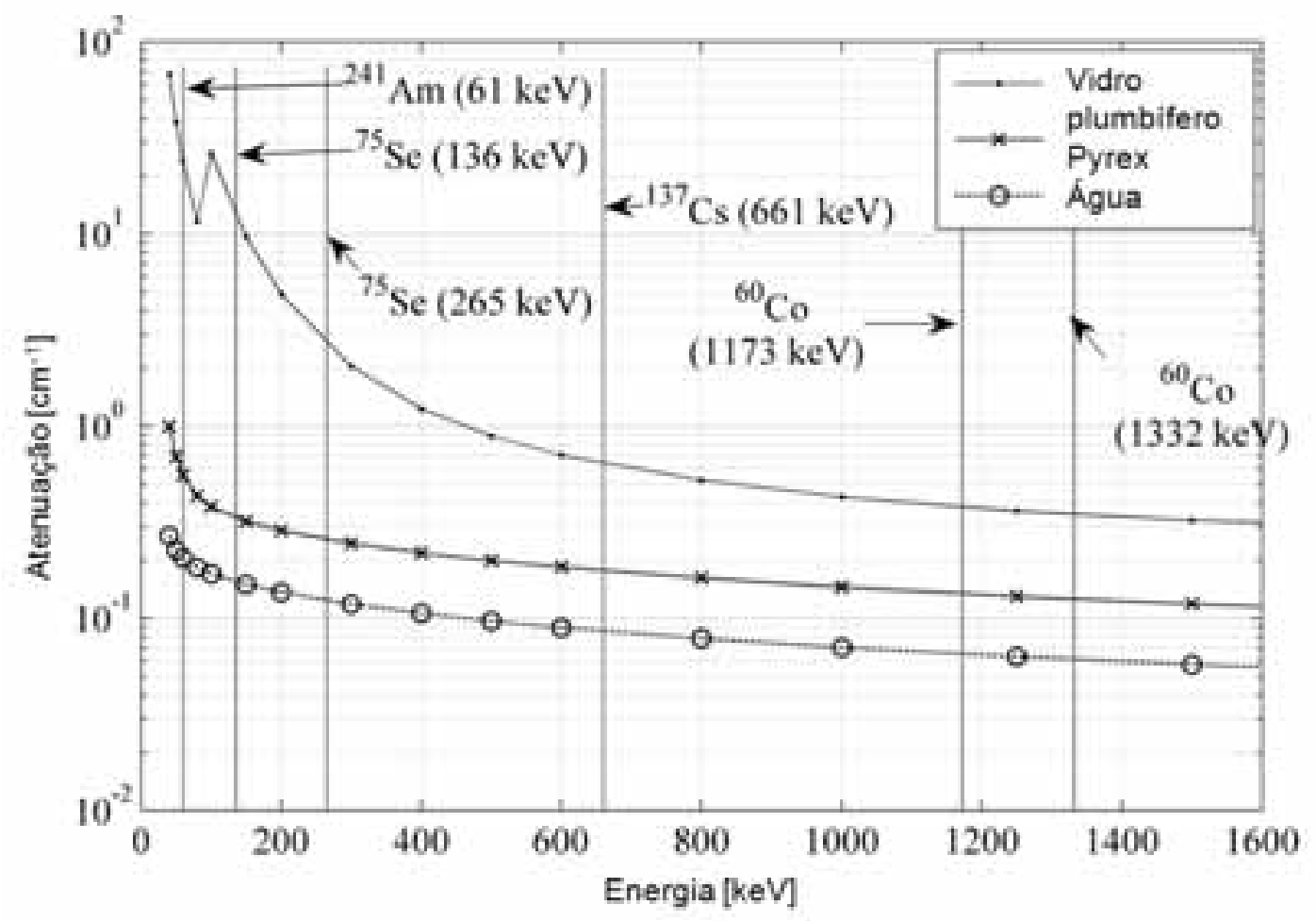

FIGURA 42 - Coeficiente de atenuação em função da energia para vidro plumbífero, pyrex é água(a). NIST (Hubbell \& Seltzer, 1996) 
A FIGURA 42 mostra o comportamento dos coeficientes de atenuação em função da energia para água, vidro plumbífero e pyrex (borosilicato); materiais que representam limites inferior e superior para partículas de catalisador utilizadas em estudos sem reação (cold studies). O inverso da atenuação pode representar o valor médio da penetração dos fótons em um material. Se a penetração é baixa e o domínio de estudo é grande, a relação sinal por ruído é pobre. Para os materiais em questão, na região de baixas energias as atenuações são altas. Os radioisótopos disponíveis comercialmente, assim como, as suas atenuações que dependem da energia também são apresentados. Detalhes adicionais relacionados a meia vida e disponibilidade foram discutidos na seção 4 . Notoriamente, os radioisótopos de ${ }^{241} \mathrm{Am}$ e ${ }^{75} \mathrm{Se}$ apresentam maior atenuação para os materiais considerados. Se utilizadas estas fontes para estudos de domínios relativamente grandes $(>18 \mathrm{~cm})$ seriam necessárias grandes atividades, incrementado os problemas de manipulação de material radioativo e de proteção radioló gica. A figura mostra também que os isótopos de ${ }^{137} \mathrm{Cs}$ e ${ }^{60} \mathrm{Co}$ não são completamente atenuados e fornecem contagens razoáveis.

\subsection{Aproximação utilizando a Minimização Alternativa Monoenergética (MAME)}

A distribuição de holdup para sistemas com duas fases dinâmicas é determinada com base na imagem de atenuação global do sistema e no fato de que a soma das frações do holdup fases é igual à unidade. O coeficiente de atenuação da fase pura precisa também ser conhecido com antecedência. Assim, a distribuição de holdup para um sistema com três fases segue o mesmo procedimento.

O coeficiente de atenuação do sistema gás-líquido-sólido pode se representado como segue: 


$$
\mu(x, E)=\sum_{i \in\{G, L, S\}} \mu_{i}(E) \varepsilon_{i}(x)
$$

O termo $\mu(x, E)$ representa a imagem contendo os coeficientes de atenuação do sistema multifásico, $\mu_{i}(E)$ representa o coeficiente de atenuação da fase $i$, onde $i \epsilon\{G, L, S\}$. Os termos $E$ e $x$ são os índices da energia dos fótons e dos pixels na imagem. Devido ao fato do holdup de uma fase ser uma fração do volume da mesma, a soma dos holdups das fases é igual a unidade:

$$
\sum_{i \in\{G, L, S\}} \varepsilon_{i}(x)=1
$$

Onde, $\varepsilon_{i}(x)$ representa o holdup da fase $i$ no pixel $x$. Se o domínio for estudado com fótons com duas energias diferentes $E=1$ e $E=2$, é possível obter duas equações a partir da equação( 59 ). Estas duas equações em conjunto com a equação ( 60 ) formam o sistema de equações para a determinação da distribuição do holdup presente no sistema. Este sistema pode ser representado como uma matriz $\hat{\boldsymbol{\mu}}=M \boldsymbol{\varepsilon} \quad$ :

$$
\left[\begin{array}{c}
\hat{\mu}^{(k+1)}(x, 1) \\
\hat{\mu}^{(k+1)}(x, 2) \\
1
\end{array}\right]=\left[\begin{array}{ccc}
\mu_{S}(1) & \mu_{L}(1) & \mu_{G}(1) \\
\mu_{S}(2) & \mu_{L}(2) & \mu_{G}(2) \\
1 & 1 & 1
\end{array}\right] \times\left[\begin{array}{c}
\varepsilon_{S}(x) \\
\varepsilon_{L}(x) \\
\varepsilon_{G}(x)
\end{array}\right]
$$

onde:

$$
M=\left[\begin{array}{ccc}
\mu_{S}(1) & \mu_{L}(1) & \mu_{G}(1) \\
\mu_{S}(2) & \mu_{L}(2) & \mu_{G}(2) \\
1 & 1 & 1
\end{array}\right]
$$


Se os termos da esquerda da equação ( 61 ) e os valores dos coeficientes que constituem $M$ forem conhecidos, o holdup pode ser determinado invertendo-se a matriz $M$, como mostrado a seguir:

$$
\left[\begin{array}{l}
\hat{\varepsilon}_{S}(x) \\
\hat{\varepsilon}_{L}(x) \\
\hat{\varepsilon}_{G}(x)
\end{array}\right]=\left[\begin{array}{ccc}
\mu_{S}(1) & \mu_{L}(1) & \mu_{G}(1) \\
\mu_{S}(2) & \mu_{L}(2) & \mu_{G}(2) \\
1 & 1 & 1
\end{array}\right]^{-1} \times\left[\begin{array}{c}
\hat{\mu}^{(k+1)}(x, 1) \\
\hat{\mu}^{(k+1)}(x, 2) \\
1
\end{array}\right]
$$

O processo iterativo descrito na seção 5.2 .2 baseado na equação ( 38 ) é utilizado para determinar as imagens dos coeficientes de atenuação $\hat{\mu}^{(k+1)}(x, 1)$ e $\hat{\mu}^{(k+1)}(x, 2)$ para as energias $E=1$ e $E=2$ do sistema multifásico. Os termos da matriz $M$ podem ser obtidos da literatura quando a composição das fases é conhecida. Se os dados não estiverem disponíveis, devem ser realizadas varreduras de referência, enchendo o sistema com uma fase pura de cada vez. Assim, os dados de transmissão poderiam então ser processados utilizando-se a equação ( 38 ) para determinar os coeficientes de atenuação das fases puras, onde o holdup é a unidade. No caso anterior $M$ pode ser representada desta forma:

$$
M=\left[\begin{array}{ccc}
\mu_{S}(x, 1) & \mu_{L}(x, 1) & \mu_{G}(x, 1) \\
\mu_{S}(x, 2) & \mu_{L}(x, 2) & \mu_{G}(x, 2) \\
1 & 1 & 1
\end{array}\right]
$$

Onde, $\mu_{i}(x, E)$ para $i \epsilon\{G, L, S\}$ e $E \epsilon\{1,2\}$ representa o coeficiente de atenuação para o domínio preenchido completamente com o componente $i$ e,

$$
\varepsilon_{i}(x)=1
$$


Os termos marcados com “^” na equação ( 63 ) são os estimadores das variáveis indicadas. Devido ao fato de $\varepsilon_{i}(x)$ ser calculada com base nos coeficientes de atenuação estimados do sistema multifásico, está representado como um estimador também.

Para determinar as imagens dos coeficientes de atenuação $\hat{\mu}^{(k+1)}(x, 1)$ e $\hat{\mu}^{(k+1)}(x, 2)$ é utilizado um algoritmo apropriado. Os termos da matriz $M$ são determinados em função dos dados dos coeficientes de atenuação da literatura ou de experimentos de densitometria. O sistema de equaçõ es lineares independentes representado na expressão ( 63 ) é utilizado para determinar as imagens do holdup.

Devido ao fato da reconstrução das imagens dos coeficientes de atenuação do procedimento descrito ser uma etapa intermitente para a determinação das imagens das distribuições do holdup, este processo é conhecido como um método de "pós processamento" para a determinação da distribuição do holdup. Este pós - processamento é chamado também de aproximação monoenergética para duas fontes radioativas, pois, a reconstrução é feita individualmente para cada fonte. A aproximação monoenergética é o método padrão citado na literatura para sistemas com duas fontes radioativas (Rebgetz et. al. 1991; Bukur et al. 1996; Froy stein et al. 2005; Nikitidis et al. 1999; Rizescu et al. 2001; Yazdi \& Esmaeilnia 2003; Hale, 2007).

$\mathrm{Na}$ literatura, os algoritmos utilizados para determinar $\mu(x, E)$ do sistema multifásico são discrepantes. Algoritmos baseados na FBP são os mais utilizados. Neste estudo, a minimização alternativa monoenergética descrita na seção 5.2 .2 baseada na equação ( 38 ) foi utilizada para determinar os coeficientes de atenuação $\hat{\mu}^{(k+1)}(x, 1)$ e $\hat{\mu}^{(k+1)}(x, 2)$. Um número aleatório entre 0 e 1 foi escolhido como valor inicial para 
$\hat{\mu}^{(k=0)}(x, E)$. O sistema foi estudado com $1,5 \times 10^{4}$ iterações, por ser este valor um bom critério de convergência (seção 5.4.2). Os coeficientes de atenuação das fases puras utilizados na matriz $M$, equação ( 64 ), foram determinados por densitometria e estão representados na TABELA 11. Assim, as imagens para a distribuição do holdup do phantom da FIGURA 23 foram determinadas em função da equação ( 63 ).

\subsection{Minimização Alternativa Polienergética (MAPE)}

$\mathrm{O}$ espectro dos raios X é de natureza polienergética. Aplicações médicas da tomografia com raios $\mathrm{X}$ têm desenvolvido algoritmos que modelam o espectro polienergético, representando adequadamente o processo físico de transmissão (Chye Hwang et al. 2000; De Man et al. 2001; Elbakri \& Fessler 2002 e O'Sullivan \& Benac 2007). O motivo principal para o desenvolvimento de um modelo que leve em conta a energia dos fótons é reduzir o aparecimento de $\operatorname{artefatos}^{10}$ que aparecem nas imagens reconstruídas de imagens, quando utilizada a aproximação monoenergética para casos de natureza polienergética. Estes artefatos aparecem principalmente com materiais de alta atenuação, como, ossos ou implantes metálicos (aplicações médicas).

O espectro gama consiste de várias regiões (Ex. Comptom) e de um ou mais fotopicos (dep endendo do isótopo). Isto permite a utilização de discriminação electrônica de energia, usando o hardware associado ao sistema de aquisição de dados para detectar as contagens dos fótons com uma energia específica, mesmo se trabalhando com detectores de baixa resolução energética. Este procedimento evita a contagem na região de

\footnotetext{
10 Artefatos são falsas imagens, sombras, manchas nas tomografias que aparecem após o processo de reconstru ção.
} 
espalhamento Comptom, especialmente, quando utilizada uma fonte gama que possui um só fotopico $\left({ }^{137} \mathrm{Cs}\right)$. Desta forma, as aproximações monoenergéticas são utilizadas para modelar a transmissão de fótons; e o ap arecimento de artefatos é raramente provocado pela utilização de fótons de alta energia. Nesta seção, a minimização alternativa polienergética (MAPE) proposta por O'Sullivan \& Benac (2007) é aplicada ao caso da CT dual (duas fontes radioativas).

A nomenclatura explicada na FIGURA 22 é utilizada nesta discussão. Se $\mu(x)$ na equação ( 35 ), representado por:

$$
q(y: \mu)=I_{o}(y) \exp \left(-\sum_{x \in X} h(y \mid x) \mu(x)\right)
$$

é substituído pela equação ( 59 ) e as variáveis que dependem da energia são indexadas $\operatorname{com} E$, então, o modelo para transmissão da radiação pode ser representado por $q(y, E: \varepsilon)$, assim, tem-se:

$$
q(y, E: \varepsilon)=I_{o}(y, E) \exp \left(-\sum_{x \in X} h(y \mid x) \sum_{i \in\{G, L, S\}} \mu_{i}(E) \varepsilon_{i}(x)\right)
$$

Do mesmo modo, a I-divergência, anteriormente representada pela equação ( 36 ) pode ser modificada para in corporar as variáveis dep endentes da energia:

$$
I(d \| q)=\sum_{E} \sum_{y \in Y}\left[d(y, E) \ln \left(\frac{d(y, E)}{q(y, E: \varepsilon)}\right)-d(y, E)-q(y, E: \varepsilon)\right]
$$


O termo $q(y, E: \varepsilon)$ é função do holdup $\varepsilon_{i}(x)$, onde, $i \in\{G, L, S\}$ é o índice das fases. O objetivo fundamental do algoritmo é minimizar a equação ( 68 ) em relação ao conjunto do holdup das fases $\left\{\varepsilon_{i}(x)\right\}$. Assim, o problema global é encontrar $\left\{\varepsilon_{i}(x)\right\}$ de forma que:

$$
\min _{\left\{\varepsilon_{i}\right\}} I(d \| q)
$$

A minimização proporciona a função de atualização iterativa para estimar o holdup, descrita a seguir:

$$
\hat{\varepsilon}_{i}^{(k+1)}(x)=\hat{\varepsilon}_{i}^{(k)}(x)-\frac{1}{Z_{i}(x)} \ln \left[\frac{\tilde{b}_{i}(x)}{\hat{b}_{i}^{(k)}(x)}\right]
$$

Para, $i=G, L, S$. Este estudo envolve uma aplicação, onde, são disponíveis exclusivamente os dados de dois fotopicos, portanto, a equação ( 70 ) é utilizada para $i=L, S$ somente. Para $i=G$, equação( 60 ) é utilizado um loop iterativo dado por:

$$
\hat{\varepsilon}_{G}^{(k+1)}=1-\left(\hat{\varepsilon}_{L}^{(k+1)}+\hat{\varepsilon}_{S}^{(k+1)}\right)
$$

Assim, como no caso monoenergético, os termos $\tilde{b}_{i}(x)$ e $\hat{b}_{i}^{(k)}(x)$ da equação ( 70 ) são as retroprojeções das contagens dos raios gama $d(y, E)$ e do estimador atualizado $\hat{q}^{(k)}(y, E: \varepsilon)$, respectivamente para $E=1$ e 2 : 


$$
\begin{gathered}
\widetilde{b}_{i}(x)=\sum_{y \in Y} \sum_{E} \mu_{i}(E) h(y \mid x) d(y, E) \\
\hat{b}_{i}^{(k)}(x)=\sum_{y \in Y} \sum_{E} \mu_{i}(E) h(y \mid x) \hat{q}^{(k)}(y, E)
\end{gathered}
$$

onde:

$$
\hat{q}^{(k)}(y, E: \varepsilon)=I_{o}(y, E) \exp \left[-\sum_{x \in X} h(y \mid x) \sum_{i} \mu_{i}(E) \hat{\varepsilon}_{i}^{(k)}(x)\right]
$$

O processo iterativo inicia-se na escolha de um valor aleatório para $\hat{\varepsilon}^{(k=0)}(x)$ tal que $0 \leq \hat{\varepsilon}^{(k)}(x) \leq 1$ para todo i e x para calcular $\hat{q}^{(k)}(y, E: \varepsilon)$ na equação ( 74 ). A equação ( 74 ) é utilizada para calcular $\hat{b}_{i}^{(k)}(x)$ na equação ( 73 ). A retroprojeção $\widetilde{b}_{i}(x)$ é calculada só uma vez, utilizando $d(y, E)$ para $E=1$ e 2. Os valore de holdup $\left\{\varepsilon_{i}^{(k+1)}(x)\right\}$ são atualizados pelas equações ( 72) e ( 73 ), e o processo de iteração é iniciado novamente, utilizando os valores atualizados de holdup (definindo $k=k+1$ ). A condição de não negatividade é aplicada para os valores de holdup. Desta forma, quando $\varepsilon_{i}^{(k+1)}(x)<0$ é corrigido como $\varepsilon_{i}^{(k+1)}(x)=0$. Da mesma forma, a escolha do fator de escalonamento $Z_{i}(x)$ para cada $x$ da equação ( 70 ) obedece o seguinte critério (O'Sullivan \& Benac 2007):

$$
\sum_{i} \sum_{x \in X} h(y \mid x) \mu_{i}(E) \frac{1}{Z_{i}(x)} \leq 1
$$


Neste caso, o produto do comprimento da maior projeção através de um pixel com a atenuação da fase à maior energia foi escolhido com o valor de $Z_{i}(x)$. As equações ( 70 ) e ( 71 ) são utilizadas para a determinação das imagens que contem os dados da distribuição do holdup do sistema com três fases.

Se utilizados radioisótopos que emitam mais que dois fotopicos de energia, teoricamente, o MAPE pode ser utilizado. Se os dados de transmissão para raios gama provenientes de $n$ energias forem disponíveis para $n+1$ fases (holdups) pode ser utilizado o algoritmo MAPE. O uso da equação ( 71 ) continua sendo aconselhável para dados de transmissão provenientes de $n$ ou mais fotopicos com sistema de três fases, mesmo que uma delas seja gasosa $i=G$; pois a equação ( 70 ) poderia gerar valores infinitos (blow-up), quando os coeficientes de atenuação $\mu_{G}(E)$ dos gases apresentam valores muito pequenos (quase igual a zero) para as energias dos raios gama utilizadas.

Esta aplicação do MAPE pode ser vista como um caso especial da dupla minimização $\min _{p} \min _{q} I(d \| q)$ de O'Sullivan \& Benac (2007). Devido ao fato dos dados da contagem de radiação $d(y, E)$ utilizados nestes estudos terem sido previamente discriminados na energia, este algoritmo é mais simples que a forma geral apresentada por O’Sulliv an \& Benac (2007).

\subsection{Materiais e Métodos}

Neste estudo foi analisado o phantom da seção 5 por apresentar características de sistemas com três fases. Os detalhes deste foram descritos na seção indicada. $O$ phantom foi estudado com o sistema DSCT descrito na seção 5.3.2. 


\subsubsection{Condições de operação do DSCT}

O DSCT foi dotado de 15 detectores para ${ }^{137} \mathrm{Cs}$ e de 15 detectores para ${ }^{60} \mathrm{Co} . \mathrm{O}$ phantom foi centralizado e estudado, usando-se 9 detectores por arranjo, pois, com este número de detectores o leque formado cobria completamente o objeto. Os experimentos foram efetuados utilizando-se 197 ângulos (views) ou posições das fontes e 189 (21 x 9) projeções ou medidas dos detectores por ângulo. No total foram obtidas 37.233 projeções (197 x 189) por experimento, usando-se um tempo de contagem de 0,1 s. (10Hz.). Para melhorar a estatística das medidas, cada projeção foi determinada, como, a média de uma amostragem de $80(n=80)$. Cada varredura durou entre 6 e 7 horas.

\subsection{Resultados e Discussão}

Os dados de transmissão obtidos para o phantom (FIGURA 23) foram processados utilizando-se os algoritmos MAME e MAPE. As imagens foram reconstruídas em 80x80 pixels de resolução. Para poder comparar facilmente os resultados de holdup, todas imagens foram criadas usando a mesma escala de cor entre 0 e 1 . Portanto, os valores holdup, que é uma fração, deveriam estar dentro deste intervalo. O holdup transversal também foi representado sob estas condições.

Os valores dos coeficientes de atenuação das fases puras, necessários para a aplicação dos algoritmos MAME e MAPE foram obtidos de experimentos de densitometria. O procedimento foi detalhado na seção 5.3.1. 


\subsubsection{Limitações da aproximação MAME}

Este método pode apresentar problemas relacionados ao condicionamento da matriz M utilizada nas equações ( 62 ) e ( 64 ). O número de condicionamento da matriz $M$ é definido em função da norma, como a seguir:

$$
\kappa(M)=\left\|M^{-1}\right\| .\|M\|
$$

Os coeficientes de atenuação dos materiais utilizados no phantom, que dependem da energia dos radioisótopos ${ }^{137} \mathrm{Cs}$ e ${ }^{60} \mathrm{Co}$ determinam os valores de $\kappa(M)$. Valores altos indicam mal condicionamento. A matriz $M$ provoca pequenos erros no cálculo dos estimadores $\hat{\mu}^{(k+1)}(x, 1)$ e $\hat{\mu}^{(k+1)}(x, 2)$ quando utilizada a equação ( 38 ), que são amplificados quando determinadas as imagens do holdup com a equação ( 63 ). Este fato é inevitável devido a natureza estocástica da radiação. Portanto, resultados de baixa qualidade podem ser relacionados a valores elevados do número de condicionamento de $M$. Esta matriz é definida por propriedades físicas, assim, trocar o material de estudo para obter um valor aceitável de $\kappa(M)$ não é a solução. A alternativa seria utilizar uma fonte com menor energia que a do ${ }^{137} \mathrm{Cs}(662 \mathrm{keV})$, mas, isto implicaria nos problemas de atividade e proteção radiológica explicados anteriormente. Os exemplos citados na literatura utilizam energias de até $150 \mathrm{keV}$ com a limitação de somente se poder estudar pequenos domínios $(5-6 \mathrm{~cm}$.). 


\subsubsection{Reconstrução de imagens utilizando a aproximação monoenergética MAME}

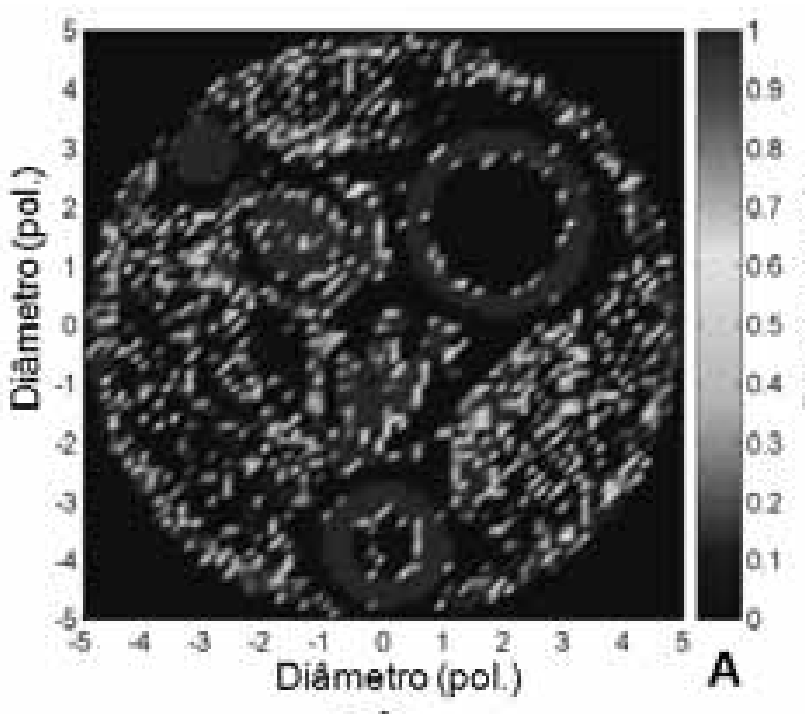

Gás

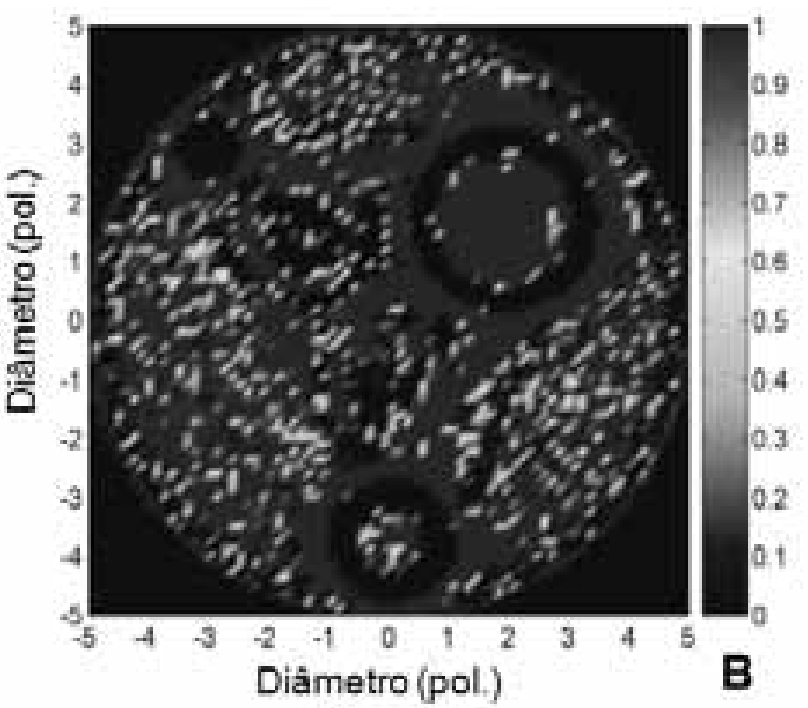

Liquido

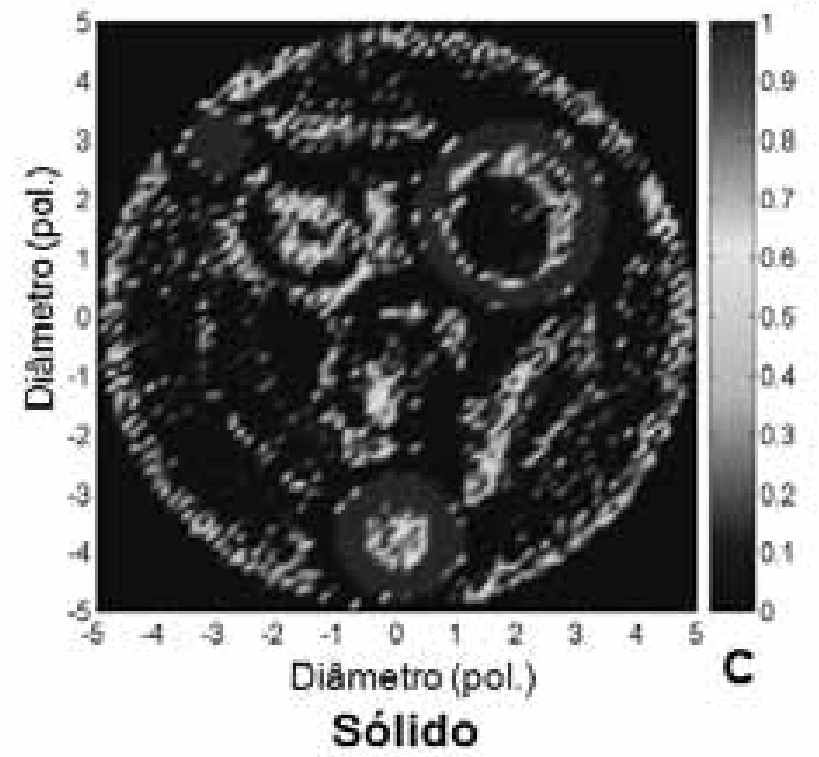

FIGURA 43 - MAME - Distribuição do holdup para o Caso 1. (A) Gás, (B) Líquido e (C) Sólido.

Os dados de transmissão obtidos pelo DSCT foram reconstruídos com a finalidade de se obter os coeficientes de atenuação monoenergéticos onde foi aplicada a aproximação polienergética para calcular os valores dos holdups. As distribuições dos coeficientes de atenuação foram calculados utilizando-se a equação ( 38 ) com $10^{4}$ iterações, para se obter um bom critério de convergência (seção 5.4.2). Nas imagens 
obtidas foi aplicada a aproximação monoenergética, empregando-se a equação ( 63 ) da seção 7.3. As imagens foram processadas utilizando-se 80x80 pixels de resolução.

A FIGURA 43 e a FIGURA 44 mostram as imagens do holdup para o gás, líquido e sólido para os casos 1 e 2 respectivamente.
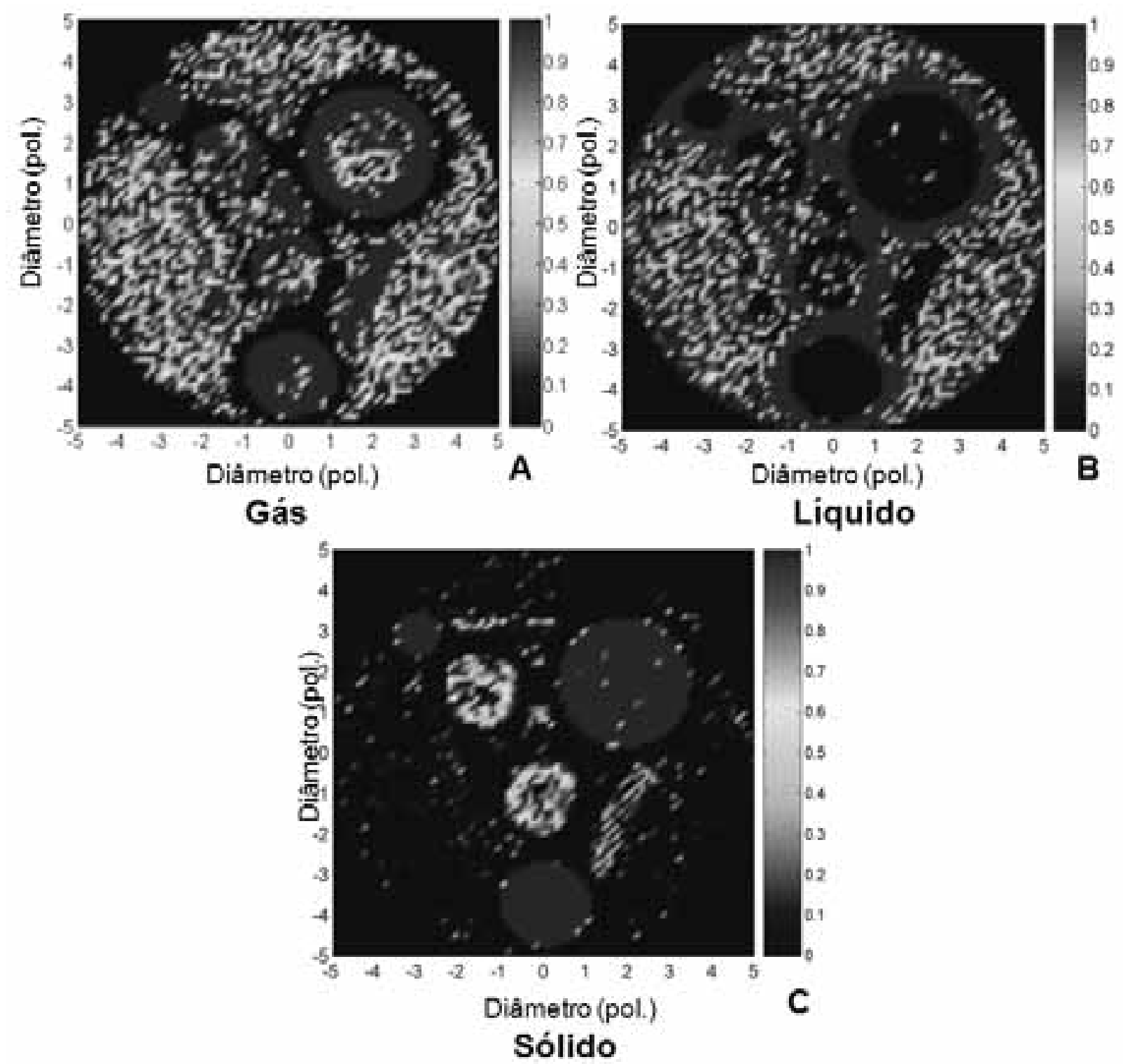

FIGURA 44 - MAME - Distribuição do holdup para o Caso 2. (A) Gás, (B) Líquido e (C) Sólido. 


\subsubsection{Características de convergência da MAPE}

O algoritmo MAPE oferece alta precisão dos resultados com pouca sensibilidade ao número de condicionamento da matriz $M$, sendo necessário um número alto de iterações para minimizar a I-divergência. A FIGURA 45 mostra o efeito do valor inicial escolhido para as variáveis do holdup no comportamento da I-divergência em função do número de iterações utilizando a equação ( 68 ).

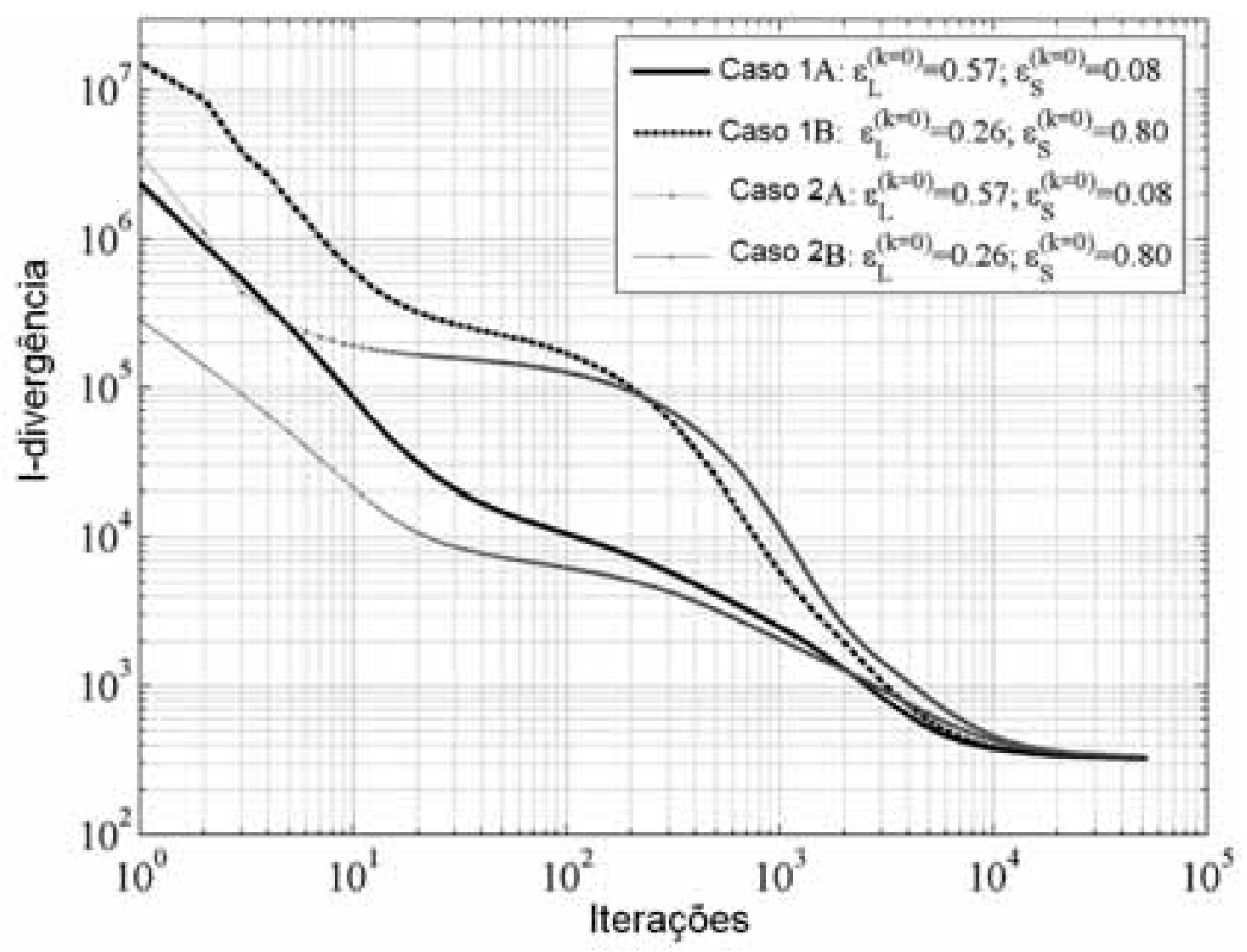

FIGURA 45 - I-divergência em função do número de iterações para diferentes valores iniciais do holdup para os Casos 1 e 2.

A figura acima mostra que a convergência não depende do valor inicial de holdup escolhido, sendo necessárias entre $3 \times 10^{4}$ e $5 \times 10^{4}$ iterações para atingir o valor mínimo da I-divergência. De todas formas, a escolha de um valor próximo ao verdadeiro acelera o processo de convergência. 


\subsubsection{Reconstrução de imagens utilizando a aproximação polienergética MAPE.}

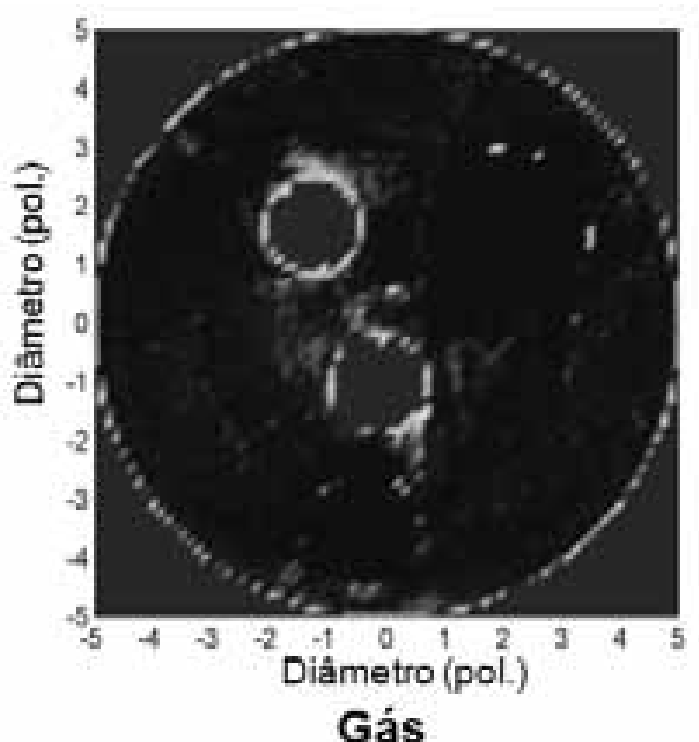

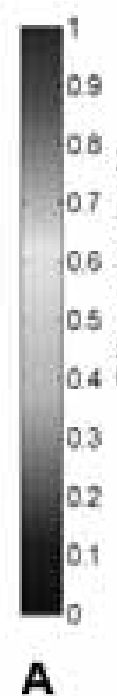

A

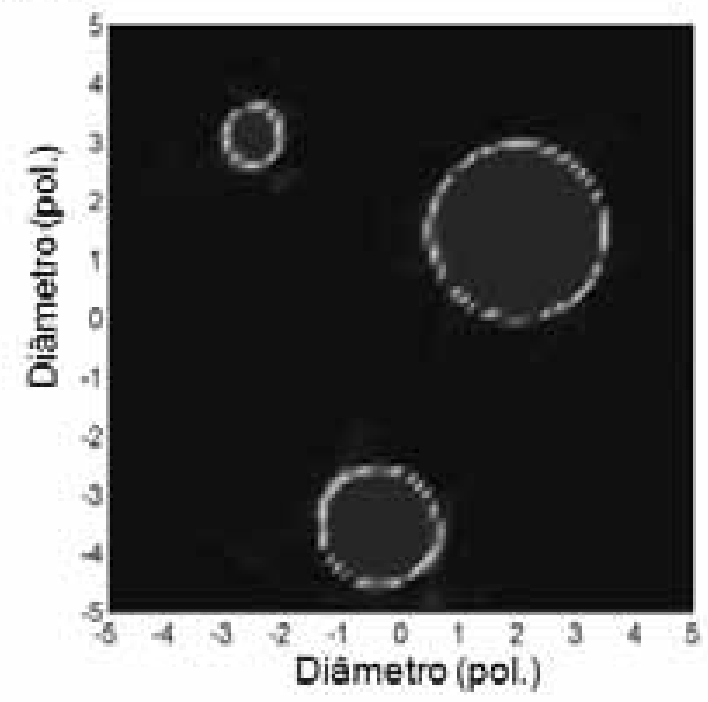

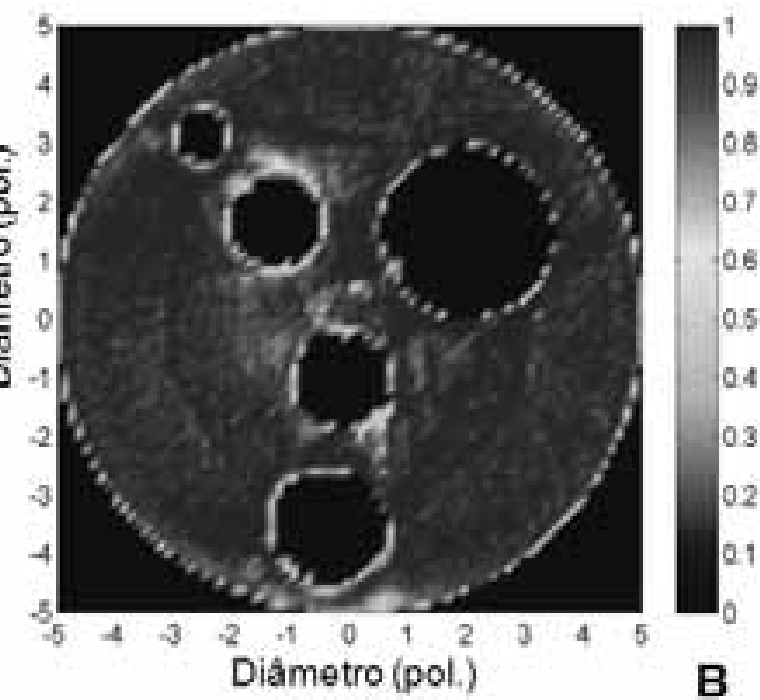

Liquido

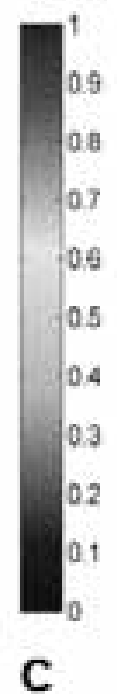

FIGURA 46 - MAPE - Distribuição do holdup para o Caso 1. (A) Gás, (B) Líquido e (C) Sólido.

Os dados de transmissão gerados por este experimento foram processados por meio do método explicado na seção 7.4. A equação ( 70 ) foi iterada $5 \times 10^{4}$ vezes para gerar as imagens do holdup dos casos 1 e 2 do phantom. Além da condição de nãonegatividade discutida na seção 7.4, foi aplicada uma adicional que atribui o valor da unidade para o máximo holdup encontrado. Assim, para todo $k$, quando $\varepsilon_{i}^{(k+1)}(x)<0$ é 
substituído por $\varepsilon_{i}^{(k+1)}(x)=0$; e se $\varepsilon_{i}^{(k+1)}(x)>1$, este será substituído como sendo $\varepsilon_{i}^{(k+1)}(x)=1$. Os resultados são apresentados em imagens de 80x80 pixels de resolução. A FIGURA 46 e a FIGURA 47 mostram os resultados do holdup para os casos 1 e 2, respectivamente.

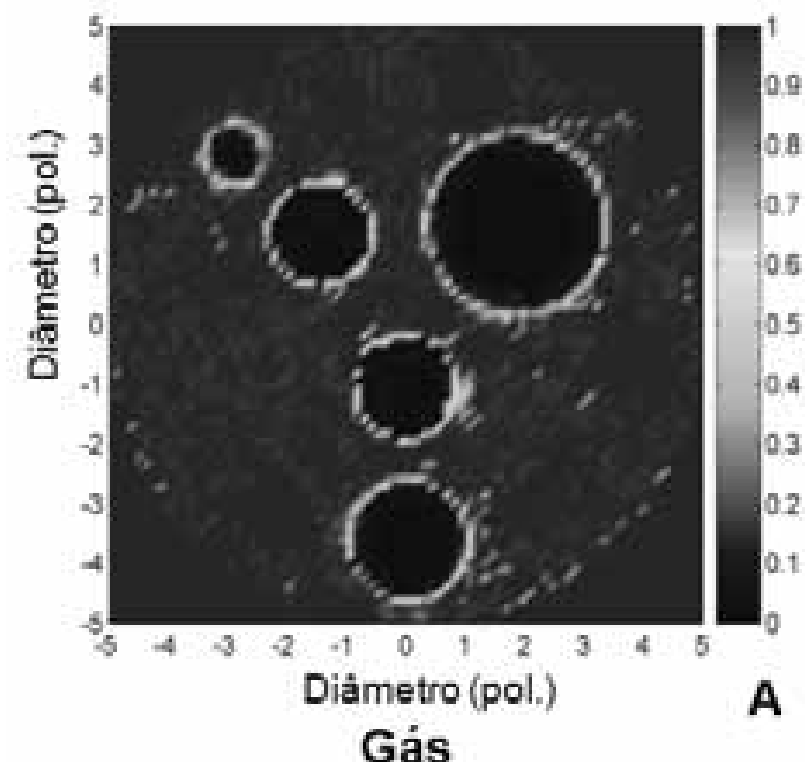

Gás
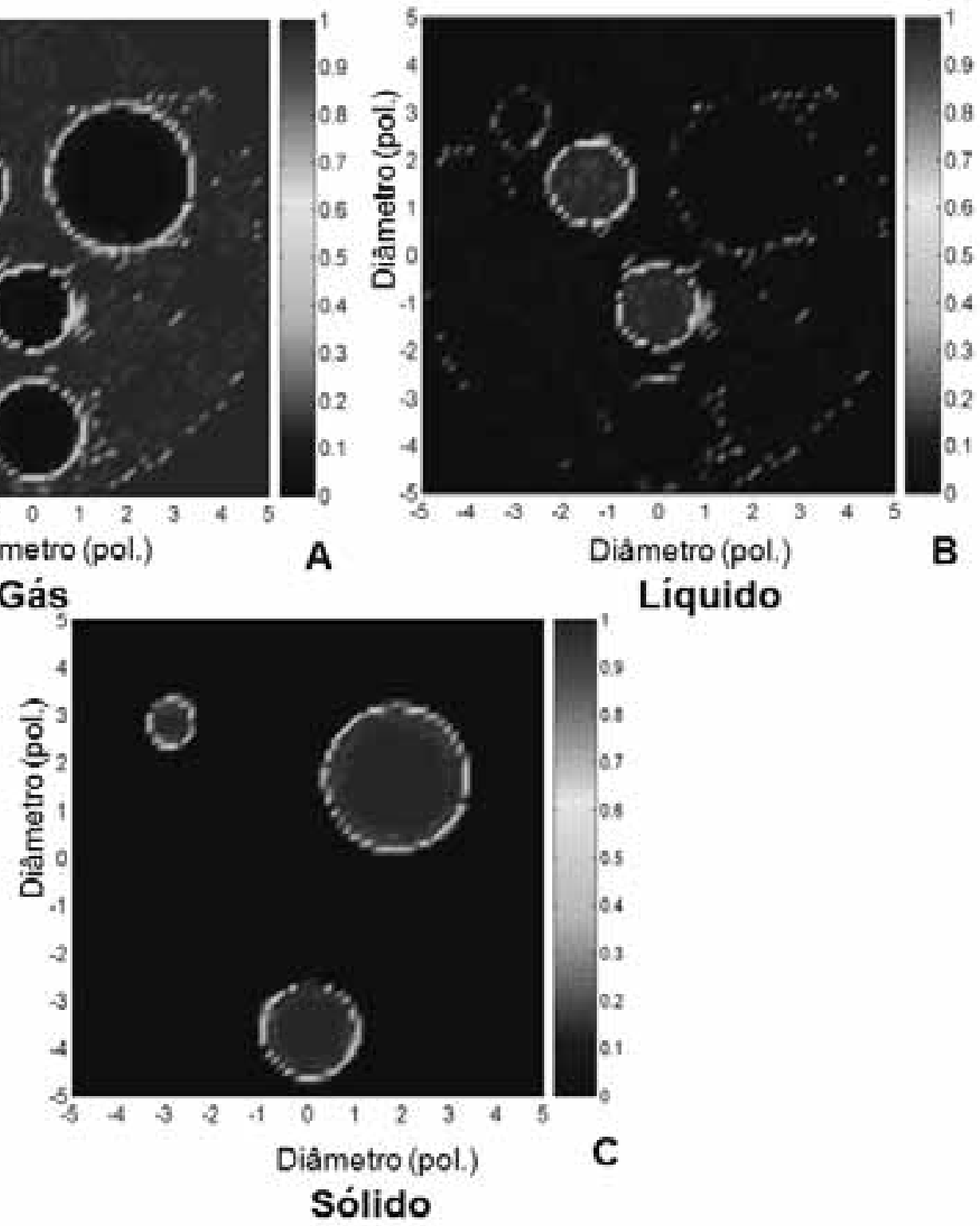

FIGURA 47 - MAPE Distribuição do holdup para o Caso 2. (A) Gás, (B) Líquido e (C) Sólido. 


\subsubsection{Discussão dos resultados}

As imagens do holdup calculadas utilizando o método da MAME produziram resultados com um grande erro. O holdup do sólido foi difícil de diferen ciar no phantom do caso 1. No caso 2 o domínio do sólido foi melhor definido, porém, os domínios do líquido C1-C2 apareceram dentro do holdup do sólido. Evidentemente, a aproximação MAME não proporciona informação qualitativa ou quantitativa da distribuição de holdup das três fases. As imagens obtidas com a MAPE foram superiores para ambos os casos estudados, onde o holdup apresentou valores unitários quando a fase pura estava presente no domínio reconstruído.

Uma análise mais detalhada é possível examinando o perfil do holdup. A FIGURA 48 e a FIGURA 49 mostram as comparações da seção central transversal da imagem dos holdups para gás, líquido e sólido dos casos 1 e 2, respectivamente. Para ambos os casos, os perfis da MAME não seguem o comportamento físico, apresentando valores fora da escala, indicando a existência de valores de holdup maiores que a unidade e negativos, indo contra o sentido físico do holdup. As flutuações aleatórias indicam que os pequenos erros nos coeficientes de atenuação são amplificados quando o holdup é calculado utilizando a equação ( 63 ). Os perfis de holdup apresentados pela MAPE seguiram o comportamento ideal para os dois casos estudados com flutuações mínimas. 

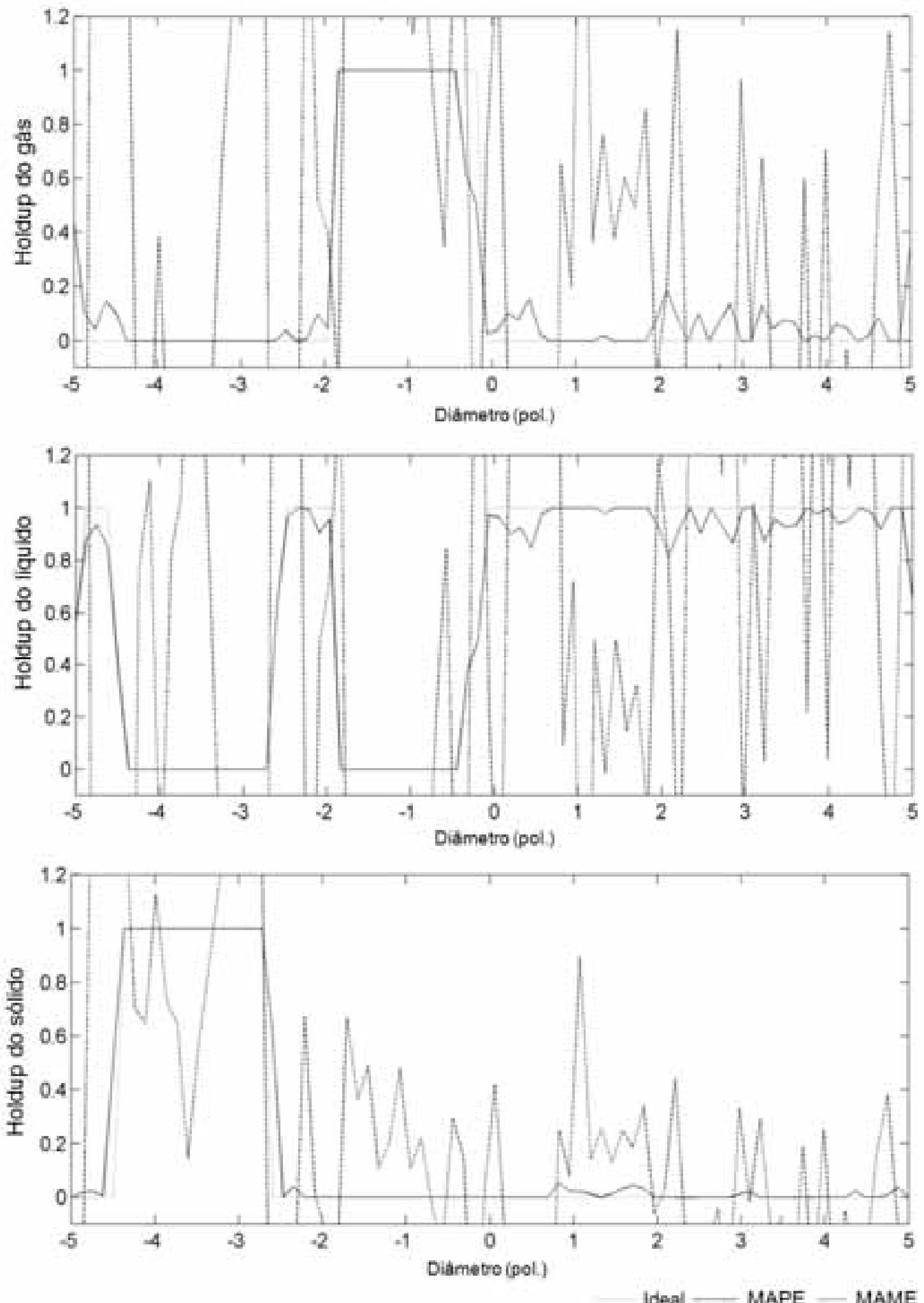

FIGURA 48 - Comparação do holdup ideal com os resultados obtidos com MAPE e MAME ao longo da linha do diâmetro (seção transversal) para o Caso 1. 

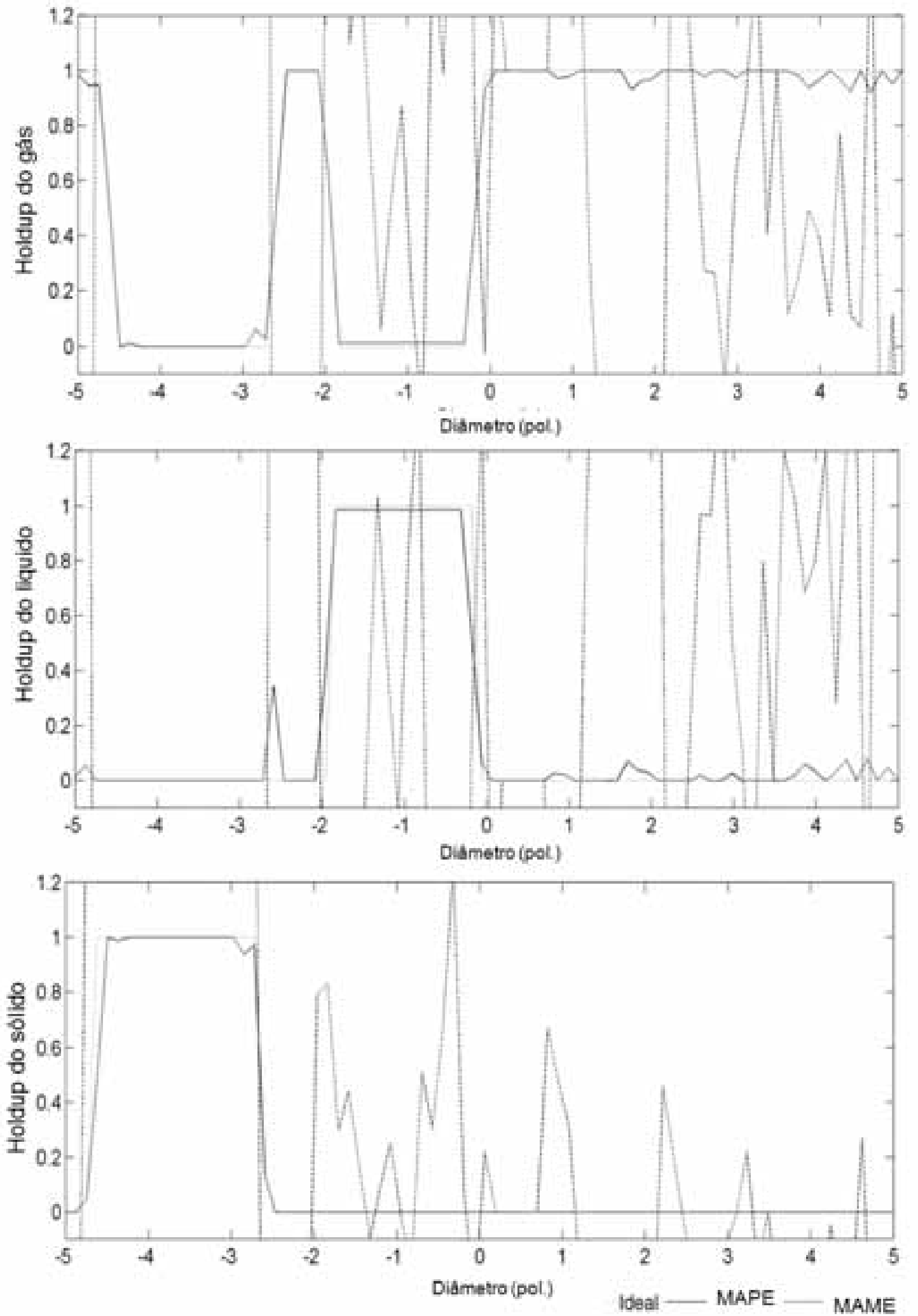

FIGURA 49 - Comparação do holdup ideal com os resultados obtidos com MAPE e MAME ao longo da linha do diâmetro (seção transversal) para o Caso 2. 
A condição impostapara valores de holdup maiores que a unidade, substituição de $\varepsilon_{i}^{(k+1)}(x)>1$ como sendo $\varepsilon_{i}^{(k+1)}(x)=1$, foi removida por motivos de análise. Os resultados indicaram que poucos pixels tinham valores maiores à unidade, principalmente na faixa entre 1,05 e 1,1. Artefatos com forma de anel foram observados ao redor dos domínios S1-S3 e C1-C2 para todas as imagens de holdup obtidas com ambos algoritmos, sendo mais intensos para as imagens obtidas com a MAME. Estes artefatos, provavelmente, são provocados pelos "borrões" observados nas imagens reconstruídas utilizando ${ }^{60} \mathrm{Co}$, como mostrado pelas FIGURA 35 e FIGURA 36 quando analisadas as regiões R2-R4. Este comportamento foi observado em outros casos utilizando o ${ }^{60} \mathrm{Co}$ (Capítulo 4) e pode estar relacionado à alta energia dos fótons de ${ }^{60} \mathrm{Co}$. De qualquer forma, este feito de borrado não afetou drasticamente os resultados da distribuição de holdup com o algoritmo MAPE.

\subsection{Conclusões}

Os resultados obtidos com a aproximação MAME para o DSCT não apresentaram boa definição para as energias dos radioisótopos utilizados e não foi possível definir os limites dos holdups das fases. O condicionamento da matriz que relaciona os coeficientes de atenuação com o holdup apresentou valores elevados interferindo na etapa de pós - processamento. Esta limitação restringiu-se à aplicação deste algoritmo a domínios pequenos com baixas energias.

O algoritmo MAPE quando aplicado ao DSCT forneceu imagens de alta qualidade que definiram o holdup das fases sem restrições externas ou a aplicação de métodos de regularização. Os resultados não foram limitados pelas características físicas dos materiais e as fontes utilizadas. O processamento das imagens não representou um 
grande problema quando feito off-line. A escolha adequada do valor inicial da fase de menor atenuação (nesta caso liquida) determina a velocidade de convergência do algoritmo. A MAPE representa uma solução para tomó grafos que utilizem alta energia com propósitos de alta penetração (aplicação industrial), abrindo-se desta maneira, possibilidades na área da pesquisa de sistemas multifásicos.

O DSCT apresentou várias vantagens práticas, comparado com sistemas SSCT. As fontes de alta energia utilizadas possibilitaram o estudo de sistemas grandes com materiais de alta atenuação. A separação das duas fontes em dois leques permitiu evitar a interferência nas contagens de uma fonte na outra (efeito Comptom do ${ }^{60} \mathrm{Co}$ no ${ }^{137} \mathrm{Cs}$ ). O sistema de discriminação eletrônico de energias foi de suma importância permitindo separar as regiõ es dos fotopicos.

O DSCT foi validado com êxito no estudo de uma phantom com 3 fases. Os resultados da distribuição do holdup mostrados neste capítulo forneceram a evidência experimental que confirmou a possibilidade de estudar sistemas com três fases utilizando o ${ }^{60} \mathrm{Co}$ e o ${ }^{137} \mathrm{Cs}$. 


\section{ESTUDO DE UM BIOREATOR ANAERÓBICO EM ESCALA PILOTO UTILIZANDO A TOMOGRAFIA POLIENERGÉTICA - DSCT}

\subsection{Introdução}

A produção de energia de fontes renováveis aumentou em duas vezes nos últimos cinquenta anos (EIA, 2006), sendo a madeira e as hidroeléctricas os principais geradores. Uma pequena quantidade é proveniente dos rejeitos e de bio-combustíveis. A área dos bio-combustíveis tem crescido significativamente com os avanços na geração de etanol, de celulose, de milho e de cana-de-açúcar. Biomassa proveniente de resíduos agrícolas contendo grande quantidade de celulose é convertida em etanol através de hidrólise enzimática e fermentação. Etanol obtido de biomassa é um substituto renovável e limpo para o petróleo e gás natural para propósitos de transporte. Os rejeitos (ou lixo) são uma outra fonte biológica de energia renovável. O metano gerado por digestão anaeróbica a partir de rejeitos animais ou aterros pode ser utilizado para produzir eletricidade ou aquecimento e pode também ser convertido em gás de síntese para o processo FisherTropsh. Gerar energia de rejeitos produz o benefício extra da redução da poluição do meio ambiente. Porém, atualmente a contribuição na geração de energia a partir de rejeitos é muito pequena, sendo uma área de alto potencial para pesquisa e desenvolvimento.

Os rejeitos animais e de fazendas agrícolas não têm sido explorados amplamente como uma fonte de energia renovável. Segundo Sheffield (2002), os Estados Unidos geram aproximadamente 230 milhões de toneladas de rejeitos animais anualmente (peso em base seca). A maior parte deste é descarregado no meio ambiente sem tratamento, 
provocando vários problemas relacionados à poluição, como, contaminação superficial e da água de leitos freáticos, mal cheiro, efeito estufa e problemas provocados por percolação de amônia. O metano, que possui um potencial maior que o dióxido de carbono para gerar o efeito estufa, é gerado da decomposição natural destes materiais e poderia ser recuperado e consumido como energia.

O processo de biodegradação natural pode ser realizado por digestão anaeróbica em um bioreator anaeróbico. Nas últimas décadas, o processo de digestão anaeróbica tem sido aplicado a diferentes tipos de resíduos agrícolas, animais e industriais (Speece, 1996; Gosh, 1997). Nas primeiras plantas de tratamento, o objetivo fundamental foi a eliminação de odores (Lusk, 1998), logo com a crise energética dos anos setenta cresceu o interesse da recuperação do metano. Os maiores desafios, no que diz respeito, ao desempenho e eficiência dos bioreatores anaeróbicos estão relacionados às configurações e ao desenho dos sistemas de mistura (Lusk, 1998). A mistura incrementa o processo de ventilação do biogás gerado, evitando estratificações, ajudando a manter a temperatura e o pH uniformes, garantindo o contato íntimo entre as bactérias e o substrato. Em outras palavras, condições de uma mistura adequada fornecem um ambiente uniforme para a degradação bioló gica dos rejeitos. Porém, nem a quantificação do regime de escoamento de digestores nem os efeitos da mistura no desempenho destes tem sido bem estudado ou publicado na literatura. Resultados do efeito da mistura em reatores anaeróbicos têm sido contraditórios e não tem quantificado o desempenho destes sistemas de forma estruturada (Hashimoto, 1982; Ho \& Tan, 1985; Rivard et al., 1995; Smith et al., 1996; Angenent \& Sung, 2001; Angenent, 2002; Hoffmann, 2005; Karim et al., 2005).

Assim, como a maioria de sistemas multifásicos, os bioreatores anaeróbicos são opacos, devido à natureza dos materiais tratados que apresentam três fases móveis. 
Neste ponto, técnicas avançadas como a CT gama e a CARPT podem ajudar a visualizar estes sistemas. A CT gama pode determinar a distribuição de holdups e a CARPT pode quantificar o regime de escoamento em termos de circulação de líquido, parâmetros de turbulência e tempos de residência locais e globais.

Vesvikar (2005) estudou pela primeira vez a hidrodinâmica de bioreatores com técnicas não intrusivas. Vesvikar (2006) e Varma \& Al-Dahhan (2007) efetuaram simulações CFD e aplicaram a CT e a CARPT para determinar as distribuições de holdup de gás, velocidades de líquido e as regiões de mistura pobre em um bioreator com recirculação de gás. Nestes estudos foi também medido o desempenho de dois tipos de aeradores (injetores ou distribuidores de gás), um anel de orifício simples e um anel multiorifício, sendo que este último apresentou os melhores resultados em relação a distribuição do holdup. A existência de regiões de mistura pobre foi também verificada, onde o anel multi orifício melhorou drasticamente esta situação, sendo definidos os valores específicos para as vazões de gás adequadas.

Este estudo é a continuação do trabalho iniciado por Vesvikar (2006) e posteriormente por Varma \& Al-Dahhan (2007). Foi conduzido em um bioreator de escala piloto, nas mesmas condições de mistura dos trabalhos citados anteriormente, avaliando-se a influência de um aerador redesenhado. Com a ajuda do DSCT foram determinadas as distribuições de holdup de gás e o grau de má distribuição das mesmas. 


\subsection{Materiais e Métodos}
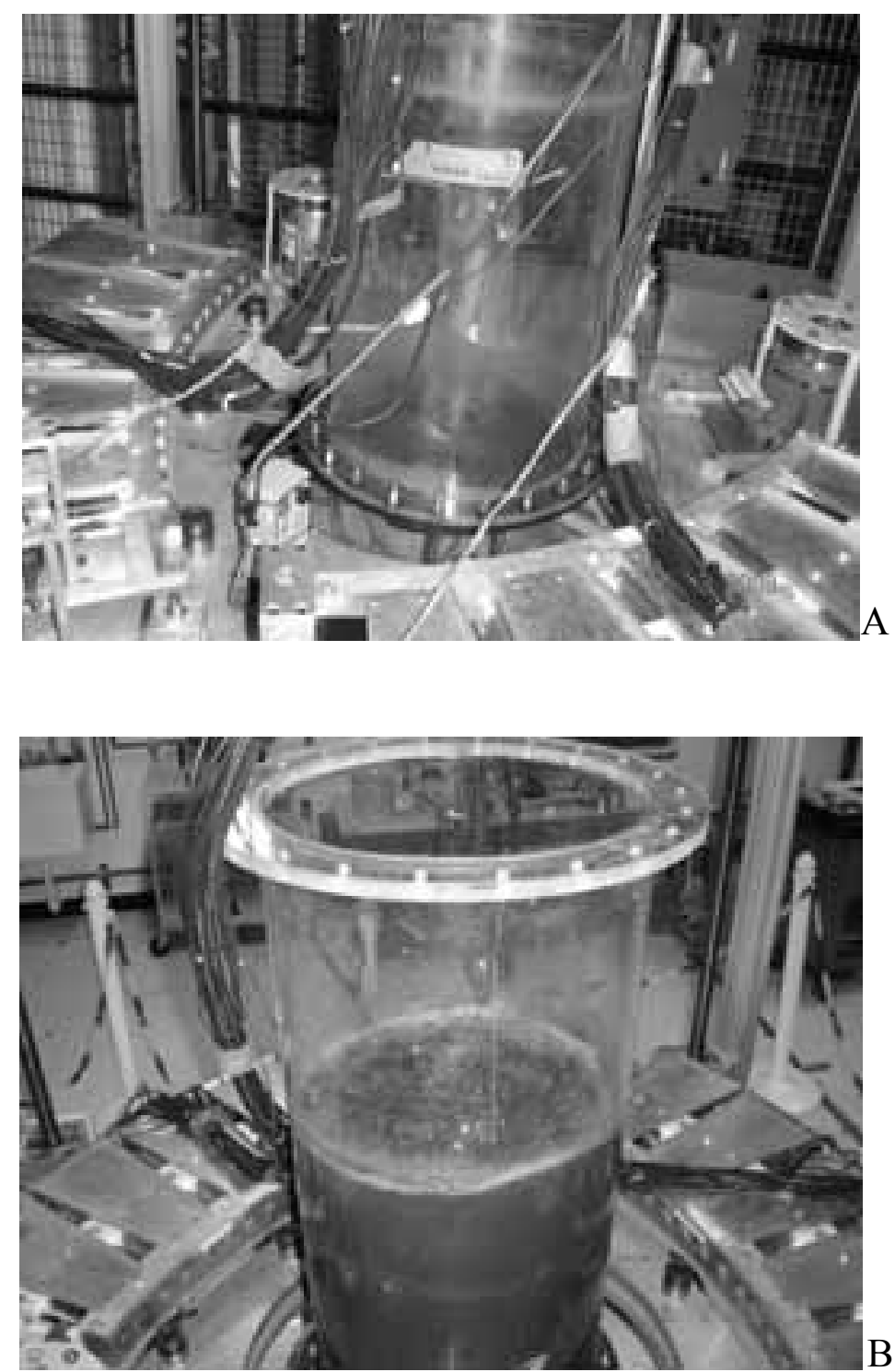

FIGURA 50 - Bioreator estudado com o sistema DSCT. (A) Reator vazio. (B) Reator carregado.

Nestes experimentos foi analisado o desempenho de um bioreator em escala piloto, como mostrado na FIGURA 50, utilizando-se o DSCT descrito na seção 5.3.2. O reator foi construído em acrílico para que se pudesse observar o seu funcionamento e diminuir os efeitos da atenuação da radiação nas paredes do mesmo. Varma \& Al-Dahhan (2007) estudaram o efeito do tipo de aerador e verificaram que para as vazões de gás 
estudadas não era necessário trabalhar com todos os orifícios abertos (anel multi orifício) por motivos da queda de pressão $(\Delta P)$. Assim, o aerador de anel multi orifício foi redesenhado para um aerador em cruz com quatro orifícios para saída do gás. Os orifícios foram localizados em um círculo hipotético que ocupava a metade da aérea da tubulação guia para garantir a distribuição do gás dentro desta tubulação.

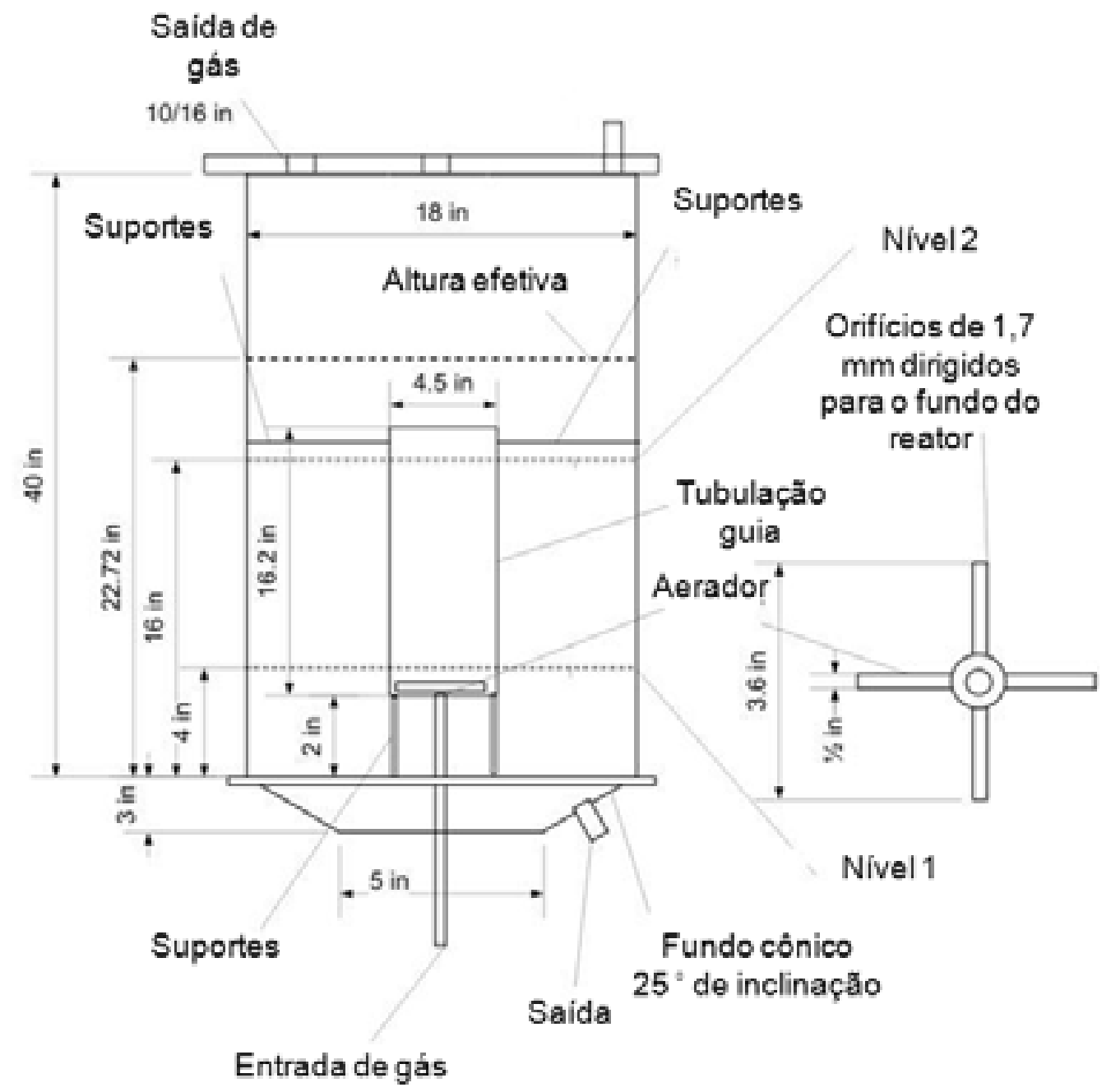

FIGURA 51 - Esquema do bioreator e aerador utilizados.

A FIGURA 51 mostra os detalhes do bioreator e do aerador utilizados. A relação entre o diâmetro do bioreator e a tubulação guia $(\sim 4)$ foi a mesma que a reportada por Varma \& Al-Dahhan (2007). A tubulação guia foi fixada nas paredes do bioreator com 
a ajuda de três pés de acrílico colocados equidistantes ao redor da parte superior desta e três pés na parte inferior, como um tripé. $\mathrm{O}$ bioreator possui um fundo cônico com uma saída para remoção da lama.

Na parte inferior do bioreator está localizada a entrada de gás para o aerador. $\mathrm{O}$ aerador encontra-se na parte inferior da tubulação guia, assim garante-se que o gás liberado dentro da tubulação guia permanece dentro desta.

O reator foi carregado em $6 \%(\mathrm{~V} / \mathrm{V})$ com esterco de vaca e água, operando em condições semi-batch, variando-se a vazão de gás alimentado ao sistema, como mostrado na TABELA 19. Adicionalmente, são apresentados os valores da energia necessária (potência) para realizar este processo, calculados com a expressão desenvolvida por Casey (1986):

$$
\frac{P}{V}=\frac{G_{r}}{\left(\frac{\lambda-1}{\lambda}\right)}\left[\left(\frac{P_{1}}{P_{2}}\right)^{\left(\frac{\lambda-1}{\lambda}\right)}-1\right]
$$

Onde, $P$ é a potência, $V$ é o volume ativo do reator, $\mathrm{G}_{\mathrm{r}}$ é a taxa de recirculação do biogás, $P_{2}$ e $P_{1}$ são as pressões na superfície do reator e na entrada do gás (pressão estática da lama), respectivamente e $\lambda=1,03$. Segundo a EPA (1979), estes valores encontram-se dentro dos limites recomendados para este tipo de aplicações.

TABELA 19 - Condições de operação do bioreator

\begin{tabular}{|c|c|c|}
\hline $\begin{array}{c}\text { Vazão de gás } \mathrm{Q}_{\mathrm{g}} \\
(\mathrm{L} / \mathrm{min})\end{array}$ & $\begin{array}{c}\text { Velocidade } \\
\text { superficial do gás } \\
\text { na tubulação guia } \\
(\mathrm{cm} / \mathrm{s})\end{array}$ & $\begin{array}{c}\text { Energia } \\
\text { necessária } \\
\left(\mathrm{W} / \mathrm{m}^{3}\right)\end{array}$ \\
\hline 4,5 & 0,731 & 4,25 \\
\hline 9,0 & 1,462 & 8,49 \\
\hline 18,0 & 2,923 & 16,99 \\
\hline
\end{tabular}




\subsubsection{Condições de operação do tomógrafo DSCT}

$\mathrm{O}$ contraste entre os coeficientes de atenuação para as fontes de ${ }^{60} \mathrm{Co}$ e ${ }^{137} \mathrm{Cs}$ foi muito pobre, devido ao fato do sólido utilizado possuir elementos de número atômico baixo e ao fato de que a sua densidade era muito similar à da água. Experimentos de densitometria foram feitos no reator contendo a mistura multifásica e foi demonstrado que o raio de transmissão era quase o mesmo para as duas fontes, portanto, aplicou-se o algoritmo MAPE (ver seção 7.4). Como o reator apresentou um diâmetro relativamente grande, de 45,72 cm (18 pol.), foram utilizados os 15 detectores de cada arranjo (total 30 ). Foram obtidas 315 projeções por ângulo para 197 posições das fontes (ângulos), contabilizando um total de 62.055 (315 x 197) projeções por fonte. O tempo de contagem foi fixado em $0,2 \mathrm{~s}$ (5 Hz.). As imagens foram reconstruídas, utilizando-se uma resolução de 80 × 80 pixels. As tomografias foram efetuadas em dois níveis, sendo que o nível 1 estava localizado acima do aerador e nível 2 na parte sup erior da tubulação guia.

\subsection{Resultados e Discussão}

A FIGURA 52 mostra as distribuições de holdup do gás na região da tubulação guia nos níveis 1 e 2 para as condições de vazão de gás estudadas. Os resultados mostram que o gás distribuí-se de maneira uniforme na região da tubulação guia. No nível 1 foram observadas mudanças na cor da imagem (laranja), revelando a saída do gás do aerador. O gás foi bem distribuído, quando este subiu pelo tubo guia. 

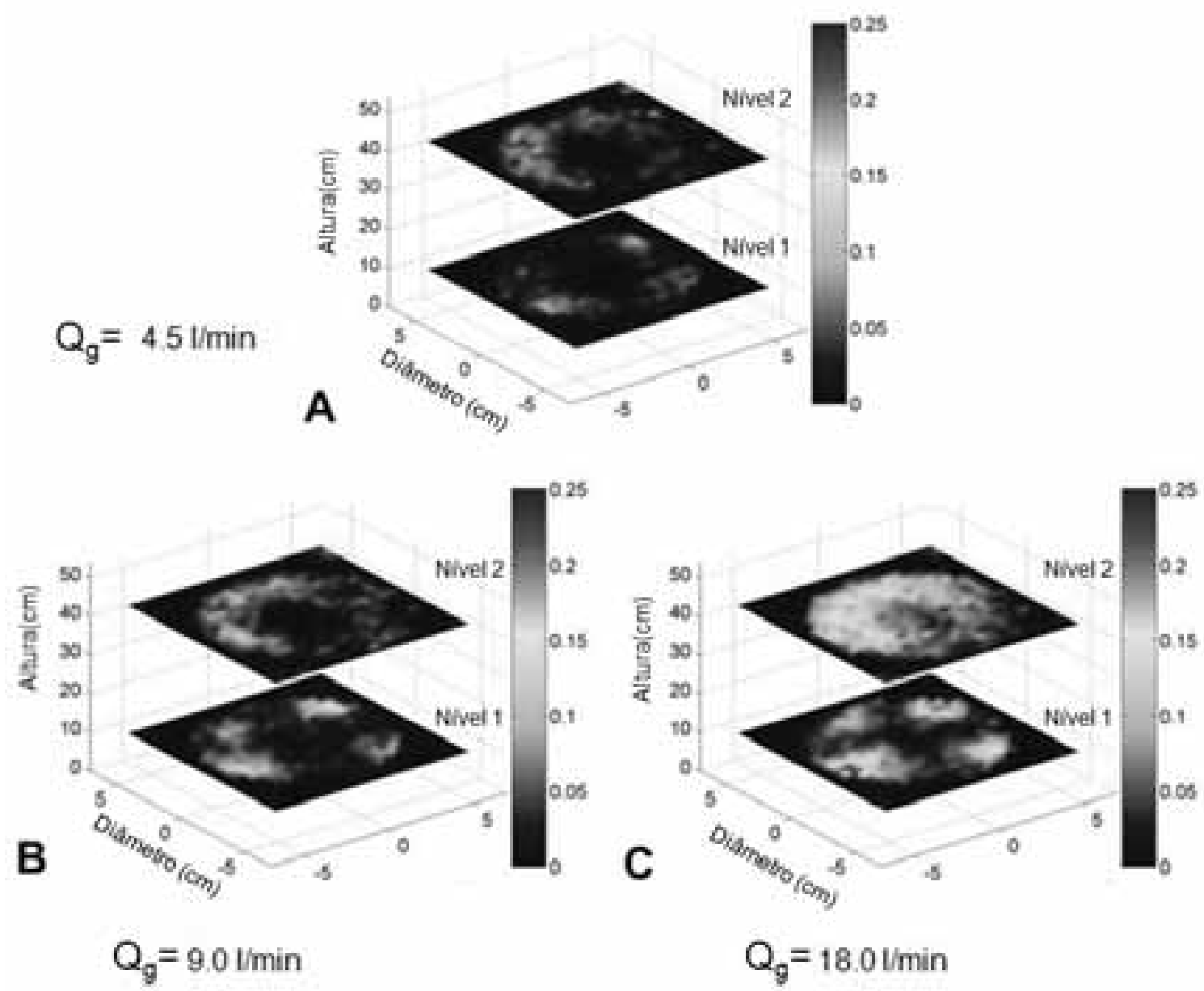

FIGURA 52 - Distribuições do holdup (time averaged) na tubulação guia para os Niveis 1 e 2. (A) $Q_{g}=4,5 \mathrm{l} / \mathrm{min},(B) Q_{g}=9,0 \mathrm{l} / \mathrm{min},(C) Q_{g}=18,9 \mathrm{l} / \mathrm{min}$.

Para analisar a distribuição do holdup do gás foi determinado o fator de má distribuição (desvio padrão), utilizando-se a expressão normalizada a seguir (Marcandelli et al., 2000; Jiang, 2000):

$$
\sigma=\sqrt{\frac{1}{N} \sum_{i, j}\left(\frac{\varepsilon_{i, j}-\bar{\varepsilon}}{\bar{\varepsilon}}\right)^{2}}
$$


Quando este fator é próximo a zero, significa que a distribuição do holdup é completamente uniforme. Para um melhor entendimento podem ser calculados os valores médios da distribuição de holdups, utilizando a seguinte equação:

$$
\bar{\varepsilon}_{g}=\frac{\sum_{x=1}^{N} \varepsilon_{g}(x)}{N}
$$

Onde, $x$ representa o índice do pixel, $\mathrm{N}$ o número total de pixels na região da tubulação guia. Assumindo que cada pixel tem a mesma área, $\bar{\varepsilon}_{g}$ também representa o valor médio do holdup do gás ponderado ou pesado pela área. A TABELA 20 apresenta os resultados para os valores médios do holdup para gás e para os fatores de má distribuição para as condições estudadas. Adicionalmente, foram incluídos dados referenciais da percentagem do volume morto do reator obtidos por Vesvikar (2005), usando exp erimentos de CARPT.

TABELA 20 - Valores médios da distribuição do holdup do gás e valores do fator de má distribuição dentro da tubulação guia.

\begin{tabular}{|c|c|c|c|c|c|}
\hline $\begin{array}{c}\text { Vazão do gás } \\
(1 / \mathrm{min})\end{array}$ & \multicolumn{2}{|c|}{ Holdup do gás } & \multicolumn{2}{|c|}{ Fator de má distribuição } & \multirow{2}{*}{$\begin{array}{c}\text { \% Volume } \\
\text { morto do reator }\end{array}$} \\
\hline & Nível 1 & Nível 2 & Nível 1 & Nível 2 & \\
\hline 4.5 & 0,017 & 0,029 & 1.147 & 0,930 & 13,63 \\
\hline 9.0 & 0,033 & 0,034 & 0,932 & 0,830 & 8,19 \\
\hline 18.0 & 0,055 & 0,086 & 0,798 & 0,442 & 5,20 \\
\hline
\end{tabular}

Os resultados indicam que para todas as vazões de gás, o holdup foi aumentado na seção superior da tubulação guia (nível 2), comparado com a entrada inferior (nível 1). O fator de má distribuição apresentou valores menores para o nível 2 (superior), quando comparado com o nível 1; indicando que o gás foi se distribuindo melhor quando subiu pela tubulação guia. 


\subsection{Conclusões}

Os resultados obtidos das tomografias indicam que o gás foi bem distribuído dentro da região da tubulação guia. Quando a vazão do gás aumenta, o fator de má distribuição diminui. Com vazões elevadas de gás ainda existem zonas mortas dentro do bioreator. Observando-se o bioreator, pode ser verificada a existência de material sólido insolúvel no fundo. Este problema poderia ser solucionado, incrementando-se a vazão de gás, mas a geração de metano seria diminuída; portanto uma melhor estratégia seria fazer um pré-tratamento para a eliminação deste material. Como o esterco de vaca vem com areia utilizada, como camada na coleta do mesmo, o processo no bio-digestor poderia ser modificado, para que estes materiais fossem drenados, recirculando somente os orgânicos, eliminando-se os insolúveis. 


\section{ESTUDO DO EFEITO DO DISTRIBUIDOR DE UM REATOR MONOLÍTICO UTILIZANDO A TOMOGRAFIA POLIENERGÉTICA - DSCT}

\subsection{Introdução}

Sistemas que envolvem reações multifásicas entre gás e líquido sobre uma superfície sólida de catalisador têm sido utilizadas extensivamente na indústria química, petroquímica, bioquímica, de materiais e meio ambiente. Exemplos destas aplicações incluem a hidrogenação catalítica de frações do petróleo para remoção de impurezas de enxofre (Irandoust et. al. 1990) e a oxidação catalítica de hidrocarbonetos líquidos com ar ou oxigênio (Levenspiel, 1996; Levenspiel, 1998).

Vários tipos de sistemas têm sido utilizados nestas aplicações, tais como, reatores agitados de lama (stirred tank slurry), colunas de lama com borbulhamento (slurry bubble column), reatores de leito empacotado, etc. (Krishna et al., 1994, Kapteijn et al., 2001; Nijhuis et al., 2001). A escolha do reator tem sido regida pelas reações químicas, fatores hidrodinâmicos, simplicidade de uso e manufatura, e sobre tudo para intensificar a transferência de massa (Dudukovic et al., 2002). Porém, os reatores convencionais apresentam diversos problemas. Por exemplo, em reatores de leito empacotado é verificada uma grande queda de pressão, mesmo com vazões de gás e líquido moderadas; limitando a sua operação a altas velocidades e a sua produtividade. Altas quedas de pressão são traduzidas em altos consumos de energia. Em reatores agitados é necessária uma grande quantidade de energia mecânica para garantir as condições de mistura e quando o processo é finalizado, faz-se necessário separar e reciclar o catalisador do produto final, 
incrementando os custos de operação. Ainda que, os reatores convencionais continuem a figurar com o papel principal em várias indústrias, pesquisadores começaram a procurar alternativas para mitigar os problemas mencionados anteriormente.

Uma alternativa ao uso dos reatores convencionais é o reator monolítico, um reator tubular, contendo monólitos revestidos ou impregnados com catalisador. A FIGURA 53 mostra um monólito, no qual vários canais paralelos estão separados por paredes, geralmente, feitas de cordierite (alumino silicato) ou materiais cerâmicos, não existindo desta forma, transporte na direção radial. Os monólitos podem carregar o catalisador de duas maneiras, a superfície pode ter sido banhada com catalisador, ou a estrutura pode ter sido impregnada com o catalisador. Os monólitos são fabricados industrialmente pela extrusão de uma pasta contendo partículas de catalisador ou de mistura onde será fixado o catalisador. Geralmente, a seção transversal dos reatores monolíticos é retângular, no entanto, existem geometrias mais complexas, tais como, círculos, hexágonos, triângulos, etc. Pequenas rebarbas internas são fornecidas para aumentar a área superficial e para estabilizar o ef eito do fluxo gás - líquido, permitindo-se a operação em contra - corrente e evitando-se problemas de flooding (Heibel et al. 2004; Lebens et al. 1999, 1997). Uma revisão detalhada das características, fabricação e aplicações pode ser encontrada em Gulati (1998), Williams (2001) e Garcia-Bordeje et al. (2002).

Os monólitos como tais, não são uma novidade na comunidade científica e na indústria. Monólitos têm sido utilizados com sucesso em reações gasosas catalisadas (gássólido), tais como, os catalisadores de automóveis e na remoção de NOx e CO de usinas elétricas (Cybulski et al. 1998). A Akzo Nobel iniciou a produção de peróxido de hidrogénio utilizando um reator monolítico multifásico de escala industrial para a hidrogenação de antraquinonas em hidroquinonas (Albers et. al 2001). 


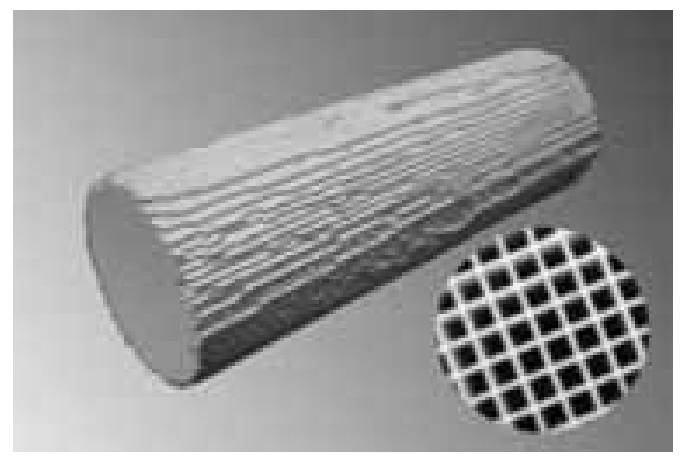

FIGURA 53 - Esquema de um reator monolitico.

A pesquisa e a utilização de monólitos como reatores multifásicos estão começando, detalhes da operação destes equipamentos estão longe de ser bem conhecidos. Regimes de escoamento para otimizar o funcionamento não têm sido estudados com profundidade. Assim, pequenas melhoras no desempenho de reatores multifásicos podem ser traduzidas na diminuição de custos operacionais significativos.

Como em outros sistemas multifásicos, a hidrodinâmica influencia grandemente a eficiência dos reatores monolíticos (Krishna et al. 1994; Dudukovic et al. 2002). A chave fundamental está na utilização total do catalisador, o que significa distribuição uniforme de gás e líquido na entrada do reator.

O conhecimento da distribuição do holdup do líquido permite modelar e diagnosticar o desempenho de um reator monolítico. O holdup do líquido é a fração ocupada pelo líquido com relação ao volume do reator vazio, sendo esta uma medida da fração de catalisador em contato com a fase líquida para o caso de monólitos (Roy, 2006).

A grande maioria das referências bibliográficas não introduz os efeitos hidrodinâmicos na modelagem deste tipo de sistemas (Nijhuis et al. 2003; Liu 2002; Edvinsson et al. 1994), baseando-se em um modelo de uma simples tubulação, assumindose que o comportamento de cada canal é idêntico. Outras pesquisas têm se restringido a um 
tubo capilar ou canal simples (Biswas et al. 1985; Bercic et al. 1997; Hatziantoniou et al. 1982; Irandoust et al. 1992; Liu 2002) ou a diâmetros de monólitos pequenos de até $1 \mathrm{~cm}$ (Nijhuis et. al. 2001, Broekhuis et al. 2001). Desta forma, o modelo de tubulação simples deveria ser modificado, incorporando-se os efeitos hidrodinâmicos. Quase todas as simulaçõ es CFD para visualização dos regimes de escoamento têm sido feitas em canais simples (van Baten \& Krishna, 2004; Salmi et al. 2003; Kreutzer et al., 2001).

Um dos argumentos utilizados para investir na pesquisa de reatores monolíticos refere-se ao fato destes possuírem um desempenho superior aos reatores de leito empacotado (aleatório). Porém, tais afirmações baseiam-se nas modelagens de reatores monolíticos e de leito empacotado, onde foram assumidas as distribuições de fases homogêneas (Nijhuis et al. 2003; Salmi et al., 2003; Edvinsson et al. 1994). Assim, muitas comparações, com outros tipos de reatores, utilizavam o reator monolítico nas suas condições máximas de produtividade. Este não é o caso real, pois, o desempenho de um reator monolítico depende de fatores que afetam a distribuição do fluxo (Roy, 2006). Portanto, faz-se necessário um melhor entendimento dos aspectos hidrodinâmicos deste tipo de reator.

Neste trabalho foi utilizada a tomografia gama com duas fontes radioativas DSCT pela primeira vez para o estudo de um reator monolítico de 4,148 cm de diâmetro e $40 \mathrm{~cm}$ de comprimento com o intuito de ter acesso à informação da distribuição do holdup do gás e do líquido em diferentes níveis do reator (entrada, região central e saída), avaliando-se o desempenho de um distribuidor (static mixer) e identificando-se os intervalos de operação que proporcionam uma distribuição uniforme. O reator e o distribuidor foram fornecidos por M.T. Kreutzer da Delft University of Technology (Holanda). Kreutzer afirmou que o distribuidor estático projetado sempre produz uma boa 
ou razoável homogeneidade, baseado em estudos prévios com a técnica de tempo de residência RTD. Tanto o reator monolítico, como, o distribuidor foram utilizados anteriormente em vários outros estudos da mesma universidade (Bakker, 2003; Yawalkar et al., 2005; Kreutzer et at., 2005). O reator foi operado em co-corrente, seguindo as condições de escoamento do regime de Taylor, por apresentar melhores condições de transferência de massa (Cybulski et al., 1998).

\subsection{Características geométricas dos reatores monolíticos}

O número de canais por unidade de área transversal é conhecido como densidade da célula e tipicamente varia entre 25 e 1200 canais por polegada quadrada (cpsi). A fração de vazio varia entre 0,5 e 0,9 e frequentemente é expressada como área frontal aberta (OFA). A espessura da parede varia entre 0,05 e $0,5 \mathrm{~mm}$. Desta forma, a estrutura de um monólito é caracterizada pela espessura da parede e pela densidade de célula, fatores independentes entre si. A seguir, são apresentadas as definições matemáticas dos parâmetros que definem a estrutura de um monólito (Cybulski et al., 1998).

Densidade de célula (células por polegada quadrada - cpsi):

$$
n=\frac{1}{L^{2}}
$$

Área frontal aberta (fração ou porcentagem):

$$
O F A=n\left(L-t_{w}\right)^{2}=\frac{\left(L-t_{w}\right)^{2}}{L^{2}}
$$


Área superficial geométrica $\left(\mathrm{m}^{2} / \mathrm{m}^{3}\right)$ :

$$
G S A=4 n\left(L-t_{w}\right)=4 \frac{\left(L-t_{w}\right)}{L^{2}}
$$

Diâmetro hidráulico (mm):

$$
d_{h}=4\left(\frac{O F A}{G S A}\right)=\left(L-t_{w}\right)
$$

Onde, $t_{w}$ é espessura da parede, $L$ é o comprimento entre o centro da parede de um canal a outro. A FIGURA 54 mostra o esquema da seção transversal de um canal de um reator monolítico.

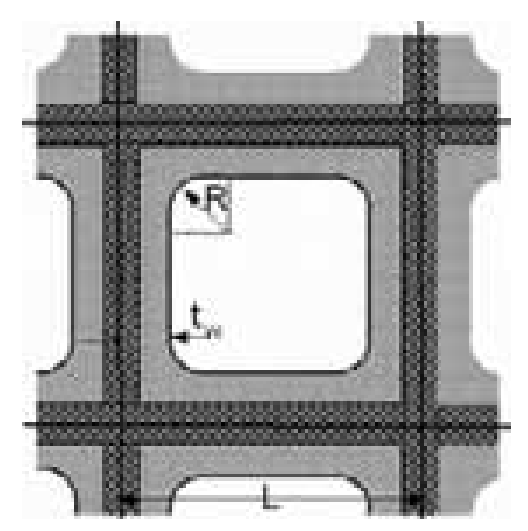

FIGURA 54 - Seção transversal de uma celular simples. $R$ é o raio de curvatura do canal (normalmente não é especificado). (Roy, 2006).

\subsection{Condições de operação dos reatores monolíticos}

Estudos importantes caracterizando os regimes de escoamento em tubos capilares simples têm sido realizados na área de engenharia nuclear, enfocando a transferência de calor, sendo os resultados aplicados aos monólitos (Zhao et al. 2001; 
Triplett et al. 1999; Coleman et al. 1999; Mishima et al. 1996). A FIGURA 55 mostra os principais resultados destes experimentos e a localização das condições de trabalho deste estudo.

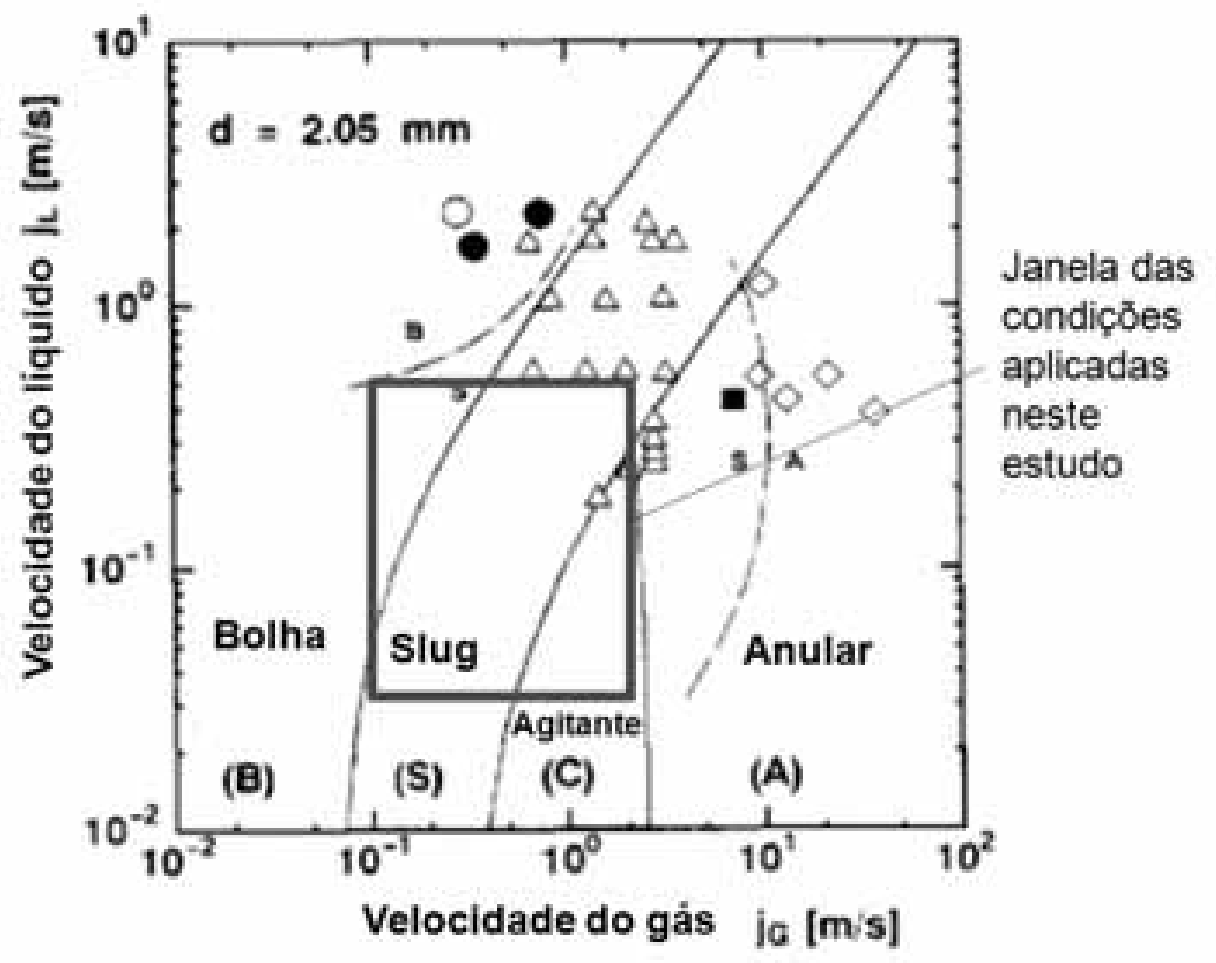

FIGURA 55 - Regime de escoamento em um capilar simples $(d=0,5 \mathrm{~mm})$ : em bolhasbubbly flow, pistonado ou intermitente - slug, agitante - churn e anular; Mishima et al. 1996. Janela com as condições experimentais aplicadas neste trabalho.

Os reatores monolíticos podem ser operados em dois regimes de escoamento, no regime de Taylor (pistonado ou intermitente - slug flow) e no regime anular (Coleman et al., 1999). O regime de Taylor é caracterizado pelo movimento em forma de trem que alterna bolhas de gás com porções de líquido (slugs), através dos canais capilares do monólito. Neste regime, o comprimento das bolhas de gás é várias vezes maior que o diâmetro do canal e o seu diâmetro é quase igual ao diâmetro do canal (Cybulski et al. 1998, Thulasidas et al. 1999; Bercic et al. 1997). Uma camada muito fina de líquido (30 a $70 \mu \mathrm{m}$ - filme) separa a fase gasosa da parede do canal (Irandoust et al. 1989). Por outro 
lado, no regime anular, o líquido desce pelas paredes dos capilares e o gás flui pelo centro. Este regime pode ser obtido com vazões baixas de líquido e altas de gás. Recentemente, o regime anular vem sendo estudado com a possibilidade de apresentar benefícios relacionados ao escoamento (Roy et al. 2002, 2004; Heibel et al. 2003, 2005).

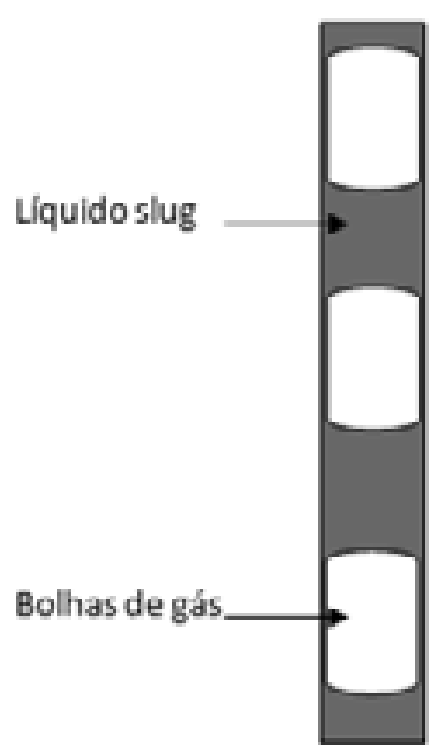

A

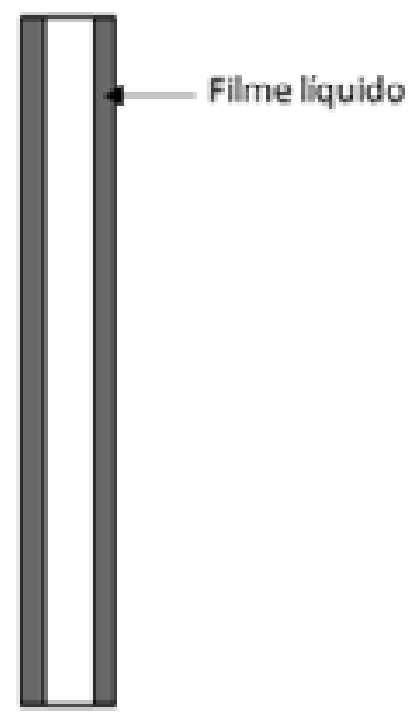

B

FIGURA 56 - Esquema dos regimes de escoamentos recomendados para reatores monoliticos (A) Pistonado ou intermitente (Slug), (B) Anular.

Um reator monolítico operado nos dois regimes de escoamento indicados acima, tem várias vantagens; como, baixa queda de pressão, excelentes propriedades de transferência de massa, elevad as razões superfície/volume, entre outras (Boger et al. 2004; Nijhuis et al. 2001; Edvinsson et al. 1998). Porém, existem ainda problemas operacionais relacionados aos altos custos de fabricação e baixa transferência de calor. Mesmo assim, monólitos metálicos têm sido estudados para reações exotérmicas (Boger et al. 2005). 
Um fator muito importante na operação destes reatores multifásicos é a distribuição na entrada de gás e de líquido, pois a não existência de transporte convectivo na direção radial implicaria que uniformidade das fases estaria regida pelo sistema de distribuição, levando a uma utilização adequada do catalisador e do desempenho do reator. Vários estudos têm sido feitos sem avaliar a distribuição local do holdup (Satterfield et al. 1977; Irandoust et al. 1989; Crynes et al. 1995; Broekhuis et al. 2001). Outros estudos têm utilizado a ressonância magnética nuclear, tomografia por capacitância elétrica e a tomografia gama convencional, demonstrando a existência de uma janela de condições de trabalho para uniformidade (Reinecke et al. 1996; Heibel et al. 2003; Roy, 2006).

\subsection{Materiais e Métodos}

Neste estudo foi usado um reator monolítico de $40 \mathrm{~cm}$ de comprimento e 4.148 cm de diâmetro, utilizando-se o sistema DSCT, como, mostrado na FIGURA 57. O tomógrafo utilizado encontra-se detalhado na seção 5.3.2 O reator foi empacotado dentro de uma tubulação de PVC de 2 pol. de diâmetro. Os espaços entre a tubulação de PVC e o reator foram selados com teflon e silicone, de forma que o líquido e o gás só poderiam se movimentar dentro do reator. O sistema foi composto por: um distribuidor (static mixer), constituído por duas regiões de recheio estruturado específico, um reator monolítico contido dentro da tubulação de PVC e um sistema de alimentação de gás e de líquido com seus respectivos rotâmetros. O distribuidor de gás e líquido foi acoplado na parte superior do conjunto contendo o reator monolítico. 


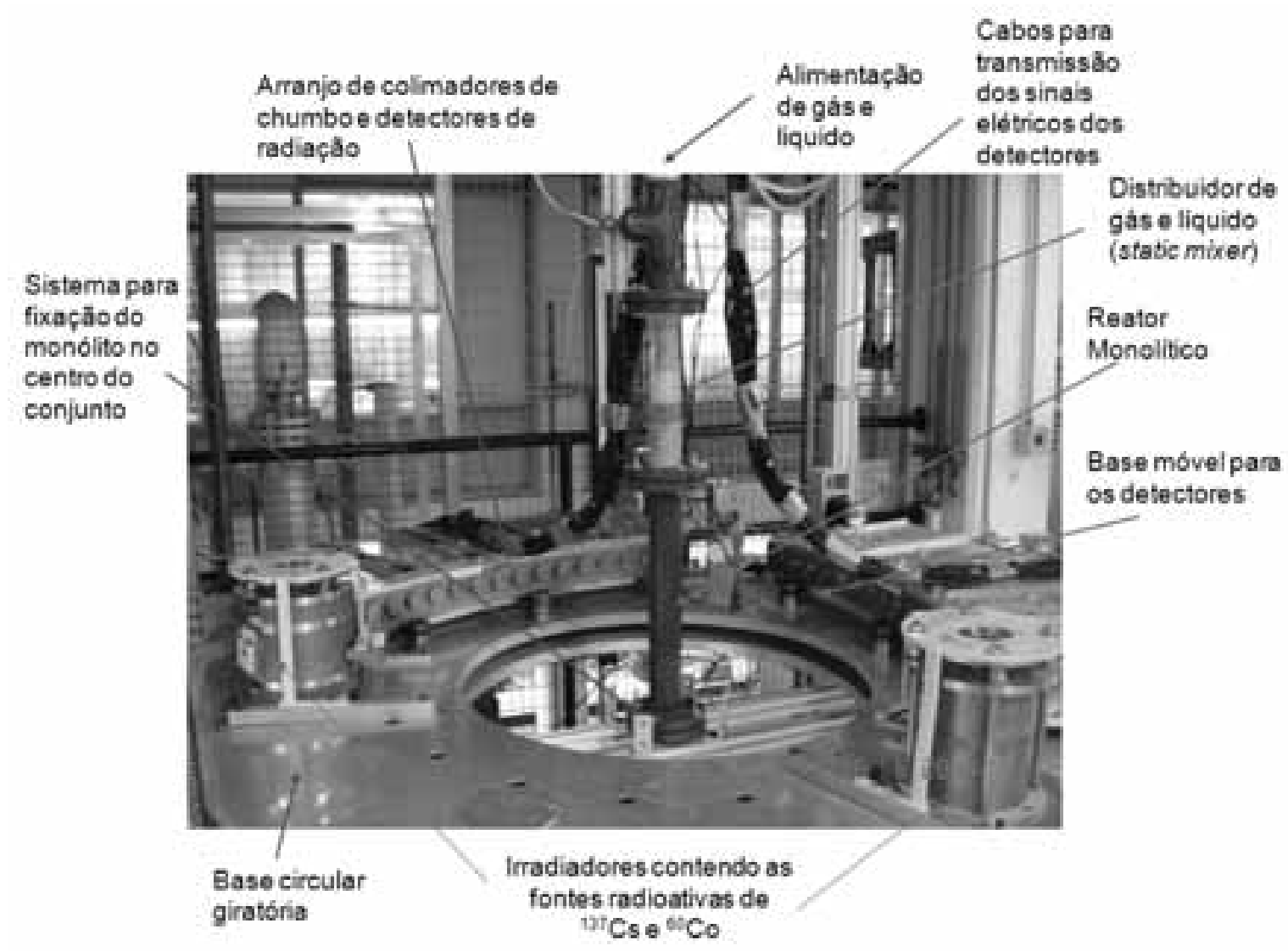

FIGURA 57 - Detalhe do reator monolitico instalado no centro do sistema DSCT.

A FIGURA 58 mostra o esquema do funcionamento do reator usado. A TABELA 21 apresenta as principais características do monólito utilizado. As tomografias foram realizadas em três níveis definidos pela relação do comprimento do reactor (L) pelo diâmetro do mesmo (D): $\mathrm{L} / \mathrm{D}=2, \mathrm{~L} / \mathrm{D}=5$ e $\mathrm{L} / \mathrm{D}=7$.

TABELA 21 - Características do reator monolítico.

\begin{tabular}{|c|c|}
\hline \multicolumn{2}{|c|}{ Reator monolítico } \\
\hline Material de fabricação & $\begin{array}{c}\text { Cordierite } \\
\text { (alumina silicato de magnésio) }\end{array}$ \\
\hline OFA fração de vazio $(\%)$ & 81,2 \\
\hline GSA área superficial geométrica $\left(\mathrm{m}^{2} / \mathrm{m}^{3}\right)$ & 3,57 \\
\hline Diâmetro Hidráulico $d_{h}(\mathrm{~mm})$ & 0,91 \\
\hline Espessura de parede $t_{w}(\mathrm{~mm})$ & 0,1 \\
\hline Densidade de célula $\mathrm{n}(\mathrm{cpsi})$ & 633 \\
\hline
\end{tabular}




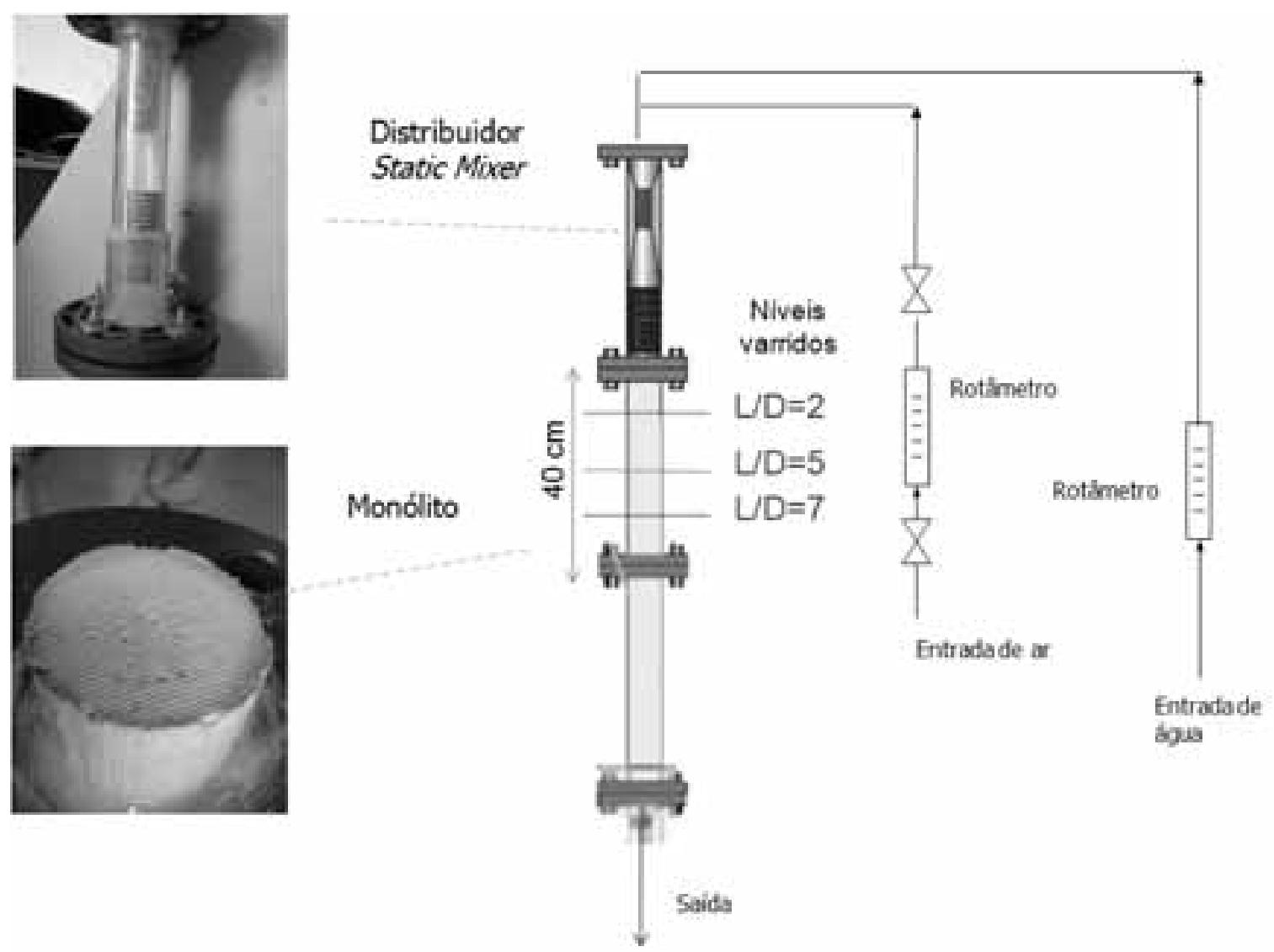

FIGURA 58 - Esquema do reator monolítico operado em co-corrente. Detalhe do distribuidor. Niveis escaneados pelo DSCT L/D=2, 5 e 7.

A TABELA 22 apresenta as condições experimentais aplicadas neste estudo. $\mathrm{O}$ reator foi operado em co-corrente a pressão atmosférica, com intervalos de velocidades superficiais de gás entre 13 e $100 \mathrm{~cm} / \mathrm{s}$ e do líquido entre 5 e $26 \mathrm{~cm} / \mathrm{s}$; dentro do regime de Tay lor, pois a maioria das aplicações industriais en contram-se dentro destas condições (ver seção 9.3). 
TABELA 22 - Condições exp erimentais das velocidades superficiais de gás e de líquido.

\begin{tabular}{|c|c|c|c|c|c|}
\hline & & \multicolumn{4}{|c|}{ Velocidade superficial do líquido $\left(\mathrm{u}_{\mathrm{L}}\right), \mathrm{cm} / \mathrm{s}$} \\
\hline \multirow{5}{*}{ 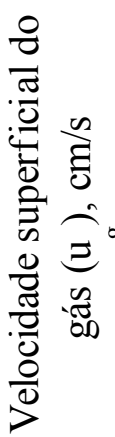 } & & 5 & 10 & 20 & 26 \\
\hline & 13 & • & • & • & $\checkmark$ \\
\hline & 20 & • & • & • & $\checkmark$ \\
\hline & 50 & $\checkmark$ & $\checkmark$ & $\checkmark$ & $\checkmark$ \\
\hline & 100 & $\checkmark$ & $\checkmark$ & $\checkmark$ & $\checkmark$ \\
\hline
\end{tabular}

(• ) Kreutzer, 2003; Bakker, 2003; Yawalkar et al., 2005; Bercic \& Pintar, 1997; Nijhius et al. 2001; Kreutzer et al. 2001.

$(\bullet / \checkmark)$ Mishima et al., 1996; Roy, 2006; este trabalho.

\subsubsection{Condições de operação do tomógrafo DSCT}

Desta forma, foram realizadas 16 tomografias por nível, contabilizando um total de 48 (16 x 3 níveis). Para a reconstrução de imagens foi utilizado o algoritmo MAPE citado na seção 7.4. O sistema trabalhou com 15 detectores por cada arranjo (total 30). Foram obtidas 315 projeções por ângulo para 197 posições das fontes (ângulos), somando um total de 62.055 (315 x 197) projeções por fonte. O tempo de contagem foi fixado em 0,1 s (10 Hz.). As imagens foram reconstruídas usando-se uma resolução de 60 x 60 pixels. Quando processados, somente foram analisados os dados das projeções criadas pelos detectores que se encontravam na região da coluna (diâmetro 2 pol.). 


\subsection{Resultados e Discussão}

\subsubsection{Distribuição transversal do holdup}

As distribuições de holdup do líquido $\varepsilon_{l}$ e de holdup do gás $\varepsilon_{g}$ foram determinadas utilizando-se o algoritmo para reconstrução MAPE. Os detalhes deste procedimento encontram-se na seção 7.4. Os resultados representaram a média dos dados obtidos no intervalo do tempo usado para efetuar a tomografia (time averaged).

A FIGURA 59 e a FIGURA 60 mostram as distribuições de holdup do gás e do líquido para $\mathrm{L} / \mathrm{D}=2$, respectivamente. A FIGURA 61 e a FIGURA 62 mostram as distribuições de holdup do gás e do líquido para $\mathrm{L} / \mathrm{D}=5$, respectivamente. A FIGURA 63 e a FIGURA 64 mostram as distribuições de holdup do gás e do líquido para L/D=7, respectivamente. De maneira geral e como era esperado, para todos os níveis estudados, o holdup do gás aumentou com o incremento da vazão de gás, assim como, o holdup do líquido aumentou com o incremento da vazão do mesmo (mudança da cor do gráfico de azul a laranja). Analisando as imagens do holdup do líquido, pode ser verificado que a baixas velocidades do líquido, este foi distribuído só na parte externa do monólito (anel), melhorando com o aumento da velocidade. Falta de uniformidade foi observada para quase todos os casos. Este fato revelou de forma preliminar a má distribuição para o líquido e o gás. Como explicado em seções anteriores, no caso de sistemas com 3 fases, sólido líquido e gás; a soma do holdup de cada uma delas deve ser igual a unidade $\left(\varepsilon_{S}+\varepsilon_{g}+\varepsilon_{L}=1\right)$. 


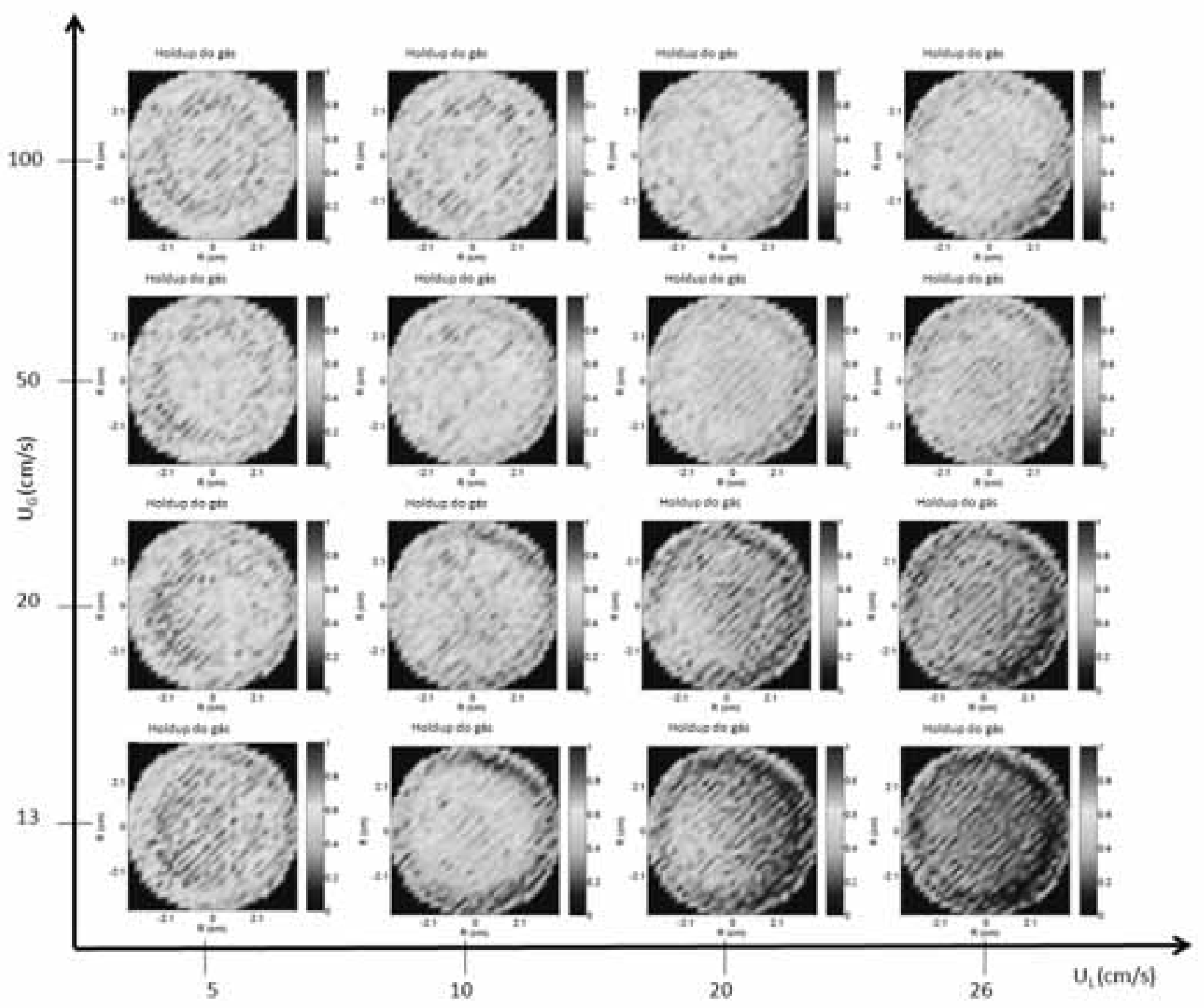

FIGURA 59 - Distribuição do holdup do gás para $L / D=2$. 


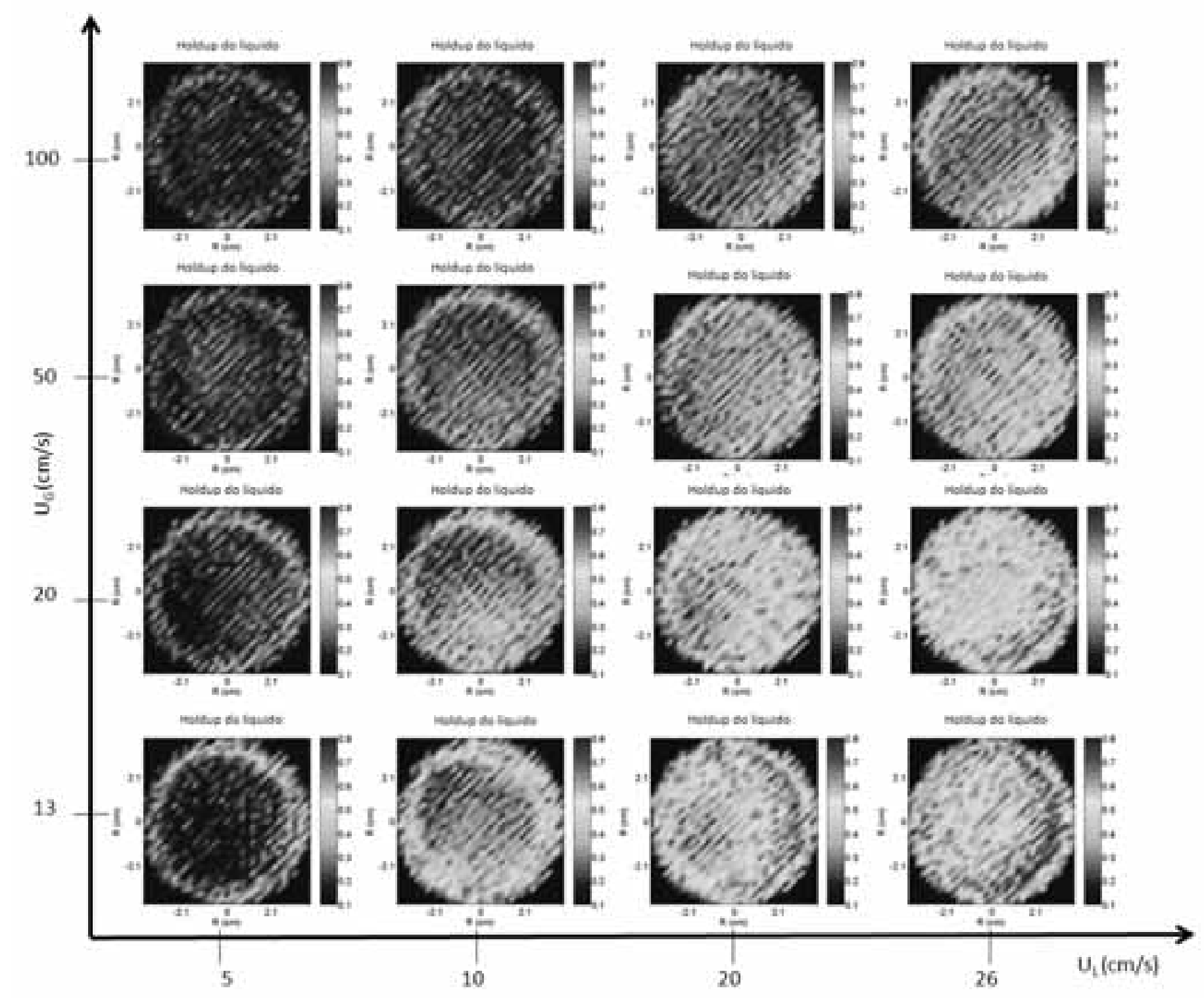

FIGURA 60 - Distribuição do holdup do líquido para $L / D=2$. 


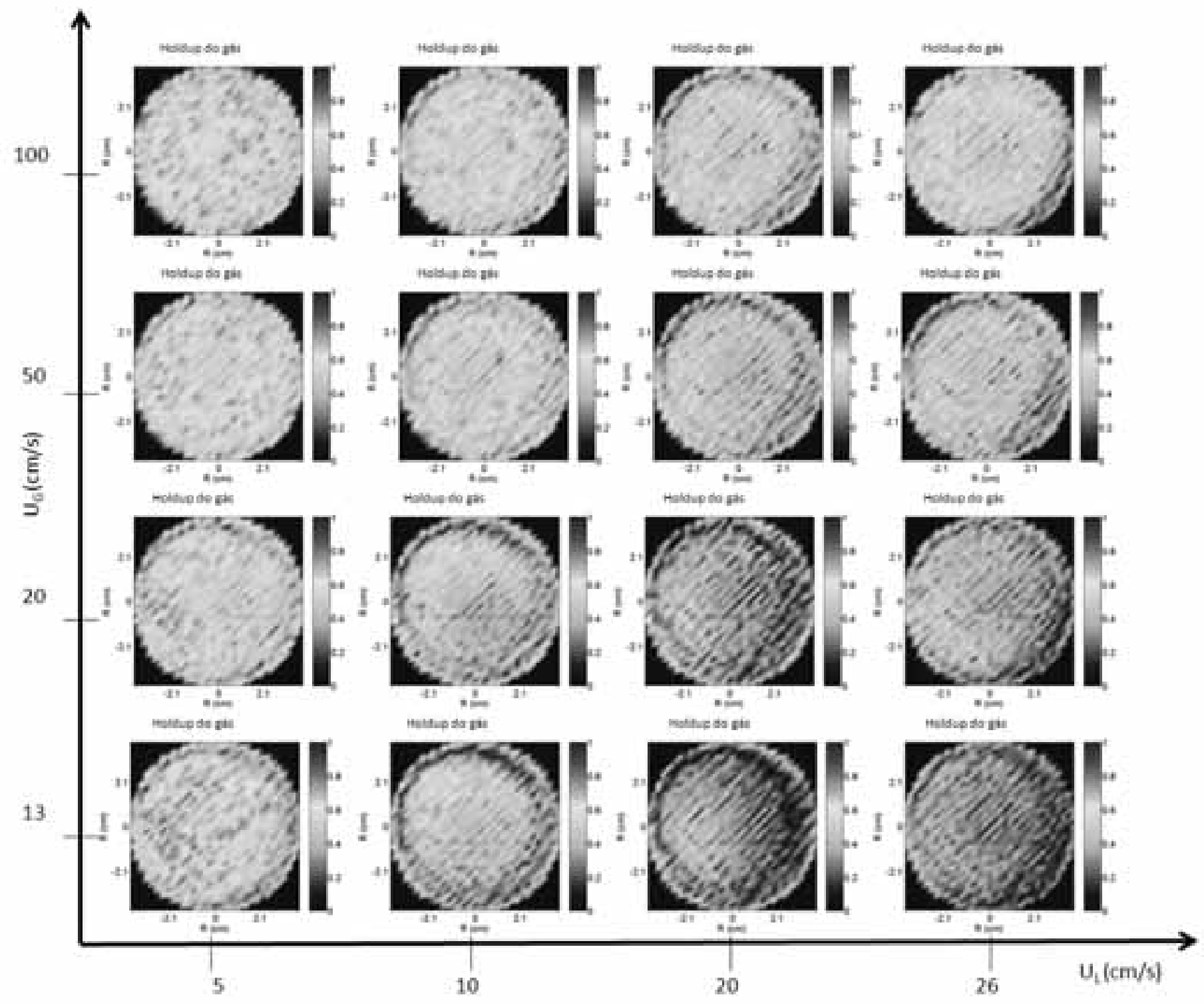

FIGURA 61 - Distribuição do holdup do gás para $L / D=5$. 


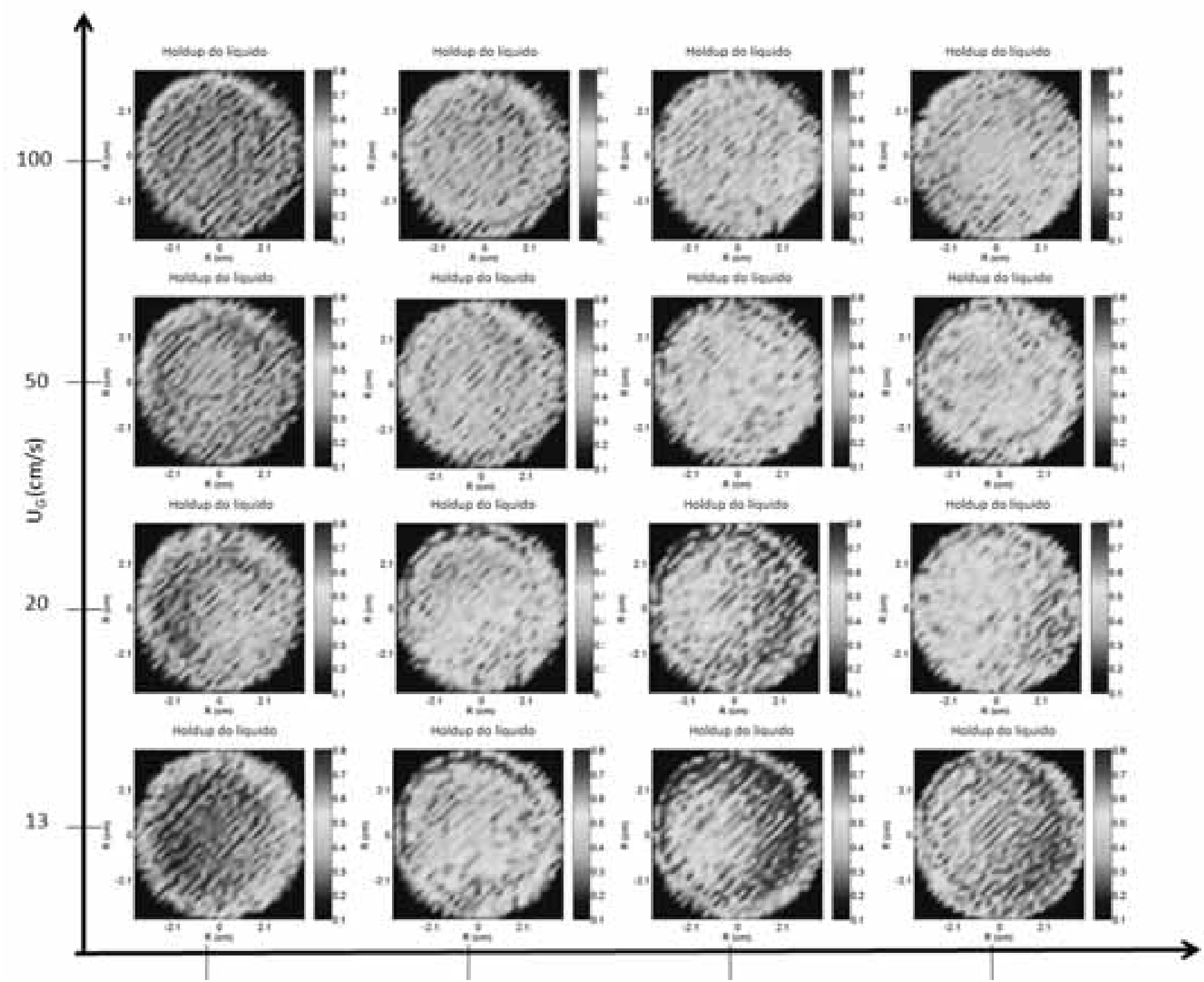

FIGURA 62 - Distribuição do holdup do líquido para $L / D=5$. 


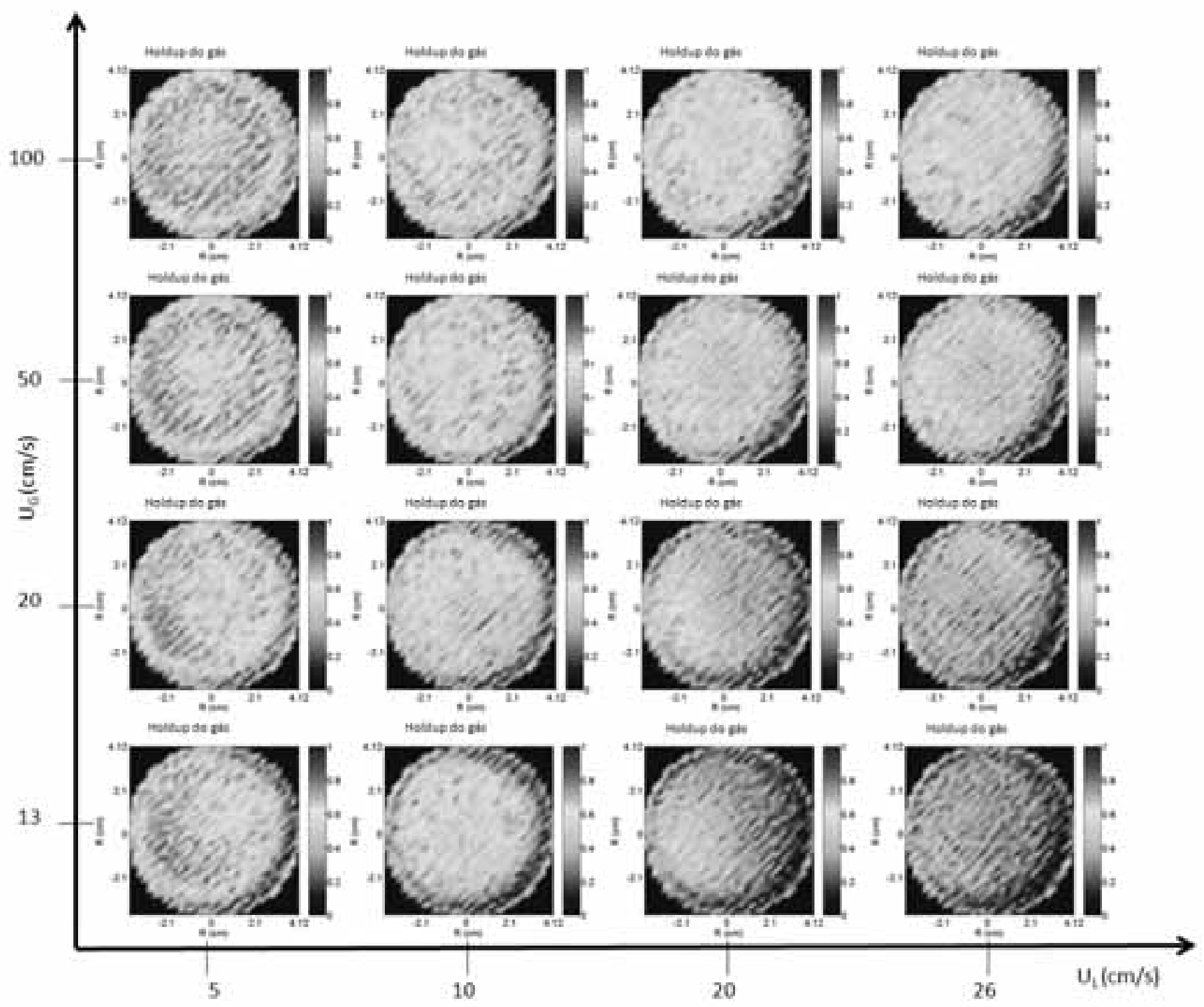

FIGURA 63 - Distribuição do holdup do gás para $L / D=7$. 


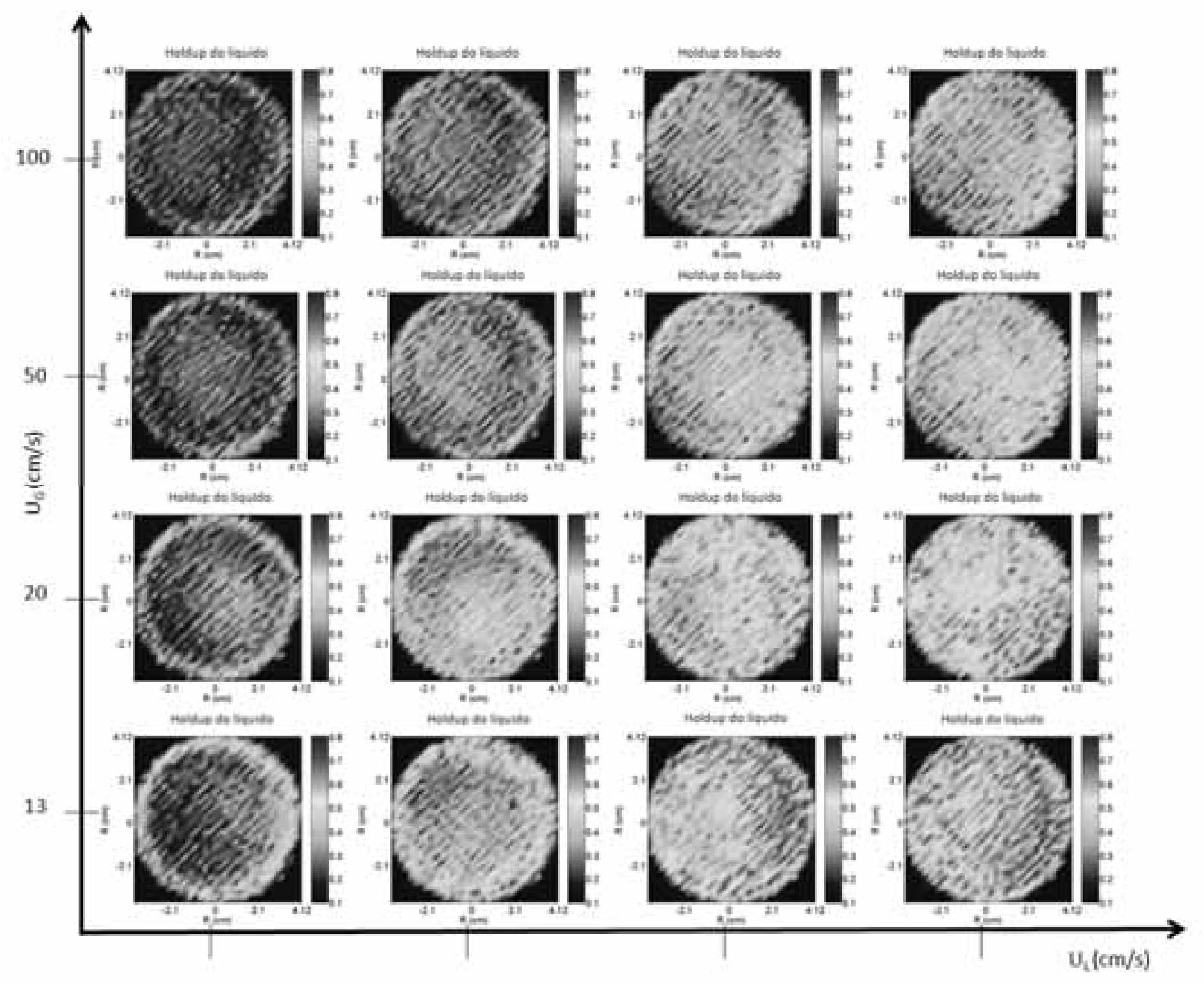

FIGURA 64 - Distribuição do holdup do líquido para $L / D=7$. 

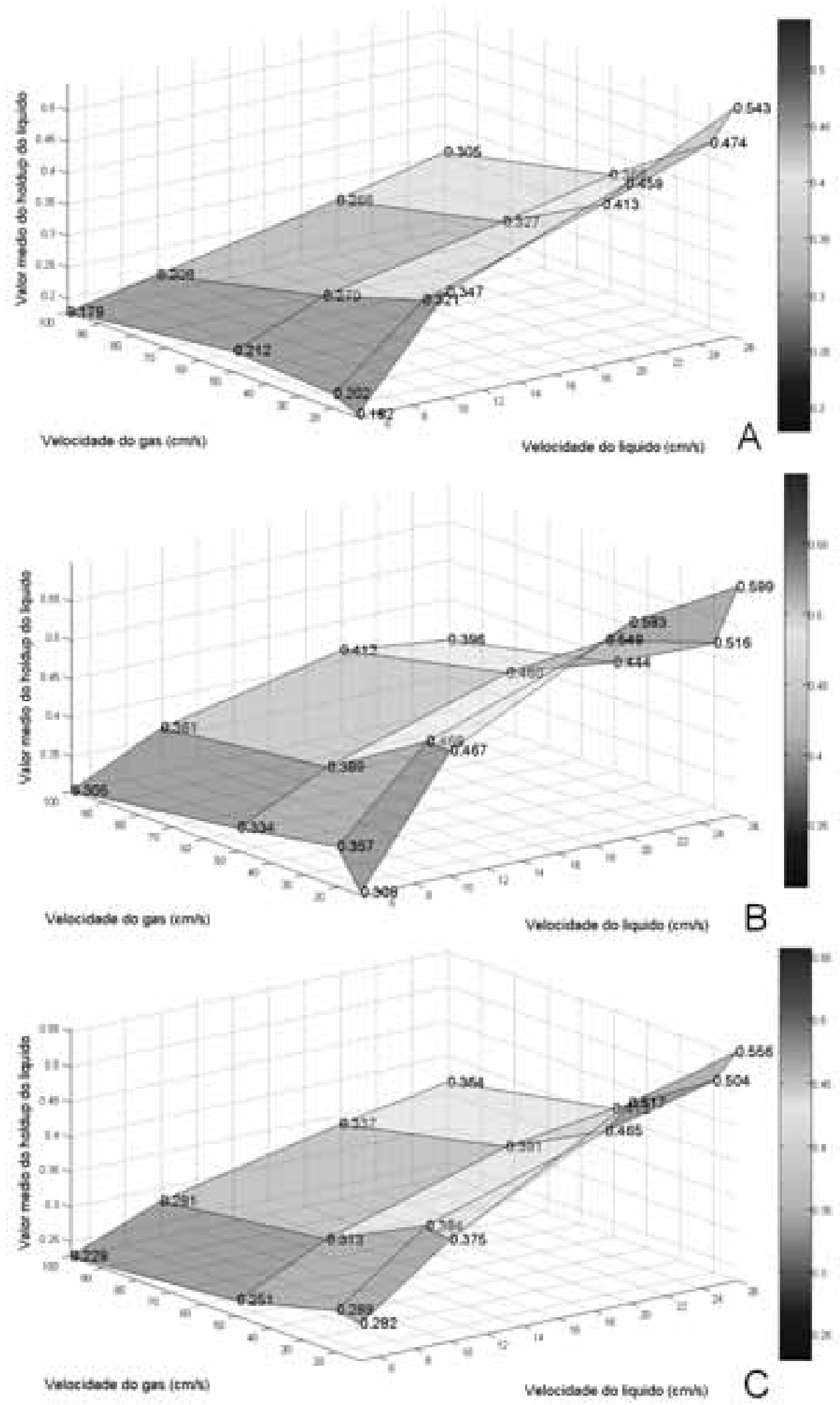

FIGURA 65 - Valores médios do holdup para (A) $L / D=2$, (B) $L / D=5$, (C) $L / D=7$ 
A FIGURA 65 mostra os valores médios do holdup do líquido para as condições analisadas nos níveis $L / D=1, L / D=2$ e $L / D=3$. Estes valores foram calculados utilizando-se a equação ( 79 ). Os resultados confirmaram que, ao longo do reator o holdup do líquido foi aumentando até atingir os maiores valores para $\mathrm{L} / \mathrm{D}=5$, para $\operatorname{logo}$ diminuir em $\mathrm{L} / \mathrm{D}=7$. Esta diminuição não atingiu os valores mais baixos, encontrados para $\mathrm{L} / \mathrm{D}=2$. A variação do holdup de líquido foi maior para as regiões de altas velocidades de gás e baixas de líquido $(\sim 50 \%-70 \%)$ do que para as regiões de alta velocidade de líquido e baixa de gás ( $7 \%-15 \%)$. Este problema pode ser atribuído as características do distribuidor, que poderia provocar quedas de pressão significativas em função das velocidades dos fluidos estudados.

\subsubsection{Distribuição radial do holdup}

Para poder analisar a distribuição de uma melhor forma foi necessário calcular a distribuição do holdup radial do líquido, seguindo o procedimento mostrado na seção 6.2.3. Este valor representou a média azimutal do holdup calculada em forma de anéis concêntricos a partir do centro geométrico do sistema. A FIGURA 66 e a FIGURA 67 mostram a influência da velocidade do gás e a influência da velocidade do líquido na distribuição do holdup do líquido, respectivamente para $\mathrm{L} / \mathrm{D}=2$. A FIGURA 68 e a FIGURA 69 apresentam a influência da velocidade do gás e a influência da velocidade do líquido na distribuição do holdup do líquido para L/D=5. A FIGURA 70 e a FIGURA 71 mostram a influência da velocidade do gás e a influência da velocidade do líquido na distribuição do holdup do líquido para $\mathrm{L} / \mathrm{D}=7$. 
Os resultados demonstraram que a distribuição do holdup do líquido foi influenciada com maior intensidade pela variação das velocidades tanto do gás quanto do líquido na entrada do reator $\mathrm{L} / \mathrm{D}=2$. Esta variação foi mais uniforme para $\mathrm{L} / \mathrm{D}=5$ e $\mathrm{L} / \mathrm{D}=7$. O holdup do líquido aumentou e diminuiu levemente quando se aproximou das paredes do reator, podendo-se atribuir este comportamento ao distribuidor. 

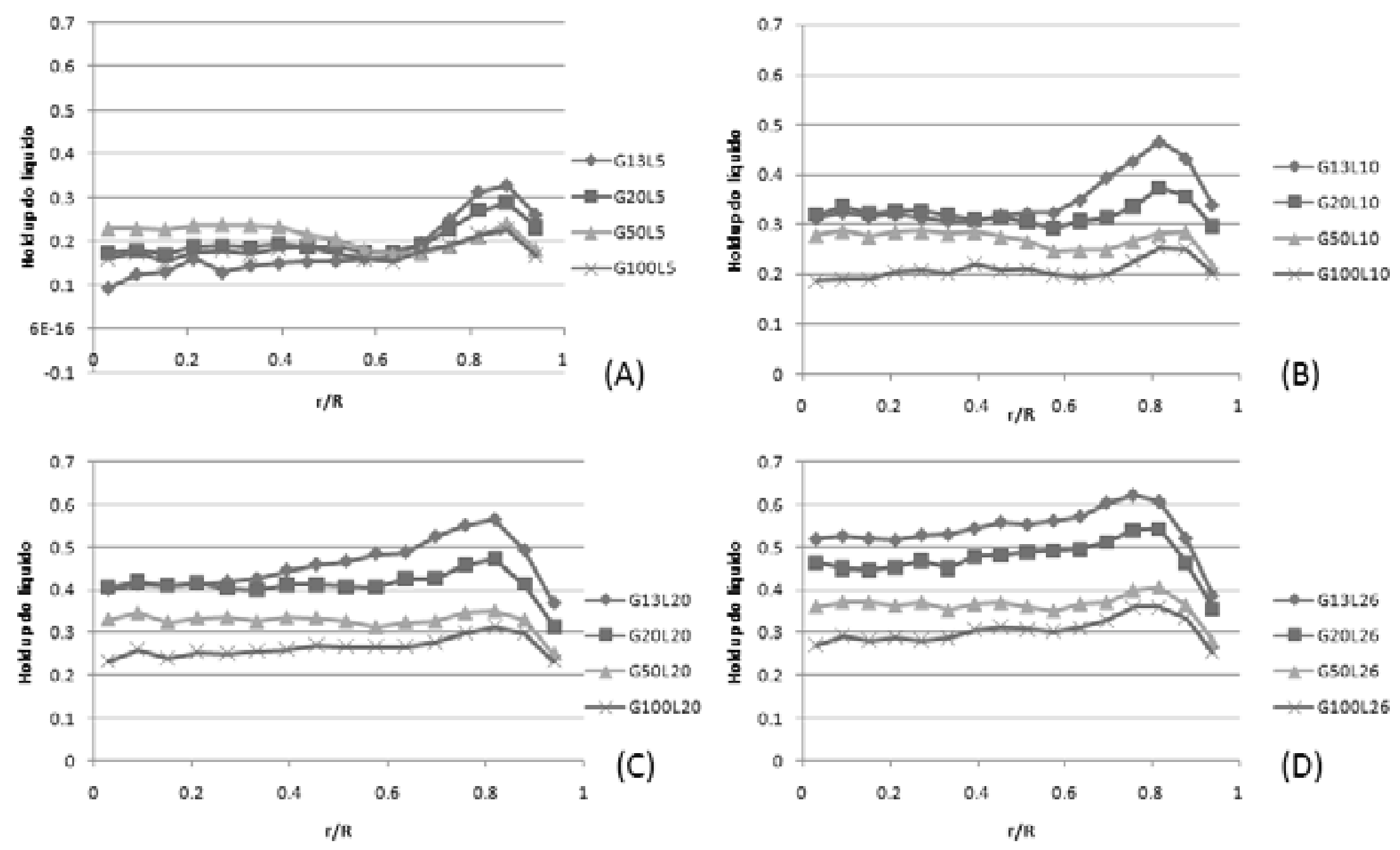

FIGURA 66 - Influência da velocidade do gás na distribuição radial do holdup do líquido para $L / D=2:(A) U_{L}=5 \mathrm{~cm} / \mathrm{s}$, (B) $U_{L}=10 \mathrm{~cm} / \mathrm{s}$, (C) $U_{L}=20 \mathrm{~cm} / \mathrm{s}$ e (D) $U_{L}=26 \mathrm{~cm} / \mathrm{s}$ 

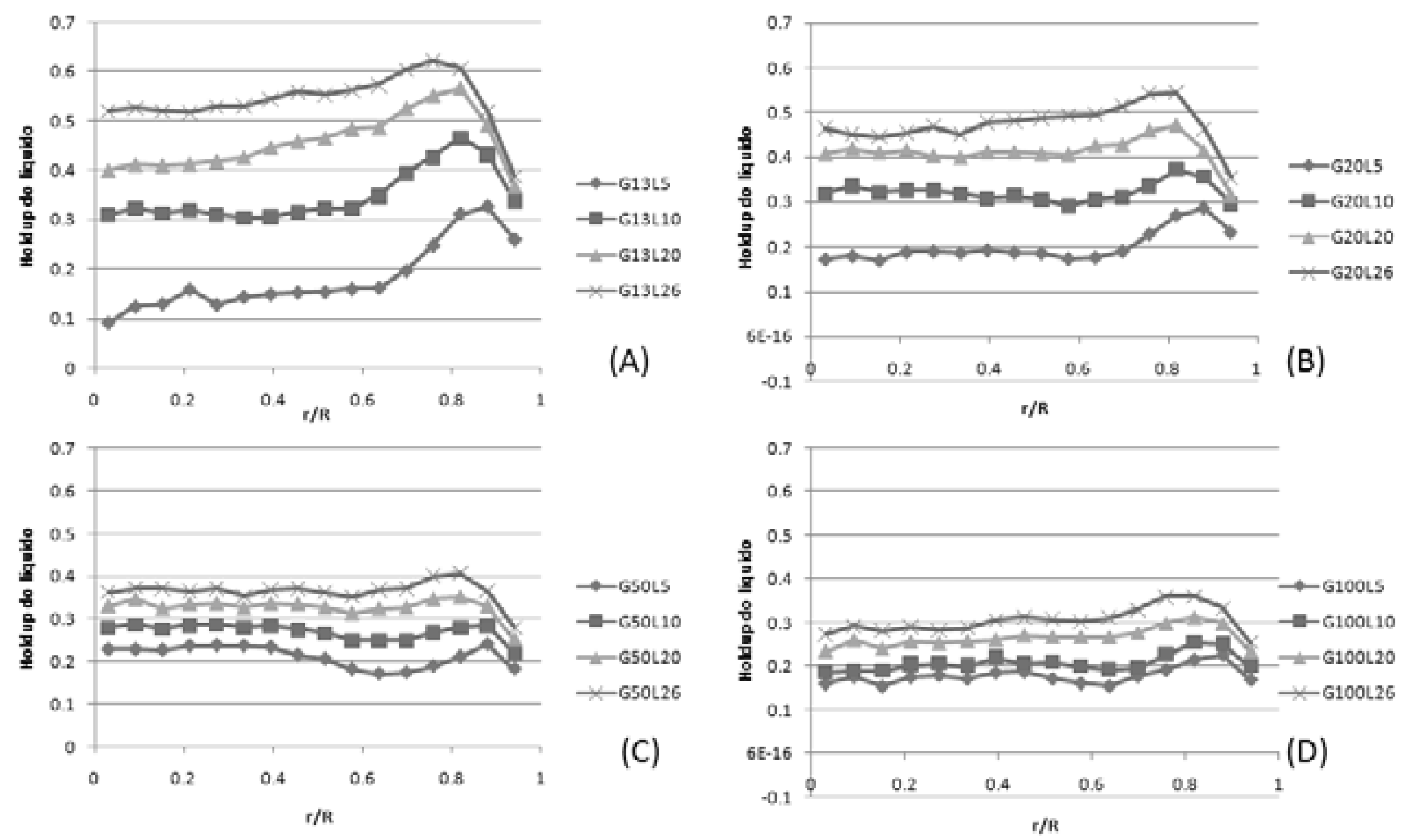

FIGURA 67 - Influência da velocidade do líquido na distribuição radial do holdup do líquido para $L / D=2$. (A) $U_{G}=13 \mathrm{~cm} / \mathrm{s}$, (B) $U_{G}=20 \mathrm{~cm} / \mathrm{s}$, (C) $U_{G}=50 \mathrm{~cm} / \mathrm{s}$ e (D) $U_{G}=100 \mathrm{~cm} / \mathrm{s}$ 

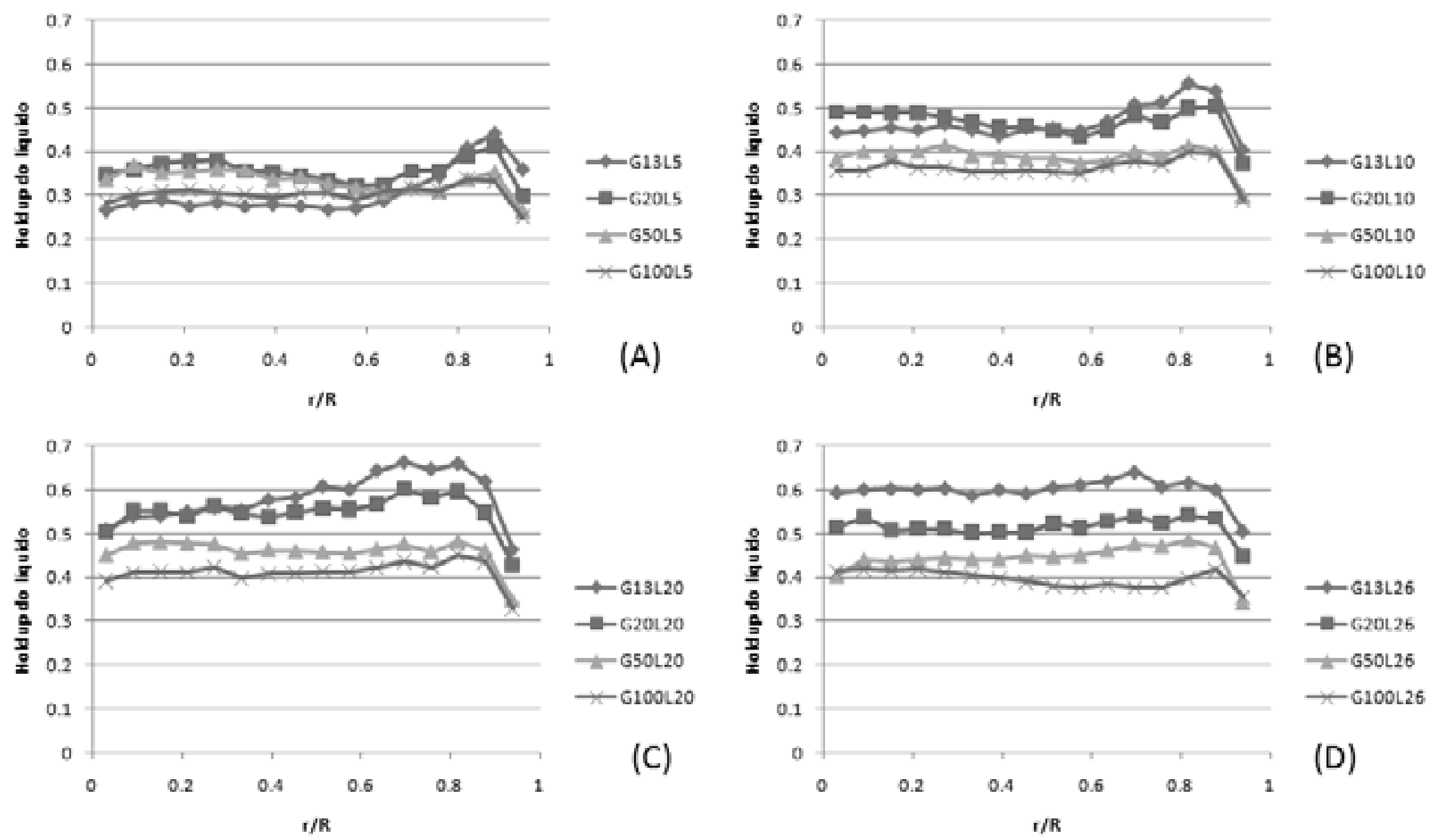

FIGURA 68 - Influência da velocidade do gás na distribuição radial do holdup do líquido para $L / D=5$. (A) $U_{L}=5 \mathrm{~cm} / \mathrm{s}$, (B) $U_{L}=10 \mathrm{~cm} / \mathrm{s}$, (C) $U_{L}=20 \mathrm{~cm} / \mathrm{s}$ e (D) $U_{L}=26 \mathrm{~cm} / \mathrm{s}$ 

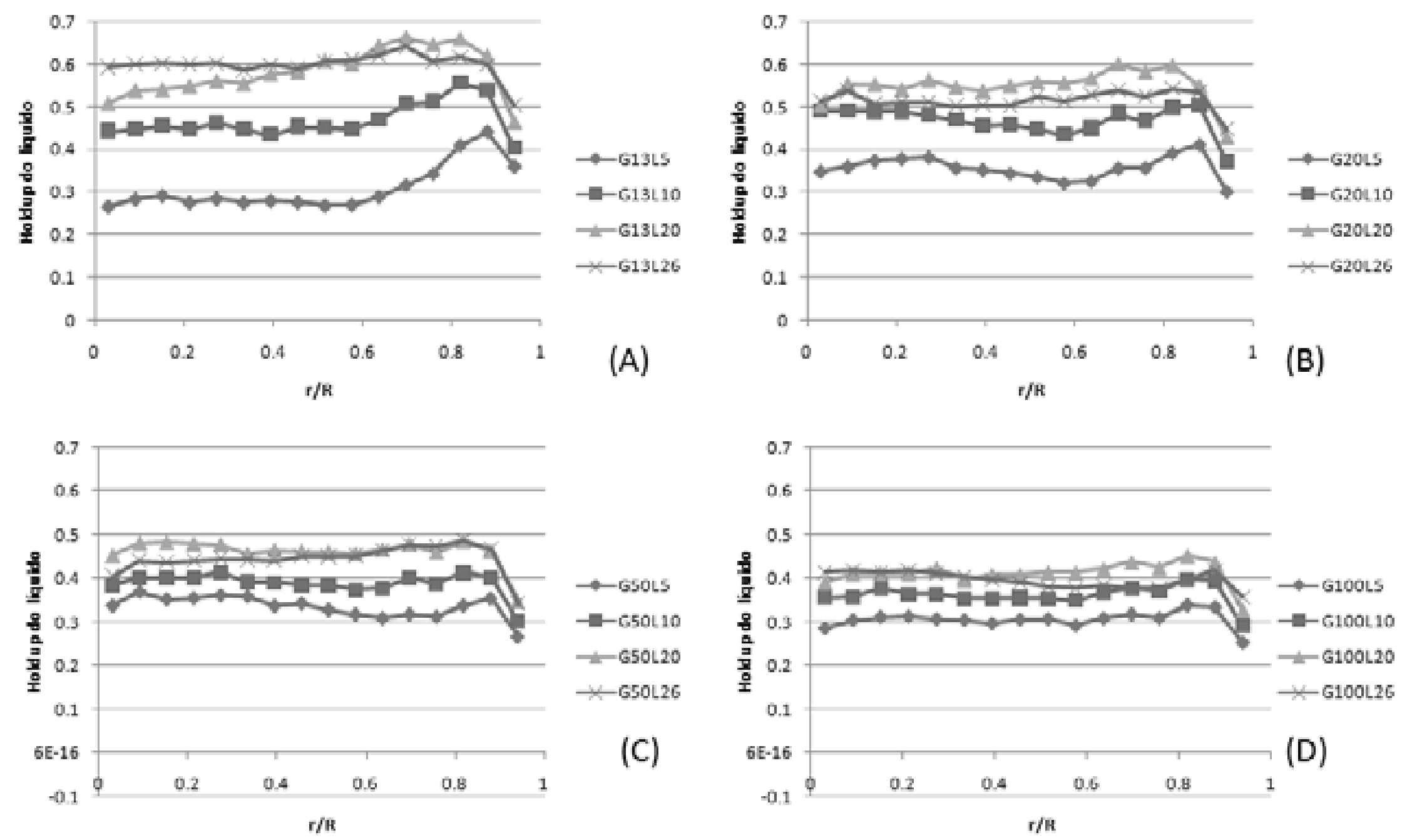

FIGURA 69 - Influência da velocidade do líquido na distribuição radial do holdup do líquido para $L / D=5 . U_{G}=13 \mathrm{~cm} / \mathrm{s}$, (B) $U_{G}=20 \mathrm{~cm} / \mathrm{s}$, (C) $U_{G}=50 \mathrm{~cm} / \mathrm{s}$ e (D) $U_{G}=100 \mathrm{~cm} / \mathrm{s}$ 

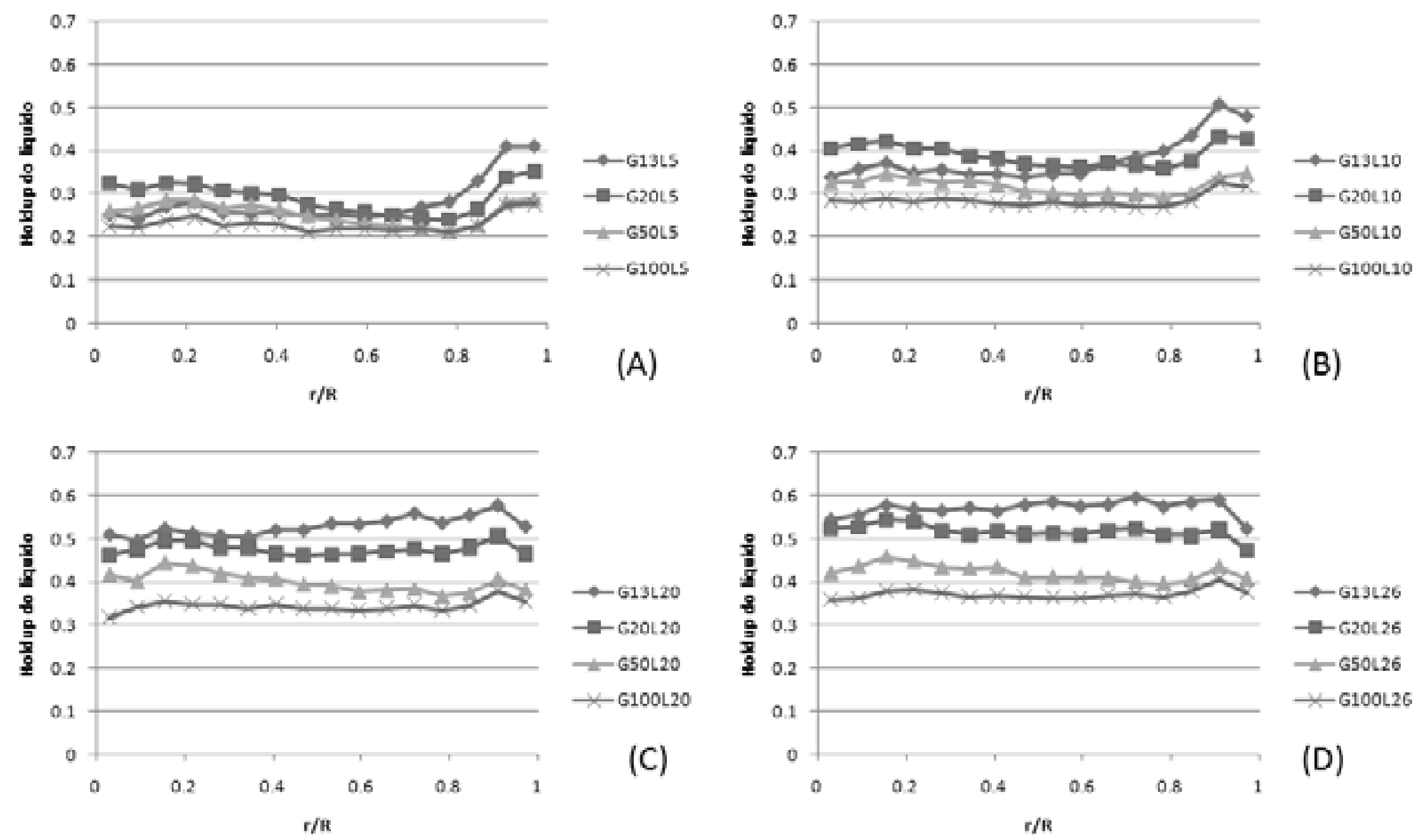

FIGURA 70 - Influência da velocidade do gás na distribuição radial do holdup do líquido para $L / D=7$. (A) $U_{L}=5 \mathrm{~cm} / \mathrm{s}$, (B) $U_{L}=10 \mathrm{~cm} / \mathrm{s}$, (C) $U_{L}=20 \mathrm{~cm} / \mathrm{s}$ e (D) $U_{L}=26 \mathrm{~cm} / \mathrm{s}$ 

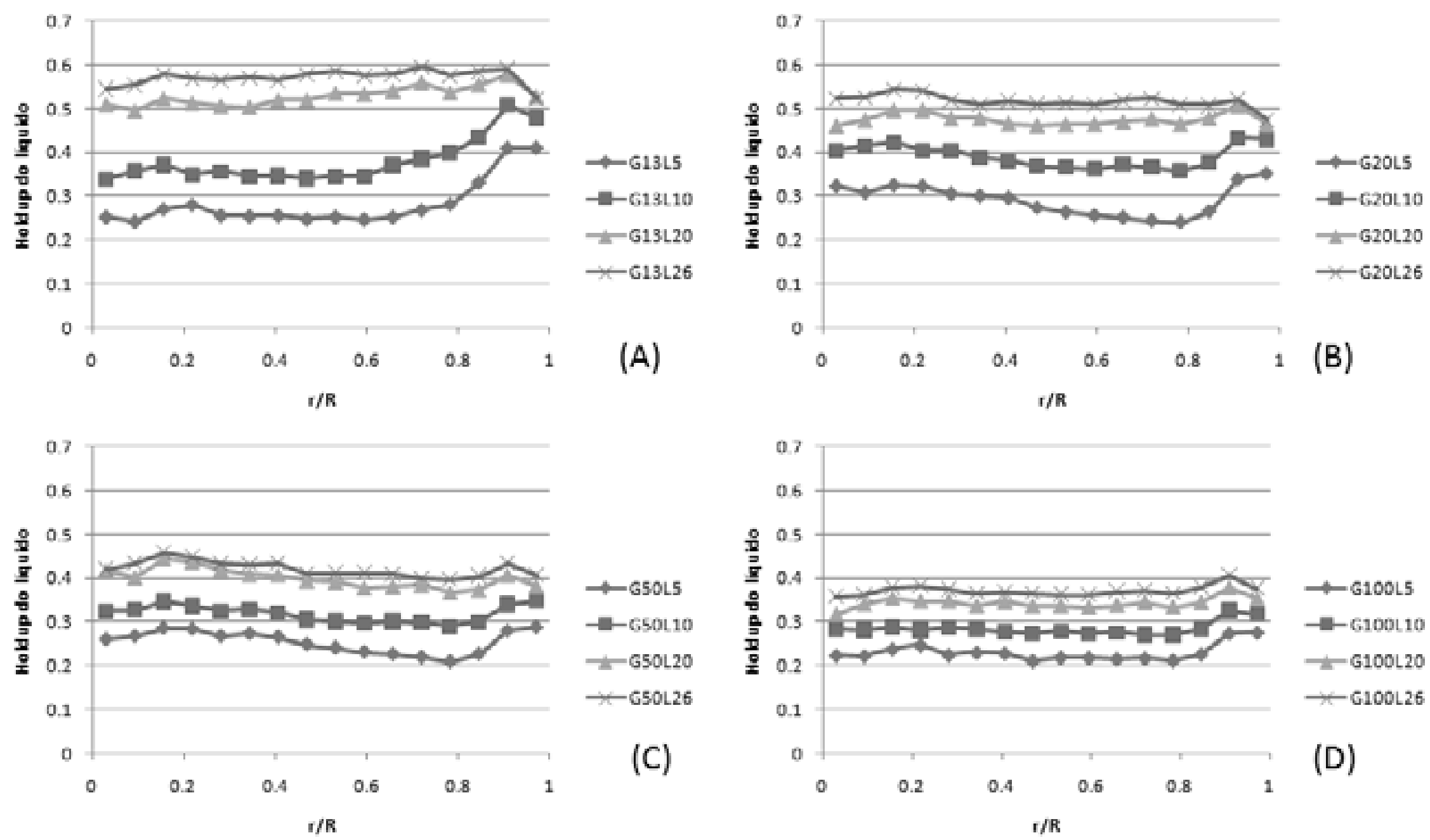

FIGURA 71 - Influência da velocidade do líquido na distribuição radial do holdup do líquido para $L / D=7$. (A) $U_{G}=13 \mathrm{~cm} / \mathrm{s}$, (B) $U_{G}=20 \mathrm{~cm} / \mathrm{s}$, (C) $U_{G}=50 \mathrm{~cm} / \mathrm{s}$ e (D) $U_{G}=100 \mathrm{~cm} / \mathrm{s}$ 


\subsubsection{Grau de uniformidade}

Para poder quantificar a uniformidade da distribuição de holdup transversal do líquido é necessário analisar os resultados utilizando-se um método estatístico. O grau de má distribuição ou uniformidade foi definido, calculando-se o desvio padrão da distribuição de holdups com relação à média obtida da distribuição radial $\bar{\varepsilon}$ (Roy, 2006; Al-Dahhan et al., 2007). Este método calculou o desvio padrão como um valor ponderado pela área $A_{i, j}$ de cada ponto da distribuição em relação à área total $A_{\text {tot }}$, como indicado na equação ( 84 ):

$$
\sigma=\sqrt{\sum_{x \in X} \frac{A_{x}}{A_{t o t}}\left(\frac{\varepsilon_{x}-\bar{\varepsilon}}{\bar{\varepsilon}}\right)^{2}}
$$

Quando $\sigma=0$, significa que há uma distribuição ideal uniforme. De forma geral, os menores valores de $\sigma$ significam maior uniformidade. A TABELA 23, a TABELA 24 e a TABELA 25 apresentam os resultados do grau de uniformidade para o holdup do líquido para $\mathrm{L} / \mathrm{D}=2, \mathrm{~L} / \mathrm{D}=5$ e $\mathrm{L} / \mathrm{D}=7$, respectivamente. 
TABELA 23 - Grau de uniformidade $\sigma$ representado pelo desvio padrão da distribuição do holdup do líquido para $\mathrm{L} / \mathrm{D}=2$.

\begin{tabular}{|c|c|c|c|c|c|}
\hline & & \multicolumn{4}{|c|}{$\begin{array}{l}\text { Velocidade superficial do } \\
\text { líquido }\left(\mathrm{u}_{\mathrm{L}}\right), \mathrm{cm} / \mathrm{s}\end{array}$} \\
\hline \multirow{5}{*}{ 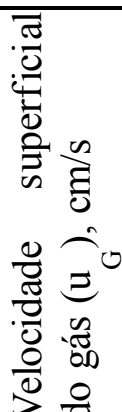 } & & 5 & 10 & 20 & 26 \\
\hline & 13 & 0,3894 & 0,3909 & 0,3198 & 0,3131 \\
\hline & 20 & 0,3632 & 0,3503 & 0,2841 & 0,273 \\
\hline & 50 & 0,4623 & 0,3097 & 0,2927 & 0,2746 \\
\hline & 100 & 0,6587 & 0,3382 & 0,2886 & 0,2515 \\
\hline
\end{tabular}

TABELA 24 - Grau de uniformidade representado pelo desvio padrão da distribuição do holdup do líquido para $\mathrm{L} / \mathrm{D}=5$.

\begin{tabular}{|c|c|c|c|c|c|}
\hline & & \multicolumn{4}{|c|}{$\begin{array}{l}\text { Velocidade superficial do } \\
\text { líquido }\left(\mathrm{u}_{\mathrm{L}}\right), \mathrm{cm} / \mathrm{s}\end{array}$} \\
\hline \multirow{5}{*}{ 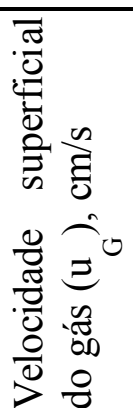 } & & 5 & 10 & 20 & 26 \\
\hline & 13 & 0,3238 & 0,2899 & 0,2803 & 0,3321 \\
\hline & 20 & 0,2949 & 0,2847 & 0,2832 & 0,2353 \\
\hline & 50 & 0,3073 & 0,2799 & 0,2877 & 0,2036 \\
\hline & 100 & 0,3528 & 0,2889 & 0,2831 & 0,1859 \\
\hline
\end{tabular}

TABELA 25 - Grau de uniformidade representado pelo desvio padrão da distribuição do holdup do líquido para $\mathrm{L} / \mathrm{D}=7$.

\begin{tabular}{|c|c|c|c|c|c|}
\hline & & \multicolumn{4}{|c|}{$\begin{array}{ll}\text { Velocidade superficial do } & \text { do } \\
\text { líquido }\left(\mathrm{u}_{\mathrm{L}}\right), \mathrm{cm} / \mathrm{s} & \\
\end{array}$} \\
\hline \multirow{5}{*}{ 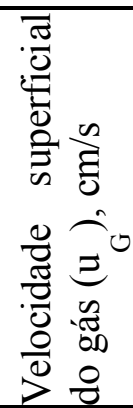 } & & 5 & 10 & 20 & 26 \\
\hline & 13 & 0,3289 & 0,2713 & 0,2493 & 0,2518 \\
\hline & 20 & 0,3128 & 0,2567 & 0,2297 & 0,2318 \\
\hline & 50 & 0,3065 & 0,2373 & 0,2432 & 0,2194 \\
\hline & 100 & 0,3992 & 0,2978 & 0,2373 & 0,2192 \\
\hline
\end{tabular}


Os dados apresentados nas tabelas anteriores são melhor visualizados na FIGURA 72 onde podem ser diferenciadas as regiões de distribuição mais uniforme com cor azul. Para todas as velocidades de gás estudadas e para todos os níveis escaneados, houve má distribuição nas regiões de baixa velocidade do líquido e alta velocidade do gás. A distribuição melhorou com velocidades de gás maiores que 20 $\mathrm{cm} / \mathrm{s}$ para $\mathrm{L} / \mathrm{D}=2$ e $\mathrm{L} / \mathrm{D}=5$. Uma melhor uniformidade foi obtida para $\mathrm{L} / \mathrm{D}=7$. De forma geral, com o incremento da velocidade do líquido, a distribuição foi mais uniforme.

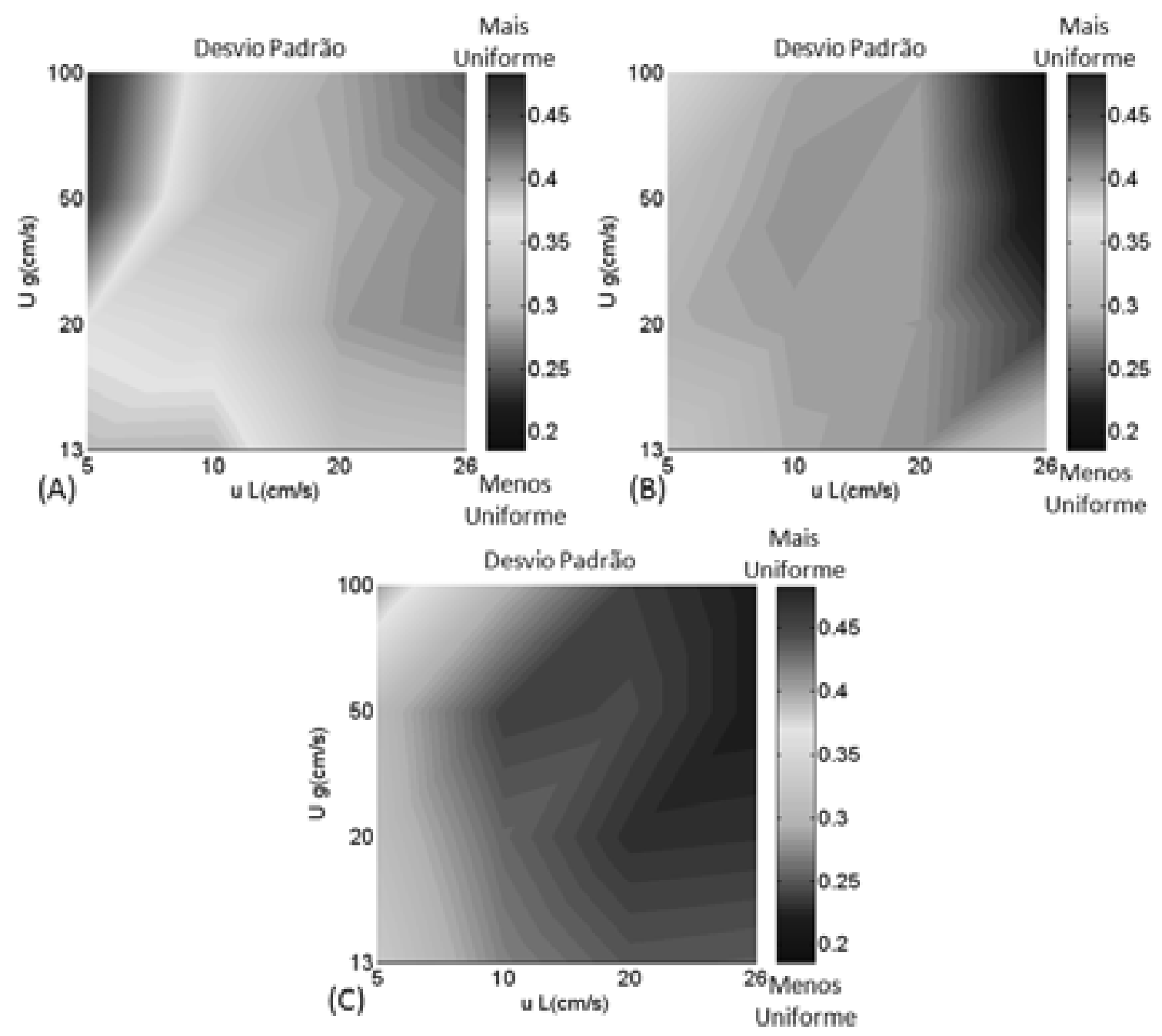

FIGURA 72 - Grau de uniformidade para (A) $L / D=2$, (B) $L / D=5$, (C) $L / D=7$. Valores baixos significam maior uniformidade (azul). 


\subsubsection{Imagens 3D}

A FIGURA 73 mostra um exemplo de reconstrução 3D da distribuição do holdup do líquido com os dados obtidos das tomografias para $\mathrm{L} / \mathrm{D}=2,5$ e 9 para $\mathrm{U}_{\mathrm{g}}=20 \mathrm{~cm} / \mathrm{s}$ e $\mathrm{U}_{\mathrm{L}}=20 \mathrm{~cm} / \mathrm{s}$, utilizando-se o método de convolução de Gauss ( box Gaussian convolution kernel smoothing voxel).
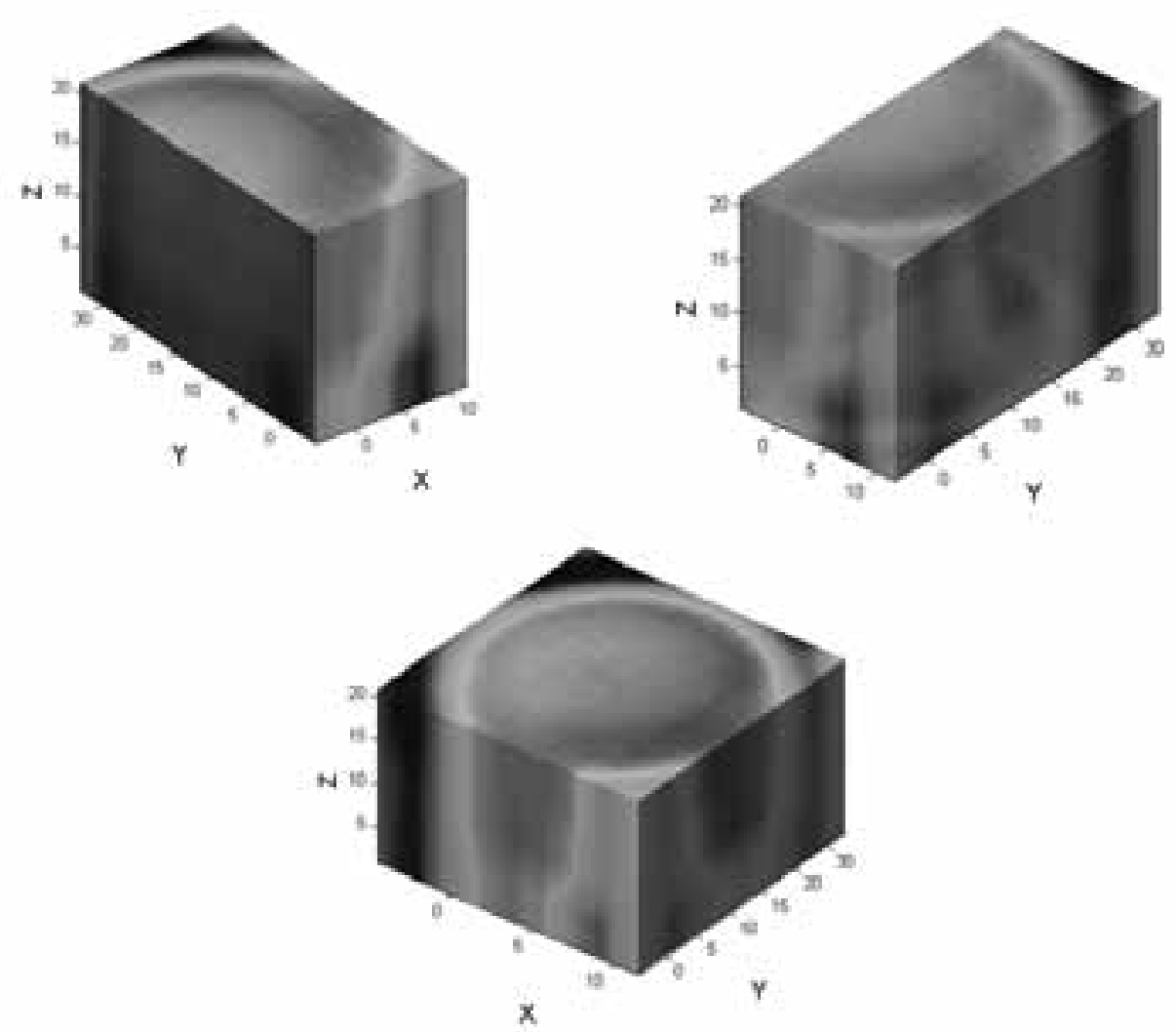

FIGURA 73 - Reconstrução $3 D$ do holdup do líquido para $L / D=2, L / D=5$ e $L / D=7$. 


\subsection{Conclusões}

O DSCT mostrou ser uma ferramenta versátil e útil para o estudo de reatores monolíticos, permitindo a obtenção dos holdups para o gás e o líquido diretamente sem necessidade de varreduras referen ciais (seção 6.2.2).

A distribuição do holdup de gás e líquido em um reator monolítico operado em co-corrente no regime de Taylor foi estudada. O desempenho de um distribuidor (static mixer) foi avaliado para diferentes velocidades de gás e líquido, encontrando-se uma janela para condições de uniformidade. A velocidade do gás afetou a distribuição do holdup do líquido, diminuindo a mesma na região de altas velocidades.

Este foi o primeiro estudo efetuado num reator de $40 \mathrm{~cm}$ de comprimento, onde, foi verificada a variação do holdup do líquido ao longo do mesmo. As informações obtidas são de suma importância para o entendimento do escoamento dentro dos reatores monolíticos e o scale-up dos mesmos. O desenho do distribuidor do líquido e do gás é fundamental e rege o desempenho de um reator monolítico. 


\section{CONCLUSÕES}

\subsection{Desenvolvimento e validação do SSCT}

O SSCT projetado e montado no CTR/IPEN foi validado por meio da análise do phantom enviado pela AIEA. Dos resultados obtidos utilizando a FBP e a MA na determinação das distribuições de coeficientes de atenuação e no cálculo do holdup, pode-se destacar:

- A sofisticação do sistema de aquisição permitiu discriminar as regiões do fotopico sem a influência do Comptom. Nestes sistemas vários detectores podem ser acoplados e analisados simultaneamente.

- A validação do SSCT, foi realizada por meio da análise de um phantom com duas fases. Pela primeira vez obteve-se evidência experimental de que fótons de alta energia $\left({ }^{60} \mathrm{Co}\right)$ podem ser utilizados para avaliar sistemas multifásicos de grande porte.

- O SSCT apresentou alta resolução espacial (abaixo de $2 \mathrm{~mm}$ ) apesar de pobre resolução temporal.

\subsection{Algoritmos para tomografia de processos multifásicos}

Neste estudo, algoritmos relacionados à tomografia de raios gama por transmissão para sistemas com duas e três fases foram estudados. Simulações utilizando-se o método de Monte Carlo foram efetuadas para desenvolver o algoritmo FBP que posteriormente foi aplicado a dados experimentais, validando o 
tomógrafo de fonte única SSCT. No caso da CT de fonte única, os algoritmos de retroprojeção filtrada (FBP), esperança - maximização (EM) e minimização alternativa (MA) foram implementados. Um estudo comparativo detalhado dos algoritmos FBP, EM e MA foi realizado com dados experimentais tomográficos, podendo-se destacar os seguintes aspectos:

- As imagens das distribuições dos coeficientes de atenuação obtidas com o algoritmo MA foram mais precisas do que as obtidas com a EM e a FBP, onde as diferenças mais acentuadas foram encontradas nas regiões do sólido.

- Quando comparadas as imagens adquiridas com os três algoritmos, foram encontrados artefatos e borrões nas imagens obtidas com a FBP. A EM gerou imagens com grãos quando comparadas com as obtidas com a MA, indicando que o algoritmo MA diminui a influência do ruído consideravelmente. As imagens geradas pelo MA são mais estáveis do que as obtidas com o EM, devido ao número de iterações.

- As diferenças no desempenho, especificamente nos materiais de alta atenuação, são atribuídos as simplificações utilizadas na EM na função de atualização e na FBP, devido ao fato de que este algoritmo não toma em conta a natureza estatística da radiação.

- A FBP apresentou-se como uma técnica rápida de reconstrução, mas pouco precisa na definição de materiais de densidade similar.

- Para estudos utilizando fontes ${ }^{137} \mathrm{Cs} \mathrm{e}{ }^{60} \mathrm{Co}$ com tomografia dual, deve-se trabalhar preferivelmente no fotopico de $1332 \mathrm{keV}$ por este apresentar melhores resultados.

Para sistemas com duas fases, a MA permitiu o cálculo das distribuições de holdup para o caso da CT de fonte única. As imagens do holdup foram geradas 
utilizando o método de pós - processamento a partir das imagens das atenuações previamente reconstruídas.

Para sistemas com três fases, foram necessários dados de transmissão de duas energias gama diferentes para obter um sistema de equações adequado. Para o estudo de sistemas de grande diâmetro são requeridos fótons gama de alta energia. Os dados experimentais das projeções foram obtidos por meio de um phantom com três fases, onde foram calculadas as distribuições de holdup, seguindo o método de pós - processamento com a aproximação da minimização alternativa monoenergética (MAME). As imagens geradas por este método apresentaram erro inaceitável.

O algoritmo da minimização alternativa polienergética (MAPE) foi aplicado para determinar as imagens do holdup sem necessidade da aproximação com pós - processamento, podendo-se destacar os seguintes aspectos:

- A aproximação monoenergética utilizada para o problema da CT com duas fontes (extensão do procedimento seguido para o sistema de duas fases) forneceu imagens com valores de erros elevados. Muitos dos pixels destas imagens apresentaram valores negativos ou maiores que a unidades.

- O erro elevado pode ser atribuído ao condicionamento do sistema de equações lineares utilizado na determinação do holdup. O mau condicionamento é atribuído à matriz que contém os valores dos coeficientes de atenuação das fases.

- A alta precisão das imagens das atenuações do sistema com três fases geradas pelo algoritmo monoenergético MA não é suficiente para produzir imagens de holdup precisas. A utilização de fontes de baixa energia pode melhorar a qualidade das imagens, pois assim, os valores dos coeficientes de atenuação 
seriam muito diferentes, melhorando-se o condicionamento do sistema mencionado anteriormente, com a desvantagem de que somente podem ser estudados domínios pequenos.

- $\mathrm{O}$ algoritmo da minimização alternativa polienergética (MAPE) gera imagens do holdup de alta qualidade, enquanto a MAME não funciona. A MAPE não é afetada pelo condicionamento como no caso do MAME, isto porque a MAPE não está baseada no pós - processamento para a determinação do holdup, pois, este é calculado diretamente, permitindo correções dentro do processo iterativo.

- A MAPE é lenta em convergência, e são necessários grandes períodos para o cálculo computacional com número de interações elevadas. A convergência depende dos valores dos coeficientes de atenuação das fases. Quando o contraste entre as fases é baixo, a convergência leva muito tempo.

- Com o algoritmo MAPE, a imagem do holdup da fase do material de alta atenuação converge mais rápido do que as outras imagens, pelo contorno desigual da I-divergência. A I-divergência é a função principal a ser minimizada para a reconstrução das imagens.

- O DSCT foi validado, aplicando-se as técnicas de reconstrução anteriormente mencionadas na análise de um phantom multifásico utilizando fontes de ${ }^{60} \mathrm{Co}$ e ${ }^{137}$ Cs.

\subsection{Distribuição do holdup em sistemas com duas fases}

A técnica para análise de sistemas com duas fases foi detalhada e validada por extenso. Basicamente, esta aproximação pode ser usada em sistemas com três fases, quando a fase sólida é estacionária. Neste estudo foram determinadas, pela primeira vez, as distribuições do holdup do sólido e do gás 
(porosidade) para uma coluna de recheios metálicos, utilizando-se o SSCT, onde podem ser destacados os seguintes aspectos:

- Para análise de colunas com recheio de alta densidade foram necessárias atividades relativamente altas de material radio ativo $(\sim 3,6 \mathrm{GBq})$.

- A resolução espacial melhora quando trabalha-se com abertura de colimação de até 2 ou $3 \mathrm{~mm}$.

- A MA é o melhor método de reconstrução para sistemas multifásicos e foi aplicado com sucesso neste estudo.

- Os métodos utilizados para o cálculo do holdup em função das distribuições de atenuação se mostraram adequados gerando imagens de alta definição.

- A porosidade varia em função do diâmetro da coluna e depende do tipo e tamanho do recheio utilizado, não sendo adequado realizar aproximações de homogeneidade para o desenvolvimento de modelos CFD.

\subsection{Hidrodinâmica do bioreator em escala piloto}

Dos estudos hidrodinâmicos, realizados em um bioreator redesenhado em escala piloto, para determinar as distribuições do holdup do gás na região da tubulação guia, por meio do DSCT, podem-se destacar os seguintes aspectos:

- Com altas vazões de gás para intensificar a mistura, eliminou-se o problema de zonas mortas e garantiu-se que todos os sólidos do reator flutuem. Porém, isto prejudicou a geração do biogás.

- A melhor estratégia para o problema dos sólidos insolúveis seria reciclá-los periodicamente, para sua posterior remoção, sem afetar as condições de operação do bioreator. 
- O aerador utilizado apresentou boas propriedades, tendo mostrado que a uniformidade da distribuição do holdup aumenta com a altura do bioreator.

\subsection{Efeito do distribuidor no reator monolítico}

Neste estudo foi analisado o distribuidor desenvolvido por Kreutzer (2005), utilizando-se o DSCT na análise de um reator monolítico operado em cocorrente, determinando-se as distribuições de holdup do gás e do líquido para diferentes níveis do reator, destacando-se o seguintes aspectos:

- Para as velocidades de líquido e gás analisadas (regime de Taylor) foi encontrada uma janela de operação para condições de uniformidade, sendo que as condições melhoram na região das altas velocidades de líquido.

- A distribuição do holdup do líquido varia ao longo do reator, atingindo os máximos valores para $\mathrm{L} / \mathrm{D}=5$ e os menores valores na entrada do reator $\mathrm{L} / \mathrm{D}=2$.

- Claramente, o distribuidor utilizado não é uniforme, provocando variações na queda de pressão em função das condições de operação.

- Os modelos matemáticos baseados na suposição de que cada canal tem o mesmo comp ortamento devem ser revistos com as condições reais de distribuição.

- Esta foi a primeira vez que um reator monolítico foi estudado, utilizando-se o DSCT. 


\section{RECOMENDAÇÕES E TRABALHOS FUTUROS}

As técnicas apresentadas nesta tese têm um alto potencial para a pesquisa na área da hidrodinâmica de uma enorme quantidade de sistemas multifásicos de grande porte e com duas ou três fases móveis. Os dados gerados podem auxiliar a entender vários parâmetros de desenho e operação que afetam estes sistemas.

\subsection{Melhorias das técnicas tomográficas}

O SSCT utilizado, permitiu analisar satisfatoriamente sistemas de duas fases, mas faz necessária a evolução para um sistema de terceira geração, isto é, com um sistema de detectores em leque $(11$ - 15) acoplados a um sistema rotatório, montados em uma base que permita mudar a altura ou nível de estudo em função do tamanho do sistema analisado. $\mathrm{O}$ irradiador da fonte radioativa deve ser também aperfeiçoado, pois não permite a saída de um feixe completamente colimado e a abertura deste não é automática, podendo incrementar o risco radioló gico. Os tempos de contagem recomendáveis devem estar entre 0,1 e $0,5 \mathrm{~s}$. Cada medida deve ser repetida entre 80 e 150 vezes por projeção. As principais vantagens desta mudança seriam a facilidade e a versatilidade da análise de sistemas dinâmicos sem a necessidade de se rotacionar o objeto de estudo e com a diminuição do tempo de análise, garantindo uma maior reprodutibilidade dos resultados com menor erro.

A análise de sistemas com três fases pode ser melhorada, utilizando-se o radioisótopo denominado ${ }^{75} \mathrm{Se}$, por possuir cinco fotopicos discretos distribuídos em 
entra baixas e altas energias. Este radioisótopo pode ser instalado diretamente no SSCT melhorado ou no DSCT; e precisaria somente um sistema de leque de detectores. Assim, o MAPE pode ser aplicado diretamente para a obtenção das imagens do holdup. Os dados obtidos desta forma poderiam apresentar alguns desafios para trabalhar, com a influên cia do espalhamento de energias (Comptom). A utilização de um sistema adequado de aquisição de dados que permita a discrimin ação eletrônica de energias em janelas, pode minimizar este trabalho. Cinco destas janelas poderiam ser configuradas para obter-se a contagem de cada uma destas janelas separadamente. O maior problema desta fonte é sua curta meia vida comparada com as fontes de ${ }^{137} \mathrm{Cs}$ e ${ }^{60} \mathrm{Co}$. Fontes de ${ }^{75} \mathrm{Se}$ são disponíveis em altas atividades, onde, basicamente a blindagem projetada para um irradiador de ${ }^{60} \mathrm{Co}$ pode ser utilizada para fontes de ${ }^{137} \mathrm{Cs}$ ou ${ }^{75} \mathrm{Se}$. Os fotopicos de baixa energia do ${ }^{75} \mathrm{Se}$ são muito mais penetrantes do que as energias utilizadas em estudos anteriores (Froystein et al., 2005), podendo ser assim, utilizados para o estudo de fases que apresentem baixa contraste na atenuação com diâmetros moderados.

\subsection{Imagens em tempo real com boa resolução espacial}

Os sistemas apresentados nesta tese, SSCT e DSCT têm excelente resolução espacial, porém, baixa resolução temporal. O compromisso entre resoluções temporais e espaciais tem sempre sido objeto de discussão e polêmica em todo tipo de tomógrafo. As principais limitações não estão nos algoritmos de reconstrução de imagens e sim no hardware. Na tomografia em tempo real, o equipamento deve ser capaz de obter uma quantidade suficiente de projeções em um intervalo de tempo muito menor do que os eventos ocorridos no sistema estudado. Isto significa, que para a maioria de sistemas multifásicos, estes intervalos estão na 
escala de milisegundos ou microsegundos. O número de projeções deve ser suficiente para fornecer uma resolução espacial aceitável, para que se possa realizar as medidas qualitativas. Para a maioria dos casos reportados na literatura, o número de projeções é muito menor do que o número de pixels utilizados na reconstrução das imagens, gerando sistemas de equações indeterminados. A solução pode ser encontrada na utilização de múltiplos leques em posições fixas, cada um com uma fonte independente (Johansen, 2005; Mudde et al. 2005) ou com rotação do domínio de estudo em altas velocidades (Hampel et al. 2007). O número de projeções destes sistemas está limitado pelo tamanho dos detectores utilizados. Geralmente, são usados cristais de tamanho considerável para que se possa absorver fótons de alta energia. Assim, a utilização de detectores menores com alta eficiência para as energias propostas e que possam ser colocados dentro do leque, poderiam incrementar o número de projeções (Hampel, 2007). Avanços na área de detectores, tais como, semicondutores e outros dispositivos sensíveis à posição, poderiam ajudar no desenvolvimento de um tomógrafo fixo que forneça um número grande de projeções, e desta forma, imagens em tempo real com alta resolução.

\subsection{Imagens em 3D}

Os sistemas SSCT e DSCT são tomógrafos que basicamente produzem imagens de duas dimensões (2D). Vários níveis podem ser escaneados produzindo várias fatias que podem ser arranjadas em imagens 3D. O feixe de radiação poderia ter forma cônica e o detector poderia ser um painel retangular com sensibilidade posição milimétrica, girando-se a fonte e o detector, fazendo com que a coluna inteira pudesse ser analisada. Desta forma, a reconstrução das imagens seria feita em 
função de voxels. Com ajuda de vários pares fonte -detector nestas disposições, fixados em posições fixas, imagens 3D em tempo real poderiam ser obtidas.

\subsection{Outros estudos de sistemas multifásicos com o DSCT}

As colunas de lama borbulhante ou Slurry Bubble Columns (SBC) têm sido estudadas, utilizando-se a CT de fonte única, como foi indicado na seção 2.2. Nestes estudos, assumiu-se que a distribuição de holdup dos sólidos era constante, o que leva a grandes limitações operacionais.

Um trabalho experimental inicial, utilizando o DSCT foi feito em uma coluna de 4 pol. de diâmetro, usando dois tipos diferentes de sólidos (titanato de bário e esferas de vidro) para a determinação da distribuição de holdup em diversas concentrações de sólidos (10, 25 e $40 \%$ ) e velocidades gás $(8,12$ e $18 \mathrm{~cm} / \mathrm{s})$. Varreduras foram realizadas em $\mathrm{L} / \mathrm{D}=2$ e $\mathrm{L} / \mathrm{D}=5,5$, onde estes dados estão sendo processados e serão publicados em um artigo. 


\section{REFERÊNCIAS BIBLIOGRÁFICAS}

1. ADLER, S.; BEA VER, E.; BRYAN, P.; ROGERS, J.E.L; ROBINSON, S.; RUSSOMANNO, C. Vision 2020: Separations Roadmap. AIChE, 1998.

2. ALBERS, R.E.; NYSTRÖM, M.; SIVERSTRÖM, M.; SELLIN, A.; DELLVE, A.C.; ANDERSSON, U.; HERRMANN, H.; BERGLIN, T.H. Development of Monolith Based Process for $\mathrm{H}_{2} \mathrm{O}_{2}$ Production: From Idea to Large-Scale Implementation. Catalysis Today, v.69, p. 247-252, 2001.

3. AL-DAHHAN, M.H.; KEMOUN, A.; CARTOLANO, A.R.; ROY, S.; DOBSON, R.; WILLIAMS, J. Measuring gas-liquid distribution in a pilot scale monolith reactor via an Industrial Tomography Scanner (ITS). Chemical Engineering Journal, v.130(2-3), p.147-152, 2007.

4. ALMEIDA, G.; SILVANI, M.; FURIERI, R.; GONÇALVES, M.; LOPES, R.T. Development of a simulator for tomographic images generated by radiation transmission. Braz. J. Phys., v.34(3a), 2004.

5. ALMEIDA, G.L. ; SILVANI, M. ; FURIERI, R.C.A.A. ; GONÇALVES, M.J. ; LOPES, R. T. . Forecasting the Effect of Neutron Beam Divergence on the Quality of Tomographic Images. Nuclear Instruments \& Methods in Physics Research A, v. 579, p. 231-234, 2007.

6. ANGENENT, L.T.; SUNG, S. Development of anaerobic migrating blanket reactor (AMBR), a novel anaerobic treatment system. Water Research, v.35(7), p.1739-1747, 2001.

7. ANGENENT, L.T.; SUNG, S.; RASKIN, L. Methanogenic population dynamics during startup of a full-scale anaerobic sequencing batch reactor treating swine waste. Water Research, v.36(18), p.4648-4654, 2002.

8. BAKKER, J. Gas-Liquid Distribution in Monoliths. 2003. Dissertação (Mestrado) - Delft University of Technology, Delft.

9. BAROUCH, G.; LEGOUPIL, S.; STUTZ, B.; WOO, R. Measurements within cloud cavitation by means of X-ray attenuation device. Nucl. Instr. Meth., Section B, v. 213, p. 503-506, 2004.

10. BENAC, J. Alternating minimization algorithms for $X$-ray computed tomography : multigrid acceleration and dual energy application. 2005. Tese (Doutorado) - Washington University, St. Louis.

11. BENENATI, R.F.; BROSILOW, C.B. Void fraction distribution in beds of spheres. AIChE J., v.8, p. 359-361, 1962.

12. BERCIC, G.; PINTAR, A. The Role of Gas Bubbles and Liquid Slug Lengths on Mass Transport in the Taylor Flow Through Capillaries, Chem. Eng. Sci.; v. 52(21-22), p. 3709-3719, 1997.

13. BHUSARAPU S. Solids flow mapping in gas-solid risers. 2005. Tese (Doutorado) - Washington University, St. Louis.

14. BIEBERLE, M.; HAMPEL, U. Evaluation of a limited angle scanned electron beam x-ray CT approach for two-phase pipe flows. Measurement Science and Technology, v.17(8), p.2057-2065, 2006. 
15. BISWAS, J.; GREENFIELD, P.F. Two-Phase Flow through Vertical Capillaries-Existence of a Stratified Flow Pattern. Int. J. Multiphase Flow, v.11(4), p. 553-563, 1985.

16. BOGER, T.; HEIBEL, A.K. Heat Transfer in Conductive Monolith Structures. Chem. Eng. Sci. v.60(7), p.1823-1835, 2005.

17. BOGER, T.; HEIBEL, A.K.; SORENSEN, C.M. Monolithic Catalyst for the Chemical Industry. Ind. Eng. Chem. Res., v.43(16), p.4602-4611, 2004.

18. BRAZ, D. ; ALMEIDA, P.E.S. ; MOTTA, L. M. G. ; BARROSO, R.C. ; LOPES, R. T. . Study of the concrete overlay (whitetopping in Paving using Computed Tomographic System. Nuclear Instruments \& Methods in Physics Research A, v. 579, p. 510-513, 2007

19. BRAZ, D. ; LOPES, R. T. ; MOTTA, L. M. G. . Research on fatigue cracking growth parameters in asphaltic mixtures using computed tomography. Nuclear Inst. and Methods in Physics Research B, v. 213, p. 498-502, 2004.

20. BROEKHUIS, R.R.; MACHADO, R.M.; NORDQUIST, A.F. The EjectorDriven Monolith Loop Reactor - Experiments and Modeling. Catalysis Today, v.(69)1-4, p.87-93, 2001.

21. BROOKS, R. A.; DICHIRO, G. Principles of computer-assisted tomography (CAT) in radiographic, radio isotope imaging. Phys. Med. Biol., v. 21, p. 689, 1976.

22. BROWNE, J.A.; HOLMES, T.J. Developments with maximum likelihood X-ray computed tomography. Medical Imaging, IEEE Transactions on, v.11(1), p. 40-52, 1992.

23. BUKUR, D.B.; DALY, J.G.; PATEL, S.A. Application of $\gamma$-ray Attenuation for Measurement of Gas Holdups and Flow Regime Transitions in Bubble Columns. Industrial and Engineering Chemistry Research., v.35(1), p.70-80, 1996.

24. CASEY, T.J. Requirements and methods for mixing in anaerobic digesters. In: Kouzeli-Katsiri A, Bruce AM, Newman PJ, editors. Anaerobic Digestion of Sewage Sludge and Organic Agricultural Wastes, Amsterdam: Elsevier Applied Science, 1986. p. 90-103.

25. CHAOUKI, J.; LARACHI, F.; DUDUKOVIC, M. Noninvasive Tomographic and Velocimetric Monitoring of Multiphase Flows. Ind. Eng. Chem. Res., v. 36, p. 4476-4503, 1997.

26. CHEN, J.; RADOS, N. Particle Motion in Packed/ Ebullated Beds by CT and CARPT. A.I.Ch.E. J., v. 47, n. 5, p. 994-1004, 2001.

27. CHU, C.F.; NG, K.M. Flow in packed tubes with a small tube to particle diameter ratio. AIChE J., v.35, p.148-156, 1989.

28. CHYE HWANG, Y.; WHALEN, R.T.; BEAUPRE, G.S.; YEN, S.Y.; NAPEL, S. Reconstruction algorithm for polychromatic CT imaging: application to beam hardening correction. Medical Imaging, IEEE Transactions on, v.19(1), p.1$11,2000$.

29. COHEN, Y.; METZNER, A.B. Wall Effects in Laminar Flow of Fluids Through Packed Beds. AIChE.J., v.27(75), p.705-715, 1981.

30. COLEMAN, J.W.; GARIMELLA, S. Characterization of Two-Phase Flow Patterns in Small Diameter Round and Rectangular Tubes. Intermational Journal of Heat and Mass Transfer, v.42(15), p. 2869-2881, 1999.

31. CRYNES, L.L.; CERRO, R.L.; ABRAHAM, M.A. Monolith Froth Reactor: Development of a Novel Three-Phase Cataly tic System. AIChE J., v.41(2), p. 337-345, 1995. 
32. CSISZÁR, I. Why Least Squares and Maximum Entropy? An Axiomatic Approach to Inference for Linear Inverse Problems. Annals of Statistics, v.9, p.2033-2066, 1991.

33. CYBULSKI, A.; MOULIJN, J.A. Structured Catalysts and Reactors. New York, N.Y.: Marcel Dekker, Inc., 1998.

34. DE MAN, B.; NUYTS, J.; DUPONT, P.; MARCHAL, G.; SUETENS, P. An iterative maximumlikelihood polychromatic algorithm for CT. Medical Imaging, IEEE Transactions on, v.20(10), p.999-1008, 2001.

35. DE VUONO, A. C.; SCHLOSSER, P. A.; KULACKI, F. A.; MUNSHI, P. Design of an isotopic CT scanner for two-phase flow measurements. IEEE Trans. Nucl. Sci., v. NS27, p. 814, 1980.

36. DREIKE, P.; BOYD, D. P. Convolution reconstruction of fan-beam projections. Comput. Graph. Image Process., v. 5, p. 459, 1976.

37. DSCT Manual, CREL- Washington University, St. Louis, July 2007.

38. DUDUKOVIC, M.P. Opaque multiphase flows: experiments and modeling. Experimental Thermal and Fluid Science, v. 26, n. , p. 747-761, 2002.

39. DUDUKOVIC, M.P. Relevance of Mutiphase Reaction Engineering to Modern Technological Challen ges. Ind. Eng. Chem. Res., v. 46, p. 8674-8686, 2007.

40. EDVINSSON, R.K.; CYBULSKI, A. A Comparative Analysis of the TrickleBed and the Monolithic Reactor for Three-Phase Hydrogenations. Chem. Eng. Sci., v.49(24), p.5653-5666, 1994.

41. EDVINSSON, R.K.; HOUTERMAN, M.J.J.; VERGUNST, T.; GROLMAN, E.; MOULIJN, J.A. Novel Monolithic Stirred Reactor. AIChE Journal., v.44(11), p.2459-2464, 1998.

42. EIA. Annual Energy review 2006. Energy Information Administration (EIA). Office of Energy Markets and End Use, U.S. Department of Energy. Washington, DC 20585, 2007. p.441.

43. ELBAKRI, I.A.; FESSLER, J.A. Statistical image reconstruction for polyenergetic X-ray computed tomography. Medical Imaging IEEE Transactions, v.21(2), p.89-99, 2002.

44. EPA U. Process Design Manual for Sludge Treatment and Disposal Cincinnati, OH, USA. editor. 1979. p. 79-110.

45. FINCKE, J. R.; BERGGREN, M. J.; JOHNSON, S. A. The application of reconstructive tomography to the measurement of density distribution in twophase flow. Proceedings of the 26th International Instrumentation Symposium, Seattle, p 235,1980.

46. FOUMENY, E.A.; PAHLEVANZADEH, H. Evaluation of plug flow assumption in packed beds. Chem. Eng. Technol., v.13, p.161-171, 1990.

47. FROYSTEIN, T.; KVANDAL, H.; AAKRE, H. Dual energy gamma tomography system for high pressure multiphase flow. Flow Measurement and Instrumentation, v. 16(2-3), p.99-112, 2005.

48. FROYSTEIN, T.; KVANDALB, II. Dual energy gamma tomography system for high pressure. Flow Measurement and Instrumentation, v. 16, p. 99-112, 2005.

49. GARCIA-BORDEJE, E.; KAPTEIJN, F.; MOULIJN, J.A. Preparation and Characterisation of Carbon-Coated Monoliths for Catalyst Supports, Carbon, v.40(7), p. 1079-1088, 2002.

50. GEHRKE, S.; WIRTH, K.E. Application of conventional- and dual-energy Xray tomography in process engineering. Sensors Journal IEEE , v.5(2), p.183$187,2005$. 
51. GEORGE, D.L.; SHOLLENBERGER, K.A. Three-phase material distribution measurements in a vertical flow using gamma-densitometry tomography and electrical-impedance tomo graphy. International Joumal of Multiphase flow, v. 27, n., p. 1903-1930, 2001.

52. GEORGE, D.L.; SHOLLENBERGER, K.A.; TORCZYNSKI, J.R.; O'HERN, T.J.; CECCIO, S.L. Three-phase material distribution measurements in a vertical flow using gamma-densitometry tomography and electrical-impedance tomography. International Journal of Multiphase Flow, v.27(11), p.1903-1930, 2001 .

53. GOSH, S. Anaerobic digestion for renewable energy and environmental resto ration. Jap an, Sendai International Center, Send ai, 1997.

54. GULATI, S.T. Ceramic Catalyst Supports for Gasoline Fuel. In: CYBULSKI, A.; MOULIJN, _J.A. Structured Catalysts and Reactors. Marcel Dekker, Inc., 1998, p.15-58.

55. HALE, C.P.H.; HU, B.; RICHARDSON, S.M.; WONG, W. L. Gammas and Xray tomography of liquid-liquid and gas-liquid-liquid flows. Multiphase Science and Technology, v.19(3), p.241-267, 2007.

56. HAMPEL, U.; HRISTOV, H.V.; BIEBERLE, A.; ZIPPE, C. Application of high-resolution gamma ray tomography to the measurement of gas hold-up distributions in a stirred chemical reactor. Flow Measurement and Instrumentation, v.18(5-6), p. 184-190, 2007.

57. HASHIMOTO, A.G. Effect of mixing duration and vacuum on methane production rate from beef cattle waste. Biotechnology and Bioengineering, v.24(1), p.9-23, 1982.

58. HATZIANTONIOU, V.; ANDERSSON, B. Solid-Liquid Mass Transfer in Segmented Gas-Liquid Flow Through a Capillary. Ind. Eng. Chem. Fundam., v.21(4), p. 451-6, 1982.

59. HEIBEL, A.K.; JAMISON, J.A.; WOEHL, P.; KAPTEIJN, F.; MOULIJN, J. Improving Flooding Performance for Countercurrent Monolith Reactors. Industrial \& Engineering Chemistry Research, v.43(16), p.4848-4855, 2004.

60. HEIBEL, A.K.; LEBENS, P.J.M.; MIDDELHOFF, J.W.; KAPTEIJN, F.; MOULIJN, J. Liquid Residence Time Distribution in the Film Flow Monolith Reactor. AIChE Journal, v.51(1), p.122-133, 2005.

61. HEIBEL, A.K.; VERGELDF, F.J.; VAN AS, H.; KAPTEIJN, F.; MOULIJN, J.; BOGER, T. Gas and Liquid Distribution in the Monolith Film Flow Reactor, AIChE Joumal, v.49(12), p.3007-3017, 2003.

62. HJERTAKER, B.T.; TJUGUM, S.A.; HAMMER, E.A.; JOHANSEN, G.A. Multimodality tomography for multiphase hydrocarbon flow measurements. Sensors Journal IEEE, v.5(2), p.153-160, 2005.

63. HO, C.; TAN, Y. Anaerobic treatment of palm oil mill effluent by tank digesters. Journal of Chemical Technology and Biotechnology, v.35(B), p.155164, 1985.

64. HOFFMANN RA. 2005. Effect of shear on the performance and microbial ecology of anaerobic digesters treating cow manure from dairy farms. 2005. Dissertação (Mestrado) - Washington University, St. Louis.

65. HOSSEINI-ASHRAFI, M. E.; TUZUN, U. A tomographic study of voidage profiles in axially symmetric granular flows. Chem. Eng. Sci, v. 48, p. 53, 1993. 
66. HU, B.; STEWART, C.; HALE, C.P.; LAWRENCE, C.J.; HALL, A.R.W.; ZWIENS, H.; HEWITT. G.F. Development of an X-ray computed tomography (CT) system with sparse sources: application to three-phase pipe flow visualization. Experiments in fluids, v.39(4), p.667- 678, 2005.

67. HUBBELL, J.H.; SELTZER, S.M. Tables of X-Ray Mass Attenuation Coefficients and Mass Energy-Absorption Coefficients. National Institute of Standards and Technology (NIST), 1996 http://physics.nist.gov/PhysRefData

68. IAEA-TECDOC-1589 Industrial Process Gamma Tomography, Viena, Maio 2008.

69. IRANDOUST, S.; ANDERSSON, B. Liquid Film in Taylor Flow through a Capillary. Ind. Eng. Chem. Res., v.28(11), p. 1684-1688, 1989.

70. IRANDOUST, S.; ERTLE, S.; ANDERSSON, B. Gas-liquid Mass Transfer in Tay lor flow through a Capillary. Can. J. Chem. Eng., v.70(1), p.115-119, 1992.

71. IRANDOUST, S.; GAHNE, O. Competitive hydrodesulfurization and hydrogenation in a monolithic reactor. AIChE J. v.36(5), p. 746-752, 1990.

72. JIANG, Y. Flow distribution and its impact on performance of packed bed reactors. 2000. Tese (Doutorado) - Washington University, St. Louis.

73. JOHANSEN, G.A. Nuclear tomography methods in industry. Nuclear Physics A, v.752, p. 696-705, 2005.

74. JOHANSEN, G.A.; FROEYSTEIN, T.; HJERTAKER, B.T.; OLSEN, O. A dual sensor flow imaging tomographic system. Measurement Science \& Technology, v.7(3), p.297-307, 1996.

75. JOHANSEN, G.A.; FROYSTEIN, B.T. The development of a dual mode tomograph for three - component flow imaging. Chem. Eng. J., v. 56, p. 175182, 1995.

76. KAK, A.; SLANEY, M. Principles of Computerized Tomographic Imaging. 2001. Society of Industrial and Applied Mathematics, Electronic Copy. p. 49112.

77. KAPTEIJN, F.; NIJHUIS, T.A.; HEISZWOLF, J.J.; MOULIJN, J.A. New nontraditional multiphase catalytic reactors based on monolithic structures. Catalysis Today, v.66(2-4), p. 133-144, 2001.

78. KARIM, K.; VARMA, R.; VESVIKAR, M.; AL-DAHHAN, M.H. Flow pattern visualization of a simulated digester. Water Research, v. 38(17), p. 3659-3670, 2004.

79. KARIM, K.; HOFFMANN, R.; KLASSON, T.; AL-DAHHAN, M.H. Anaerobic digestion of animal waste: effect of mode of mixing. Water Res., v.39(15), p.3597-606, 2005.

80. KARIM, K.; HOFFMANN, R.; KLASSON, T.; AL-DAHHAN, M.H. Anaerobic digestion of animal waste: waste strength versus impact of mixing. Bioresour Technol, v.96(16), p.1771-81, 2005.

81. KEMOUN, A.; CHENG ONG, B.; DUDUKOVIC, M.P. Gas holdup in bubble columns at elevated pressure via computed tomography. Int. J. Multiphase Flows, v. 27, p. 929946, 2001.

82. KEMOUN, A.; RADOS, N. Gas holdup in a trayed cold-flow bubble column. Chem. Eng. Sci., v. 56, p. 1197-1205, 2001.

83. KHOPKAR, A.R.; RAMMOHAN, A.R.; RANADE, V.V.; DUDUKOVIC, M.P. Gas-liquid flow generated by a Rushton turbine in stirred vessel: CARPT/CT measurements and CFD simulations. Chemical Engineering Science, v. 60(8-9), p. 2215-2229, 2005. 
84. KOURI, R.J.; SOHLO, J. Liquid and Gas Flow Patterns in Random Packing. Chem. Eng. J. v.61, p.95-105, 1996.

85. KREUTZER, M.T. Hydrodynamics of Taylor flow in capillaries and monolith reactors. 2003. Dissertação (Mestrado) - Delft University of Technology, Delft.

86. KREUTZER, M.T.; DU, P.; HEISZWOLF, J.J.; KAPTEIJN, F.; MOULIJN, J.A. Mass Transfer Characteristics of Three-Phase Monolith Reactors, Chem. Eng. Sci, v. 56(21-22), p. 6015-6023, 2001.

87. KREUTZER, M.T.; MOULIJN J.A.; HEISZWOLFB, J. Multiphase monolith reactors: Chemical reaction en gineering of segmented flow in microchannels. Chem. Eng. Sci., v. 60, p. 5895-5916, 2005.

88. KREUTZER, M.T; BAKKER, J., MOULIJN, J.A. Scaling-up Multiphase Monolith Reactors: Linking Residence Time Distribution and Feed Maldistribution. Ind. Eng. Chem. Res., v. 44, p. 4898-4913, 2005.

89. KRISHNA, R.; SIE, S.T. Strategies for Multiphase Reactor Selection. Chemical Engineering Science, v.49(24A), p. 4029-65, 1994.

90. KUMAR S. Tomographic Measurements of Void Fraction and Modeling of the Flow in Bubble Columns. 1994. Tese (Doutorado) - Washington University, St. Louis.

91. KUMAR, S. B.; DUDUKOVIC, M. P. Computer-assisted gamma and X-ray tomography: Application to multiphase flow. In Non-Invasive Monitoring of Multiphase Flows; Chaouki, J., Larachi, F., Dudukovic, M. P., Eds.; Elsevier: Amsterdam, The Netherlands, 1997; Chapter 2, p 48.

92. KUMAR, S.B.; MOSLEMIAN, D.; DUDUKOVIC, M.P. A gamma-ray tomographic scanner for imaging voidage distribution in two-phase flow systems. Flow Measurement and Instrumentation, v. 6(1), p.61-73, 1995.

93. KUMAR, S.B.; MOSLEMIAN, D.; DUDUKOVIC, M.P. Gas-holdup measurements in bubble columns using computed tomography. AIChE Journal, v.43(6), p.1414-1425, 1997.

94. LANGE, K.; CARSON, R. EM Reconstruction Algorithims for Emission and Transmission Tomography. Journal of Computer Assisted Tomography, v.8(2), p.306-316, 1984.

95. LEBENS, P.J.M.; HEISZWOLF, J.J.; KAPTEIJN, F.; SIE, S.T.; MOULIJN, J.A. Gas-Liquid Mass Transfer in an Internally Finned Monolith Operated Countercurrently in the Film Flow Regime. Chemical Engineering Science, v.54(21), p. 5119-5125, 1999.

96. LEBENS, P.J.M.; KAPTEIJN, F.; SIE, S.T.; MOULIJN, J.A. Potentials of Internally Finned Monoliths as a Packing for Multifunctional Reactors. Chemical Engineering Science., v.54(10), p.1359-1365, 1999.

97. LEBENS, P.J.M.; STORK, M.M.; KAPTEIJN, F.; SIE, S.T.; MOULIJN, J.A. Hydrodynamics and Mass Transfer Issues in a Countercurrent Gas-Liquid Internally Finned Monolith Reactor. Chemical Engineering Science, v.54(1314), p.2381-2389, 1999.

98. LEBENS, P.J.M.; VAN DER MEIJDEN; R.; EDVINSSON, R.K.; KAPTEIJN, F.; SIE, S.T.; MOULIJN, J.A. Hydrodynamics of Gas-Liquid Countercurrent Flow in Internally Finned Monolithic Structures. Chemical Engineering Science, v.52(21-22), p.3893-3899, 1997.

99. LEDERE, M.C.; HOLLANDER, J.M.; PERLMAN, I. Table of Isotopes. New York: John Wiley \& Sons, Inc., 1966. 
100.LEVENSPIEL, O. Chemical Reaction Engineering, New York, N.Y.: John Wiley \& Sons, 1998

101.LEVENSPIEL, O. The chemical reactor omnibook, Oregon: OSU book stores, Inc. 1996.

102.LIMA, I. ; ROCHA, M.S. ; LOPES, R. T. . Ethanol bone Evaluation using 3D Microtomography. Micron, v. 39, p. 617-622, 2008

103.LIU W. Ministructured Cataly st Bed for Gas-Liquid-Solid Multiphase Catalytic Reaction. AIChE Journal; v.48(7), p. 1519-1532, 2002.

104.LIU, S.; WANG, H. A New Image Reconstruction Method for Tomographic Investigation of Fluidized Beds. A.I.Ch.E. J., v. 48, n. 8, p. 1631-1638, 2002.

105.LOPES, R. T. ; DE ALMEIDA, G.L. ; FURIERI, R.C.A.A. ; LOPES, R. T. ; GONÇALVES, M.J. . Thermal Neutron Computed Tomography at the Argonauta Reactor. Brazilian Joumal of Physics, v. 35(3B), p. 775-778, 2005.

106.LOPEZ, R.T. Tomografia Computadorizada em Testes Não Destrutivos. 1988. Tese (Doutorado) - Universidade Federal do Rio de Janeiro, UFRJ, Brasil.

107.LUO H-P. Analyzing and modeling of air lift photobioreactors for microalgal and cyanobacteria cultures. 2005. Tese (Doutorado) - Washington University, St. Louis.

108.LUSK P. Methane Recovery from Animal Manures: A Current Opportunities Casebook. National Renewable Energy Laboratory 3.ed. Golden: CO, 1998.

109.MARCANDELLI, C.; LAMINE, A.; BERNARD, J.; WILD, G. Liquid Distribution in Trickle-bed Reactor. Oil \& Gas Science and TechnologyReview., v. 55(4), p. 407-415, 2000.

110.McCUAIG, N.; SEVILLE, J. P. K.; GILBOY, W. B.; CLIFT, R. Application of gamma-ray tomography to gas fluidized beds. Appl. Opt. v.24, p.4083, 1985.

111.McGREAVY, C.; FOUMENY, E.A.; JAVED, K.H. Characterization of transport properties for fixed bed in terms of local bed structure and flow distribution, Chem. Eng. Sci., v.41, p.787-797, 1986.

112.MCNP Manual, LA-12625-M, Version 4B, 1997.

113.MISHIMA, K.; HIBIKI, T. Some Characteristics of Air-Water Two-Phase Flow in Small Diameter Vertical Tubes. International Journal of Multiphase Flow, v. 22(4), p. 703-712, 1996.

114.MUDDE, R.F.; BRUNEAU, P.R.P.; VANDERHAGEN, T.H.J.J. TimeResolved gamma- Densitometry Imaging within Fluidized Beds. Ind. Eng. Chem. Res., v. 44(16), p.6181-6187, 2005.

115.MUDDE, R.F.; HARTEVELD, W.K. Gamma radiation densitometry for studying the dynamics of fluidized beds. Chem. Eng. Sci., v. 54, n. , p. 20472054, 1999.

116.NIJHUIS, T.A.; DAUTZENBERG, F.M.; MOULIJN, J.A. Modeling of Monolithic and Trickle-Bed Reactors for the Hydrogenation of Styrene. Chemical Engineering Science. V.58, p.1113-1124, 2003.

117.NIJHUIS, T.A.; KREUTZER, M.T.; ROMIJN, A.C.J.; KAPTEIJN, F.; MOULIJN, J.A. Monolithic Catalysts as Efficient Three-Phase Reactors. Chem. Eng. Sci., v. 56(3), p. 823-829, 2001.

118.NIKITIDIS, M.S.; TÜZÜN, U.; SPYROU, N.M. Determination of Phase Velocities in Multi-Phase Flows in Hoppers Using Dual Photon Gamma-Ray tomography. Chemical Engineering Communications, v. 175(1), p. 3 - 24, 1999. 
119.NIKITIDIS, M.S.; TUZUN, U. ; SPYROU, N.M. Determination of Phase Velocities in Multi-Phase Flows in Hoppers Using Dual Photon Gamma-Ray tomography. Chemical Engineering Communications, v. 175(1), p. 3 - 24, 1999.

120.NIKITIDIS, M.S.; TUZUN, U.; SPYROU, N.M. Measurement of size segregation by self-diffusion in slow-shearing binary mixture flows using dual photon gamma-ray tomography. Chem. Eng. Sci., v. 53, n. 13, p. 2335-2351, 1998.

121.NIU, M.; AKIYAMA, T.; TAKAHASHI, R.; YAGI. Reduction of the Wall Effect in a Packed Bed by Hemispherical Lining, J., AIChE J., v.42, p.11811186, 1996.

122.OLLINGER, J.M. Maximum-likelihood reconstruction of transmission images in emission computed tomography via the EM algorithm. Medical Imaging, IEEE Transactions on, v. 13(1), p. 89-101, 1994.

123.O'SULLIVAN, J.A.; BENAC, J. Alternating Minimization Algorithms for Transmission Tomography. Medical Imaging, IEEE Transactions, v.26(3), p.283-297, 2007.

124.PATEL, A.K.; PATWARDHAN, A.W.; THORAT, B.N. Comparison of MLEM algorithm and ART for reconstruction of gas hold-up profile in a bubble column. Chemical Engineering Journal, v.130(2-3), p.135-145, 2007.

125.PEREIRA, G.R. ; CONCEIÇÃO, S.C. ; LOPES, R. T. ; ANJOS, M. J. ; OLIVEIRA, L. F. ; ROCHA, H. S. ; Perez, C.A. . Elemental Distribuition in Breast Tissue Samples using X-ray Fluorescence Microtomography. Journal of Radioanalytical and Nuclear Chemistry, v. 269(2), p. 469-473, 2006.

126.PEREIRA, G.R. ; LOPES, R. T. ; ANJOS, M. J. ; ROCHA, H. S. ; PEREZ, C. . X-ray Fluorescence Microtomography Analyzing Reference Samples. Nuclear Instruments \& Methods in Physics Research A, v. 579, p. 322-325, 2007.

127.PEREIRA, G.R. ; ROCHA, H. S. ; ANJOS, M. J. ; FARIA , P. ; PEREZ, C.A. ; LOPES, R. T. . Computed Tomography and X-ray Fluorescence CT of Biological Samples. Nuclear Instruments \& Methods in Physics Research A, v. 580, p. 951-954, 2007

128.RADOS, N. Slurry bubble column hydrodynamics. 2003. Tese (Doutorado) Washington University, St. Louis.

129.RADOS, N.; SHAIKH, A.; AL-DAHHAN, M. Phase Distribution in a High Pressure Slurry Bubble Column via a Single Source Computed Tomography. The Canadian Joumal of Chemical Engineering, v. 83, p. 104-112, 2005.

130.RADOS, N.; SHAIKH, A.; AL-DAHHAN, M.H.. Solids flow mapping in a high pressure slurry bubble column. Chem. Eng. Sci., v. 60(22), p.6067-6072, 2005.

131.RAMMOHAN A. Characterization of single and multiphase flows in stirred tank reactors. 2002. Tese (Doutorado) - Washington University, St. Louis

132.RAPAPORT, M.S.; GAYER, A.; ISZAK, E.; GORESNIC, C.; BARAN, A.; POLAK, E. A dual-mode industrial CT. Nuclear Instruments and Methods in Physics Research Section A: Accelerators, Spectrometers, Detectors and Associated Equipment, v.352(3), p.652-658, 1995.

133.REBGETZ, M.D.; WATT, J.S.; ZASTAWNY, H.W. Determination of the volume fractions of oil, water and gas by dual energy gamma-ray transmission. Nuclear Geophysics, v.5(4), p. 479- 90, 1991. 
134.REINECKE, N.; MEWES, D. Flow Regimes of Two Phase Flow in Monolith Catalyst. In: 5TH WORLD CONGRESS ON CHEMICAL ENGINEERING, San Diego, CA, 1996.

135.RIBEIRO, J.L.B. ; QUEIROZ, J.C. ; LOPES, R. T. ; ANJOS, M. J. ; BIANCO, L.C.B. ; D ALMEIDA, A.R. ; CAMPOS, E. F. . New methodology for Analysis of the Performance for Diverting A gents in Unconsolidated Sandstones in Real Time with Physical Simulator using Computed Tomography. Nuclear Instruments \& Methods in Physics Research A, v. 579, p. 481-485, 2007

136.RIVARD, C.J.; KAY, B.D.; KERBAUGH, D.H.; NAGLE, N.J.; HIMMEL, M.E. Horsepower requirements for high-solid anaerobic digestion. Applied Biochemistry and Biotechnology, v.51/52, p.155-162, 1995.

137.RIZESCU, C.T.; GEORGESCU, G.N.; DULIU, O.G.; SZOBOTKA, S.A. 3-D dual gamma- ray computer axial tomography investigation of polymetallic nodules. Deep Sea Research Part I: Oceanographic Research Papers, v.48(11), p. 2529-2540, 2001.

138.ROBLEE, L.H.S.; BAIRD, R.M.; TIERNEY, J.W. Radial porosity variations in packed beds. AIChE J., v. 4, p.460-464, 1958.

139.ROY, S. Phase distribution and performance studies of gas-liquid monolith reactor. 2006. Tese (Doutorado) - Washington University, St. Louis.

140.ROY, S. Quantification of two-phase flow in liquid-solid risers. 2000. Tese (Doutorado) - Washington University, St. Louis.

141.ROY, S.; AL-DAHHAN M. Flow distribution characteristics of a gas-liquid monolith reactor. Catalysis Today, v. 105(3-4), p.396-400, 2005.

142.ROY, S.; BAUER, T.; AL-DAHHAN, M.H.; LEHNER, P.; TUREK, T. Monolith as Multiphase Reactor: A Review, AIChE J, v.50(11), p. 2918-2938, 2004

143.ROY, S.; CHEN, J.; AL_DAHHAN, M. Tomographic and Particle Tracking Studies in a Liquid-Solid Riser. Ind. Eng. Chem. Res., v. 36, p. 4666-4669, 1997.

144.ROY, S.; KEMOUN, A.; AL-DAHHAN, M.; DUDUKOVIC, M.P.; SKOURLIS, T.B.; DAUTZENBERG, F.M. Countercurrent flow distribution in structured packing via computed tomography. Chemical Engineering and Processing, v. 44(1), p.59-69, 2004.

145.SALMI, T.; WARNA, J.; MIKKOLA; JYRI-PEKKA; AUMO, J.; RONNHOLM, M.; KUUSISTO, JYRKI. Residence time distributions from CFD in monolith reactors - combination of avant-garde and classical modelling, Computer-Aided Chemical Engineering, v.14 (European Symposium on Computer Aided Process Engineer ing--13, 2003), p. 905-910, 2003.

146.SATTERFIELD, C.N.; OZEL, F. Some Characteristics of Two-Phase Flow in Monolithic Catalyst Structures. Ind. Eng. Chem. Fundam. v.16(1), p. 61-67, 1977.

147.SCHIEWE, K.E.; TUZLA, K. Measurements of Solid Concentration in a Downward Vertical Gas - Solid Flow. A.I.Ch.E. J., v. 45 n. 5, p. 949-955, 1999.

148.SCHLOSSER, P. A.; DE VUONO, A. C.; KULACKI, F. A.; MUNSHI, P. Analysis of high speed CT scanners for non-medical applications. IEEE Trans. Nucl. Sci., v. NS27, n. 788, 1980.

149.SESHADRI, M. D.; MUNSHI, P.; DHARIYAL, I. D.; RATHORE, R. K. S. Application of digital tomography in two-phase flow studies. Nud. Instrum. Methods, v.A251, p.577, 1986. 
150.SEVILLE, J. P. K.; MORGAN, J. E. P.; CLIFT, R. Tomographic determination of the voidage structure of gas fluidized beds in the jet region. In Fluidization $\boldsymbol{V}$; Engineering Foundation: New York, p 87, 1986.

151.SHAIKH, A.; AL-DAHHAN, M.H. Characterization of the hydrodinamic flow regime in bubble columns via computed tomography. Flow Measurement and Instrumentation, v. 16, p. 91-98, 2005.

152.SHEFFIELD, J. Financial approaches to animal manure management. Joint Institute for Energy and Environment. 314 UT Conference Center Building Knoxville, TN 37996-4138, 2002.

153.SIMONS, S.J.R.; WILLIAMS, R. A. Particle size measurement using noninvasive dielectric sensors. Powder Technol., v.73, p.85, 1993.

154.SMITH, L.C.; ELLIOT, D.J.; JAMES, A. Mixing in upflow anaerobic filters and its influence on performance and scale-up. Water Research, v.30(12), p.30613073, 1996.

155.SNYDER, D.L.; SCHULZ, T.J.; O'SULLIVAN, J.A. Deblurring Subject to Nonnegativity Constraints. IEEE transactions on signal processing, v.40(5), p.1143-1150, 1992.

156.SOUZA, M.; ALMEIDA, G.; FURIERI, R.; LOPES, R.T.; DE JESUS, E. BARBOSA, A. Comparison of tomographic systems for X-ray and thermal neutrons. Braz. J. Phys., v.33(2), 2003.

157.SPEECE, R.E. Anaerobic Biotechnology for Industrial Wastewaters. Nashville, T.N.: Vanderbilt University, Arachae Press, 1996.

158.THULASIDAS, T.C.; ABRAHAM, M.A.; CERRO, R.L. Dispersion during bubble-train flow in capillaries. Chemical Engineering Science, v.54(1), p. 61$76,1999$.

159.TOYE, D.; CRINE, M.; L'HOMME, G.; OLUJIC, Z.; MARCHOT, P. Measurement of the liquid distribution and hold-up in structured packing by Xray tomography. Recents Progres en Genie des Procedes. Information, Modelisation, Simulation and Optimisation., v.15(82) p. 433-440, 2001.

160.TOYE, D.; MARCHOT, P.; CRINE, M.; PELSSER A.M; L'HOMME, G. Local measurements of void fraction and liquid holdup in packed columns using X-ray computed tomography. Chem. Eng. Proc., v. 37(6), p. 511-520, 1998.

161.TRIPLETT, KA.; GHIAASIAAN, S.M.; ABDEL-KHALIK, S.I.; LEMOUEL, A.; MCCORD, B.N. Gas-liquid two-phase flow in microchannels; Part II: void fraction and pressure drop. International Journal of Multiphase Flow., v.25(3), p.395-410, 1999.

162.TRIPLETT, KA.; GHIAASIAAN, S.M.; ABDEL-KHALIK, S.I; SADOWSKI, D.L. Gas-liquid two-phase flow in microchannels Part I: two-phase flow patterns. International Journal of Multiphase Flow, v.25(3), p. 377-394, 1999.

163.TROST, B.M. The atom economy: a search for efficiency. Science, v. 254, p. 1471, 1991.

164.VAN BATEN, J.M.; KRISHNA, R. CFD simulations of mass transfer from Taylor bubbles rising in circular capillaries. Chemical Engineering Science, v.59(12), p.2535-2545, 2004.

165.VAN SANTEN, H.; KOLAR, Z. Double beam and detector $\gamma$-radiation attenuation gauge for studying bubble phenomena in gas-solid fluidized beds. Appl. Rad. Isotopes, v. 48, n. 10-12 , p. 1307-1312, 1997. 
166.VAN SANTEN, H.; KOLAR, Z.I.; SCHEERS, A.M. Photon energy selection for dual energy g- and/or x-ray absorption composition measurements in oilwater-gas mixtures. Nuclear Geophysics, v.9 (3), p.193-202., 1995.

167.VARMA R, AL-DAHHAN M. Effect of sparger design on hydrodynamics of a gas recirculation anaerobic bioreactor. Biotechnology and Bioengineering, $\mathrm{v}$. 98(6), p. 1146- 1160, 2007.

168.VASQUEZ, P.; COSTA, F. E.; RELA, P. R., CALVO; W. A. P.; LeROUX, G. A.; HAMADA, M. M. Gamma scanning evaluation for random packed columns, Nuclear Science Symposium Conference Record, 2005 IEEE, Volume 1, 23-29 Oct. 2005 Page(s):514 - 519.

169.VASQUEZ, P.; COSTA, F.E.; CALVO, W.A.P.; Hamada, M. M. Development of a Scintillator Detector System from Gamma Scan Measurements of Industrial Distillation. Nucl. Instr. and Meth. In Physics Research A, v. 537, p. $458-$ 461, 2005.

170.VASQUEZ, P.; LeROUX, G. A. C.; HAMADA, M. M. Simulated Study of Parallel-Bean Gamma Ray Tomography and Image Reconstruction. Proceedings of International Nuclear Atlantic Conference - VII ENAN. Rio de Janeiro: Associação Brasileira de Energia Nuclear, 2005. v.01. p.01 - 09.

171.VASQUEZ, P.; MESQUITA, C.H.; LeROUX, G. A. C.; HAMADA, M. Methodological analysis of gamma tomo graphy system for large random packed columns, IRMA 2007

172.VASQUEZ, P.; MESQUITA, C.H.; LeROUX, G. A. C.; HAMADA, M. Phantom study using a first generation gamma tomography system. ENAN 2007.

173.VESVIKAR, M.; VARMA, R.; KARIM, K., AL-DAHHAN, M. Flow pattern visualization in a mimic anaerobic digester: experimental and computational studies. Water Sci Technol, v. 52(1-2), p. 537-543, 2005.

174.VESVIKAR, M.S. Understanding the hydrodynamics of anaerobic digesters for bioenergy production. 2006. Tese (Doutorado) - Washington University, St. Louis.

175.VORTMEYER, D.; SCHUSTER, J. Evaluation of Steady Flow Profiles in Rectangular and Circular Packed Beds by a Variational Method. Chem. Eng. Sci., v. 38(10), p.1691-1699, 1983.

176.WAGNER, I.; STICHLMAIR, J.; FAIR, J.R. Mass transfer in beds of modern, high- efficiency random packings. Ind. Eng. Chem. Res., v.36, p.227-237, 1997.

177.WANG, Z.; AFACAN, A. Porosity distribution in random packed columns by gamma ray Tomography. Chem. Eng. Proc., v. 40, p. 209-219, 2001.

178.WILLIAMS, J.L. Monolith structures, materials, properties and uses. Catalysis Today, v.69(1-4), p. 3-9, 2001.

179.YANG, W.Q. Role of tomography in gas/solids flow measurement. Flow Measurement and Instrumentation, v. 11, n. , p. 237-244, 2000.

180.YAWALKAR, A.A; KREUTZER , M.T., MOULIJN, J.A. Axial Mixing in Monolith Reactors: Effect of Channel Size. Ind. Eng. Chem. Res., v. 44, p.2046-2057, 2005.

181.YAZDI, M.; ESMAEILNIA, S.A. Dual-energy gamma-ray technique for quantitative measurement of coal ash in the Shahroud mine, Iran. International Journal of Coal Geology, v. 55(2-4), p.151-156, 2003. 
182.YESTER, M.W.; BARNES, G.T. Geometrical limitations of computed tomography (CT) scanner resolution, Appl. Opt. Instr. In Medicine, v.VI 127, p. 296-303, 1977.

183.ZHAO, T.S.; BI, Q.C. Co-current air-water two-phase flow patterns in vertical triangular microchannels. Intemational Joumal of Multiphase Flow, v.27(5), p.765-782, 2001. 